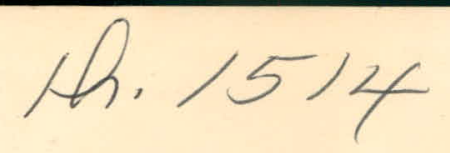

CONS/9416-1

NASA CR-135132

\title{
DURABILITY TESTING
}

AT ONE ATMOSPHERE

OF ADVANCED CATALYSTS

AND CATALYST SUPPORTS

FOR AUTOMOTIVE

GAS TURBINE ENGINE

COMBUSTORS

Part 1

R. M. Heck, M. Chang, H. Hess, and R. Carrubba

ENGELHARD INDUSTRIES

A DIVISION OF ENGELHARD MINERALS \& CHEMICALS CORPORATION

June 1977

Prepared for the

NATIONAL AERONAUTICS AND SPACE ADMINISTRATION

Lewis Research Center

Cleveland, Ohio 44135

Contract NAS 3-19416

As a part of the

ENERGY RESEARCH AND

DEVELOPMENT ADMINISTRATION

Division of Transportation Energy Conservation Heat Engine Highway Vehicle Systems Program 


\section{DISCLAIMER}

This report was prepared as an account of work sponsored by an agency of the United States Government. Neither the United States Government nor any agency Thereof, nor any of their employees, makes any warranty, express or implied, or assumes any legal liability or responsibility for the accuracy, completeness, or usefulness of any information, apparatus, product, or process disclosed, or represents that its use would not infringe privately owned rights. Reference herein to any specific commercial product, process, or service by trade name, trademark, manufacturer, or otherwise does not necessarily constitute or imply its endorsement, recommendation, or favoring by the United States Government or any agency thereof. The views and opinions of authors expressed herein do not necessarily state or reflect those of the United States Government or any agency thereof. 


\section{DISCLAIMER}

Portions of this document may be illegible in electronic image products. Images are produced from the best available original document. 


\section{NOTICE}

This report was prepared to document work sponsored by the United States Government. Neither the United States nor its agent, the United States Energy Research and Development Administration, nor any Federal employees, nor any of their contractors, subcontractors or their employees, makes any warranty, express or implied, or assumes any legal liability or responsibility for the accuracy, completeness, or usefulness of any information, apparatus, product or process disclosed, or represents that its use would not infringe privately owned rights. 


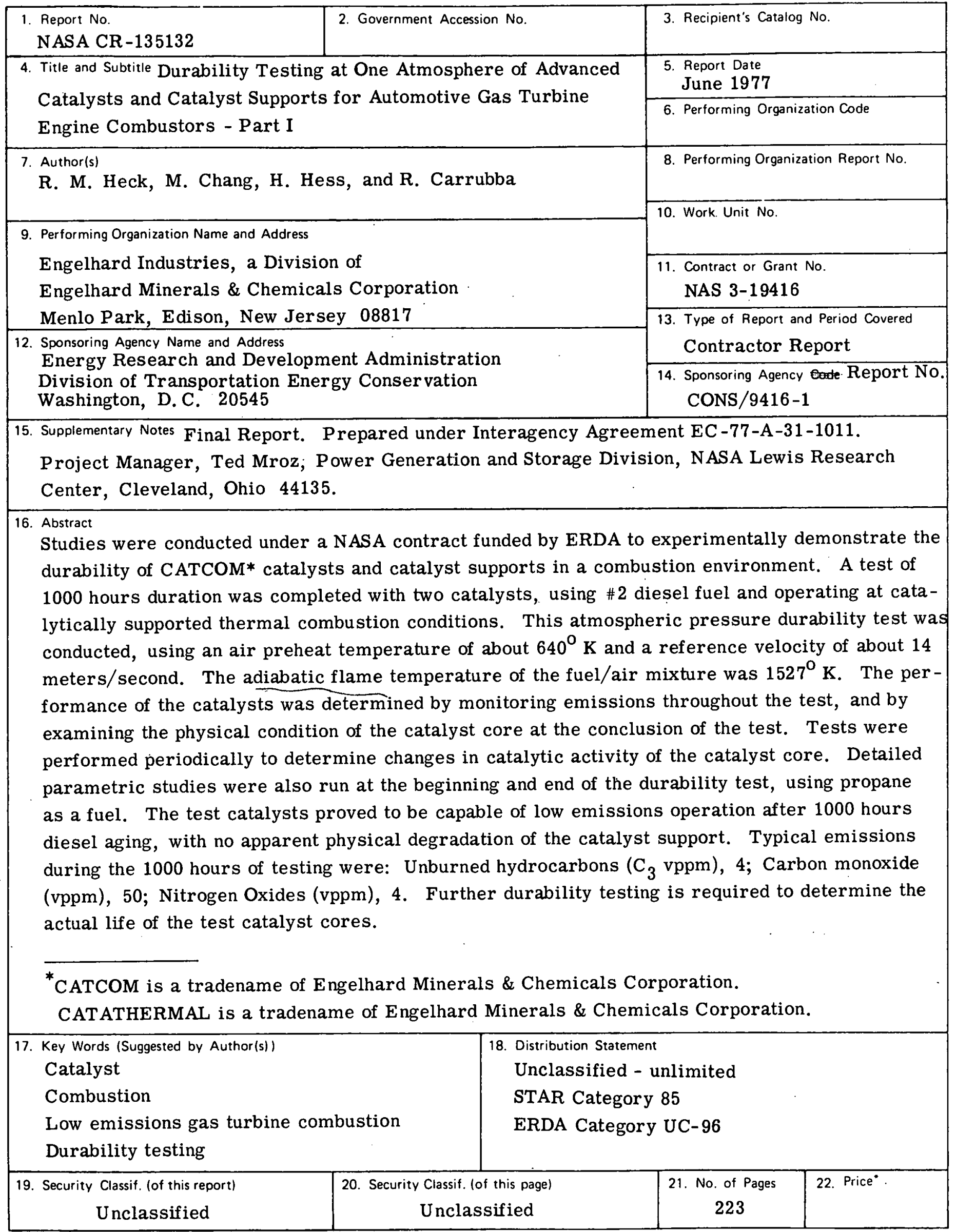

* For sale by the National Technical Information Service, Springfield, Virginia 22161 
PART I -

DURABILITY TESTING AT ONE ATMOSPHERE

OF ADVANCED CATALYST AND CATALYST SUF'PORTS

FOR AUTOMOTIVE GAS TURBINE ENGINE COMBUSTORS

by R. M. Heck, M. Chang, H. Hess and R. Carrubba

ENGELHARD INDUSTRIES

A DIVISION OF ENGELHARD MINERALS \& CHEMICALS CORPORATION

PREPARED FOR

NATIONAL AERONAUTICS AND

SPACE ADMINISTRATION

AND

ENERGY RESEARCH AND

DEVELOPMENT ADMINISTRATION

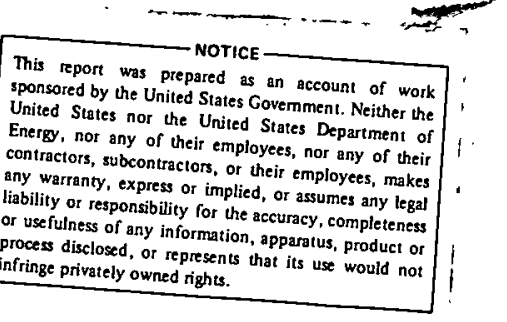


Page

I. SUMMARY 2

II. INTRODUCTION 5

III. TASK I - SELECTION OF TEST CATALYST CORES 7

A. CRITERIA AND JUSTIFICATION FOR CATALYST CORE 7 SELECTION

B. PROPOSED CATALYTIC CORES 7

C. BACKGROUND INFORMATION ON TEST CATALYST CORES 12

1. Standard Laboratory Screening Procedures 12

2. Ignition Characteristics 18

3. Catalyst Support Stability 21

4. Accelerated Thermal Aging 22

5. Emissions and Combustion Efficiencies 25

IV. TASK II - TEST FACILITIES 35

A. DESIGN AND CONSTRUCTION OF TEST RIG 35

B. TEST RIG PERFORMANCE CHECK OUT 44

1. Water-Cooled Probe Performance 44

2. Performance Comparison with Existing Test 47 Rig

C. OPERATING PROCEDURES 51

V. TASK III - PARAMETRIC AND ENDURANCE TESTING 52

A. EXPERIMENTAL TEST PROGRAM 52

1. Life Test with \#2 Diesel 54

2. Carbon Monoxide Activity Test 57

3. Propane Parametric Testing 60

B. EXPERIMENTAL RESULTS 62

1. Performance of Catalyst Core DXB-222 66 
TABLE OF CONTENTS (Cont'd.)

a. Life Testing with \#2 Diesel 0il 64

b. Carbon Monoxide Activity Test . 76

c. Propane Parametric Studies 81

d. Analysis of Propane Parametrics 88

1) Combustion Efficiency 89

2) Carbon Monoxide Emissions 89

3) Pressure Drop 92

2. Performance of Catalyst Core DXC-532 93

a. Life Testing with \#2 Diesel 0il 93

b. Carbon Monoxide Activity Test 111

c. Propane Parametric Study 114

d. Analysis of Propane Parametrics $\quad 116$

1) Combustion Efficiency 119

2) Carbon Monoxide Emissions 120

3) Pressure Drop 120

VI. DISCUSSION OF TEST RESULTS AND SELECTION OF 123 PREFERRED CATALYST CORE

A. LIFE TEST RESULTS 123

B. PROPANE PARAMETRICS $\quad 126$

c. CARBON MONOXIDE ACTIVITY TESTING 126

D. DIESEL PARAMETRICS 127

VII. CONCLUSIONS AND RECOMMENDATIONS 129

LIST OF REFERENCES 132

APPENDIX A WORK STATEMENT FOR TASKS I, II AND III OF A-1 NAS3-19476

APPENDIX B COMPUTER PRINTOUTS OF \#2 DIESEL LIFE TESTS B-1

APPENDIX $C$ COMPUTER PRINTOUTS OF PROPANE PARAMETRICS $\mathrm{C}-1$

APPENDIX D DETAILS OF GRAPHICAL ANALYSIS OF PROPANE D-1

PARAMETRIC DATA FOR DXB-222 and DXC-532

APPENDIX E DETAILED OPERATING INSTRUCTIONS E-1

APPENDIX $F$ DESIGN DRAWINGS FOR NASA TEST RIG F-1 


\section{LIST OF TABLES}

Page

III-1 Guidelines in Catalytic Core Selections • 8

III-2 Properties of Test Catalyst Cores 11

III-3 Ignition Performance of Engelhard DXA-111 19

III-4 Ignition Performance of Engelhard Catalyst Core 20 Candidates

III-5 Thermal Shock Test Results for Catalyst Core 23 Support

III-6 Thermal Stability for Catalyst Core Support 24

III-7 Emission Data For DXA-111 Using Various Fuels 29

IV-1 Operating Ranges for Unit $6 \quad 40$

IV-2 Description of Analytical Systems for Emissions 42

IV-3 Comparison Study of Unit \#6 With Unit \#5 49

IV-4 Comparison Study of Unit \#6 With Unit \#5 50 (C. P. Propane Fuel)

V-1 Analysis of \#2 Diesel Fuels Used for Catalyst 55 Life Tests

V-2 Life Test Conditions 56

V-3 Carbon Monoxide Activity Test Conditions 59

V-4 1/3 Replicated Factorial Design for 4 Variables 63 at 3 Levels

V-5 Comparison of Typical Operating Conditions and 74 Performance Data at Start and End of Life Test for Catalyst Core DXB-222

V-6 Combustion Efficiency Response of Propane 82 Parametrics Before and After 1000 Hour Life Test on Catalyst Core DXB-222

V-7 Comparison of Parametric Runs With C. P. Propane and \#2 Diesel After 1000 Hours Aging of DXB-222 
Page

V-8 Typical Statistical Models for Combustion 90 Efficiency

V-9 Typical Statistical Models for Carbon Monoxide 91 Emission

V-10 Comparison of Operating Conditions and 108 Performance Data at Start and End of Life Test for Catalyst Core DXC-532

V-11 Combustion Efficiency Response of Propane Parametrics Before and After 1000 Hour Life Tests on Catalyst Core DXB-532

VI-1 Comparison of Operating Conditions and Test Responses at 1000 Hours Life Testing

VI-2 Summary of Test Results on Catalyst Cores $D X B-222$ and DXC-532

E-1 Equations for Data Reduction Computer Program E-24

E-2 Nomenclature for Data Reduction E-25

E-3 Glossary of Terms E-32 


\section{$-v-$ \\ LIST OF FIGURES}

\begin{tabular}{|c|c|}
\hline III - ] & $\begin{array}{l}\text { Accelerated Thermal Aging Results on Selected } \\
\text { Catalyst Cores }\end{array}$ \\
\hline III-2 & $\begin{array}{l}\text { Effect of Air Preheat Temperature on Combustion } \\
\text { Efficiency for DXA-111 }\end{array}$ \\
\hline III-3 & $\begin{array}{l}\text { Effect of Catalyst Core Outlet Temperature on } \\
\text { Emissions for DXA-111 }\end{array}$ \\
\hline III-4 & $\begin{array}{l}\text { Response of Combustion Efficiency for DXA-111 to } \\
\text { Changes in Fuel/Air Ratio }\end{array}$ \\
\hline III -5 & $\begin{array}{l}\text { Effect of Space Velocity on Combustion Efficiency } \\
\text { for DXA-111 }\end{array}$ \\
\hline I I I - 6 & $\begin{array}{l}\text { Response of Hydrocarbon Conversion to Increasing } \\
\text { Air Preheat Temperature }\end{array}$ \\
\hline IV-1 & Schematic of Unit 6 Test Rig \\
\hline IV -2 & Photograph of Control Panel for Unit 6 Test Rig \\
\hline IV -3 & $\begin{array}{l}\text { Photograph Showing Physical Layout of Equipment } \\
\text { for Unit } 6 \text { Test Rig }\end{array}$ \\
\hline IV -4 & $\begin{array}{l}\text { Cooling Effect of Water-Cooled Sampling Probe } \\
\text { Under Combustion Conditions }\end{array}$ \\
\hline IV -5 & Adiabaticity of. Test Rig Reactor \\
\hline$V-1$ & $\begin{array}{l}\text { Typical Response Obtained from Carbon Monoxide } \\
\text { Activity. Test }\end{array}$ \\
\hline$V-2$ & $\begin{array}{l}\text { Hydrocarbon Emission Control Chart During Life } \\
\text { Testing of Catalyst Core } \mathrm{DXX}-222\end{array}$ \\
\hline$V-3$ & $\begin{array}{l}\text { Carbon Monoxide Emission Control Chart During } \\
\text { Life Testing of Catalyst Core DXB- } 222\end{array}$ \\
\hline$V-4$ & $\begin{array}{l}\text { NOx Emission Control Chart During Life Testing of } \\
\text { Catalyst Core DXB-222 }\end{array}$ \\
\hline$V-5$ & $\begin{array}{l}\mathrm{CO}_{2} \text { and } \mathrm{O}_{2} \text { Control Chart During Life Testing of } \\
\text { Catalyst Core DXB-222 }\end{array}$ \\
\hline
\end{tabular}


V-6. Temperature Control Chart During Life Testing of 69 Catalyst Core DXB-222

V-7 Pressure Drop Control Chart During Life Testing 70 of Catalyst Core DXB-222

V-8. Photographs of Catalyst Core DXB-222 After $1000 \quad 75$ Hours Life Testing

V-9 Carbon Monoxide Activity Test Response During 77 Life Testing of Catalyst Core DXB-222

V-10 Response of Ignition Temperature of Carbon 79 Monoxide During Activity Tests on Catalyst Core DXB-222

V-11 Response of Mass Transfer Limited Conversion of 80 Carbon Monoxide From Activity Tests on Catalyst Core DXB-222

V-12 Plot of Comparison Runs for \#2 Diesel and. C. P. Propane After 1000 Hour Diesel Aging of Catalyst Core DXB-222

V-13 Comparison of Experimental and Predicted Percent 94 Pressure Drop of Catalyst Core DXB-222 (Combustion Conditions)

V-14 Hydrocarbon Emission Control Chart During Life 96 Testing of Catalyst Core DXC-532

V-15 Carbon Monoxide Emission Control Chart During 97 Life Testing of Catalyst Core DXC-532.

V-16 Nox Emission Control Chart During Life Testing 98 of Catalyst Core DXC-532:

V-17 $\mathrm{CO}_{2}$ and $\mathrm{O}_{2}$ Control Chart During Life Testing of 99 Catalyst Core DXC-532

V-18 Temperature Control Chart During Life Testing of 100 Catalyst Core DXC-532

V-19 Pressure Drop Control Chart During Life Testing 101 of Catalyst Core DXC -532

V-20 Typical Startup Response for Catalyst Core 103 Resulting in Low Emissions Operation 


\begin{tabular}{|c|c|c|}
\hline$V-21$ & $\begin{array}{l}\text { Typical Startup Response of Catalyst Core } \\
\text { DXC-532 After } 400 \text { Hours Life Testing }\end{array}$ & 104 \\
\hline$V-22$ & $\begin{array}{l}\text { Typical Startup Response of Catalyst Core } \\
\text { DXC-532 After } 1000 \text { Hours Life Testing }\end{array}$ & 105 \\
\hline$V-23$ & $\begin{array}{l}\text { Photographs of Catalyst Core DXC-532 After } 1000 \\
\text { Hours Life Testing }\end{array}$ & 110 \\
\hline$V-24$ & $\begin{array}{l}\text { Carbon Monoxide Activity Test Response During } \\
\text { Life Testing of Catalyst Core DXC }-532\end{array}$ & 112 \\
\hline$V-25$ & $\begin{array}{l}\text { Response of Ignition Temperature of Carbon } \\
\text { Monoxide During Activity Tests on Catalyst } \\
\text { Core DXC-532 }\end{array}$ & 113 \\
\hline$V-26$ & $\begin{array}{l}\text { Response of Mass Transfer Limited Conversion of } \\
\text { Carbon Monoxide Conversion from Activity Tests } \\
\text { on Catalyst Core DXC-532 }\end{array}$ & 115 \\
\hline$V-27$ & $\begin{array}{l}\text { Comparison of Experimental and Predicted Percent } \\
\text { Pressure Drop of Catalyst Core DXC-532 } \\
\text { (Combustion Condition) }\end{array}$ & 122 \\
\hline$D-1$ & $\begin{array}{l}\text { Combustion Efficiency Versus Air Preheat } \\
\text { Temperature for Catalyst Core DXB-222 (Initial } \\
\text { Propane Parametrics) }\end{array}$ & $D-3$ \\
\hline$D-2$ & $\begin{array}{l}\text { Combustion Efficiency Versus Reference Velocity } \\
\text { for Catalyst Core DXB-222 (Initial Propane } \\
\text { Parametrics) }\end{array}$ & $D-4$ \\
\hline$D-3$ & $\begin{array}{l}\text { Combustion Efficiency Versus Operating Pressure } \\
\text { for Catalyst Core DXB-222 (Initial Propane } \\
\text { Parametrics) }\end{array}$ & $D-5$ \\
\hline$D-4$ & $\begin{array}{l}\text { Combustion Efficiency Versus Adiabatic } \\
\text { Operating Temperature for Catalyst Core DXB-222 } \\
\text { (Initial Propane Parametrics) }\end{array}$ & $D-6$ \\
\hline D-5 & $\begin{array}{l}\text { Combustion Efficiency Versus Combined Independent } \\
\text { Variables for Catalyst Core DXB-222 (Initial } \\
\text { Propane Parametrics) }\end{array}$ & D-8 \\
\hline$D-6$ & $\begin{array}{l}\text { Averaged Response of Combustion Efficiency Versus } \\
\text { Preheat Air Temperature and Operating Pressure fo } \\
\text { Catalyst Core DXB-222 (Initial Propane Parametric }\end{array}$ & D-9 \\
\hline
\end{tabular}


Versus Reference Velocity and Adiabatic Operating Temperature for Catalyst Core DXB-222 (Initial Propane Parametrics)

E-1 Schematic Showing Details of Packing of Test Catalyst Cores 
THIS PAGE

\section{WAS INTENTIONALLY LEFT BLANK}




\section{SUMMARY}

The objective of NASA contract NAS3-19416 was to experimentally demonstrate the durability of two CATCOM* catalysts in a combustion environment. Life tests** of 1,000 hours duration were successfully completed with two catalyst cores, identified as DXB-222 and DXC-532, using \#2 diesel fuel and operating at catalytically supported thermal combustion conditions. This contract was funded by ERDA and managed by NASA/Lewis.

These atmospheric life tests were conducted at steady state conditions using an air preheat temperature of $640^{\circ} \mathrm{K}$ and a reference velocity of 14 meters/second. The adiabatic flame temperature of the fuel/air mixture was $1527^{\circ} \mathrm{K}$.

The performance of the catalyst cores was determined by monitoring emissions of $U H C, C O$ and $\mathrm{NO}_{x}$ throughout the life test, and by examining the physical condition of the catalyst. core at the conclusion of the life test. Scheduled activity tests were performed periodically during the life test to determine changes in catalytic activity of the catalyst core. Detailed parametric studies were performed at the beginning and end of each life test, using propane as a fuel. Parametric testing was performed at pressures of $1 \times 10^{5} \mathrm{~N} / \mathrm{M}^{2}$ to $5 \times 10^{5} \mathrm{~N} / \mathrm{M}^{2}$, air preheat temperatures of $633^{\circ} \mathrm{K}$ to $810^{\circ} \mathrm{K}$ and reference velocities of $14 \mathrm{M} / \mathrm{S}$ to $30 \mathrm{M} / \mathrm{S}$.

\footnotetext{
*CATCOM is a trade name of Engelhard Minerals and Chemicals Corp. ** Life test implies a 1,000 hour durability test throughout this report.
} 
These studies were carried out in a test rig which was designed and constructed under the contract. The key component of this rig was a nominal one-inch diameter tubular reactor, in which the catalyst was mounted. Operation of this reactor was essentially adiabatic.

Although some catalyst degradation did occur, both catalyst cores DXB-222 and DXC-532 proved to be capable of low emissions operation after 1,000 hours of operation with \#2 diesel. Apparently there was no physical degradation of the catalyst support. For both cores, typical emissions during the 1,000 hours of life testing were:

$\begin{array}{lr}\text { Unburned Hydrocarbons ( } C_{3} \text { vppm) } & 4 \\ \text { Carbon Monoxide (vppm) } & 50 \\ \text { Nitrogen Oxides (vppm) } & 4\end{array}$

These test results proved the feasibility of using CATCOM catalysts DXB222 and DXC-532 in CATATHERMAL* combustion, catalytically supported thermal combustion, for at least 1000 hours of low emission steady state operation with \#2 diesel fuel.

The preferred catalyst core selected from these studies for further testing was $\mathrm{DXB}-222$. This catalyst proved to have a wider range of low emissions operation with \#2 diesel fuel after 1,000 hours of aging.

*CATATHERMAL is a trade name of Engelhard Minerals \& Chemicals Corporation. 


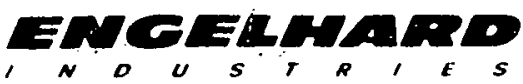

$-4-$

It is recommended that additional 1 ife testing of $D X B-222$ be carried out at higher pressures, in order to more closely simulate gas turbine engine operating conditions, and determine durability at increased operating pressure. It is further recommended that a parallel effort be carried out to test DXB-222 in realistic combustion hardware to evaluate transient and response characteristics. 


\section{INTRODUCTION}

The concept of using catalysts for low emission combustion processes has been intensively explored by Engelhard Industries Division of Engelhard Minerals and Chemicals Corporation over the past five years. Laboratory tests have shown the feasibility of low emissions operation, particularly $\mathrm{NO}_{x}$ emissions, with a wide variety of gaseous and liquid fuels $(1,2)$. Rig tests at NASA Lewis, Westinghouse and Wright Patterson Air Force Base have confirmed these laboratory results, and also showed the ease of scale-up and improved temperature pattern factor for CATCOM catalysts $(3,4,5)$.

NASA Lewis Research Center realized that information on the durability of the catalyst and catalyst support in the extreme conditions of a combustion environment was required to further demonstrate the practicality of candidate CATCOM catalysts. In addressing this question, the NASA contract NAS3-19416, entitled "Catalyst and Catalytic Substrate Material for Gas Turbine Engine Combustion" was awarded to Engelhard Industries on March 21, 1975. The period of performance of this

contract was 18 months. Under this contract relevant information was to be obtained on the long term operation capabilities of CATCOM catalysts. This contract was funded by ERDA and managed by NASA/Lewis.

The program under this contract was divided into four tasks as follows: 
Task I - Survey and Selection of Contractors Catalysts and Catalytic Substrates for Parametric and Endurance Testing

Task II - Test Facilities

Task III - Sub-scale Catalytic Substrate Parametric and Endurance Testing

Task IV - Reporting Requirements.

For reference, the detailed Work Statement is given in Appendix A.

Task I of the contract required selection of catalyst cores for endurance testing, based on catalyst screening results at Engelhard Industries. Under Task II, a test rig and adiabatic tubular reactor were constructed. Task III involved life testing of two selected catalyst cores. These life tests were conducted at conditions which simulated steady state operation of an automotive gas turbine. Testing was satisfactorily completed on two catalyst cores designated DXB-222 and DXC-532.

The details of this contract, the construction of the test rig, the performance test results and conclusions regarding the durability of the catalyst cores are discussed in this report. 
III. TASK I - SELECTION OF TEST CATALYST CORES

\section{A. CRITERIA AND JUSTIFICATION FOR CATALYST CORE SELECTION}

During the first month of the contract, a thorough review of in-house catalyst screening data was conducted in order to select the most promising catalyst cores for life testing. The guidelines upon which this selection was based are shown in Table III-1.

As the contract period progressed, on-going catalyst development programs provided supplemental information on new catalyst cores. With the approval of the NASA Program Manager, one of these catalyst cores was substituted into Task III, replacing one of the originally chosen cores. This substitution was made based on in-house test results, which showed that the new catalyst core had better potential for higher temperature stability.

For purposes of clarity, only the data pertinent to the two Engelhard catalyst cores actually tested in Task III plus a standard reference catalyst, will be reviewed.

\section{B. PROPOSED CATALYTIC CORES}

During the past five years, Engelhard Industries has been actively engaged in a catalyst core development program, aimed at 
TABLE III-1

Guidelines In Catalytic Core Selections

1. Durability and life of the catalytic core at the specified operating conditions.

2. Low emissions ( $\mathrm{NO}_{\mathrm{X}}, \mathrm{CO}$ and $\left.\mathrm{HC}\right)$ characteristics and operation at the specified operating conditions.

3. Ignition characteristics.

4. Cost of catalyst materials.

5. Availability of catalyst.

6. Compounds or elements which act as poisons to the catalysts.

7. Catalytic core degradation.

8. Catalytic core maximum operational temperature.

9. Developmental status.

10. Contractor's in-house screening test parameters (inlet and outlet temperature, inlet pressures, reference velocity, heat release rates, test fuels, test duration and fuel-air ratios).

11. In-house screening test results ( $\mathrm{NO}_{\mathrm{X}}, \mathrm{CO}$ and $\mathrm{HC}$ emissions, combustion efficiency, ignition characteristics, pressure drop and degradation, if any).

12. Identification of catalyst support materials.

13. Identification of catalytic core.

14. Differences between the screened and recommended catalytic cores. 
selection of prime candidates for combustion applications. These catalyst cores were screened using the following test sequence:

1. Ignition Properties

2. Support Performance

3. Accelerated Thermal Aging

4. Emissions at Simulated Commercial Gas Turbine Engine Operating Conditions

5. Life Testing

As this sequence progresses, candidates that fail are eliminated from the next step.

The "control" (or reference) catalyst core throughout this sequence was designated DXA-111. This "first generation" catalyst core has been tested successfully in many large scale test rigs including those at NASA-Lewis, Westinghouse and Wright Patterson AFB $(3,4,5)$. The catalyst cores proposed in Task I showed significantly improved performance over DXA-111.

In this catalyst development program, over 150 catalyst compositions were tested at one stage or another of the screening procedure. Catalytic components ranging from base metals to rare earths to precious metals, as well as combinations of these, were tested. For the NASA Program, candidates were selected on the basis of their known properties and the NASA Program requirements. 
The two proprietary Engelhard catalyst cores, which were life tested in Task III are designated as DXB-222 and DXC-532 and are described in Table III-2. Both catalyst cores have the same catalytic components with the major differences being: 1) In the ratio of $\mathrm{Pd}$ to Pt, and; 2) the specific high temperature stabilizers used. In relation to the control catalyst core DXA-111, both DXB-222 and DXC-532 are prepared on an improved ceramic support material. Catalyst cores DXB222 and DXC-532 showed the most improved ignition characteristics of all catalysts tested in-house. Both DXB-222 and DXC-532 have a broader range of low emissions operation in comparison to DXA-111. In addition, DXB-222 and DXC-532 showed excellent thermal stability throughout the screening test series. From short term testing, the combination of support, stabilizers and catalytic components on DXB-222 and DXC-532 appeared to be the most promising for long term durability in life testing. The 1000 hour life tests under this contract were necessary to determine life potential.

The following data in support of selection of catalyst core DXB-222 and DXC-532 show that the main criteria for selection was the improvement in the thermal stability and emission characteristics over the control catalyst core DXA-111. 
TABLE III-2

Properties of Test Catalyst Cores

Catalyst

Identification

DXB -222

$D \times C-532$
Catalyst

Components

Palladium and Platinum

(Combined Tevel up to $5 \%$ )

Palladium and Platinum

(Combined level up to $5 \%$ )

\section{Support}

256

Channels/in2

Zircon

Composite

256

Channels/in ${ }^{2}$

Zircon

Composite

NOTE: In all cases, the above catalyst cores contain proprietary stabilizers. These stabilizers represent major differences in the two test catalysts. 
c. BACKGROUND INFORMATION ON TEST CATALYST CORES

\section{Standard Laboratory Screening Procedures}

Frequently, the last step in the demonstration of a new catalyst core is the actual life testing of the catalyst under a commercial operating environment. This is primarily because a realistic life test is extremely time consuming and expensive. For purposes of efficiency and economy, catalysts which are not promising from an application standpoint must be eliminated prior to the life testing stage.

In developing the CATCOM catalysts, it was necessary to develop rapid but reliable screening tests for selection of catalyst core candidates for life testing. The screening test sequence was designed to select candidates having a good probability of subsequent success in life testing. Catalyst performance was first evaluated using a coarse screening procedure, which narrows down the number of candidates, followed by more detailed evaluations simulating commercial operations.

The tests used for screening catalyst cores for "catalytically supported thermal combustion" were as follows:

Ignition temperature: Will the catalyst core ignite at a useful operating temperature and sustain this ignition 
characteristic? (Some catalysts exhibited low ignition temperatures, but on subsequent ignitions, this temperature increased.)

Thermal degradation: Will the catalyst support withstand the temperature involved in combustion operations?

Accelerated thermal aging: Will the catalyst core perform adequately with sustained ignition characteristics and low emissions after exposure to combustion temperatures?

Emissions: Will the catalyst core give acceptable emissions under simulated commercial combustion conditions, with a variety of combustion fuels?

Life test: Will the catalyst core maintain acceptable performance for required operating times of the combustor application?

As these screening procedures progressed, catalyst cores that showed the most significant improvement over the control catalyst DXA-111 were selected for the next testing sequence.

A brief description of each test follows:

Ignition Temperature: The inlet temperature of the fuel/air mixture is raised in $10^{\circ} \mathrm{K}$ increments until catalytic 
reaction begins within the catalyst core. Typically, this experiment is performed under the following conditions:

\begin{tabular}{ll} 
Space VelocitynTP: & $28 \mathrm{M}^{3} / \mathrm{S}-\mathrm{M}^{3}\left(100,000 \mathrm{Ft} .3 / \mathrm{Hr} .-\mathrm{Ft}^{3}\right)$ \\
Fuel Type: & Variable \\
\hline Air/Fuel Wgt.: & $38 / 1(\mathrm{~g} / \mathrm{g})$ \\
Pressure: & $1 \times 10^{5} \mathrm{~N} / \mathrm{m}^{2}(1 \mathrm{~atm})$.
\end{tabular}

The typical temperature response on a strip chart recorder

is as follows:

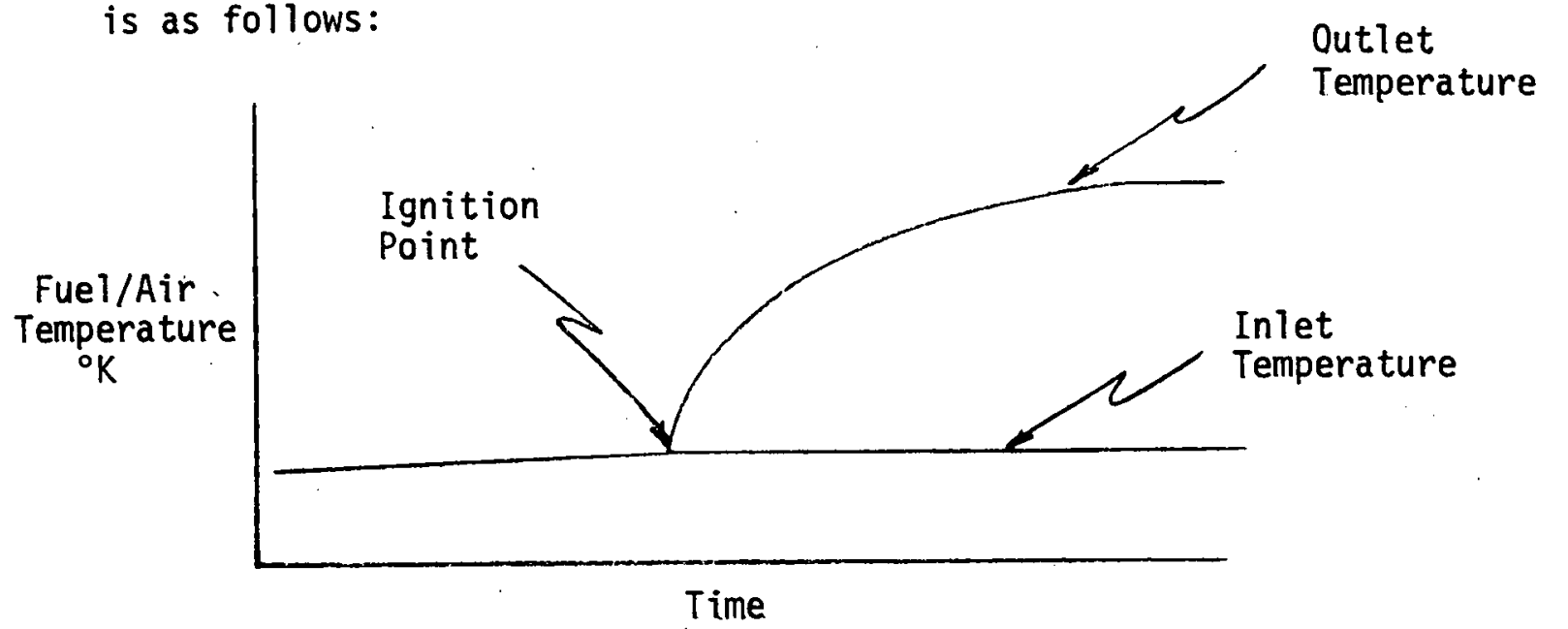

Thermal Degradation: Three separate experiments are performed on the catalyst support:

Thermal Shock: The support is placed in a furnace preheated to either $1170^{\circ} \mathrm{K}$ or $1270^{\circ} \mathrm{K}$. After 10 minutes in the furnace, the support is removed and allowed to cool in ambient air. The support is physically examined for damage after cooling is complete. This process is repeated 10 times at each temperature level. These 
test results depend on the test specimen size. As a minimum, a support block of .127M $\left(5^{\prime \prime} \Phi\right) *$ is used.

Sag and Melt Point: The support is initially placed in a preheated furnace for 24 hours at $1589^{\circ} \mathrm{K}$. At the end of this 24 hour period the support is removed and examined for structural defects due to sagging of channels or melting. These observations are recorded and the support placed back in the furnace for another 24 hour period. For each thermal cycle, the furnace temperature is raised in increments of $56^{\circ} \mathrm{K}$. The temperature at which the channels first begin to sag or support melting occurs is recorded and the test is terminated. This test is terminated at $1820^{\circ} \mathrm{K}$.

\section{Differential Thermal Analysis: The support}

is placed in a DTA apparatus and the temperature for phase transition is determined.

Accelerated Thermal Aging: As a baseline, a fresh catalyst sample is tested in the laboratory reactor to determine its "virgin" activity. The tests consist of a standard ignition test, followed by a hydrocarbon conversion test, as described below.

An identical sample is then thermally aged at $1590^{\circ} \mathrm{K}$ for 24 hours in a preheated furnace with air as the environment.

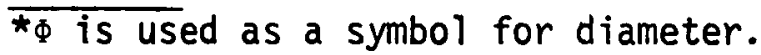


Following this aging step, the catalyst is removed from the furnace and the ignition temperature measurement and hydrocarbon conversion test are carried out.

The conditions for the hydrocarbon conversion test

are:

\begin{tabular}{ll} 
Space Velocity: & $28,56,69 \mathrm{M}^{3} / \mathrm{sec}-\mathrm{M}^{3}$ \\
& $(100,000,200,000$ and \\
& $\left.250,000 \mathrm{ft} .3 / \mathrm{hr} .-\mathrm{ft}^{3}\right)$ \\
& $80 / 1(\mathrm{~g} / \mathrm{g})$ \\
Air/Fuel Ratio: & Commercial. propane \\
Fuel: & $670^{\circ} \mathrm{K}$ \\
Inlet Temperature: & $1 \times 10^{5} \mathrm{~N} / \mathrm{m}^{2}(1 \mathrm{~atm})$. \\
\hline Pressure: &
\end{tabular}

Hydrocarbon conversion: is measured at each space velocity, once steady state has been attained.

Comparison between catalysts can be done by comparing their relative activity. Relative activity is defined as the space velocity required to maintain $50 \%$ hydrocarbon conversion level for the tested catalyst divided by the corresponding space velocity for DXA-111. 
The above conditions have been deliberately chosen so that complete combustion is not achieved, even for the best catalysts. Differences between catalysts cannot be determined if the conditions are such that complete combustion is usually achieved.

\title{
Emissions Testing: The catalyst core is tested in
}

a laboratory test rig using commercial combustor fuels under conditions which partially simulate commercial gas turbine operation. Specifically, the following parameters are set to duplicate proposed design conditions for stationary gas turbine engines:

\author{
Space velocity \\ Air preheat temperature \\ Air/fuel weight ratio
}

Combustion efficiency and emissions exiting the catalyst core are determined for performance comparisons.

Life Testing: The catalyst core is run in the laboratory test rigs using the fuel specific to the proposed commercial application, under partially simulated, full-load, commercial operating conditions. These conditions naturally vary with each commercial operation. Due to rig limitations, it is usually not possible to operate at proposed commercial operating pressures. 


\section{Ignition Characteristics}

The ignition characteristics of the catalyst core are highly dependent upon the nature of the fuel. Table III-3 shows the ignition characteristics of DXA-111 for a variety of fuels used in commercial combustion applications. Notice that the most refractory fuel is methane. Determination of improvements in the methane ignition temperature represents the first coarse screen of catalyst testing sequence.

Catalytic cores with initially good ignition characteristics may deteriorate in repeated ignitions due to thermal degradation, resulting in substantial increases in subsequent ignition temperatures. Many virgin catalysts ignited below $530^{\circ} \mathrm{K}$ but subsequent ignitions ranged as high as $810^{\circ} \mathrm{K}$. These catalysts were eliminated from further consideration.

Table III-4 shows the methane ignition results for the two proposed catalyst cores. DXB-222 and DXC-532 showed the best methane ignition characteristics, and had a total of on 1 y $5-10^{\circ} \mathrm{K}$ increase after repeated ignition experiments. This lowering of ignition temperature relative to DXA-III is attributed to the increased intrinsic activity of the catalyst components in these catalytic cores. DXB-222 and DXC532 also showed good thermal stability, in that repeated ignitions showed no significant degradation. 
TABLE III -3

Ignition Performance of Engelhard DXA-111

$\begin{array}{lc}\text { Fuel }^{\text {Catalytic Ignition }} & \begin{array}{c}\text { Catal } \\ \text { Temperature }\left({ }^{\circ} \mathrm{K}\right)\end{array} \\ \text { Hydrogen } & 290 \\ \text { Coa1 Gas } & 430 \\ \text { Methane } & 740 \\ \text { Propane } & 605 \\ \text { JP-4 } & 510 \\ \text { \#2 Diese1 } & 540 \\ \text { Methanol } & 455 \\ \text { Benzene } & 515\end{array}$

Range of Test Conditions:

$$
\begin{aligned}
& \text { Fuel/Air (wgt.) }=\frac{.0263 \mathrm{~g} / \mathrm{g}}{(.313 \mathrm{~g} / \mathrm{g} \text { for Coal Gas) }} \\
& \text { Space Velocity NTP }=28 \text { to } 83 \mathrm{~m}^{3} / \mathrm{S}-\mathrm{M}^{3}
\end{aligned}
$$


Ignition Performance of Engelhard Catalytic Core Candidates

Catalytic Core
Designation

DXA-111

$\mathrm{DXB}-222$

DXC-532
Methane Ignition

Temperature $\left({ }^{\circ} \mathrm{K}\right)$

740

550

570

\section{Test Conditions:}

Fuel $/$ Air (wgt.) $=.0263 \mathrm{~g} / \mathrm{g}$

Space Velocity NTP $=\sim 28 \mathrm{M}^{3} / \mathrm{S}-\mathrm{M}^{3}$ 


\title{
3. Catalyst Support Stability
}

The chemical and physical stability of the catalyst support is important in the selection of the catalyst core. The catalyst support must be compatible, such that the catalyst can be prepared on the catalyst support, and the catalyst support must not adversely affect the performance of the catalyst core under combustion conditions.

During this development program, over 20 support candidates were screened. Some of the common suppors materials available for high temperature operation are $\alpha-\mathrm{Al}_{2} \mathrm{O}_{3}$, cordierite, mullite, SiN and SiC. A number of manufacturers such as DuPont, American Lava, Corning, Pure Carbon, NGK, Kyocera and W. R. Grace are engaged in marketing high temperature honeycomb supports.

Engelhard has found that alumina and zircon composites are acceptable substrate materials.

The three prescreening tests used to select support candidates are:

\author{
Thermal shock $-\infty$ \\ Sag and melt point \\ Phase transition (DTA)
}


The results of the thermal shock tests on the improved support proposed for use in this program are shown in Table III-5. As a contrast, many other supports actually shattered during the first cycle of this test procedure.

The sag and melt point test explored the maximum operating excursions possible during the combustion conditions. The test results show (see Table III-6) that, even at $1820^{\circ} \mathrm{K}$, no problems in channels collapsing nor support melting were noticed. To support this conclusion, the DTA scan was run (see Table III-6) and results showed no phase change occurred up to $1820^{\circ} \mathrm{K}$. This temperature represents the upper limit for this particular DTA apparatus.

\section{Accelerated Thermal Aging}

Catalyst cores that showed significant improvements over DXA-111 in ignition and support evaluations were further tested in the accelerated thermal aging test. Experience from automotive catalyst development has shown that a catalyst must be resistant to accelerated thermal aging to sustain acceptable performance under actual operating conditions. This accelerated test procedure was designed to simulate exposure of the catalyst core to actual combustion temperatures. 


\section{TABLE III -5}

Thermal Shock Test Results For Catalyst Core Support

Test

Temperature

$1170^{\circ} \mathrm{K}$

$1270^{\circ} \mathrm{K}$

\begin{tabular}{l}
$\begin{array}{l}\text { Appearance of } \\
\text { 1st Crack }\end{array}$ \\
\hline $\begin{array}{l}\text { None after } \\
10 \text { cycles }\end{array}$ \\
None after \\
10 cycles
\end{tabular}

Appearance of
1st Crack

None after

10 cycles
Final Disposition

Complete retention of integrity

Complete retention of integrity 
TABLE III-6

Thermal Stability For Catalyst Core Support

Test

Sag and melt point

Differential

Therma 1

Analys is
Results

No change up to $1820^{\circ} \mathrm{K}$ *

No phase change up to $1820^{\circ} \mathrm{K}$

* Equipment 1 imited to $1820^{\circ} \mathrm{K}$ maximum temperature. 
The results of these tests for the proposed catalyst cores are shown in Figure III-1. Note that both cores exhibit better performance than DXA-111. In contrast many of the catalyst cores tested and rejected had conversion levels from 0 to $20 \%$.

\title{
5. Emissions and Combustion Efficiencies
}

Emissions and combustion efficiency tests represent the first test in the screening sequence where the catalyst core is tested under operating conditions approaching full-load, commercial combustion conditions. Since DXA-111 was selected as the first generation catalyst for outside testing, its characteristics were studied extensively, looking at the following responses:

\author{
Air preheat temperature (Fig.. III-2) \\ Catalyst core outlet temperature (Fig. III-3) \\ Effect of combustor fuel properties (Table III-7) \\ Fuel/air weight ratio in combustor feed (Fig. III-4) \\ Space velocity of catalyst core (Fig. III-5)
}

Figure III-3 shows that, for catalyst core operating temperatures above $1360^{\circ} \mathrm{K}$, the emissions for propane fuel are well below anticipated Federal Standards for automotive turbine and stationary turbine applications $(6,7)$. In addition, Table III-7 shows that these same low emissions can be obtained for a range of combustion fuels. 
Figure III-1

Accelerated Thermal Aging Results on Selected Catalyst Cores

Fuel: Commercial Propane Air/Fuel (wgt.): $80 / 1(\mathrm{~g} / \mathrm{g})$

Air Preheat: $670^{\circ} \mathrm{K}$ Aging Temperature: $1590^{\circ} \mathrm{K}$ Pressure: $1 \times 105 \mathrm{~N} / \mathrm{M} 2$ Aging Time: 24 hours in air

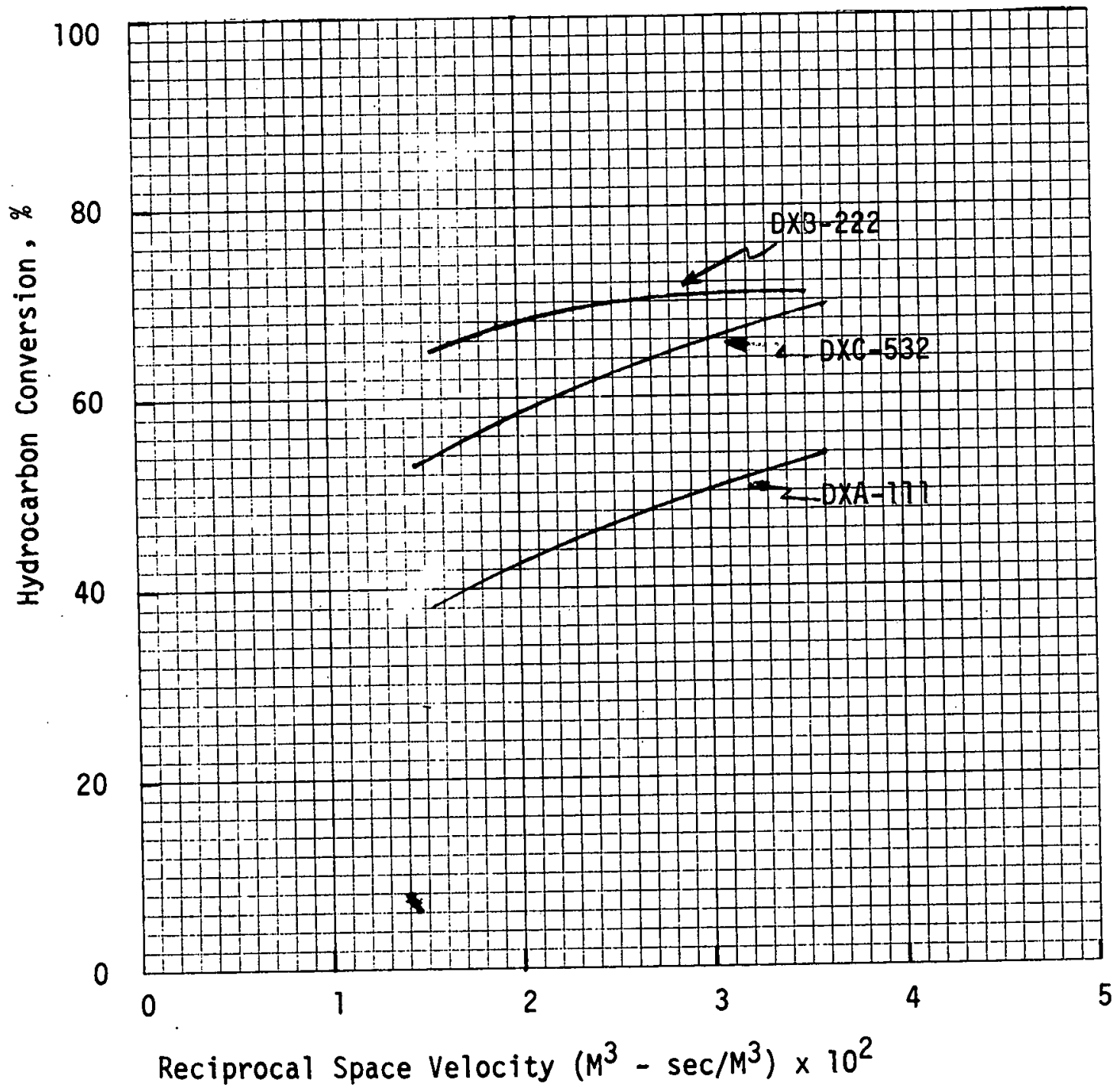


Figure III-2

Effect of Air Preheat Temperature on Combustion Efficiency For DXA-111

Fuel: Commercial Propane

Air/Fuel (wgt.): 38/1 (g/g)

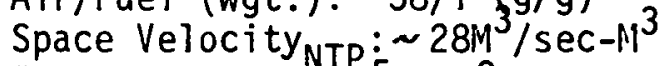

Pressure: $1 \times 105 \mathrm{~N} / \mathrm{M}^{2}$

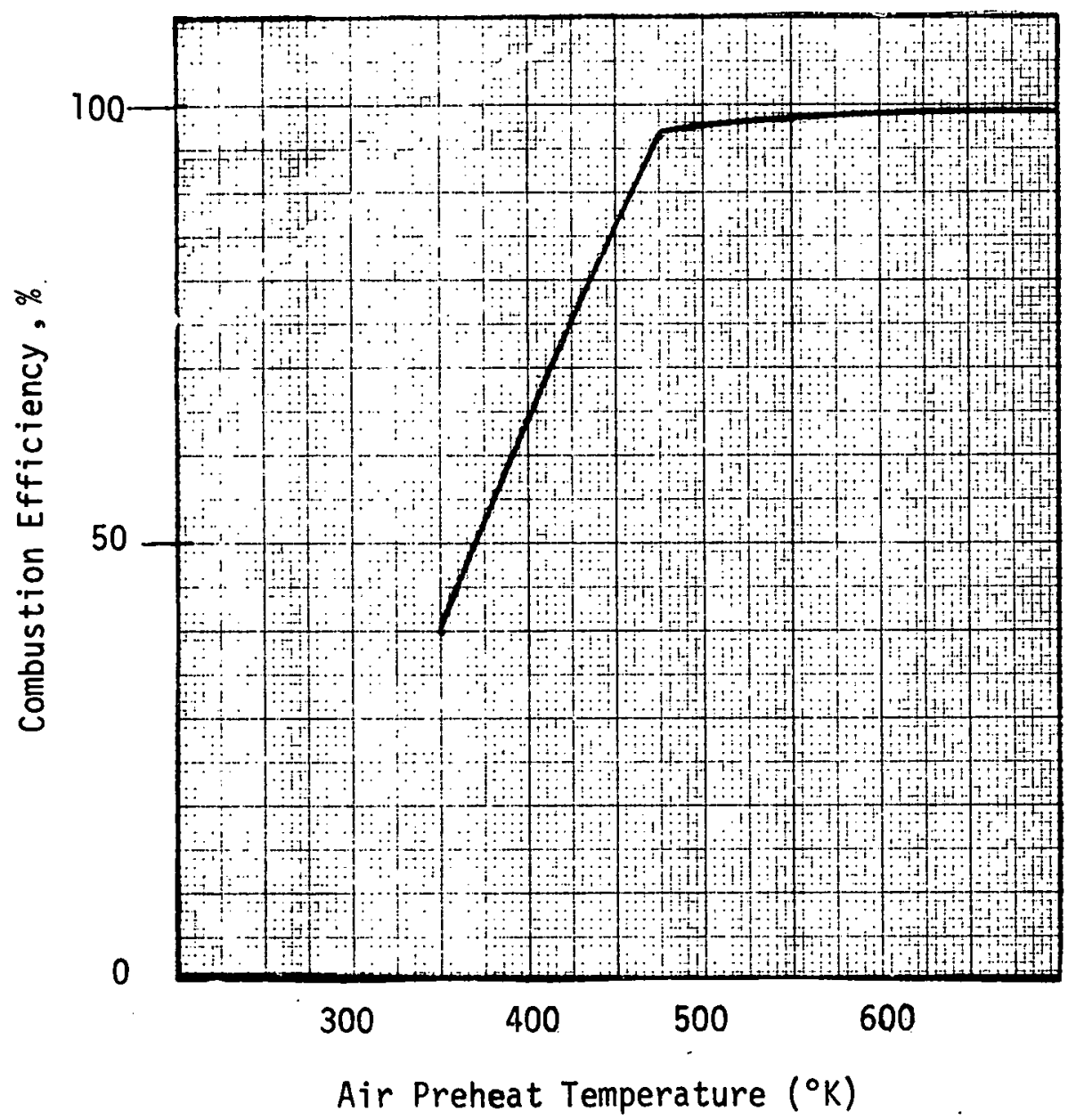


Figure III-3

Effect of Catalyst Core Outlet Temperature on Emissions for DXA-111

Fuel: Commercial Propane

Fuel/Air: $0.0263(\mathrm{~g} / \mathrm{g})$

Pressure: Atmospheric

Inlet Temperature: Varied

Space Velocity NTP: $\sim 28 \mathrm{~m} / \mathrm{s}-\mathrm{M}^{3}$

Legend:

- Carbon Monoxide

Hydrocarbons

- $\mathrm{NO}_{\mathrm{x}}$

---Instrument

Background Noise Level

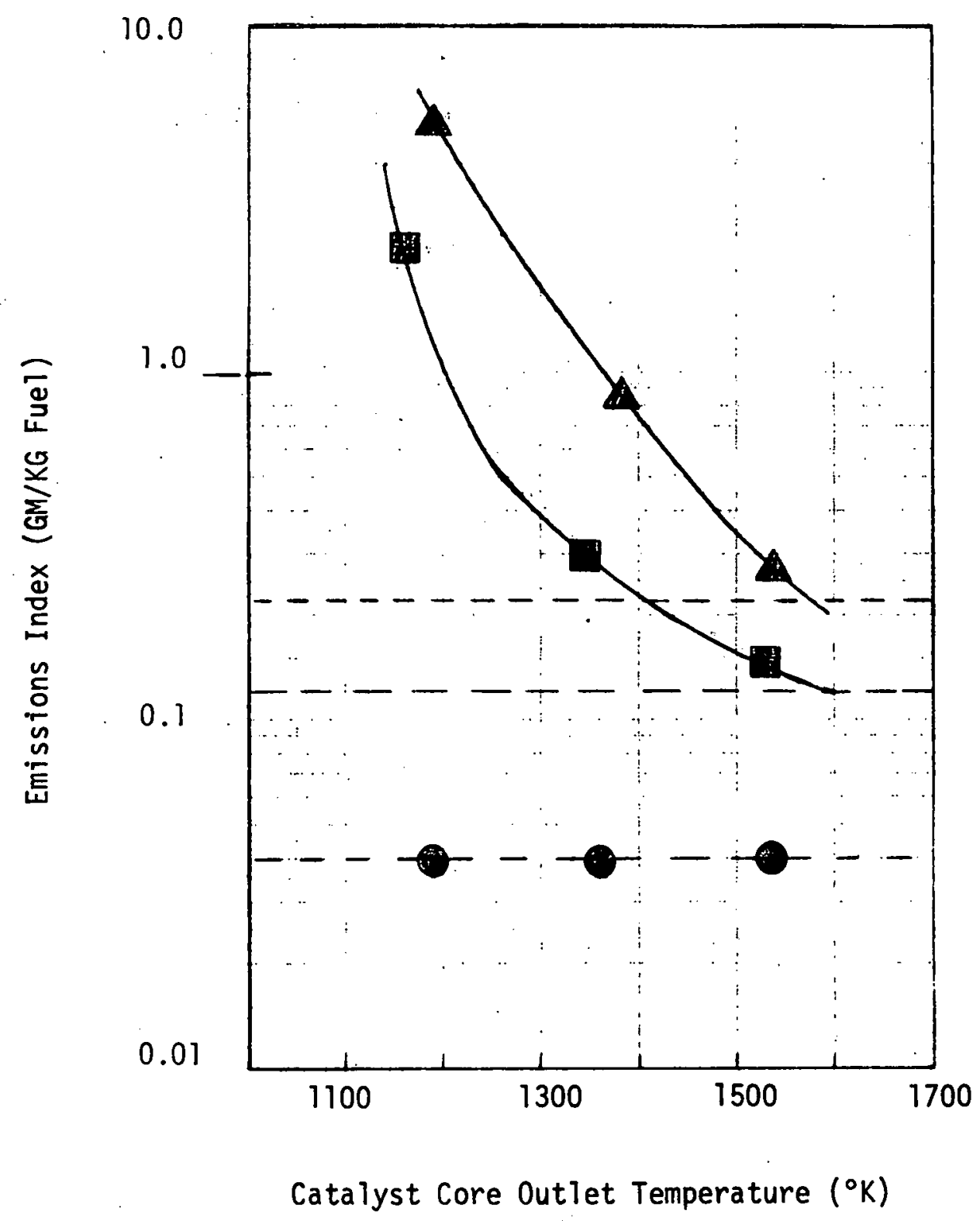




\section{TABLE II I-7}

Emission Data For DXA-111 Using Various Fuels*

Fuel

Methane

Propane

\#2 Diese1

$\mathrm{JP}-4$
$\mathrm{HC}\left(\mathrm{asC}_{3}\right)$
yppm

0

2

2

0
CO vppm

10

11

10

15
$\mathrm{NO}$

vppm

1

1

7

1

* Typical Conditions:

A/F Wgt.: $4.0 / 1(\mathrm{~g} / \mathrm{g})$

Air Preheat: $740^{\circ} \mathrm{K}$

Space Velocity NTP: $\sim 28 M^{3} / s-M^{3}$

Pressure: $1 \times 10^{5} \mathrm{~N} / \mathrm{M} 2$ 
$-30-$

Figure III-4

Response of Combustion Efficiency for

DXA-111 To Changes in Fuel/Air Ratio

Air Preheat Temperature: $\cdot 670^{\circ} \mathrm{K}$

Space Velocity NTP: $\quad \sim 28 \mathrm{M3} / \mathrm{s}-\mathrm{M} 3$

Pressure: $\quad 1 \times 10^{5} \mathrm{~N} / \mathrm{M}^{2}$

Fuel :

Commercial Propane

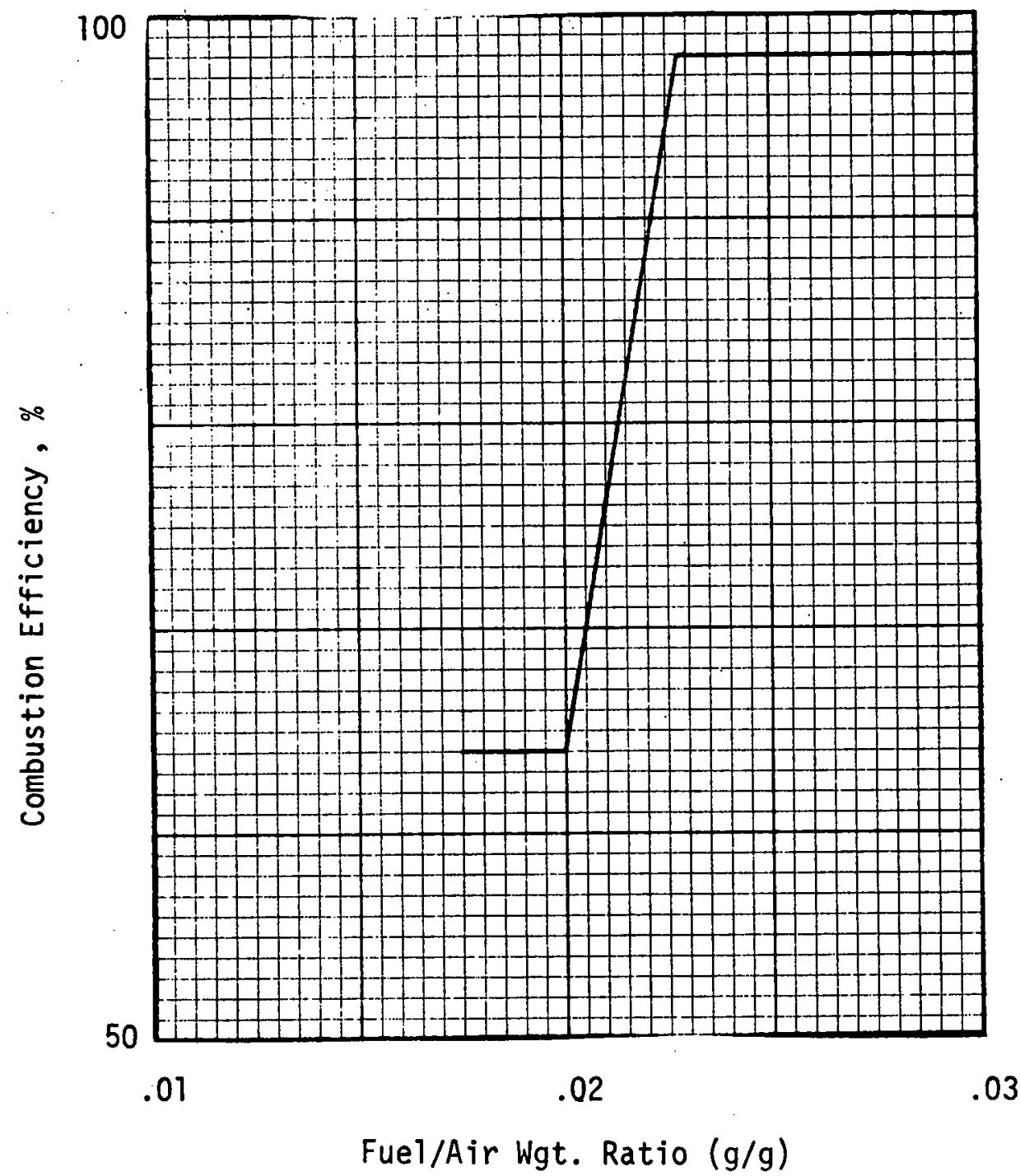


Figure III-5

Effect of Space Velocity on Combustion Efficiency For DXA-111

Fuel: Commercial Propane

Fuel/Air: $.026(\mathrm{~g} / \mathrm{g})$

Pressure: $1 \times 105 \mathrm{~N} / \mathrm{M}^{2}$

Inlet Temperature: $670^{\circ} \mathrm{K}$

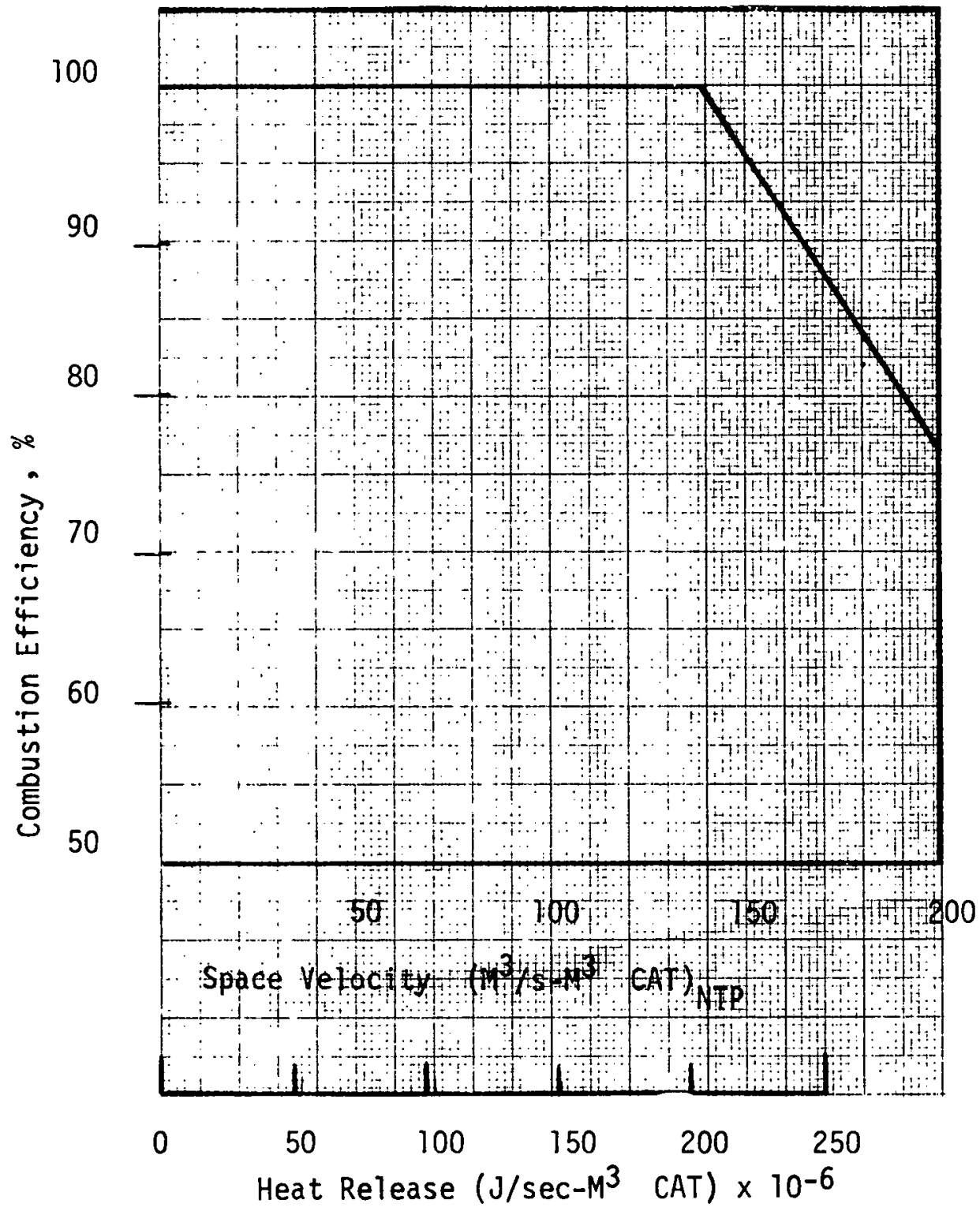


Since the emissions performance on DXA-111 was acceptable under typical commercial operating conditions (see Table III-7), improvements in the operating range were considered an important criteria in screening for catalyst core improvements. One test used was to determine the response of combustion efficiency as a function of air preheat temperatures. Improvements in catalyst core performance would be indicated by achieving high combustion efficiencies at lower preheat. temperature compared to DXA-111.

Figure III-6 demonstrates that both DXB-222 and DXC-532 yielded essentially $100 \%$ fuel conversion at temperatures as low as $500^{\circ} \mathrm{K}$, for the stated conditions. This is about $150^{\circ} \mathrm{K}$ lower than for the control catalyst, DXA-111. These improvements may result in a wider turndown range for these catalyst cores and, thus, better performance characteristics.

Many of the guidelines presented in Table III-1 for selection of test catalyst cores in Task III of this contract are satisfied as shown by the performance data for control catalyst core DXA-111. However, comparative screening tests indicate that catalyst cores DXB-222 and DXC-532 may have significant improvements over DXA-111 in

- ignition characteristics

- broader operating range for low emissions

- thermal stability 
Figure III-6

Response of Hydrocarbon Conversion

To Increasing Air Preheat Temperature

Fuel: Commercial Propane

Space Velocity: $\sim 28 \mathrm{M} 3 / \mathrm{s}-\mathrm{M}^{3}$

Air/Fuel (wgt.): $38 / 1 \cdot(\mathrm{g} / \mathrm{g})$

Pressure: $1 \times 105 \mathrm{~N} / \mathrm{M} 2$

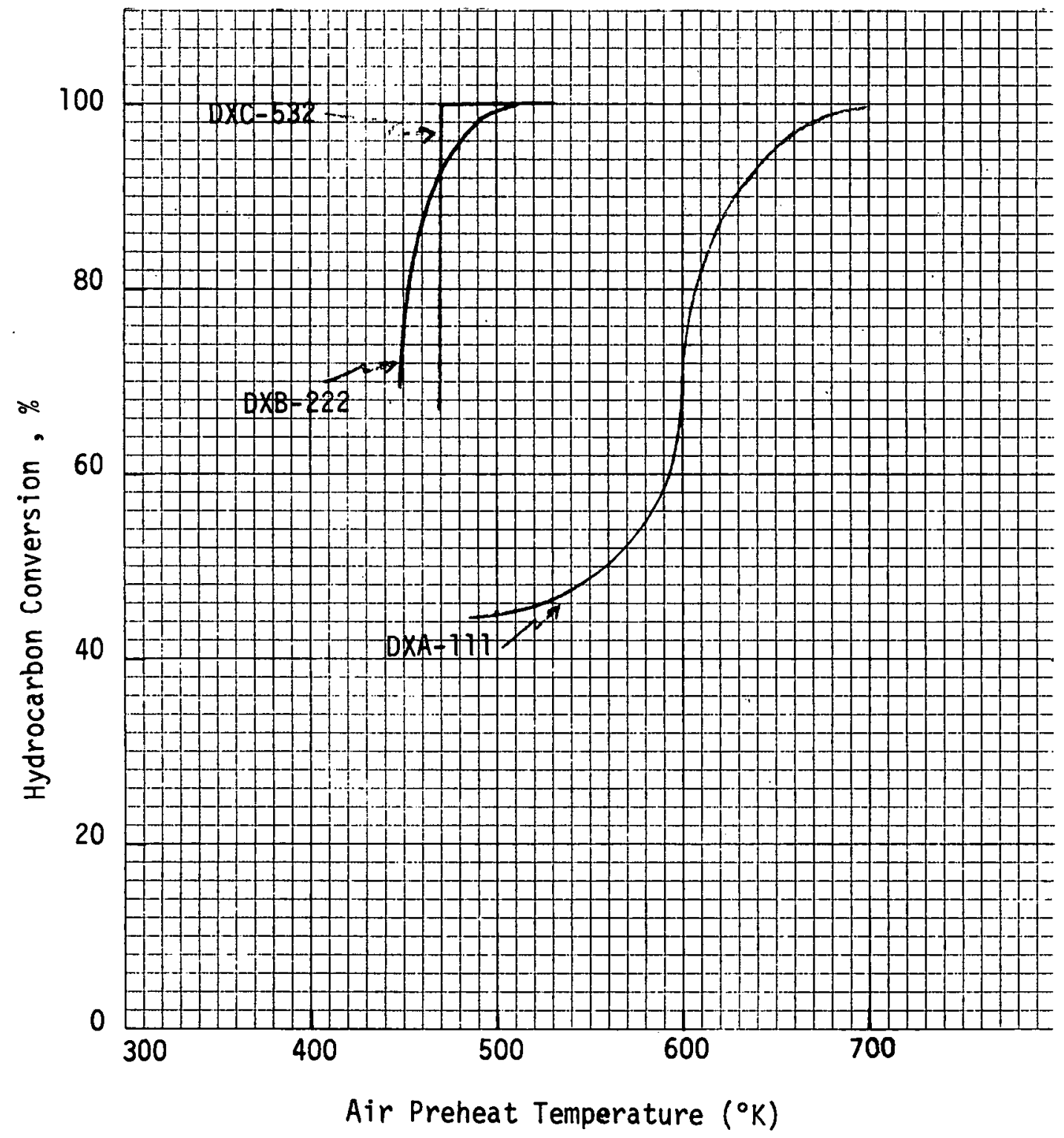

4.) 
and yet maintain all the excellent performance qualities shown for DXA-111.

The questions relating to poisons and catalyst core degradation must, by necessity, be answered with long term life testing, which represents the final rationale for testing of catalyst cores DXB-222 and DXC-532 as part of this contract. 


\section{TASK II - TEST FACILITIES}

\section{A. DESIGN AND CONSTRUCTION OF TEST RIG}

In order to accomplish the experimental program to be described in Task III, a test rig was designed, constructed and installed in the CATCOM 1aboratory at Engelhard's Menlo Park Research Laboratories. This test rig had to be capable of the following modes of operation:

1. Steady-state Tife testing using liquid fuels automated, unattended.

2. Parametric testing with either gaseous or liquid fuel - manual.

3. Activity testing with gaseòus fuel - manual.

Based on past experience in evaluating CATCOM catalysts, a $.0254 \mathrm{M}$ diameter $\left(1^{\prime \prime} \emptyset\right)$ adiabatic reactor was constructed. The reactor was designed to operate downflow with an adiabaticity ranging from 90 to $100 \%$.

The schematic for the test rig is shown in Figure IV-1. Photographs showing the completed test rig and panelboard are shown as Figures IV-2 and I.V-3. Detailed drawings are contained in Appendix F. The main elements of the test rig (designated unit \#6) are as follows: 
$-36-$

Figure IV -1

Schematic of Unit 6 Test Rig

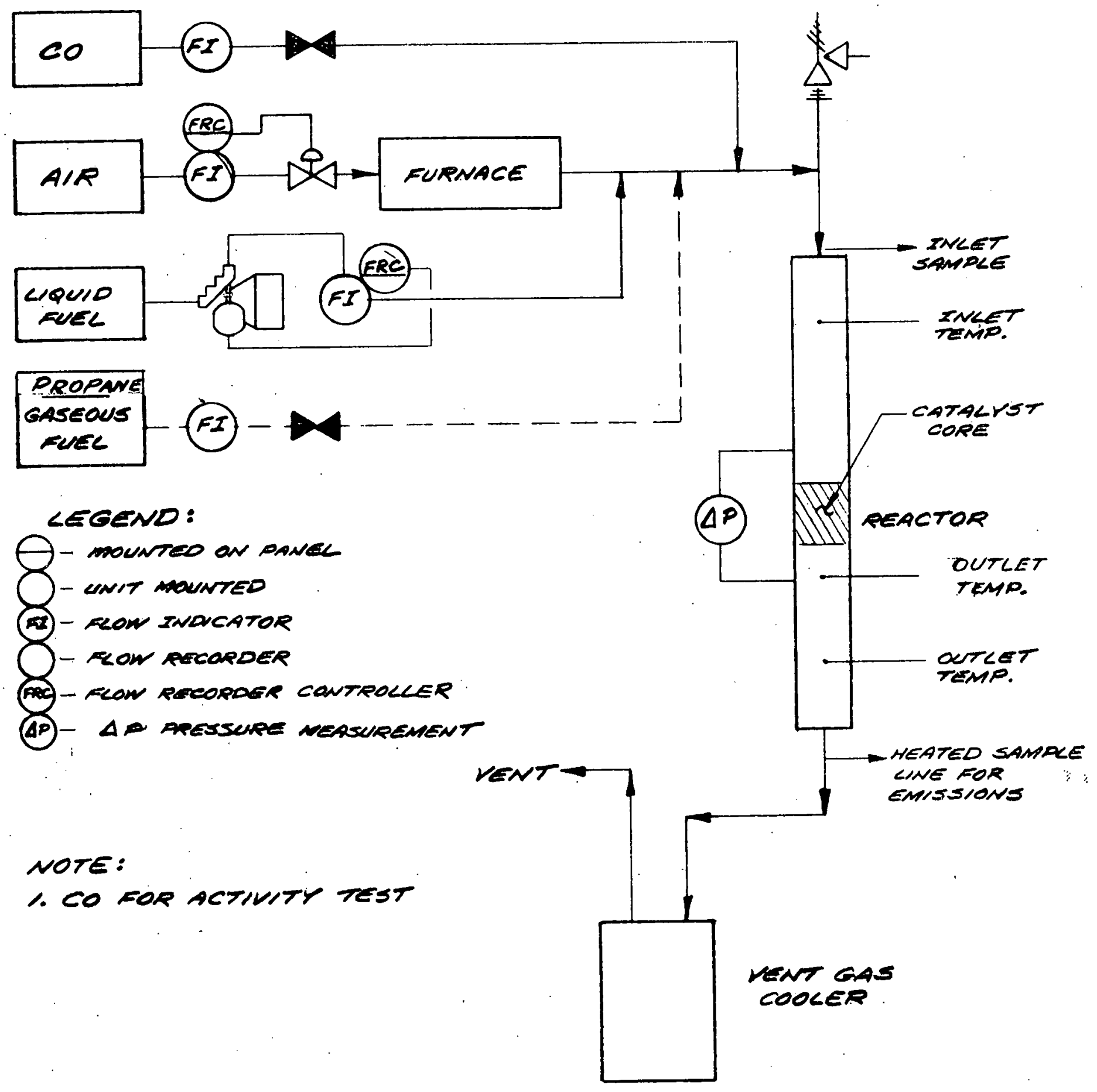

NOTE:

1. CO FOR ACTIVIT TEST

BLOCK DIAGRAM OF TEST UNIT NASA CONTACT \#N AS3-19416 
Figure IV-2

Photograph of Control Panel For Unit 6 Test Rig.

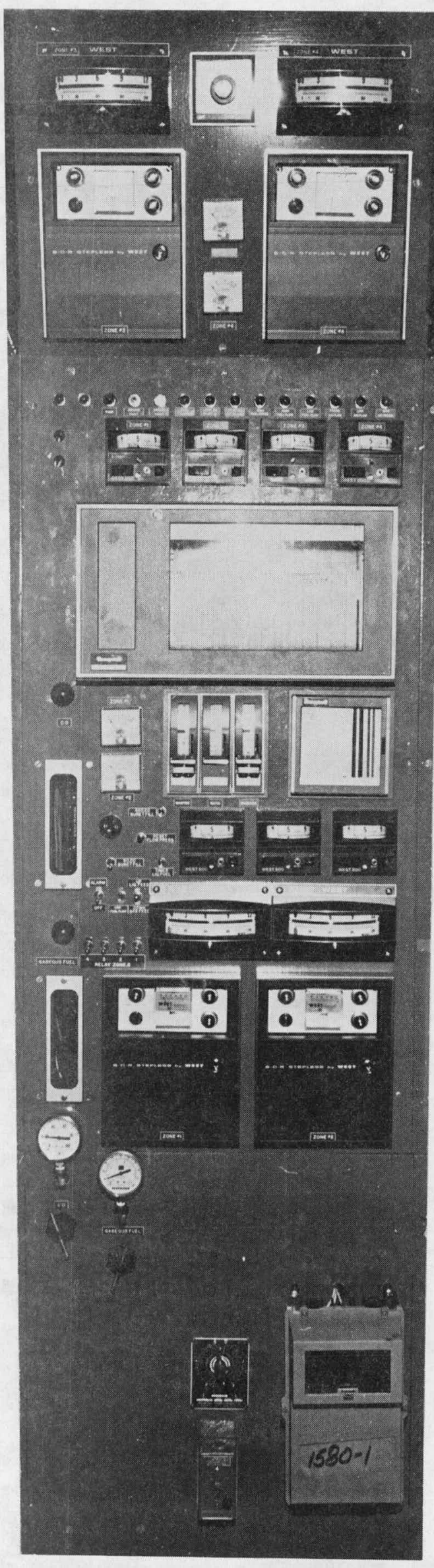




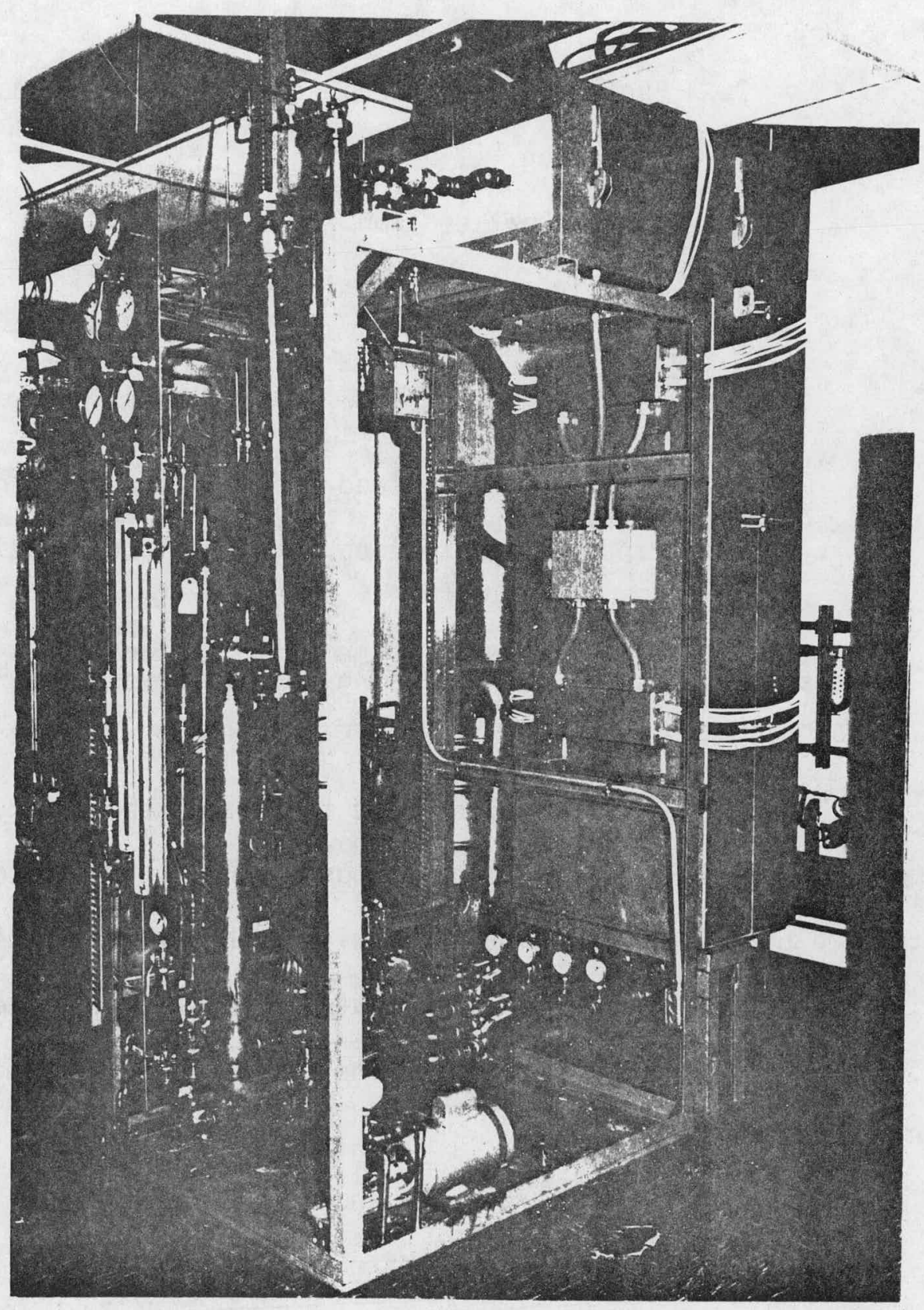

Figure IV-3 Photograph Showing Physical Layout of Equipment For Unit 6 Test Rig 
1. Air feed control loop for automatic or manual operation.

2. Fuel (1iquid) control for automatic or manual operation.

3. Air preheat section.

4. Fuel injection and mixing section.

5. Reactor section.

6. Exhaust gas cooling and venting.

7. Carbon monoxide feed for activity testing.

8. Propane feed section for parametric testing.

Table IV-1 lists the operating ranges for the test facility.

The experimental reactor used in testing the catalyst cores at combustion conditions is detailed in Appendix $F$. This reactor was constructed of Inconel 601 pipe and could be operated for endurance testing at $1533^{\circ} \mathrm{K}$ and $1 \times 10^{5} \mathrm{~N} / \mathrm{M}^{2}(1 \mathrm{~atm}$.$) and short term testing$ at $1533^{\circ} \mathrm{K}$ and $5 \times 10^{5} \mathrm{~N} / \mathrm{M}^{2}(5 \mathrm{~atm})$. The reactor was instrumented for measurement of

- catalyst core inlet and outlet temperature

- catalyst core pressure drop

- catalyst core inlet pressure

- catalyst core emissions

The pressure drop apparatus consisted of a manometer with pipe tap locations upstream and downstream of the catalyst core in accordance with ASME recommended practice. (8) 
TABLE IV-1

Operating Ranges for Unit 6

Automatic Control Operation:

$\begin{array}{ll}\text { Air Flow } & 1.85 \times 10^{-3} \text { to } 5.9 \times 10^{-3} \mathrm{~kg} / \mathrm{S} \\ \text { Air Preheat Temperature } & \text { up to } 810^{\circ} \mathrm{K} \\ \text { Fuel Flow (Liquid) } & 6.7 \times 10^{-5} \text { to } 67 \times 10^{-5} \mathrm{~kg} / \mathrm{S} \\ \text { Reactor Pressure } & 1.0 \times 10^{5} \mathrm{~N} / \mathrm{M}^{2} \text { to } 5 \times 10^{5} \mathrm{~N} / \mathrm{M}^{2} \\ \text { Adiabatic Flame Temperature* } & \text { Up to } 1533^{\circ} \mathrm{K} \\ \text { Fuel Type } & \text { \#2 Diesel }\end{array}$

Manual Operation:

Air Flow

$1.85 \times 10^{-3}$ to $66.7 \times 10^{-3} / \mathrm{kg} / \mathrm{S}$

Air Preheat Temperature

up to $810^{\circ} \mathrm{K}$

Fuel flow (Gaseous)

$1.7 \times 10^{-4}$ to $17 \times 10^{-4} \mathrm{Kg} / \mathrm{s}$

Reactor Pressure

$1.0 \times 10^{5}$ to $5.0 \times 10^{5} \mathrm{~N} / \mathrm{M}^{2}$

Adiabatic Flame Temperature *

up to $1533^{\circ} \mathrm{K}$

Fuel Type

Chemically Pure (C.P.) Propane

* For conditions of $90 \%$ reactor adiabaticity, adiabatic flame temperature may be increased to $1570^{\circ} \mathrm{K}$ without damage to reactor walls. 
The emission samples were taken with a $.00635 \mathrm{M}$ diameter $\left(1 / 4^{\prime \prime} \emptyset\right)$ water-cooled sampling probe. The sampling train adhered to SAE Standard ARP-1256. The description of each individual analytical instrument is listed in Table IV-2. The standard calibration procedure of each instrument is detailed in Appendix $E$.

The product collection and vent system were designed to cool the combustion gases sufficiently so they could be vented into existing house vent facilities.

The operation of Unit \#6 is best described by considering the start-up and line-out of the unit for life testing. The following sequence was followed:

1. Turn on electrical power to unit.

2. Set air flow on control locp to specifications in operating instructions.

3. Begin heat up of air using furnace automatic control.

4. Line-out operation of exhaust gas cooler and vent system.

5. Check out shutdown sequence for operability.

6. Check out operation of instrumentation on the reactor (thermocouples, catalyst core pressure drop, water cooled sampling probe, etc.). 
TABLE IV-2

Description of Analytical Systems for Emissions

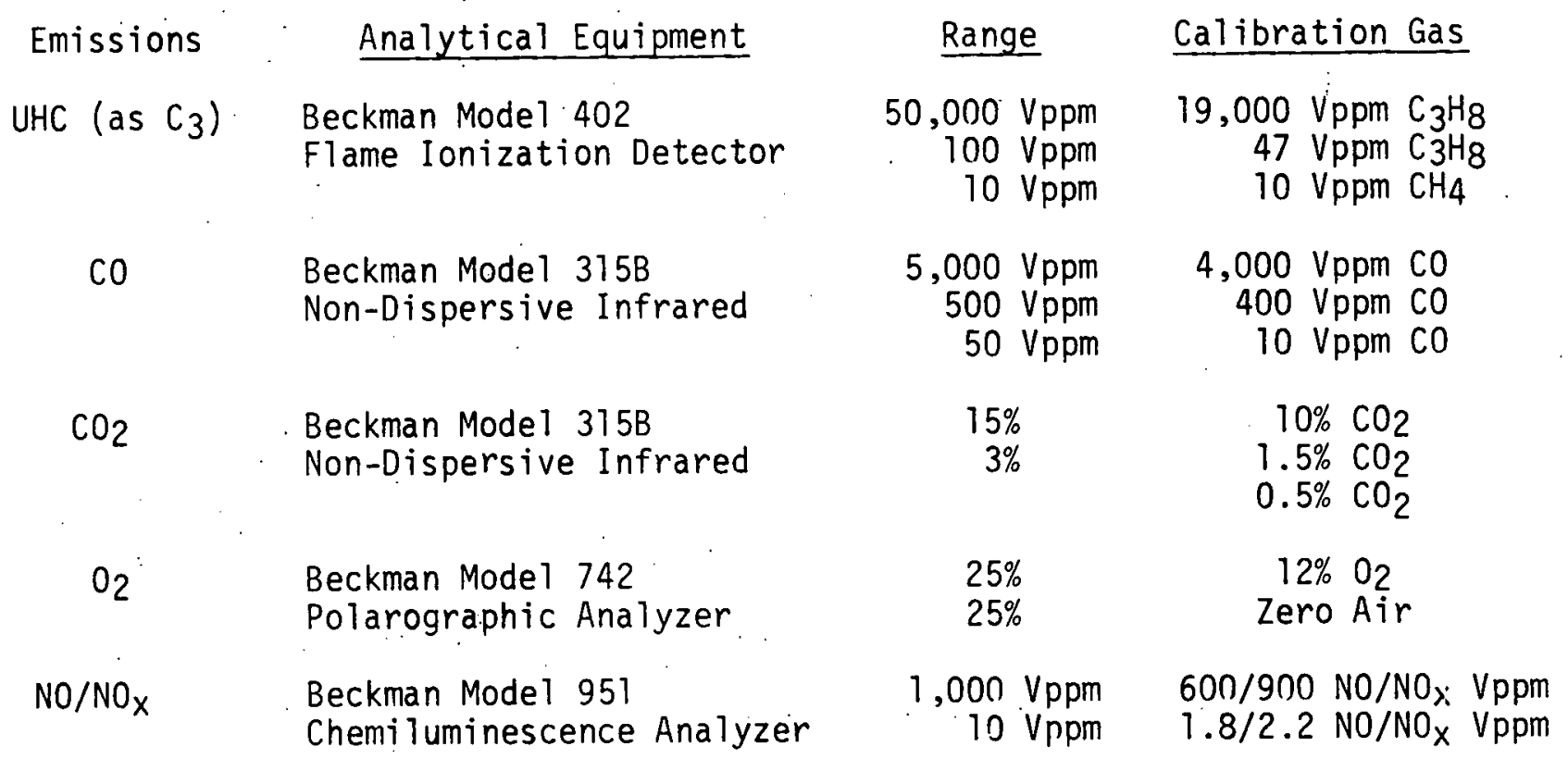


7. When the air preheat temperature to the reactor has reached specified conditions, line-out on automatic control.

8. At this point in the start-up sequence, the air flow is on automatic control and the reactor instrumentation is functioning. All safety shutdowns must be in the "off" position before fuel can be brought on.

9. The fuel flow is now ready to be brought into the unit. Using liquid fuel as an example, the flow setting on the pump is established on bypass and slowly turned into the unit.

10. As the fuel is brought on, the technician notes the temperature responses in the reactor to deter-. mine lined-out operation for life testing.

This same start-up and line-out sequence is followed for parametric testing and the carbon monoxide activity testing.

The detailed operating instructions for a 11 tests performed as part of this contract are given in Appendix $E$. 
B. TEST RIG PERFORMANCE CHECK OUT

After the operational check out, the performance of the test rig was evaluated under "catalytically supported thermal combustion" conditions. The purposes of this evaluation were:

1. Determine the effect of cooling by the watercooled sampling probe on reactor adiabaticity and emissions.

2. Compare emissions, pressure drop and outlet temperature of Unit 6 to those of an existing laboratory test rig.

\section{Water-Cooled Probe Performance}

The test rig reactor was designed to operate from 90 to $100 \%$ adiabaticity during life testing and over much of the design operating range. In this heat loss range, the performance measurements should be typical of large scale combustors. However, with the added cooling effect of the water cooled sample probe downstream of the $.0254 \mathrm{M}$ catalyst core, the performance measurements could have been in error because the probe can significantly cool the back section of the catalyst core.

The effect of the water-cooled probe was measured to deterinine: 
a. The best location for emission measurements without quenching the combustion reactions in the catalyst core.

b. The effect on reactor adiabaticity at the location selected.

A series of experiments were run measuring the probe quenching effect, defined as percentage decrease in measured outlet temperature (PD) from the catalyst core using the following equation:

$\mathrm{PD}=\frac{\text { (Temperature Measured Without Probe) }- \text { (Temperature Measured With Probe) }}{\text { (Temperature Measured Without Probe) }} \times 100$ These measurements were conducted under combustion conditions.

The results for the experiments are shown in Figure IV-4. For a probe location .1016M (4") downstream of the catalyst core, a 2-3\% decrease occurred in the measured outlet temperature. These tests were run at very conservative conditions with a mass flow approximately $60 \%$ of proposed life test conditions. Tests conducted at actual life test conditions showed that the probe (located at $.1016 \mathrm{M}$ downstream) reduced the adiabaticity of the reactor from $89 \%$ to $87 \%$. This was judged to be a reasonable trade off between satisfactory emission measurements and undesirable quenching effects during the life tests. The .1016M downstream location was selected for emissions measurements. 
Figure IV-4

Cooling Effect of Water-Cooled Sampling Probe Under Combustion Conditions

\section{Run Conditions: Reference Velocity $=9 \mathrm{M} / \mathrm{S}$ \\ Fue1/Air Ratio (Wgt.) $=.0268$ \\ Air Preheat Temperature $=653^{\circ} \mathrm{K}$ \\ Measured Outlet Temperáture $=1513^{\circ} \mathrm{K}$ \\ Pressure: $1 \times 105 \mathrm{~N} / \mathrm{M} 2$}

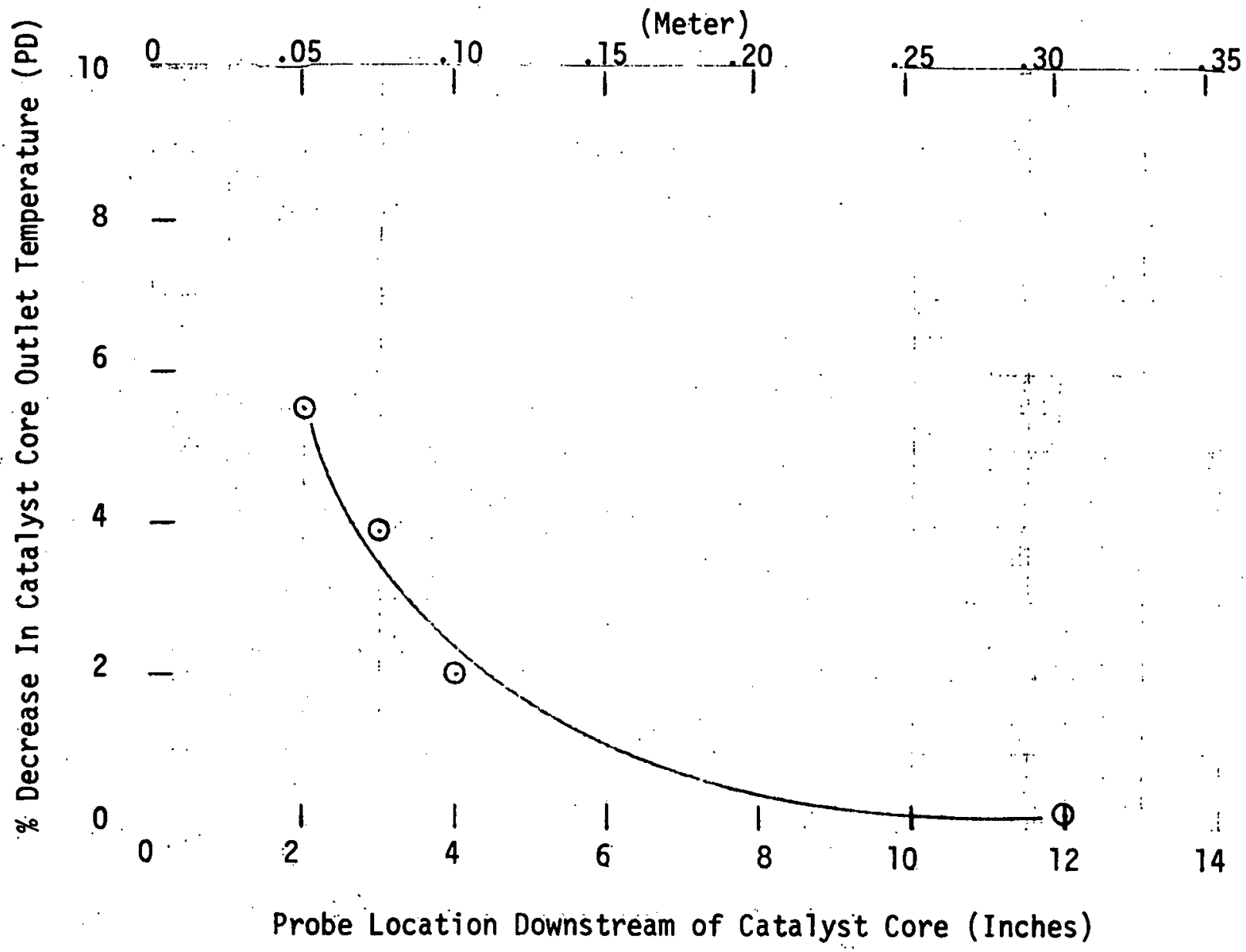


Further test results with the water-cooled sample probe defined the reactor adiabaticity over the range of design operating conditions. The percent adiabaticity (PA) of the reactor is defined as

$$
\mathrm{PA}=100 \frac{\left(\begin{array}{c}
\text { Maximum } \\
\text { Measured Outlet } \\
\text { Temperature }
\end{array}\right)-\left(\begin{array}{c}
\text { Measured Inlet } \\
\text { Temperature }
\end{array}\right)}{\left(\begin{array}{c}
\text { Adiabatic Flame } \\
\text { Temperature }
\end{array}\right)-\left(\begin{array}{c}
\text { Measured Inlet } \\
\text { Temperature }
\end{array}\right)}
$$

Initial operation at test conditions over the test rig design range resulted in the response of $P A$, as shown in Figure IV-5.

The results show that increasing the mass flow decreases the percent of heat loss and increases the percent adiabaticity. This is expected, since increasing the mass flow, at a constant air/fuel ratio, in a fixed geometry increases the heat released while the heat loss remains fairly constant. Hence, the system approaches $100 \%$ adiabaticity. The mass flow rates plotted cover the range of the parametric studies.

\section{Performance Comparison with Existing Test Rig}

The final series of check outs of Unit 6 involved sideby-side comparisons of identical experiments performed in Unit 6 and an existing Engelhard test rig (Unit 5). These comparisons were made for both \#2 diesel and C.P. propane. The results are tabulated in Tables IV3 and IV-4. These data indicate that the differences between the responses are well within experimental error. 
Figure IV-5

Adlabaticity Of Test Rig Reactor *

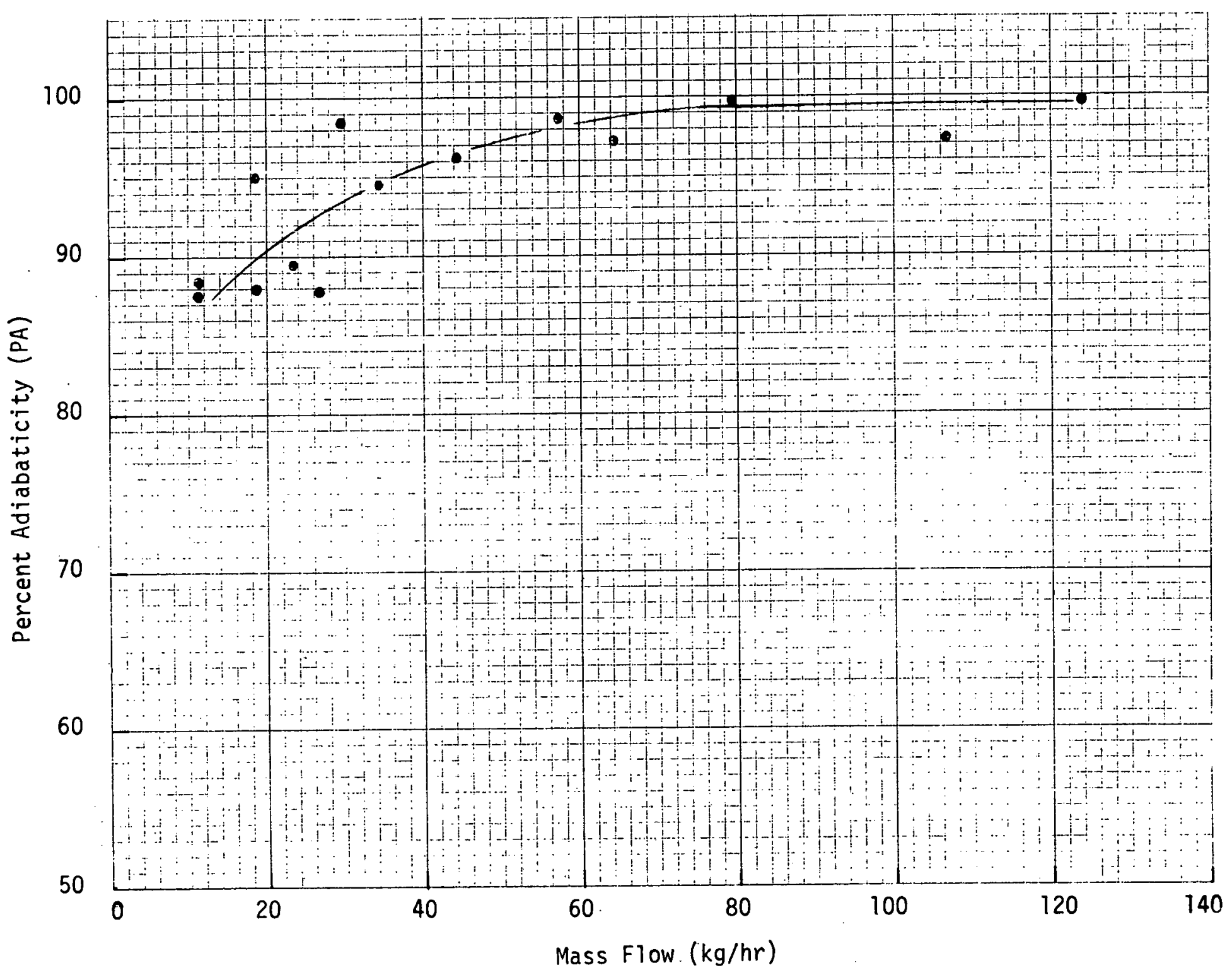

* Water cooled sampling probe located .102M downstream. 


\section{TABLE IV-3}

Comparison Study of Unit \#6

With Unit \#5 (\#2 Diesel Fuel)

Unit \#6

Run Number

Catalyst Core

Catalyst Core Dimensions

Air Flow $\left(\mathrm{Kg} / \mathrm{S} \times 10^{3}\right)$

A/F Wgt. $(g / g)$

Reference Velocity (M/S)

Pressure $\left(N / N_{1}^{2}\right)$

Air Preheat Temperature $\left({ }^{\circ} \mathrm{K}\right)$

Catalyst Core Outlet Temperature $\left({ }^{\circ} \mathrm{K}\right)$

Pressure Drop (\%)

Emissions (Vppm a Nominally $12.5 \% 0_{2}$ )*

CO

UHC (As $\left.C_{3}\right)$

$\mathrm{NO} / \mathrm{NO}_{\mathrm{X}}$

Percent Adiabaticity
$6-13 E$

DXB-412 $.0254 M \varphi \times .152 M L$

4.26

38.4

17.2

$1 \times 10^{5}$

673

1376

10.2

130

192

1

1

85
Unit \#5

$5-103 B$

DXB-412 $.0254 M \varphi \times .152 M L$

4.26

38.4

16.9

$1 \times 10^{5}$

673

1353

11.2

* Emissions at $.102 M$ downstream of outlet catalyst face with water cooled sampling probe. 
TABLE IV-4

Comparison Study of Unit \#6

With Unit \#5 (C.P. Propane Fuel)

$\begin{array}{lcc} & \frac{\text { Unit \#6 }}{6-13 \mathrm{~A}} & \frac{\text { Unit \#5 }}{5-102 \mathrm{~B}} \\ \text { Run Number } & \text { DXB-412 } & \text { DXB-412 } \\ \text { Catalyst Core } & .0254 \mathrm{M} \varphi \times .152 \mathrm{M} \mathrm{L} & .0254 \mathrm{MQX} .152 \mathrm{M} \mathrm{L} \\ \text { Catalyst Core Dimensions } & 4.26 & 4.26 \\ \text { Air Flow }\left(\mathrm{Kg} / 5 \times 10^{3}\right) & 39.5 & 39.5 \\ \text { A/F Wgt. }(\mathrm{g} / \mathrm{g}) & 17.2 & 16.8 \\ \text { Reference Velocity }(\mathrm{M} / \mathrm{S}) & 1 \times 10^{5} & 1 \times 10^{5} \\ \text { Pressure }\left(\mathrm{N} / \mathrm{M}^{2}\right) & 678 & 683 \\ \text { Air Preheat Temperature }\left({ }^{\circ} \mathrm{K}\right) & 1503 & 1533 \\ \text { Catalyst Core Outlet Temperature }\left({ }^{\circ} \mathrm{K}\right) & 11.3 & 14.5 \\ \text { Pressure. Drop }(\%) & & \end{array}$

Emissions (Vppm \& Nominally $12.5 \% 0_{2}$ )*

$\mathrm{CO}$

9.0

22

$\mathrm{UHC}\left(\mathrm{As}^{\mathrm{C}} \mathrm{C}_{3}\right)^{\star \star}$

$\mathrm{NO}_{\mathrm{X}}$

Percent Adiabaticity

92

94

* Emissions at .305M downstream of outlet catalyst face with water cooled sampling probe.

** UHC and $\mathrm{NO}_{x}$ analyzers not functioning at time of experiments. 
Another response that is typical for combustion operation in the laboratory test rigs and noted in Unit 6 is the fact that when fuel is brought on to the catalyst core, an increase in measured inlet temperature occurs. For instance, the inlet temperature response for Unit 6 and Unit 5 for the runs listed in Table IV-3 were:

Temperature Reading on Air Preheat Thermocouple

${ }^{\circ} \mathrm{K}$

Fuel off Fuel on

Unit 6

673

825

Unit 5

673

793

This is observed because of the close proximity of the inlet thermocouple, i.e., .0254 M (1") away from the catalyst core inlet face. Radiation from the catalyst inlet face and thermal conduction up the reactor wall causes the inlet thermocouple to read an artifically higher inlet temperature.

\section{OPERATING PROCEDURES}

Operation of Unit 6 included routine equipment operating procedures and special test procedures designed for evaluation of the selected catalyst cores. Data reduction procedures were also handled as part of the operation of the test units. The routine operating procedures are detajled in Appendix $E$ for reference. 
v. TASK III - PARAMETRIC AND ENDURANCE TESTING

\section{A. EXPERIMENTAL TEST PROGRAM}

The testing program selected in this study was designed to serve the following purposes:

1. Test the long-term durability of catalysts under combustion conditions.

2. Determine an acceptable low emissions operating range for the catalysts.

3. Provide adequate information for selection of a preferred catalyst core.

In addressing these requirements, a test sequence was set up, which focused mainly on low emissions operation during a 1,000 hour life test with \#2 diesel. This life test provided a means of measuring either abrupt or long-range changes in a catalyst core's overall performance. To measure more subtle changes in the activity of the catalyst core, periodic activity tests were conducted at 250 hour intervals using carbon monoxide as a fuel.

The acceptable low emissions operating range for a CATCOM catalyst was determined using $C$. P. Propane as fuel over a wide range of select variables. Two catalyst cores, designated as DXB-222 and DXC-532, were tested in this experimental program. 
The specifics of the overall testing sequence can be represented schematically as follows:

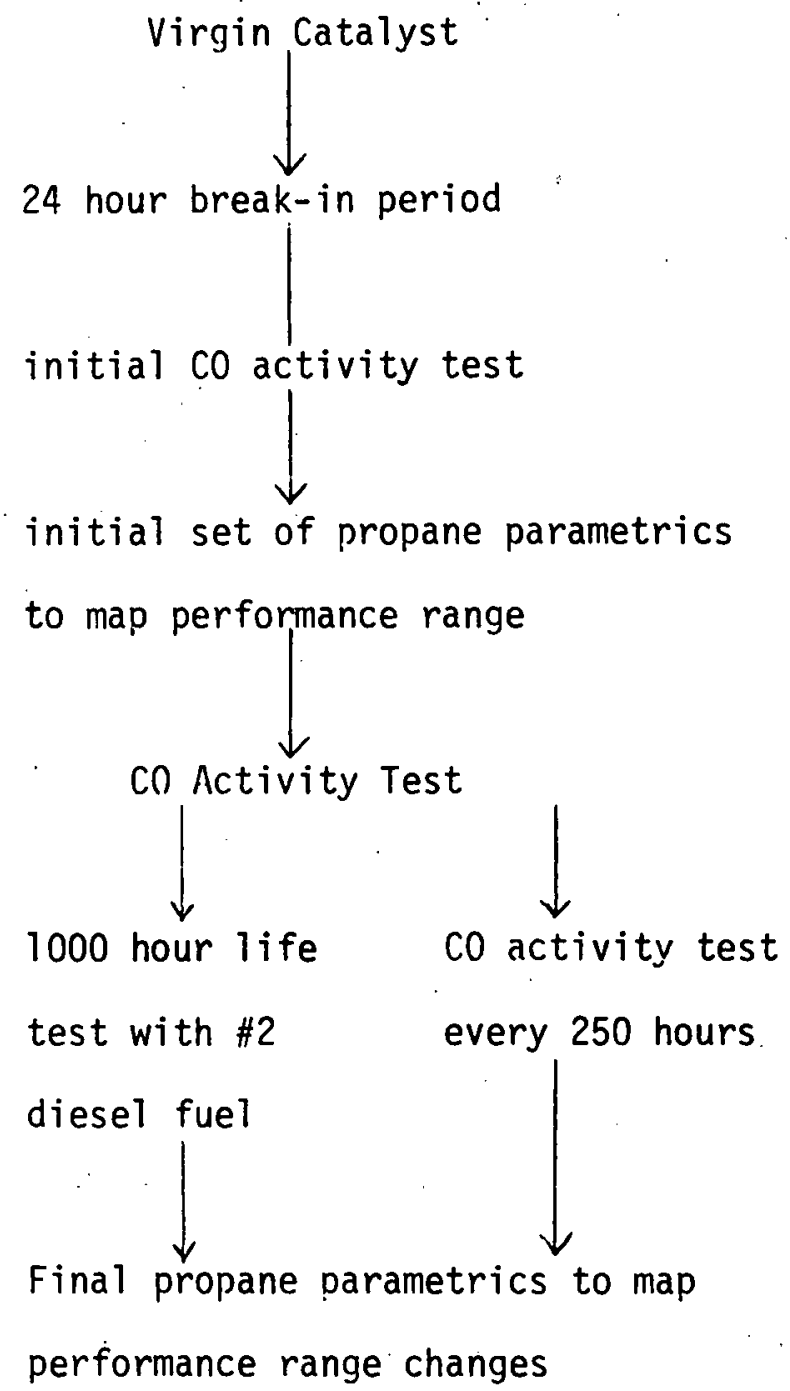

The initial 24 hour break-in period of each catalyst core was required because of the nature of each catalyst preparation. On many commercial catalyst preparations, it is very deceiving to test 
a catalyst without removing the so-called "flush" activity. It is better to have a break-in period to remove this initially high activity and stabilize the catalyst's activity level. This prevents potential problems with interpretation of experimental results due to compounding with an artifically high initial activity. The break-in period consisted of operating each catalyst core for 24 hours at the actual 1 ife test conditions (see Table V-2 for conditions).

\section{Life Test with \#2 Diesel}

Since the main purpose of this study was to measure the durability of catalyst cores at combustion conditions for extended periods of steady-state operation, the life test conditions were selected to simulate a steady-state operating point for an automotive gas turbine. The test fuel chosen was \#2 diesel, since it is the most probable fuel for this application. In addition; this fuel contains additives and impurities that provide a sound test for determining the effects of potential poisons on the catalyst core. Table $V-l$ contains the analyses of the fuels used in the life tests.

The steady-state conditions for the 1,000 hour 1ife test are shown in Table $V-2$. These life tests were conducted on a continuous basis when possible. During shutdown, a house air purge was maintained over the test catalyst cores. 
TABLE $V-1$

Analyses of \#2 Diesel Fuels Used For Catalyst Life Tests ${ }^{1}$

Test

Gravity, API o $60^{\circ} \mathrm{F}\left(289^{\circ} \mathrm{K}\right)$

Flash Point, ${ }^{\circ} \mathrm{K}$

Pour Point, ${ }^{\circ} \mathrm{K}$

Water and Sediment, V\%

Carbon Residue

Ash, Wt.\%

Distillation Temperature, ${ }^{\circ} \mathrm{K}$

Initial

$10 \%$

$50 \%$

$90 \%$

End Point

Viscosity, SU at $311^{\circ} \mathrm{K}$

Joule/Kg., gross

Sulfur, wt.\%

Nitrogen, wppm

Phosphorous, wppm

Lead, wppm
ASTM D-975

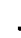

$>324.9$ or legal

$-$

$<0.05$

$<0.35$

$<0.01$

555.4 to 611.2

32.6 to 40.1

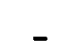

$<0.50$
$<0.004$

446.2

477.2

523.2

575.2

605.2

0.15

59.9

$<1.0$

$<1.0$

Batch $\# 2^{3}$
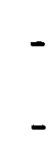

255.5

34.2

$4.55 \times 10^{7}$

0.17

71.5

$<1.0$

1.6

1 Majority of analyses performed by Saybolt and Co.

2 Batch \#1 used for DXB-222 life test.

3 Batch \#2 used for DXC-532 life test. 
TABLE V-2

Life Test Conditions

$\begin{array}{ll}\text { Air Flow: } & 3.29 \times 10^{-3} \mathrm{~kg} / \mathrm{S} \\ \text { Fuel Flow: } & 8.66 \times 10^{-5} \mathrm{~kg} / \mathrm{S} \\ \text { Air/Fuel Wgt: } & 38 / 1(\mathrm{~g} / \mathrm{g}) \\ \text { Inlet Temperature: } & 633^{\circ} \mathrm{K} \\ \text { Inlet Pressure: } & 1 \times 10^{5} \mathrm{~N} / \mathrm{M}^{2} \\ \text { Reference Velocity: } & 14 \mathrm{M} / \mathrm{S} \\ \text { Fuel Type: } & \# 2 \text { Diesel } \\ \text { Space Velocity NTP: } & 51 \mathrm{M}^{3} / \mathrm{S}-\mathrm{M}^{3} \mathrm{Cat} . \\ \text { Catalyst Test Piece: } & .0254 \mathrm{M} \times .1524 \mathrm{M} \mathrm{L} \\ \text { Adiabatic Flame Temperature: } & 1527^{\circ} \mathrm{K}\end{array}$


The maintenance of low emissions performance during the life test is considered the prime criteria for determining changes in a specific catalyst core's performance. This life test also provides a measure of the physical durability of the catalyst core support material. The results of this test would provide information on long term durability of CATCOM catalyst cores.

\section{Carbon Monoxide Activity Test}

In conducting the $\mathrm{CO}$ activity test, the life test conditions are discontinued and the CO activity test conditions are then established. The catalyst core is not disturbed and remains inside the test rig reactor.

This test consists of measuring the response of $\mathrm{CO}$ conversion to increases in the air preheat temperature. The carbon monoxide test gas was purchased from Scientific Gas Products and is rated chemically pure (C.P.) with a $99.7 \%$ minimum purity specification. The remaining test parameters are held constant and are shown in Table V-3. Typical responses for this test are shown in Figure $V-1$.

The response curve in Figure $V-1$ provides two important facts about the catalyst cores' activity. The co ignition temperature, defined as the lowest air preheat temperature required to obtain a measurable temperature rise across the catalyst core, is a measure of intrinsic catalytic activity. Increases in the ignition temperature 
Figure $V-1$

\section{Typical Response Obtained From Carbon} Monoxide Activity Test

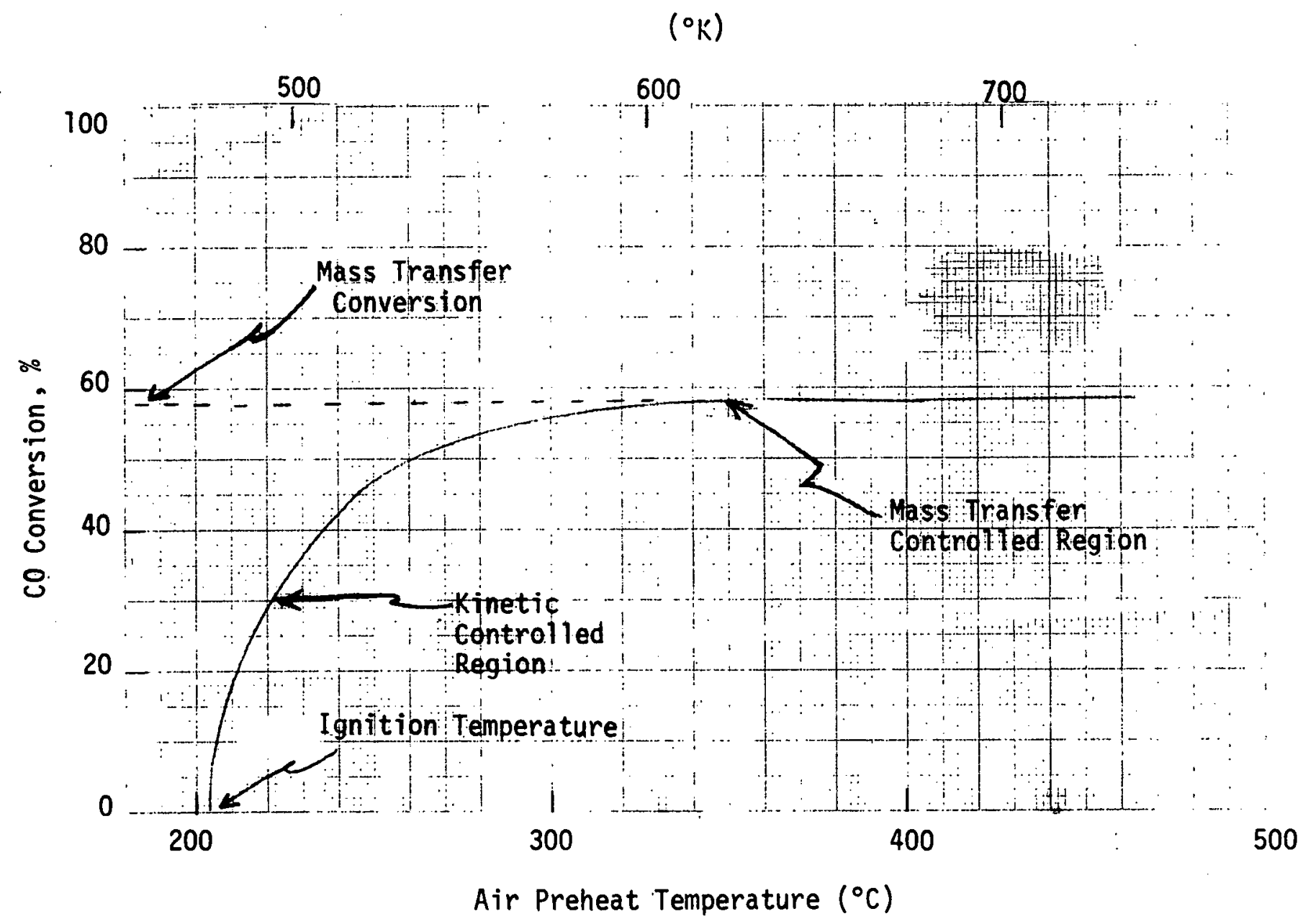


TABLE $V-3$

\section{Carbon Monoxide Activity Test Conditions}

Air flow:

Fuel Flow:

Air/Fuel Wgt.:

Inlet Temperature:

Inlet Pressure:

Reference Velocity:

Fuel Type:

Space Velocity NTP:
$10.55 \times 10^{-3} \mathrm{~kg} / \mathrm{S}$

$4.09 \times 10^{-5} \mathrm{~kg} / \mathrm{S}$

$258 / 1(g / g)$

Varied up to $773^{\circ} \mathrm{K}$

$1 \times 10^{5} \mathrm{~N} / \mathrm{M}^{2}$

$36 \mathrm{M} / \mathrm{S}$

C.P. Carbon Monoxide

$125 \mathrm{M}^{3} / \mathrm{S}-\mathrm{M}^{3}$ CAT. 
reflect possible changes in the energy of activation or pre-exponential factor using the Arrhenius rate of expression as the typical reaction rate model. The sloping portion of the response curve in Figure $\mathrm{V}-1$ indicates that in this temperature range the rate of reaction is kinetically controlled. The region showing a constant conversion level as a function of temperature is considered to be mass transfer controlled. A mass transfer controlled reaction is independent of the catalyst and temperature, and is only a function of the apparent geometric surface area of the catalyst. If the mass transfer conversion declines with catalyst age, then the apparent mass transfer area is decreasing.

The utility of this CO activity test is that it provides a means to monitor subtle changes in catalyst core activity without disturbing the catalyst test piece in the reactor.

The catalyst core that retains the highest apparent mass transfer area and lowest ignition temperature is judged the better performer, at least with regards to $\mathrm{CO}$ activity.

\section{Propane Parametric Testing}

In order to define the low emissions operating range for test catalysts, a series of parametric studies was carried out over the following operating range: 


\begin{tabular}{|c|c|}
\hline Variable & Range \\
\hline Pressure & $1 \times 10^{5}-5 \times 10^{5} \mathrm{~N} / \mathrm{M}^{2}$ \\
\hline $\begin{array}{l}\text { Air Preheat } \\
\text { Temperature }\end{array}$ & $630-810^{\circ} \mathrm{K}$ \\
\hline $\begin{array}{c}\text { Adiabatic Flame } \\
\text { Temperature }\end{array}$ & $1306-1533^{\circ} \mathrm{K}$ \\
\hline $\begin{array}{l}\text { Reference } \\
\text { Velocity }\end{array}$ & $14-30 \mathrm{M} / \mathrm{S}$ \\
\hline
\end{tabular}

C. P. Propane was selected as the test fuel because:

a. The high level of purity of the fuel and combustion properties of propane would represent a conservative test for the catalyst capabilities. Lower molecular weight paraffinic fuels of high purity are very difficult to oxidize. The propane used was purchased from Scientific Gas Products and is rated chemically pure (C.P.) with a minimum $99.0 \%$ purity specification.

b. The fuel presentation system for \#2 diesel would not function over such a broad operating range.

The propane parametrics was conducted initially at the start-of-life testing to determine the range of operation of a virgin catalyst, and at the end of life testing to determine if changes in catalyst activity had occurred for propane after 1,000 hours. 
The specific variables were studied by constructing a statistical experimental design covering 4 variables at 3 levels each. The design chosen was a $1 / 3$ replicate factorial design, which reduced the number of experimental runs from 81 to 27 . Repeat runs were also conducted as a measure of experimental error. The actual block design used is shown in Table V-4.

The initial program parametrics provided the range of acceptable low emissions operation for propane as fuel with a specific catalyst. The final propane parametric, after 1,000 hours aging, provided information on the changes in propane activity due to life testing. These criteria would al so be weighed in selecting a preferred catalyst core.

\section{B. EXPERIMENTAL RESULTS}

The experimental results for life testing, activity testing and parametric studies of the two catalyst cores, DXB-222 and DXB-532, are reviewed separately in the following sections.

Direct comparisons of results from testing of DXB-222 and DXC532 and selection of the preferred catalyst core are contained in Section VI of this report. 
TABLE V-4 - 1/3 Replicated Factorial Design For 4 Variables At 3 Levels

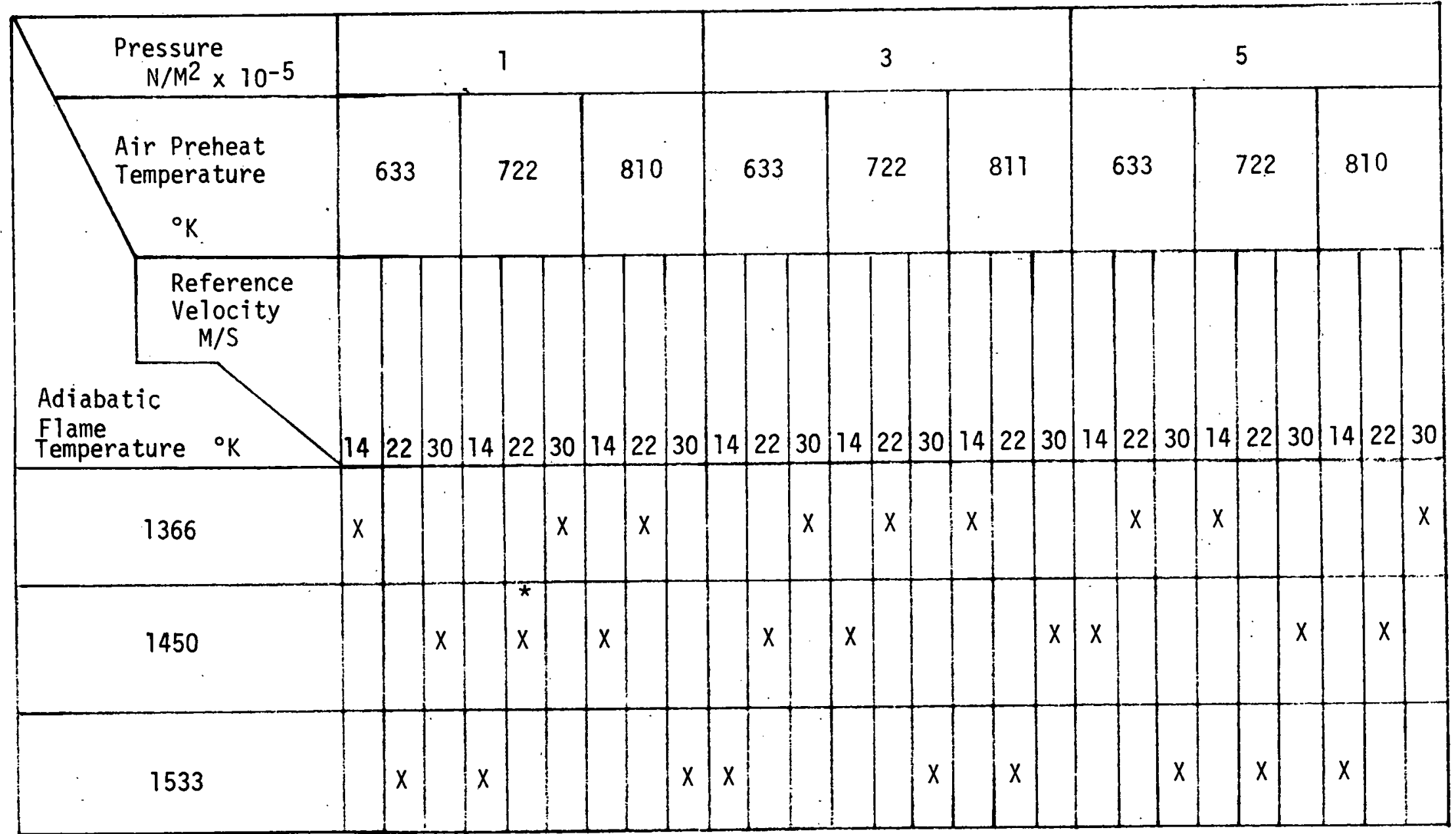

* Replicate Run to Determine Experimental Error 
1. Performance of Catalyst Core DXB-222

a. Life Testing with \#2 Diesel 0 il

The most useful technique for monitoring performance of a catalyst during life testing is to monitor daily the input variables and output responses from the test. A control plot of the most critical observations then provides a method for detecting trends which may indicate a degradation in the performance of the catalyst or problems in test rig operation.

Control charts were maintained on a daily basis for the following:

- exhaust gas composition ( $\mathrm{CO}, \mathrm{UHC}, \mathrm{NO}_{x}, \mathrm{CO}_{2}, \mathrm{O}_{2}$ )

- pressure drop

- air preheat temperature

- catalyst core outlet temperature

The resulting plots over the entire 1,000 hour life test of catalyst core DXB-222 are shown in Figures $V-2,3,4,5,6$, and 7 .

Perhaps the most significant control plot in the present life test is the exhaust gas analysis, and in particular, the emissions of $\mathrm{CO}$, UHC and $\mathrm{NO}_{\mathrm{X}}$. The gas compositions are reported as measured in the exhaust, which was nominally $12.5 \%$ oxygen. These plots provide a measurement of stable operation during life testing. 
Figure V-2 Hydrocarbon Emission Control Chart During Life Testing of Catalyst Core DXB-222

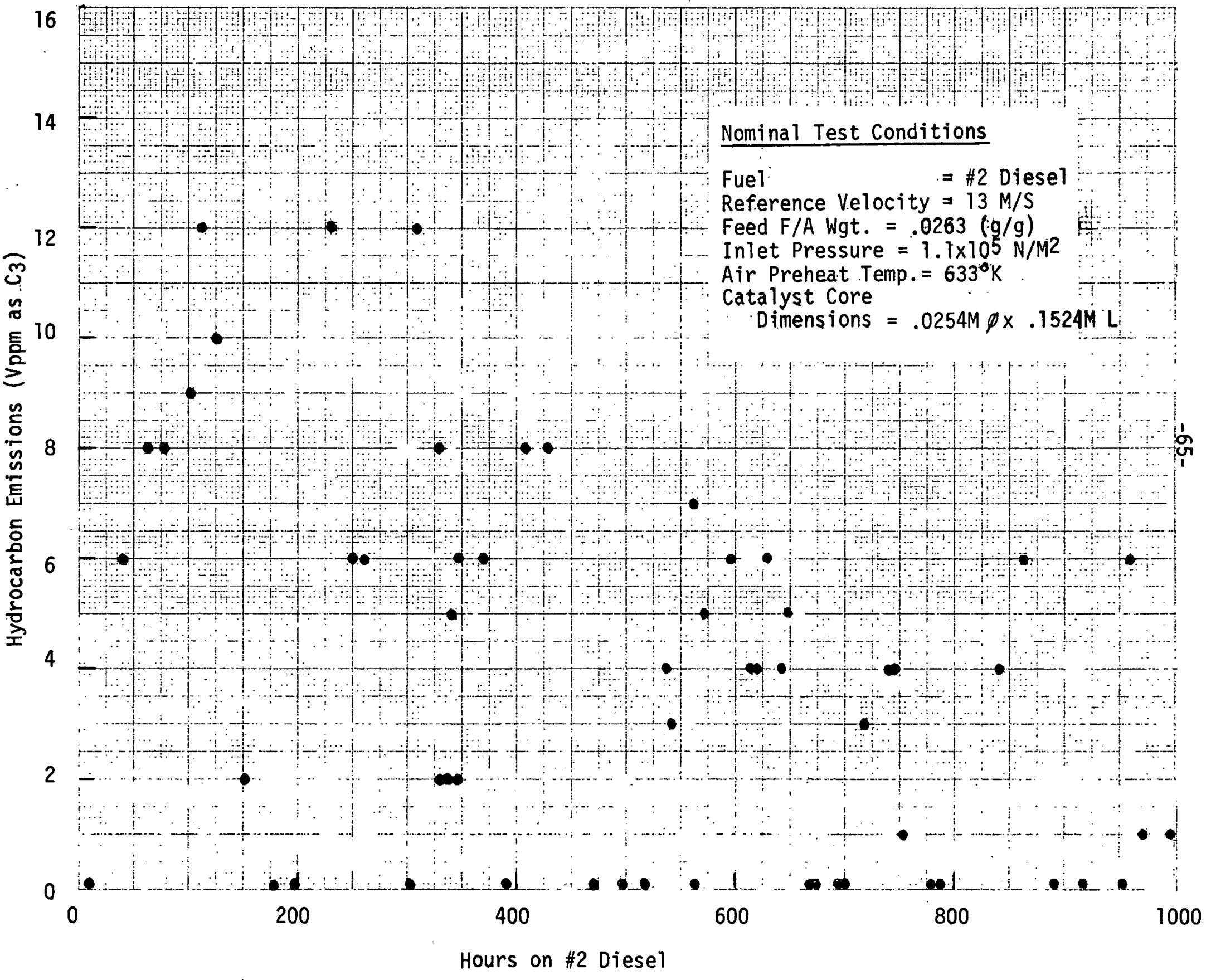


Figure V-3 Carbon Monoxide Emission Control Chart During Life Testing of Catáiyst Core DXI

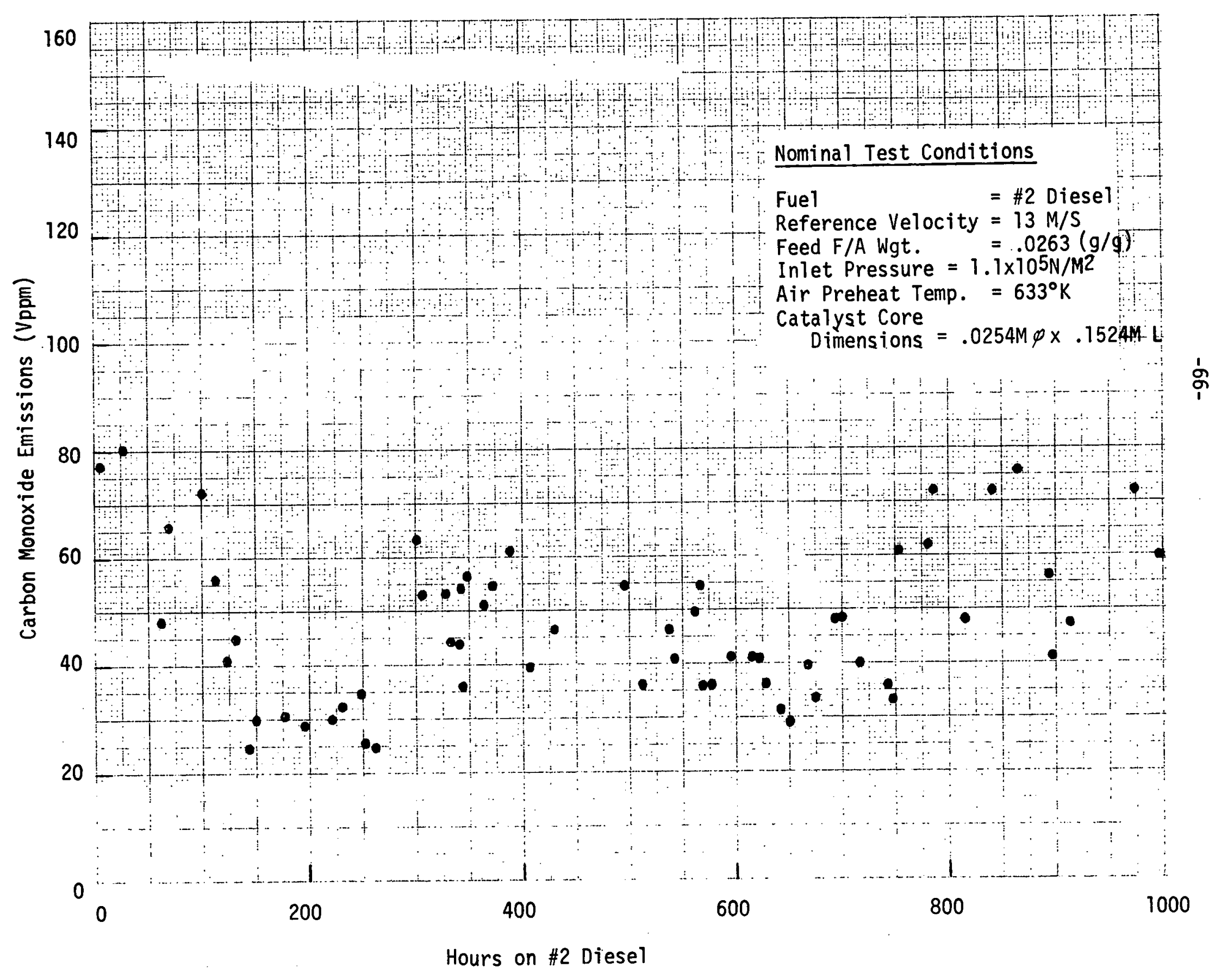


Figure V-4 NO Emission Control Chart During Life Testing of Catalyst Core DXB-222

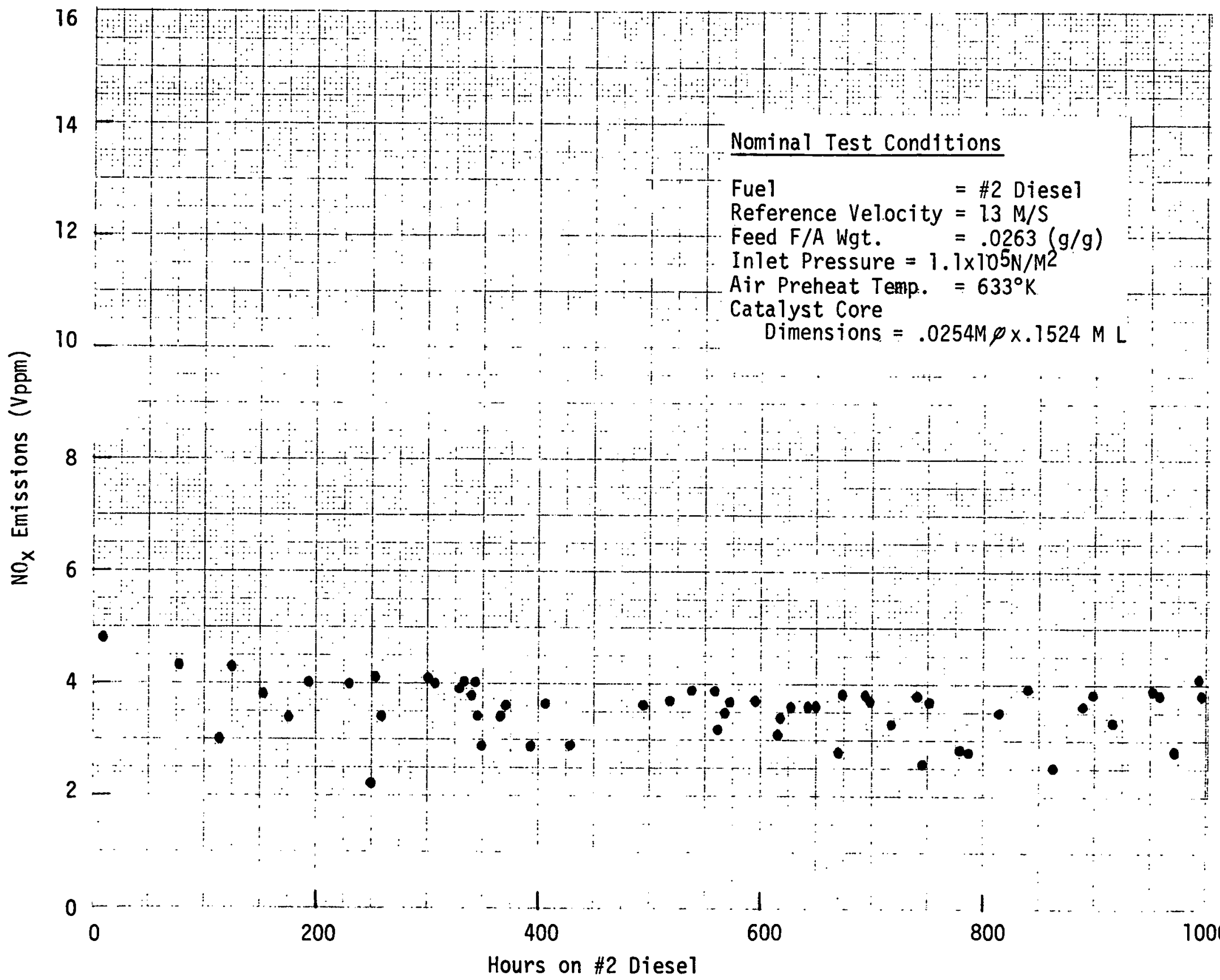


Figure V-5 $\mathrm{CQ}_{2}$ and $\mathrm{O}_{2}$ Control Chart During Life Testing of Catalyst Core DXB-222

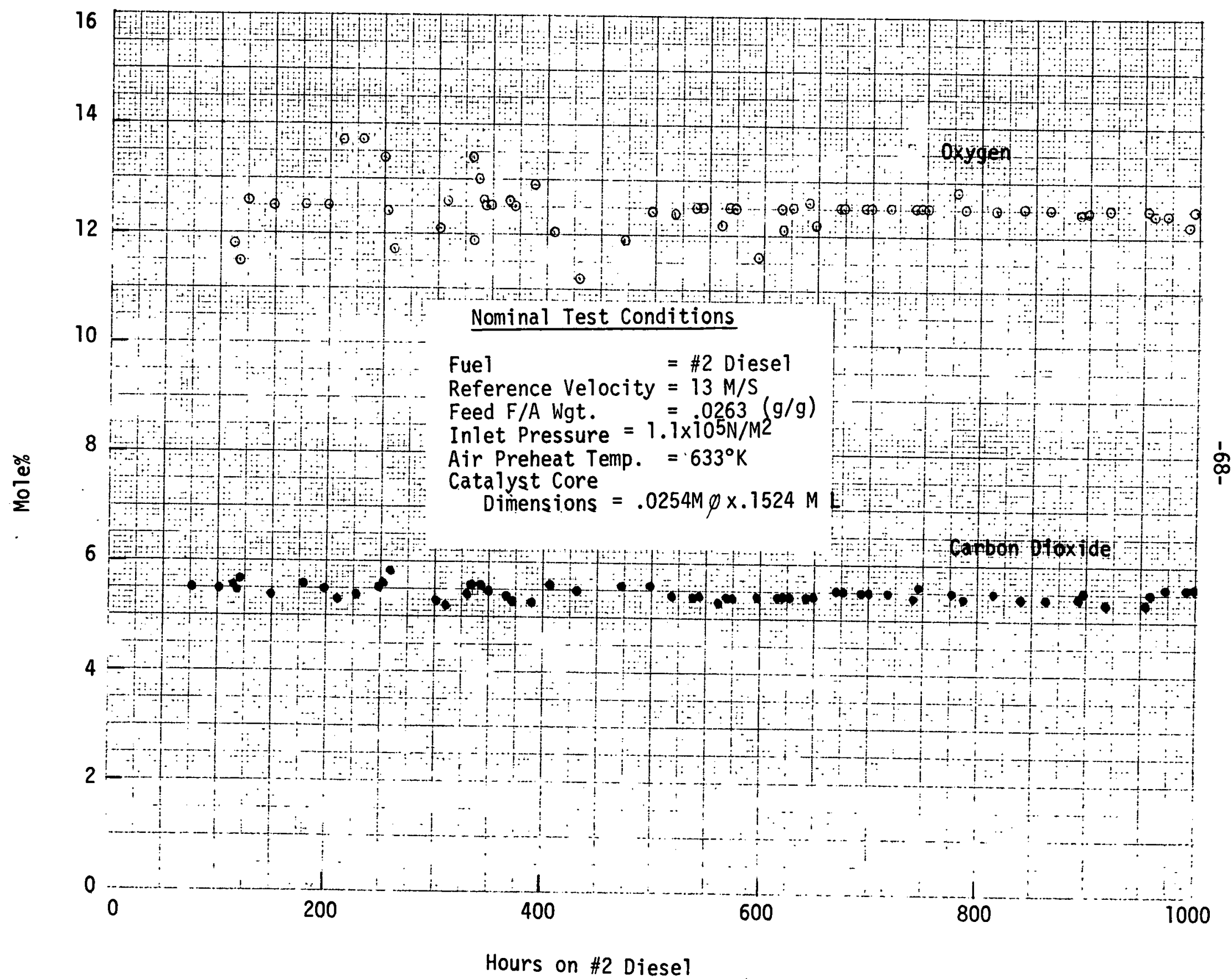




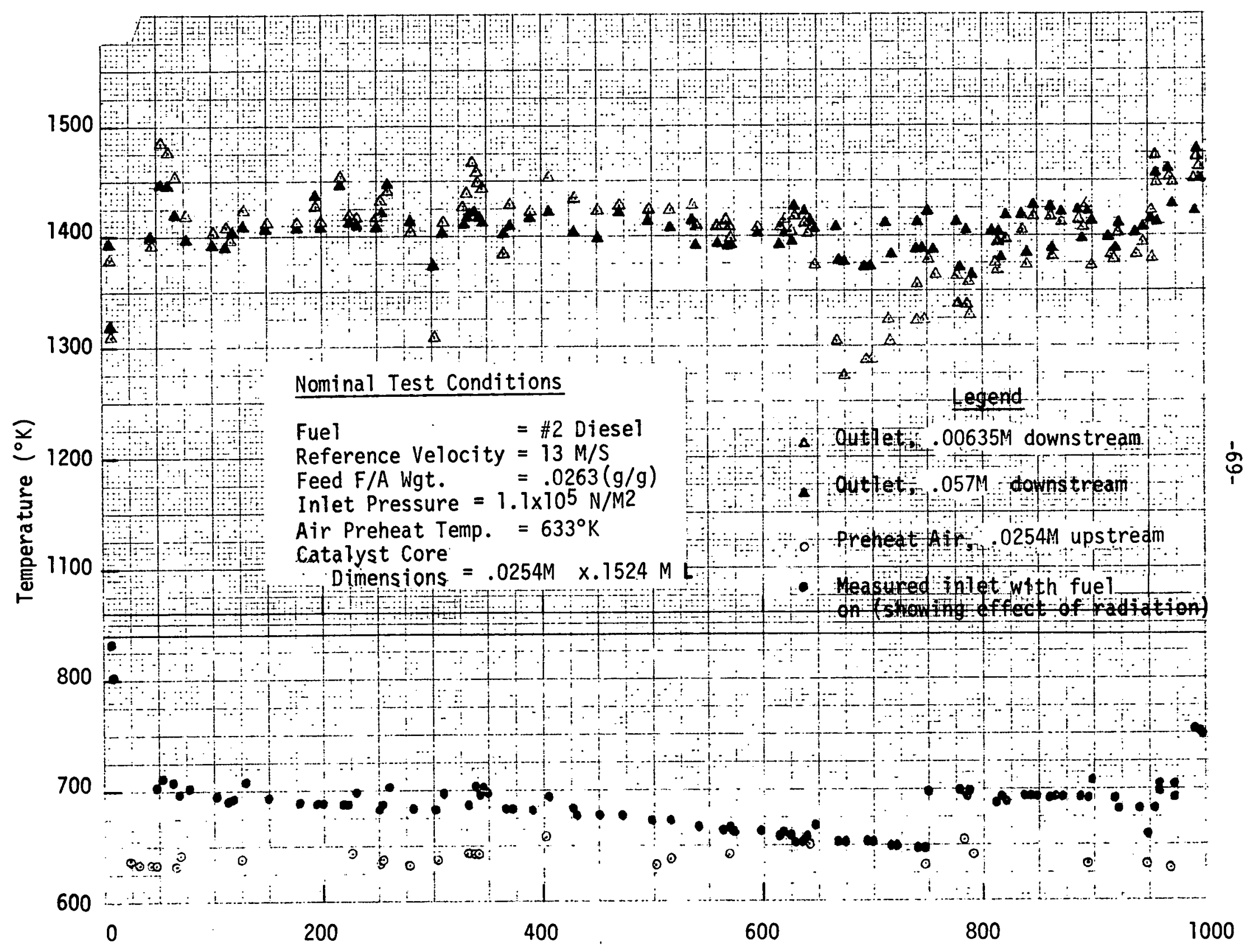

Hours on \#2 Diesel 
Figure V-7 Pressure Drop Control Chart During Life Testing of Catalyst Core DXB-222

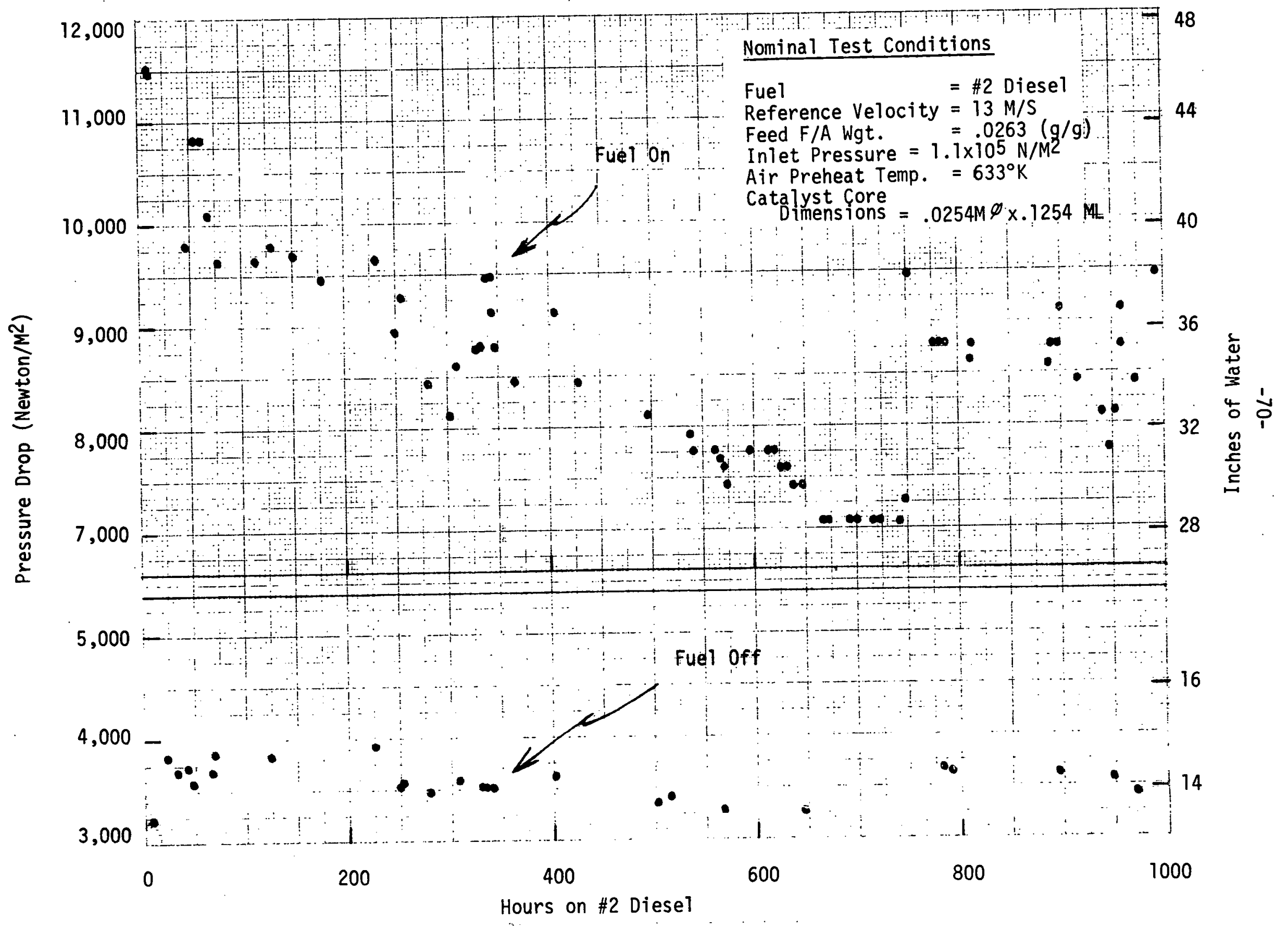


Figures $V-2,3$ and 4 indicate that the emissions of DXB-222 are essentially constant throughout the life test, showing no change in the catalyst cores overall performance.

During the 1,000 hour life test of DXB-222, the average emissions were as follows:

\begin{tabular}{lrr} 
Emission & Mean & Standard Deviation \\
\cline { 2 - 2 }$C_{3}$ ) & 3.8 & 3.6 \\
CO (vppm) & 47 & 1.4 \\
NO (vppm) & 3.5 & 0.5
\end{tabular}

The CO and UHC emission results correspond to a mean combustion efficiency of $99.89 \%$. All three emission levels are well within anticipated federal standards for stationary gas turbines(7). These emissions can also be translated into steady-state automotive gas turbine operation at 10 miles per gallon for comparison with automotive standards.

\begin{tabular}{|c|c|c|c|}
\hline \multirow[b]{2}{*}{ Emission } & \multirow{2}{*}{$\begin{array}{c}\text { Mean Measured } \\
\text { Emission Corrected } \\
\text { to.Automotive Operation } \\
\mathrm{g} / \text { mile }\end{array}$} & \multicolumn{2}{|c|}{$\begin{array}{l}\text { Automotive Standard } \\
\qquad \ldots \text { (g/mile) } \\
\therefore . \quad \text { Year }\end{array}$} \\
\hline & & 1977 & $1978^{\circ}$ \\
\hline $\mathrm{UHC}$ & 0.07 & 1.5 & .41 \\
\hline $\mathrm{CO}$ & 0.58 & 15. & 3.4 \\
\hline $\mathrm{NO}_{X}$ & 0.062 & 2.0 & .4 \\
\hline
\end{tabular}

Note that this comparison is strictly based on steady-state operation and does not account for transients nor cold start. 
It should be noted that the $\mathrm{NO}_{\mathrm{X}}$ emissions during the life testing of DXB-222 probably results from the essentially quantitative oxidation of the fuel bound nitrogen in \#2 diesel fuel (2). At the adiabatic operating temperature of the life test, no $\mathrm{NO}_{\mathrm{x}}$ formation is expected due to nitrogen fixation.

Examining the temperature control chart (Figure V-6) indicates that the outlet temperatures remained constant (within experimental error) throughout the life test. Since the temperature measured $.00635 \mathrm{M}$ downstream of the catalyst core indicated the highest value throughout the 1,000 hours, no burning was occurring downstream of catalyst core DXB-222 during life testing.

The control plots for pressure drop (Figure $V-7$ ) indicate that initially the pressure drop was higher but during the remainder of the life test no further changes were noted. This plot also proved useful in detecting an operating problem during this life test. At approximately 500 hours aging, the pressure drop declined dramatically as shown on the control chart. Removal of the catalyst holder revealed that the packing between the holder and the reactor wall had loosened and could cause bypassing. The holder was repacked in the reactor and the pressure drop resulting during the last 200 hours of life testing corresponded to the pressure drop observed at 400 hours testing.

The control charts depicting $\mathrm{CO}_{2}$ vent gas analysis (Figure V-5) show the variation in \#2 diesel fuel feed during the 1,000 hour life test. This variation in fuel feed corresponds to 
a variation in adiabatic flame temperature from 1499 to $1565^{\circ} \mathrm{K}$ during the 1,000 hour life test of DXB-222.

A summary table comparing all the control variables and test responses at the beginning and end of the life test on DXB-222 is shown in Table $V-5$. This data is indicative of the control capabilities of the experimental equipment. The table shows that no significant alterations were made to the operating conditions of DXB-222 during life testing.

Another question that arises in regards to practicality of using catalysts in combustion processes is the durability of the catalyst core support material. Figure V-8 shows the photographs taken of DXB-222 after 1,000 hours life testing. The color changes shown when viewing the catalyst core from inlet to outlet are normal, and reflect the temperature gradients within the catalyst core during combustion operation at an adiabatic temperature of $1527^{\circ} \mathrm{K}$. Physical examination of the catalyst showed that no observable physical damage to the catalyst core structure had occurred during testing. The catalyst support appears to be quite durable after 1,000 hours diesel 1ife testing.

Analytical tests were performed on catalyst core DXB-222 at the conclusion of the life test in order to determine the effect of operation at combustion conditions on the retention of the precious metal catalytic component and on the thermal stability of the catalyst core. Assay results indicated that DXB-222 retained $56 \%$ of its precious metal after 1,000 hours aging. Results from BET surface 
TABLE V-5

Comparison of Typical Operating Conditions and Performance Data

At Start and End of Life Test for Catalyst Core DXB-222

$\begin{array}{lll} & \underline{\text { Start }} & \underline{\text { End }} \\ \text { Date: } & 11 / 19 / 75 & 2 / 27 / 76 \\ \text { Hours on \#2 Diesel Fuel: } & 40 & 993 \\ \text { Air Flow (Kg/Sec.): } & 3.22 \times 10^{-3} & 3.22 \times 10^{-3} \\ \text { Fuel/Air Ratio (g/g): } & 0.0263 & 0.0268 \\ \text { Preheat Air Temperature }\left({ }^{\circ} \mathrm{K}\right): & 633 & 628 \\ \text { Outlet Temperature }\left({ }^{\circ} \mathrm{K}\right) & 1398 & 1453 \\ \text { Adiabatic Flame Temperature }\left({ }^{\circ} \mathrm{K}\right): & 1527 & 1540 \\ \left.\text { Inlet Pressure (N/M }{ }^{2}\right) & 1.1 \times 10^{5} & 1.1 \times 10^{5} \\ \left.\text { Pressure Drop (N/M }{ }^{2}\right): & 9779 & 9431 \\ \text { Percent Pressure Drop: } & 8.8 & 8.6 \\ \text { Reference Velocity }(\mathrm{M} / \mathrm{S}): & 13.0 & 12.9 \\ \text { Combustion Efficiency }(\%): & 99.85 & 99.89 \\ \text { Space Velocity NTP Nominal }\left(\mathrm{Sec}^{-1}\right) & 34.7 & 34.7 \\ \text { Heat Release Rate }\left(\mathrm{Joules} / \mathrm{S} \cdot \mathrm{M}^{3} \cdot \mathrm{N} / \mathrm{M}^{3}\right): & 4.3 \times 10^{2} & 4.4 \times 10^{2}\end{array}$

Emissions $^{1}$ (Vppm @ Nomina 11 y $12.5 \% 0_{2}$ )

CO

80

60

UHC ( $A s C_{3}$ )

6

1

$\mathrm{NO}_{\mathrm{X}}$

$-\quad 4.2$

Catalyst Core Dimensions, Nominal: $\quad 0.0254 \mathrm{M}$ in dia. by $0.152 \mathrm{M}$ Long

1 All emissions measured with water cooled sampling probe located at $0.102 \mathrm{M}$ downstream of catalyst core. 
4039520 (DXB-222)

Inlet to first

catalyst section

4039521 (DXB-222)

Inlet to second

catalyst section

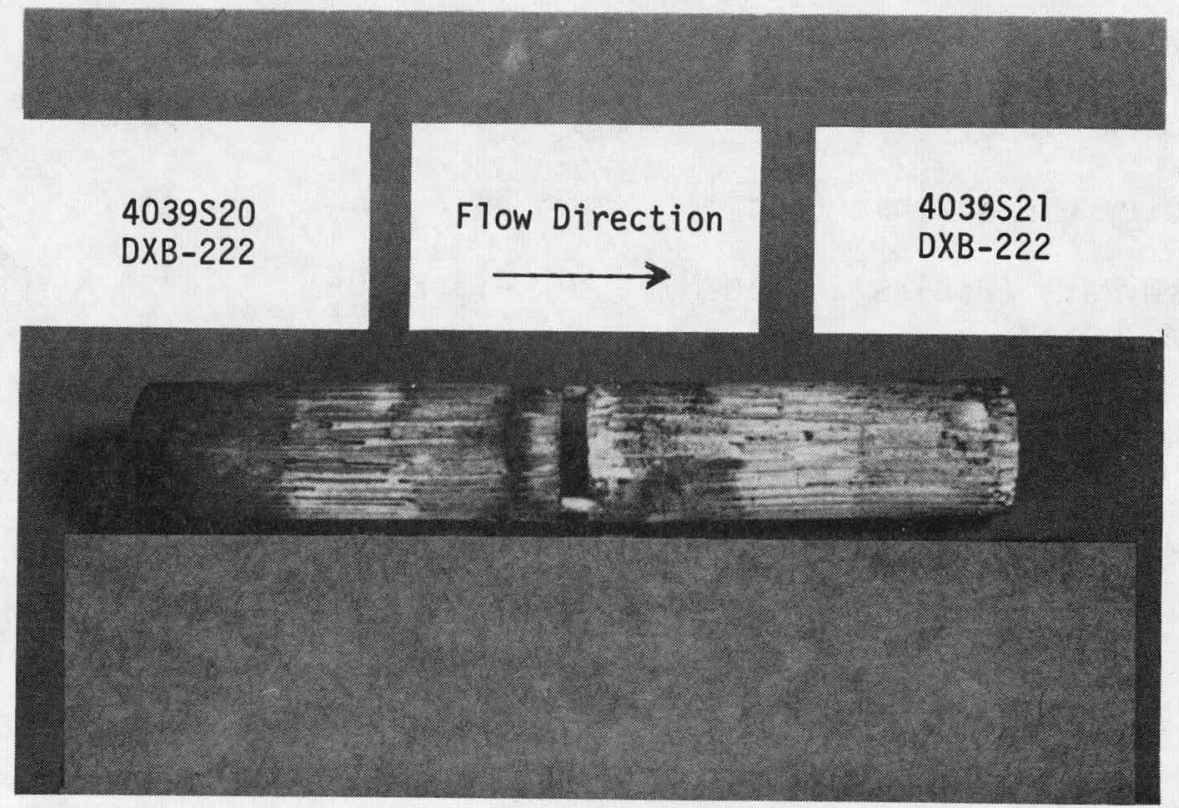

Figure V-8 Photographs of Catalyst Core DXB-222 After 1000 Hours Life Testing 
area measurements showed that catalyst core DXB-222 retained $16 \%$ of its initial surface area. These results are all relative to a lined-in catalyst core (i.e., aged 24 hours at life test conditions). At present, it is felt that the most probable mechanism for the precious metal loss is detachment of the washcoat from the support. Techniques, gained from experience in auto exhaust catalyst preparation, are available for increasing the adhesion of the washcoat to the monolith. These improved techniques should reduce the precious metal loss without decreasing the performance durability of DXB-222.

Additional analyses were obtained with a scanning electron microscope and an x-ray diffractometer. These results were negative in that no contaminants were found on DXB-222 after 1 ife testing.

Overall, the life test results indicate that CATCOM catalyst core DXB-222 can operate under combustion conditions for at lease 1000 hours without loss of low emissions performance due to physical or catalytic degradation. Although analytical measurements showed a loss of both surface area and precious metal over the course of the life test, these changes apparently do not have a significant effect on the overall catalyst performance.

\section{b. Carbon Monoxide Activity Test}

The response of carbon monoxide conversion to increasing air preheat temperature was measured on a scheduled basis during life testing of catalyst core DXB-222. These results are plotted in Figure $V-9$. 
Figure V-9 Carbon Monoxide Activity Test Response During Life Testing of Catalyst Core DXB-222

Legend

124 Hours Aging

2250 Hours Aging

3500 Hours Aging

4750 Hours Aging

51000 Hours Aging
Run Conditions

Reference Velocity $=36.5 \mathrm{M} / \mathrm{S}$

Feed $\mathrm{CO}=4000 \mathrm{Vppm}$

Pressure $=1 \times 10^{5} \mathrm{~N} / \mathrm{M}^{2}$

Catalyst. Core Dimensions $=$ $.0254 M \varnothing \times .1524 M$ L

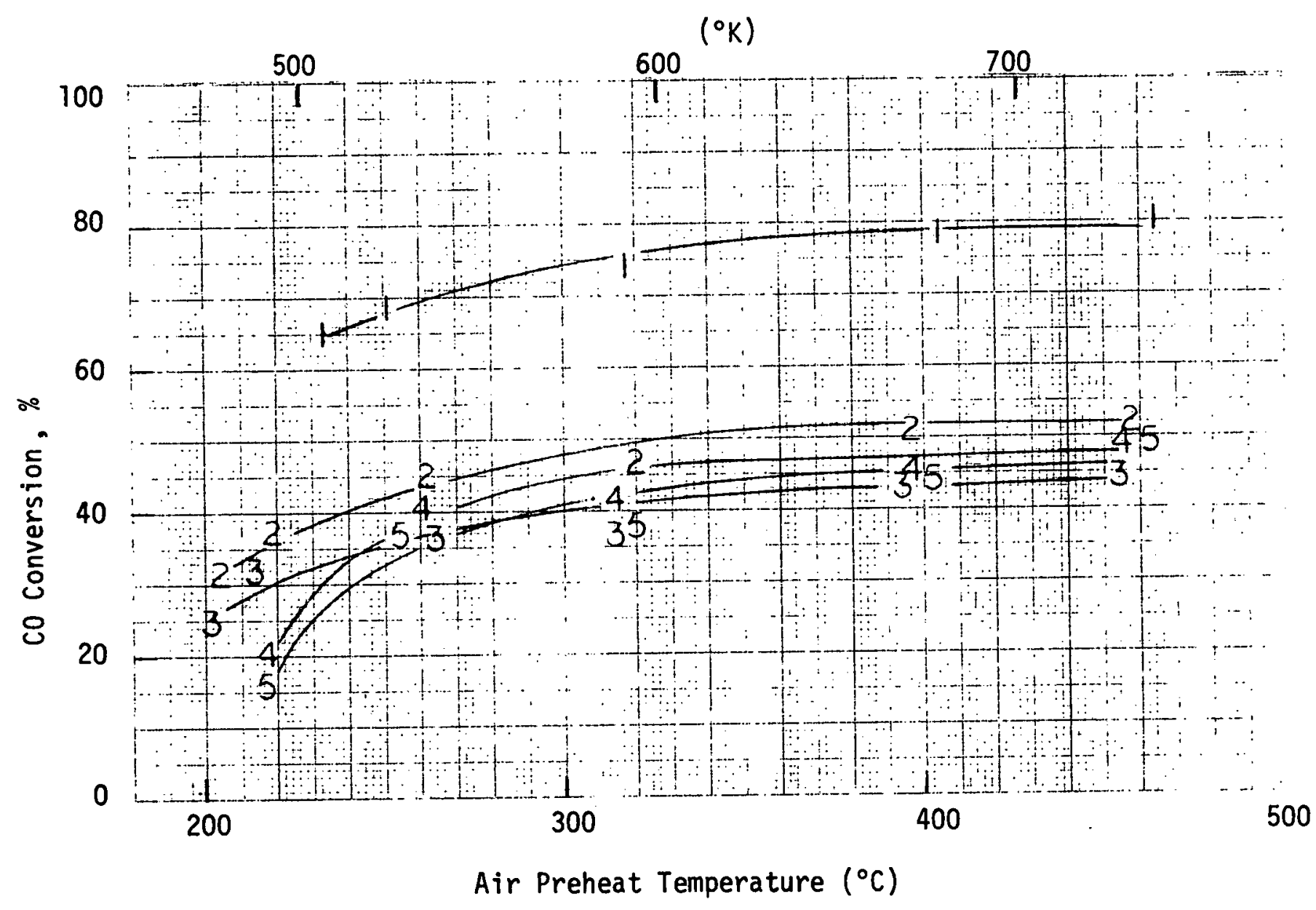


Examining each response curve indicates that between 24 hours and 250 hours of aging with \#2 diesel fuel, a significant change in the catalyst cores' activity has occurred for carbon monoxide as fuel. After 250 hours, very minor changes are occurring as determined by this test procedure. These curves can further be interpreted by considering the $\mathrm{CO}$ ignition temperature and the mass transfer limited co conversion for each test period.

Figure $V-10$ shows a plot of $c 0$ ignition temperature versus time period. Below 500 hours, the catalyst core DXB-222 ignites at the initial test temperature of $463^{\circ} \mathrm{K}$ so that an accurate measurement of the ignition temperature is not available for this time period. After 500 hours, the ignition temperature begins to increase and at 1,000 hours has reached $483^{\circ} \mathrm{K}$. Apparently, the intrinsic catalytic activity of DXB-222 for $C O$ is still changing after 1,000 hours life testing.

Figure V-11 shows the plot of mass transfer 1 imited conversion versus time period. This response indicates that the conversion level declines rapidly from $80 \%$ for the fresh catalyst to approximately $50 \%$ during the first 250 hours aging. For this to occur, the apparent mass transfer geometric area has declined $40 \%$ from that originally available. Further decline in mass transfer 1 imited conversion is negligible from 250 hours up to 1,000 hours aging. 
Figure $V-10$

Response of Ignition Temperature of Carbon Monoxide During Activity Tests on Catalyst Core DXB-222

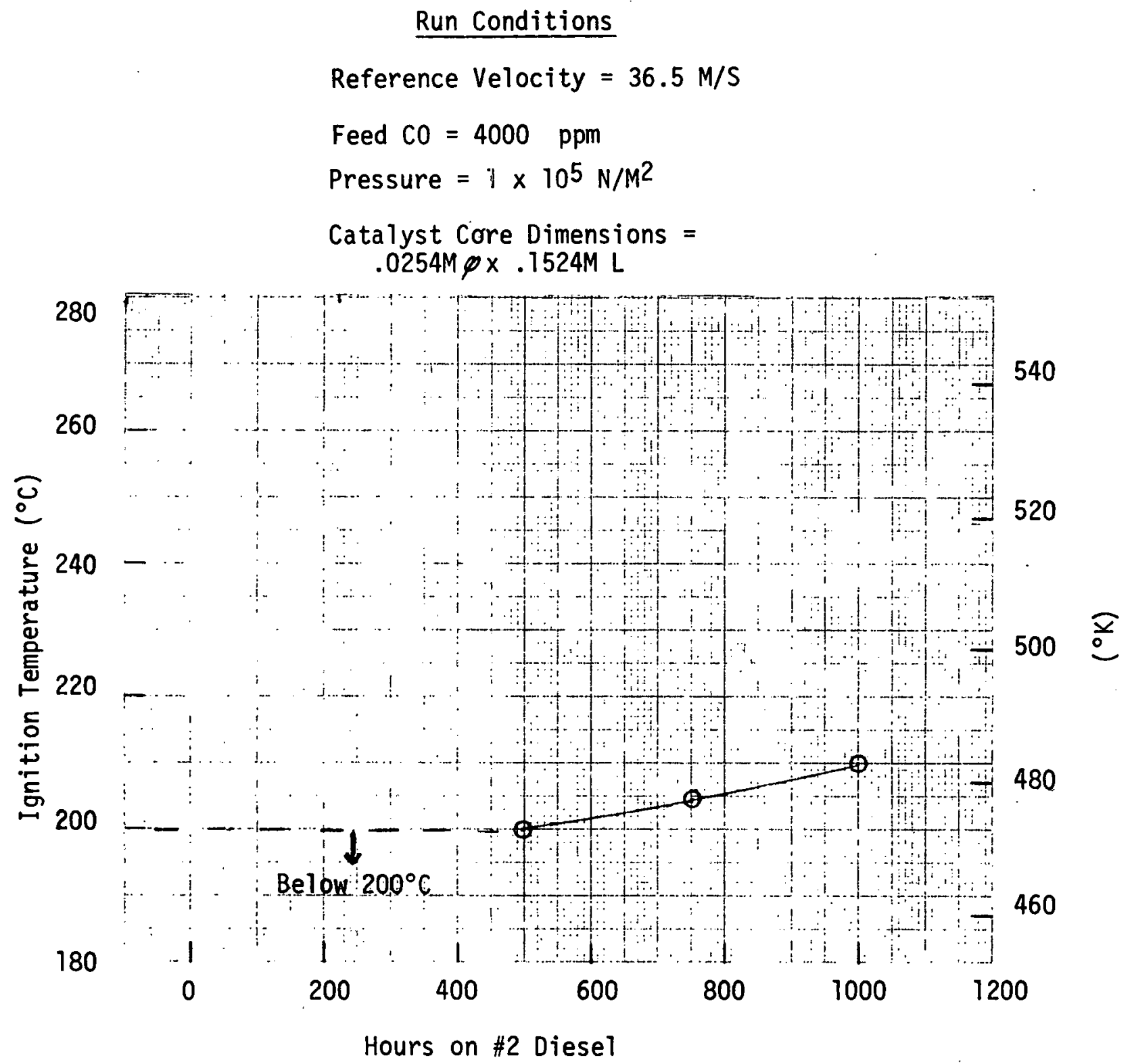




\title{
$-80-$ \\ Figure $\mathrm{V}-11$
}

Response of Mass Transfer Limited Conversion of

Carbon Monoxide From Activity Tests on Catalyst Core DXB-22

\author{
Run Conditions \\ Reference Velocity $=36.5 \mathrm{M} / \mathrm{S}$ \\ Feed $\mathrm{CO}=4000 \mathrm{vppm}$ \\ Pressure $=1 \times 105 \mathrm{~N} / \mathrm{M}^{2}$ \\ Catalyst Core Dimensions $=.0254 \mathrm{M} \times .1524 \mathrm{M} \mathrm{L}$
}

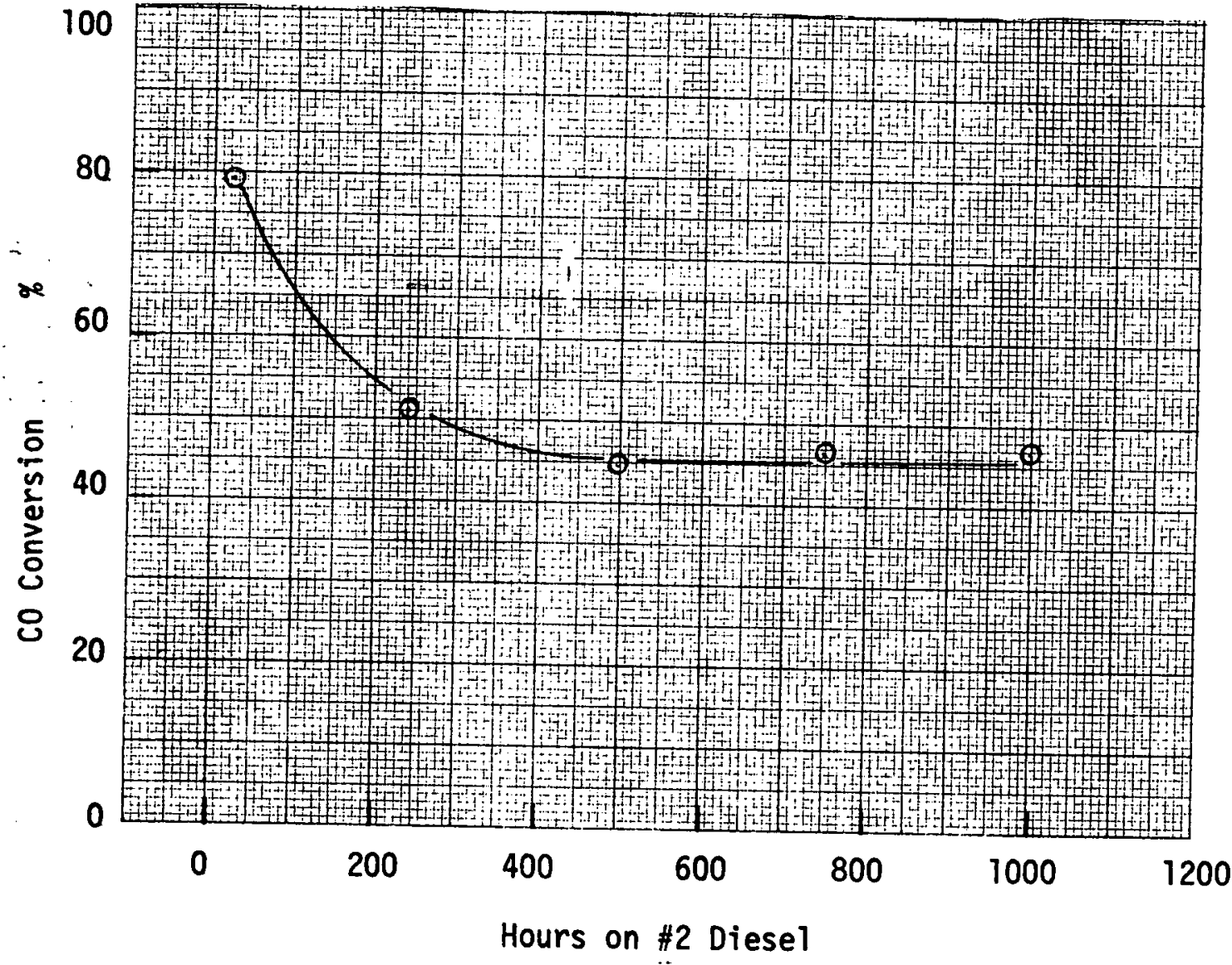


These results indicate that changes in catalyst core DXB-222's intrinsic activity for carbon monoxide are still occurring at 1,000 hours as depicted by increasing ignition temperature. However, the apparent mass transfer area of the catalyst core, as measured by the mass transfer 1 imited $C O$ conversion, appears to have stabilized after 250 hours aging.

\section{c. Propane Parametric Studies}

The propane parametric studies conducted at the beginning of the 1,000 hour life test on catalyst core DXB-222 provided information on the region of low emissions operation of a fresh CATCOM catalyst with C. P. Propane fuel. The final parametrics provided information on the effect of aging on the retention of catalytic activity for low emissions operation with C. P. Propane.

Table $v-6$ contains a tabulation of the response of combustion efficiency from the $1 / 3$ replicate factorial statistical design for four variables at these levels. Analyzing the combustion efficiency response for the initial propane parametrics indicated the following region of operation of the main control variables for low emissions: 
TABLE $\quad V-6$

Combustion Efficiency Response of Propane Parametrics

Before and After 1000 Hour Life Test on Catalyst Core DXB-222

\begin{tabular}{|c|c|c|c|c|c|c|}
\hline Run \# & $\begin{array}{l}\text { Inlet } \\
\text { Pressure } \\
\left(\times 10^{-5}\right) \\
\mathrm{N} / \mathrm{M}^{2} \\
\end{array}$ & $\begin{array}{c}\text { Preheat } \\
\text { Air } \\
\text { Temperature } \\
{ }^{\circ} \mathrm{K} \\
\end{array}$ & $\begin{array}{c}\text { Reference } \\
\text { Velocity } \\
\text { M/S } \\
\end{array}$ & $\begin{array}{c}\text { Adiabatic } \\
\text { Flame } \\
\text { Temperature } \\
{ }^{\circ} \mathrm{K} \\
\end{array}$ & $\begin{array}{l}\text { Combus } \\
\text { Efficier } \\
\text { Initial } \\
\end{array}$ & $\begin{array}{l}\text { tion } \\
\text { cy }(\%) \\
\text { Final } \\
\end{array}$ \\
\hline $\begin{array}{l}6-26 A \\
6-41 A\end{array}$ & $\begin{array}{l}3.1 \\
3.0\end{array}$ & $\begin{array}{l}734 \\
733\end{array}$ & $\begin{array}{l}13.3 \\
14.8\end{array}$ & $\begin{array}{l}1471 \\
1523\end{array}$ & 99.96 & 98.67 \\
\hline $\begin{array}{l}6-26 \mathrm{~B} 3 \\
6-41 \mathrm{~B}\end{array}$ & $\begin{array}{l}5.1 \\
5.0\end{array}$ & $\begin{array}{l}653 \\
653\end{array}$ & $\begin{array}{l}13.5 \\
15.2\end{array}$ & $\begin{array}{l}1477 \\
1482\end{array}$ & 0 & 0 \\
\hline $\begin{array}{l}6-26 C \\
6-41 C\end{array}$ & $\begin{array}{l}5.1 \\
5.1\end{array}$ & $\begin{array}{l}718 \\
722\end{array}$ & $\begin{array}{l}13.2 \\
14.5\end{array}$ & $\begin{array}{l}1375 \\
1408\end{array}$ & 98.36 & 18.65 \\
\hline $\begin{array}{l}6-26 D \\
6-41 D\end{array}$ & $\begin{array}{l}5.1 \\
5.1\end{array}$ & $\begin{array}{l}808 \\
808\end{array}$ & $\begin{array}{l}20.73 \\
22.6\end{array}$ & $\begin{array}{l}1478 \\
1475\end{array}$ & 99.93 & 84.31 \\
\hline $\begin{array}{l}6-26 E \\
6-41 E\end{array}$ & $\begin{array}{l}3.1 \\
3.1\end{array}$ & $\begin{array}{l}803 \\
808\end{array}$ & $\begin{array}{l}28.1 \\
30.9\end{array}$ & $\begin{array}{l}1473 \\
1475\end{array}$ & 99.86 & 91.51 \\
\hline $\begin{array}{l}5-109 \mathrm{~F} \\
6-41 \mathrm{~F}\end{array}$ & $\begin{array}{l}1.2 \\
1.2\end{array}$ & $\begin{array}{l}718 \\
708\end{array}$ & $\begin{array}{l}13.16 \\
14.2\end{array}$ & $\begin{array}{l}1538 \\
1530\end{array}$ & 99.89 & 99.7 \\
\hline $\begin{array}{l}6-27 A \\
6-42 A\end{array}$ & $\begin{array}{l}3.1 \\
3.1\end{array}$ & $\begin{array}{l}638 \\
653\end{array}$ & $\begin{array}{l}21.1 \\
23.5\end{array}$ & $\begin{array}{l}1462 \\
1482\end{array}$ & 99.88 & 24.54 \\
\hline $\begin{array}{l}6-27 B \\
6-42 B\end{array}$ & $\begin{array}{l}3.1 \\
3.1\end{array}$ & $\begin{array}{l}711 \\
723\end{array}$ & $\begin{array}{l}28.03 \\
31.1\end{array}$ & $\begin{array}{l}1500 \\
1545\end{array}$ & 99.81 & 24.47 \\
\hline $\begin{array}{l}4-92 E 2 \\
6-42 C\end{array}$ & $\begin{array}{l}3.1 \\
3.1\end{array}$ & $\begin{array}{l}643 \\
633\end{array}$ & $\begin{array}{l}14.5 \\
14.6\end{array}$ & $\begin{array}{l}1497 \\
1534\end{array}$ & 99.94 & 99.58 \\
\hline $\begin{array}{l}5-109 B \\
6-42 D\end{array}$ & $\begin{array}{l}1.3 \\
1.2\end{array}$ & $\begin{array}{l}721 \\
723\end{array}$ & $\begin{array}{l}19.57 \\
22.7\end{array}$ & $\begin{array}{l}1477 \\
1474\end{array}$ & 99.89 & 37.58 \\
\hline $\begin{array}{l}5-109 D \\
6-42 E\end{array}$ & $\begin{array}{l}1.4 \\
1.2\end{array}$ & $\begin{array}{l}638 \\
653\end{array}$ & $\begin{array}{l}20.55 \\
25.8\end{array}$ & $\begin{array}{l}1526 \\
1554\end{array}$ & 99.94 & 31.12 \\
\hline $\begin{array}{l}6-27 F \\
6-42 F\end{array}$ & $\begin{array}{l}5.1 \\
5.1\end{array}$ & $\begin{array}{l}718 \\
723\end{array}$ & $\begin{array}{l}27.42 \\
31.1\end{array}$ & $\begin{array}{l}1469 \\
1474\end{array}$ & 47.03 & 16.87 \\
\hline $\begin{array}{l}6-28 A \\
6-43 A\end{array}$ & $\begin{array}{l}3.1 \\
3.1\end{array}$ & $\begin{array}{l}723 \\
650\end{array}$ & $\begin{array}{l}20.8 \\
22.82\end{array}$ & $\begin{array}{l}1394 \\
1394\end{array}$ & 99.61 & 16.91 \\
\hline $\begin{array}{l}5-110 A \\
6-43 B\end{array}$ & $\begin{array}{l}1.2 \\
1.2\end{array}$ & $\begin{array}{l}828 \\
808\end{array}$ & $\begin{array}{l}13.46 \\
14.4\end{array}$ & $\begin{array}{l}1486 \\
1475\end{array}$ & 99.91 & 99.6 \\
\hline $\begin{array}{l}5-112 B \\
6-43 C\end{array}$ & $\begin{array}{l}3.1 \\
3.1\end{array}$ & $\begin{array}{l}803 \\
808\end{array}$ & $\begin{array}{l}13.1 \\
14.4\end{array}$ & $\begin{array}{l}1389 \\
1394\end{array}$ & 99.93 & 88.65 \\
\hline
\end{tabular}


TABLE V-6 (continued)

Combustion Efficiency Response of Propane Parametrics

Before and After 1000 Hour Life Test on Catalyst Core DXB-222

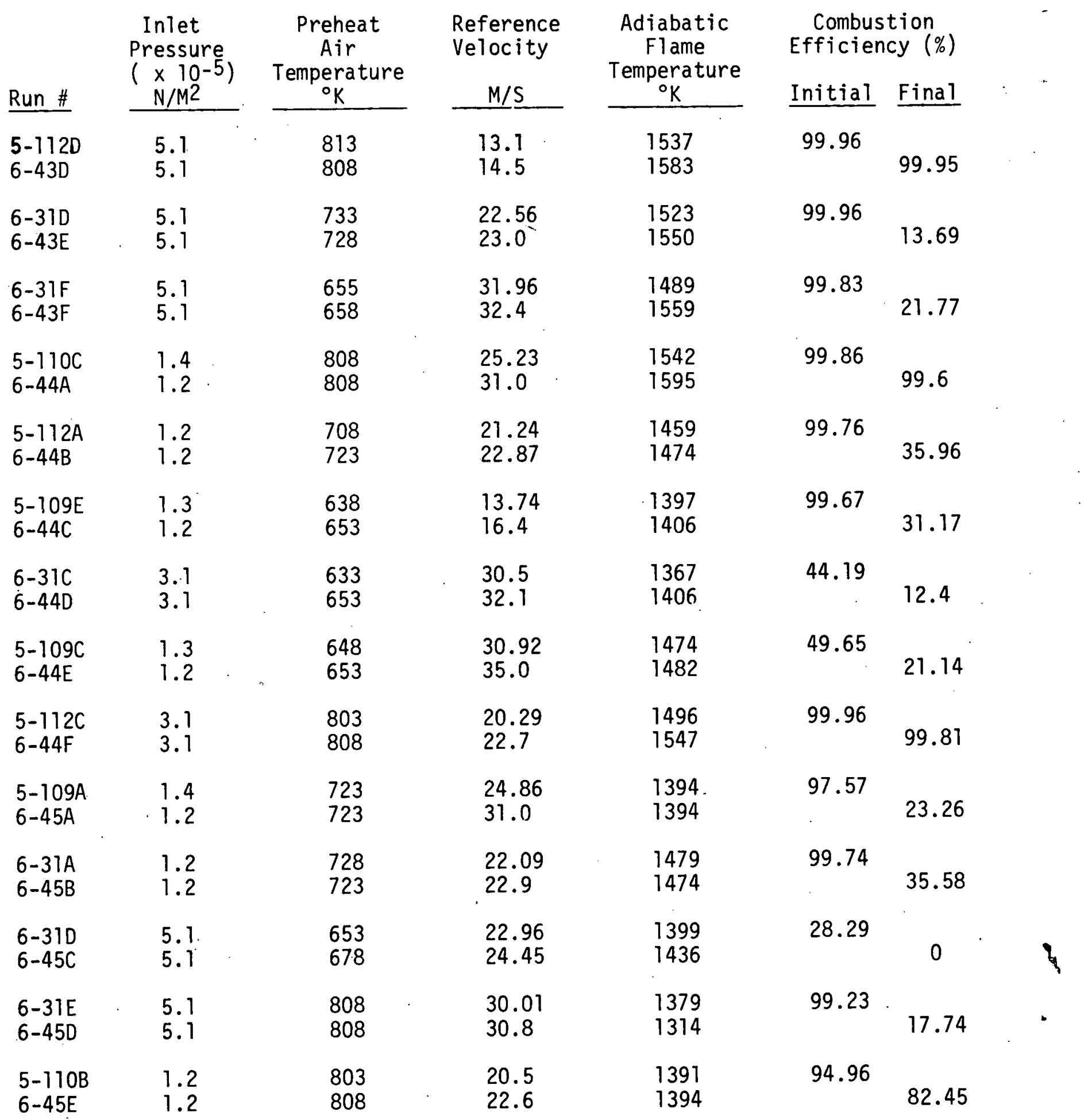




$\begin{array}{ll}\text { Air Preheat Temperature: } & \geq 653^{\circ} \mathrm{K} \\ \text { Adiabatic Flame Temperature: } & \geq 1449^{\circ} \mathrm{K} \\ \text { Reference Velocity: } & \leq 30 \mathrm{M} / \mathrm{S} \\ \text { Pressure: } & \leq 5 \times 10^{5} \mathrm{~N} / \mathrm{M}^{2}\end{array}$

The low emissions operating region for DXB-222 with C. P. Propane is very broad prior to life testing. The only marginal operating conditions are at low air preheat $\left(<653^{\circ} \mathrm{K}\right)$ and low adiabatic flame temperature $\left(<1449^{\circ} \mathrm{K}\right)$.

The results in Table $v-6$ also define the region for low emissions operation after 1,000 hours of aging as follows:

$$
\begin{array}{ll}
\text { Air Preheat Temperature: } & \geq 808^{\circ} \mathrm{K} \\
\text { Adiabatic Flame Temperature: } & \geq 1533^{\circ} \mathrm{K} \\
\text { Reference Velocity: } & \leq 22 \mathrm{M} / \mathrm{S} \\
\text { Pressure: } & 1 \times 10^{5} \mathrm{~N} / \mathrm{M}^{2}
\end{array}
$$

The performance of catalyst core DXB-222 after 1,000 hours diesel aging has declined significantly in regards to the range of low emissions operation for C. P. Propane.

The decline in activity for catalyst core DXB-222 relative to C. P. Propane fuel was not unexpected, considering the fact that low molecular weight paraffinic fuels (e.g., C. P. Propane) are more difficult to oxidize than fuels containing higher molecular weight paraffins (e.g., \#2 diesel). 
Since the results with C. P. Propane may be unduly conservative and not indicative of the catalyst's capabilities after 1,000 hours aging, a number of runs from the parametric matrix were repeated using \#2 diese1 to determine the performance of DXB-222 with a realistic fuel. These replicates covered a broad range of the region in which C. P. Propane had high emissions. Over this representative range of operating conditions from the propane parametrics, the performance of catalyst core DXB-222 with \#2 diesel was acceptable, with high combustion efficiencies, as graphically shown in Figure V-12. Comparable results for C. P. Propane and \#2 diesel fuel are also tabulated in Table V-7.

These parametrics conducted after 1,000 hours aging of DXB-222 indicate catalyst performance with a low molecular weight paraffinic fuel (propane) and a realistic high molecular weight fuel, \#2 diese1. The final diesel parametrics gave information that was more representative in terms of commercial application.

Upon removal of catalyst core DXB-222 from the reactor test rig, after the variable study with \#2 diesel, it was noticed that some internal damage to the catalyst core had occurred, blocking some support channel passages. Since no unusual increases in pressure drop occurred during life testing and the final propane parametrics, the damage had to be caused during the diesel parametrics. This damage was attributed to unvaporized fuel passing through the catalyst at 
Figure V-12 Plot of Comparison Runs for \#2 Diese1 and C. P. Propane After 1000 Hour Diesel Ageing of Catalyst Core DXB-222.

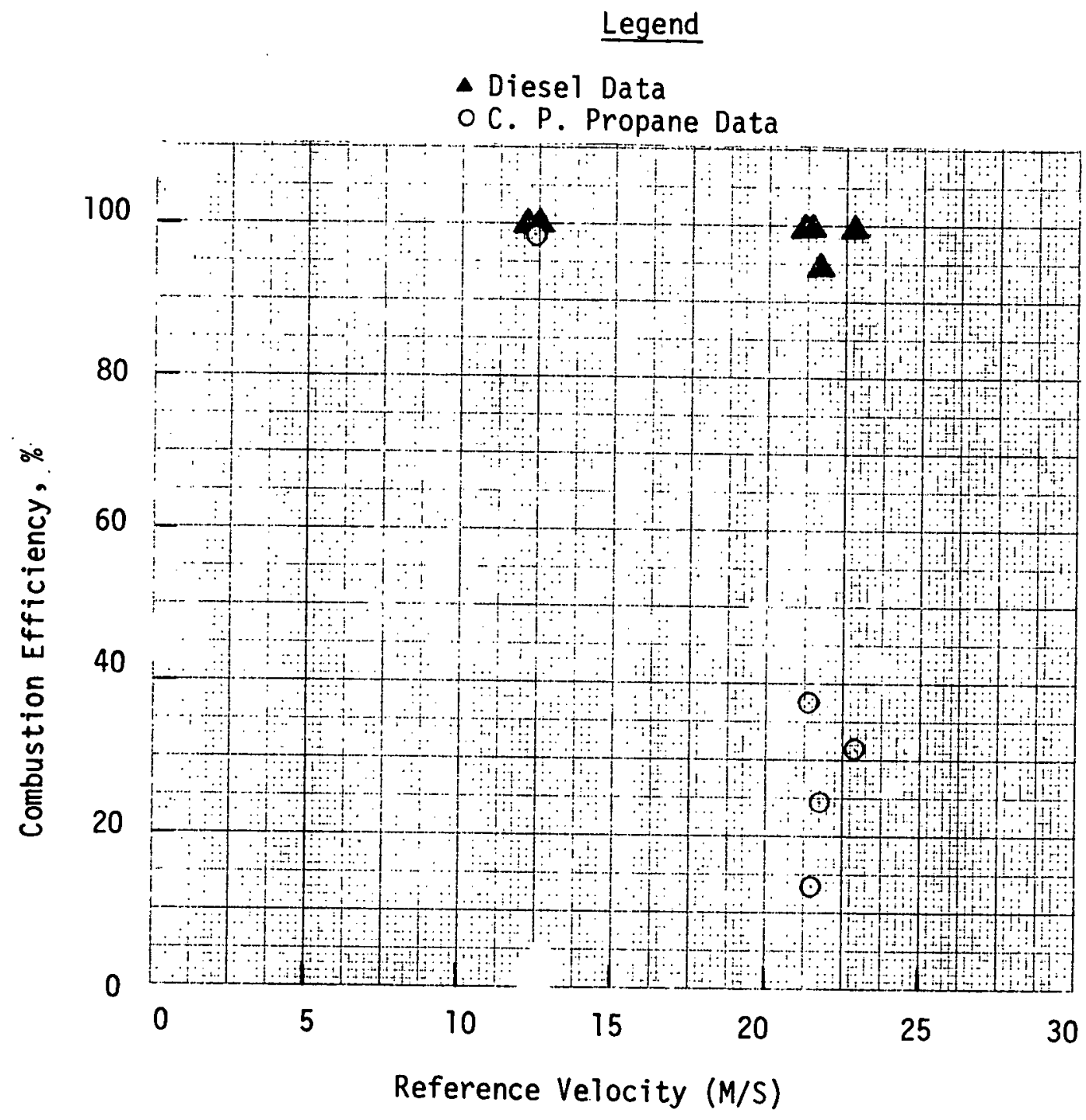


TABLE $V-7$

Comparison of Parametric Runs With C. P. Propane

And \#2 Diesel After 1000 . Hours Ageing of DXB-222

\begin{tabular}{|c|c|c|c|c|c|c|}
\hline \multirow[b]{2}{*}{ Run \# } & \multirow{2}{*}{$\begin{array}{c}\text { Inlet } \\
\text { Pressure } \\
\left(\times 10^{-5}\right) \\
\mathrm{N} / \mathrm{M}^{2} \\
\end{array}$} & \multirow{2}{*}{$\begin{array}{l}\text { Air Preheat } \\
\text { Temperature } \\
{ }^{\circ} \mathrm{K} \\
\end{array}$} & \multirow{2}{*}{$\begin{array}{c}\text { Reference } \\
\text { Velocity } \\
\text { M/S } \\
\end{array}$} & \multirow{2}{*}{$\begin{array}{c}\text { Adiabatic } \\
\text { Flame } \\
\text { Temperature } \\
{ }^{\circ} \mathrm{K} \\
\end{array}$} & \multicolumn{2}{|c|}{ Combustion Efficiency } \\
\hline & & & & & C.P. Propane & $\# 2$ Diesel \\
\hline $6-41 A$ & 3.0 & 733 & 14.8 & 1523 & 98.67 & \\
\hline $6-46 A$ & 3.1 & 723 & 14.3 & 1425 & & 99.94 \\
\hline $6-41 B$ & 5.0 & 653 & 15.2 & 1482 & 0 & \\
\hline $6-46 \mathrm{~F}$ & 5.1 & 653 & 14.8 & 1445 & & 99.96 \\
\hline $6-42 A$ & 3.1 & 653 & 23.5 & 1482 & 24.54 & \\
\hline $6-46 D$ & 3.1 & 653 & 23.3 & 1445 & & 94.43 \\
\hline $6-42 D$ & 1.2 & 723 & 22.7 & 1474 & 37.58 & \\
\hline $6-46 D$ & 1.2 & 723 & 22.6 & 1440 & & 99.76 \\
\hline $6-42 E$ & 1.2 & 653 & 25.8 & 1554 & 31.12 & \\
\hline $6-46 C$ & 1.2 & 653 & 25.5 & 1490 & & 99.8 \\
\hline $6-43 E$ & 5.1 & 728 & 23.0 & 1550 & 13.69 & \\
\hline $6-46 E$ & 5.1 & 723 & 22.6 & 1490 & & 99.92 \\
\hline
\end{tabular}


the high fuel flow rate of this variable study. Catalyst core DXB222. was still. capable of low emissions operation, however the overall pressure drop naturally increased through the catalyst core.

The results of the propane and diesel parametrics indicate that a decline of activity has occurred with respect to low molecular weight paraffinic fuels. However, catalyst core DXB-222 still maintains high combustion efficiencies over a wide operating range with \#2 diesel after the 1,000 hour 1ife test.

\section{d. Analysis of Propane Parametrics}

Detailed analysis of the propane parametrics with DXB-222 was conducted in order to obtain: 1) a graphical representation, and; 2) a statistical model describing the responses of combustion efficiency, co emissions and pressure drop. Since no control study was made to quantify modes or causes of deactivation from \#2 diesel aging, this analysis was directed only at the initial propane parametrics on $D X B-222$.

The models that were tried in this study were limited to multiple linear regressions considering the first, second and third order combinations of interactions. Typical models such as Combustion Efficiency $=A+B$ (Reference Velocity) + C (Adiabatic Flame Temperature) (Air Preheat Temperature) were considered. 


\section{1) Combustion Efficiency}

A number of graphical techniques and statistical

models were explored to represent the response of combustion efficiency to the control variables. This section contains a synopsis of these results; more detail can be found in Appendix D. The main conclusion was that no suitable description of this response was found.

Table V-8 summarizes typical results from the regression analysis models considered for describing combustion efficiency. The correlation coefficient set for selecting a satisfactory predictive model was .97 , which corresponds to a standard error of $\pm 5 \%$ (relative) in combustion efficiency. None of the models tried gave a correlation approaching this criteria.

\section{2) Carbon Monoxide Emissions}

Table V-9 lists the regression models investigated for the CO emissions response from the DXB-222 propane parametrics. This analysis showed no significant model was found for CO emissions.

No suitable graphical representation of the CO emissions data was determined from this study. 


$$
-90-
$$

TABLE $V-8$

\section{Typical Statistical Models For Combustion Efficiency}

Variable In

Regression Model

$\mathrm{Vr}$

$T_{I}$

$T_{0 D}$

$F_{\text {I }}$

$\left(T_{I}\right)\left(T_{0 D}\right)$

$\left(T_{I}\right)\left(T_{O D}\right), V r$

$(V r),\left(T_{I}\right) ;\left(P_{I}\right),\left(T_{D D}\right)$

$V r, T_{I},(V r)\left(T_{O D}\right)$, $\left(T_{I}\right)\left(T_{O D}\right)$

\section{Correlation Coefficient}

0.4337

0.4020

0.2920

0.1870

0.4616

0.5873

0.5889

0.6908

Note: All other 1st, 2nd, and 3rd order combinations of variations had correlation coefficients within range shown above. 
TABLE V-9

Typical Statistical Models For Carbon Monoxide Emission

\begin{tabular}{cc}
$\begin{array}{c}\text { Variables In } \\
\text { Regression Model }\end{array}$ & Correlation Coefficient \\
\hline$T_{O D}$ & 0.5567 \\
$P_{I}$ & 0.2736 \\
$T_{I}$ & 0.1229 \\
Vr & 0.0731 \\
$V r, T_{I}, P_{I}, T_{O D}$ & 0.6190 \\
$T_{O D}, P_{I} T_{O D}, P_{I}$ & 0.6744
\end{tabular}

Note: A11 other 1st, 2nd and 3rd order combinations of variables had correlation coefficients within range shown above. 
3) Pressure Drop

Analysis of the pressure drop responses from the propane parametrics resulted in a very satisfactory graphical and statistical representation for both isothermal and combustion pressure drop. The models that proved to be the best predictors are shown below.

\section{Isothermal}

$$
\begin{aligned}
& \frac{\% \Delta}{P}=\frac{0.0564 V^{1.6}}{p^{0.56}} \\
& \text { Standard Error }=0.582 \% \\
& \text { Maximum Error }=1.36 \% \\
& \text { Correlation Coefficient }=0.9945
\end{aligned}
$$

\section{Combustion}

$$
\% \frac{\Delta P}{P}=\frac{0.336 V^{1.3}}{p^{0.77}}
$$

Standard Error $=1.32 \%$

Maximum Error $=3.38 \%$

Correlation Coefficient $=0.9932$

Where

$$
\begin{aligned}
& P=A t m .\left(1 \times 10^{5} \mathrm{~N} / \mathrm{M}^{2}\right) \\
& V=M / S
\end{aligned}
$$


The excellent agreement between the model prediction and test results is further depicted in Figure $V-13$ for combustion pressure drop. The isothermal pressure drop model yields comparable results between predicted and experimental values.

\section{Performance of Catalyst Core $\mathrm{DXC}-532$}

a. Life Testing with \#2 Diesel $0 i 1$

The daily performance during the life testing of catalyst core DXC-532 was monitored by recording the control input variables and output responses from the test.rig. Observations were plotted daily on a control chart to monitor changes in DXC-532's performance in regards to:

- exhaust gas composition ( $\mathrm{UHC}, \mathrm{CO}, \mathrm{NO}_{x}, \mathrm{CO}_{2}, \mathrm{O}_{2}$ )

- percent pressure drop

- air preheat temperature

- catalyst core outlet temperature

The performance of DXC-532 during life testing was quite satisfactory up to 600 hours on-stream. The control charts shown in Figures $V-14,15,16,17,18$ and 19 show very steady operation with regards to maintenance of low emissions. These gas compositions are plotted as measured in the exhaust, which has nominally $12.5 \%$ oxygen. However, a close examination of the control chart depicting outlet 
Figure $V-13$

Comparison of Experimental and Predicted Percent Pressure Drop of Catalyst Core DXB-222 (Combustion Condition).

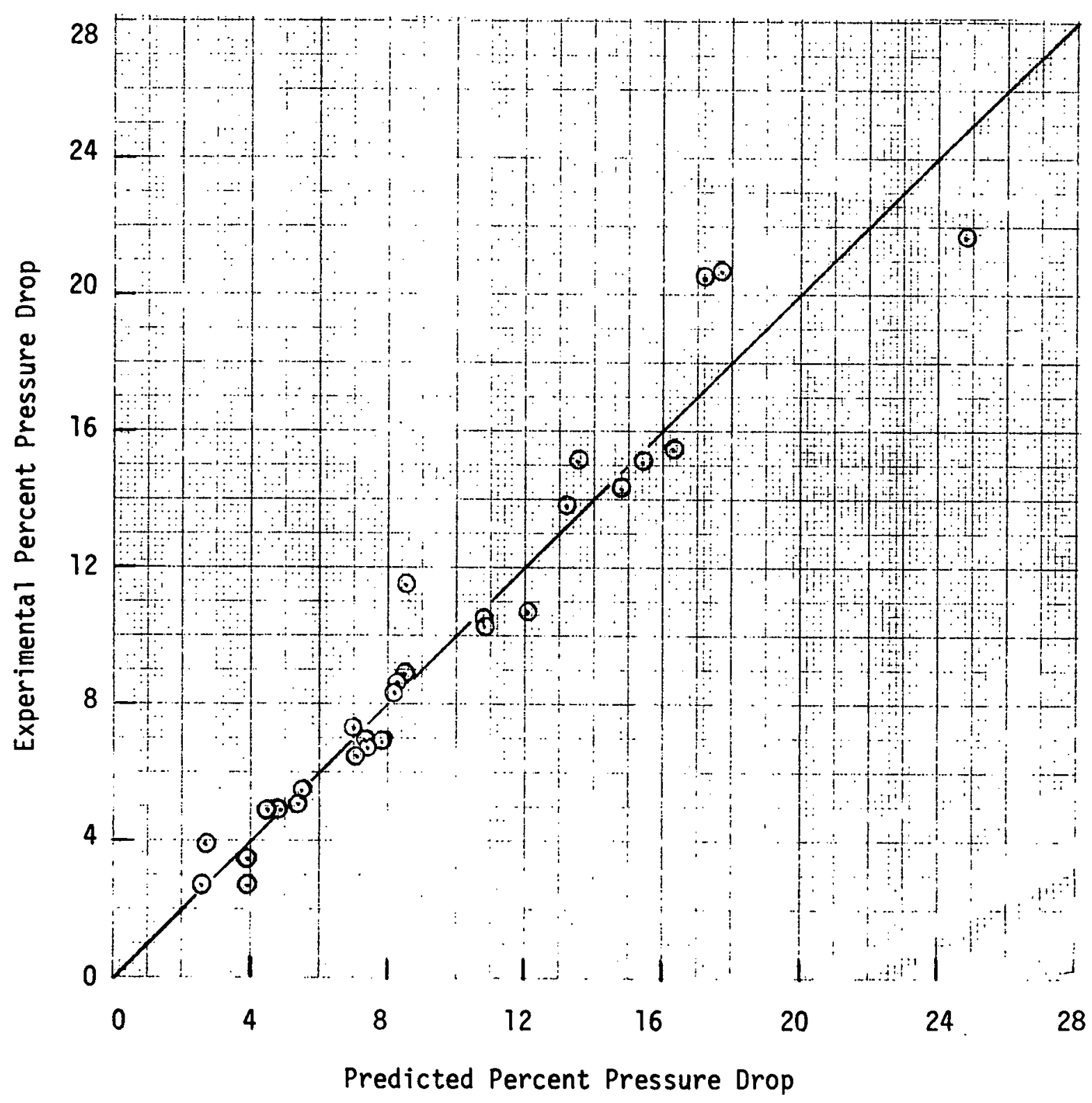


temperatures downstream of catalyst core DXC-532 revealed that after 300 hours life testing, the maximum temperature location moved from $.00635 \mathrm{M}$ downstream to $.057 \mathrm{M}$ downstream. This indicates that some combustion was occurring downstream of the catalyst. Downstream burning was not present during the first few hundred hours of the life test.

Another phenomenon began to occur during the period of 400 to 600 hours life testing, which supported the observation that less conversion may be occurring in the catalyst core DXC-532.

The temperature start-up response of a typical catalyst core, when fuel is brought on at a specific air preheat condition, is shown in Figure $V-20$. Note that the outlet temperature quickly rises to achieve catalytically supported thermal combustion conditions. This type of response was representative of $\mathrm{DXC}-532$ 's operation during the first 300 hours of 1 ife testing. Between 300 hours and up to 600 hours of life testing, the start-up response began to change, as indicated in Figure $\mathrm{V}-21$. Figure $\mathrm{V}-21$ indicated that there is a temporarv, intermediate outlet temperature of approximately $1070^{\circ} \mathrm{K}$, which appears before low emission operation is achieved. This intermediate is strictly part of the transient start-up response. Also when low emission combustion conditions are obtained, the maximum outlet temperature was located $.057 \mathrm{M}$ downstream, however the emissions measured .1016M downstream showed no significant change.

The start-ups after 600 hours life testing with air preheat of $633^{\circ} \mathrm{K}$ resulted in the intermediate conversion level 
Figure V-14. Hydrocarbon Emission Control Chart During Life Tes ing of Catalyst Core DXC-532

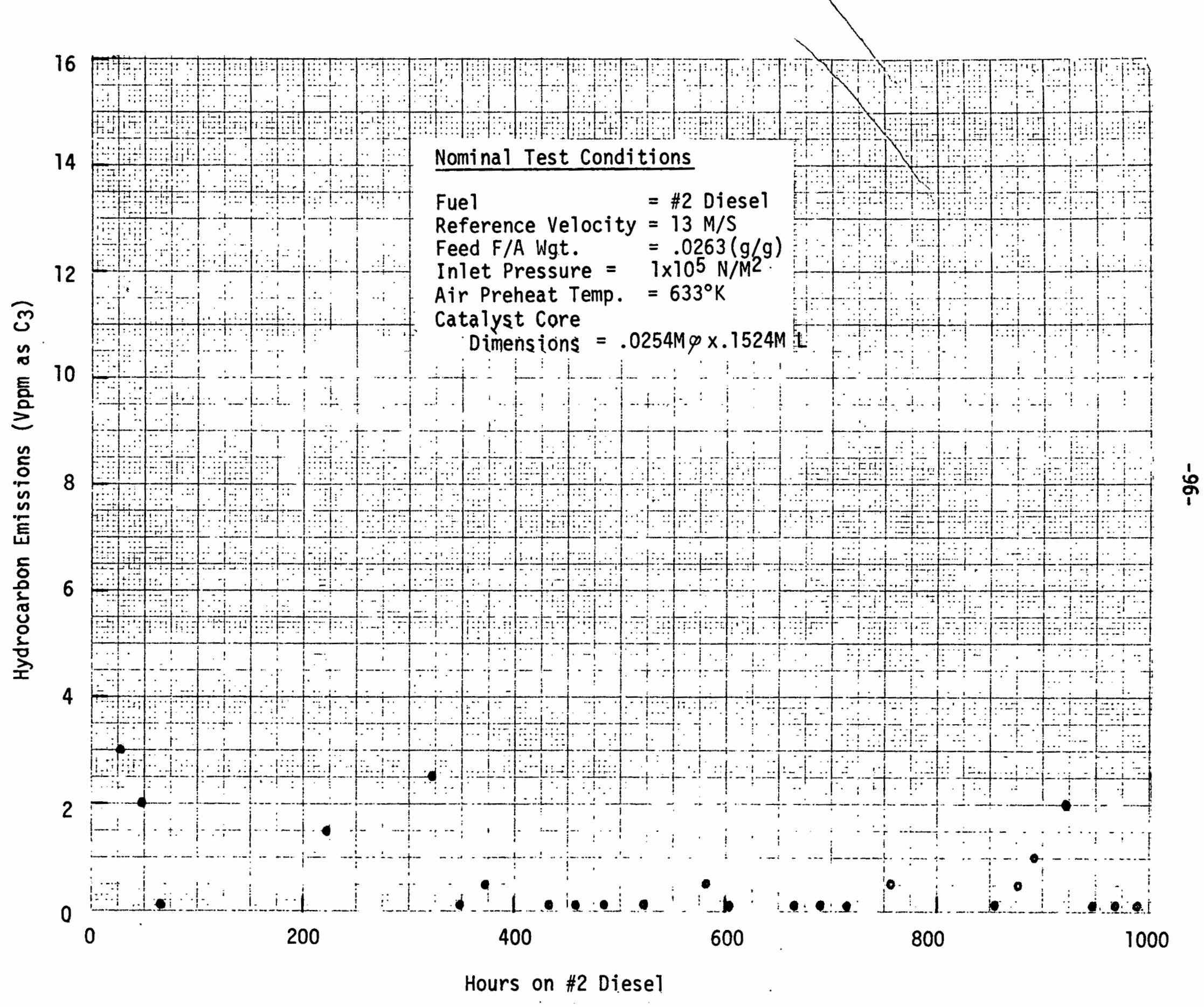




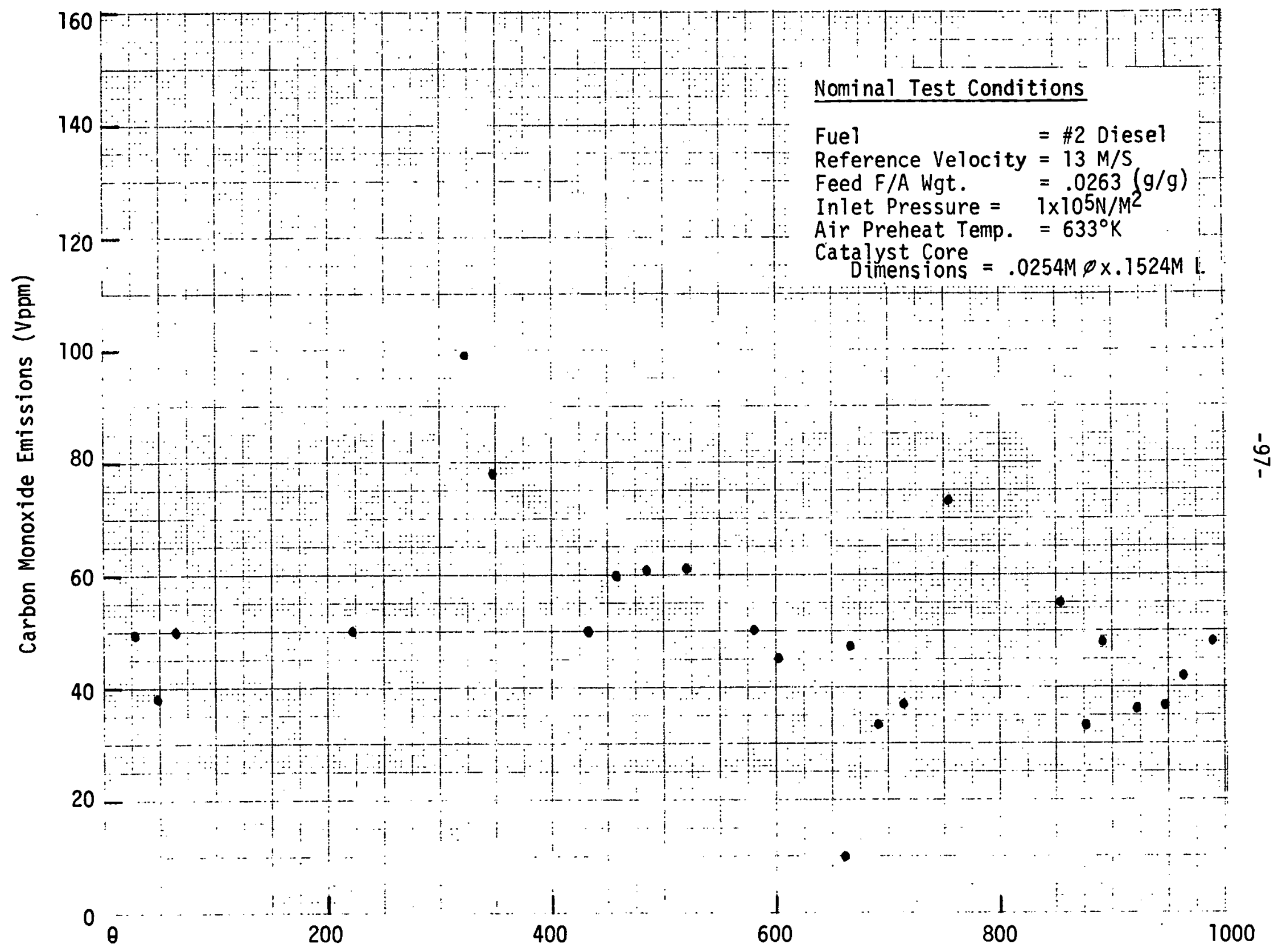

Hours on \#2 Diesel 


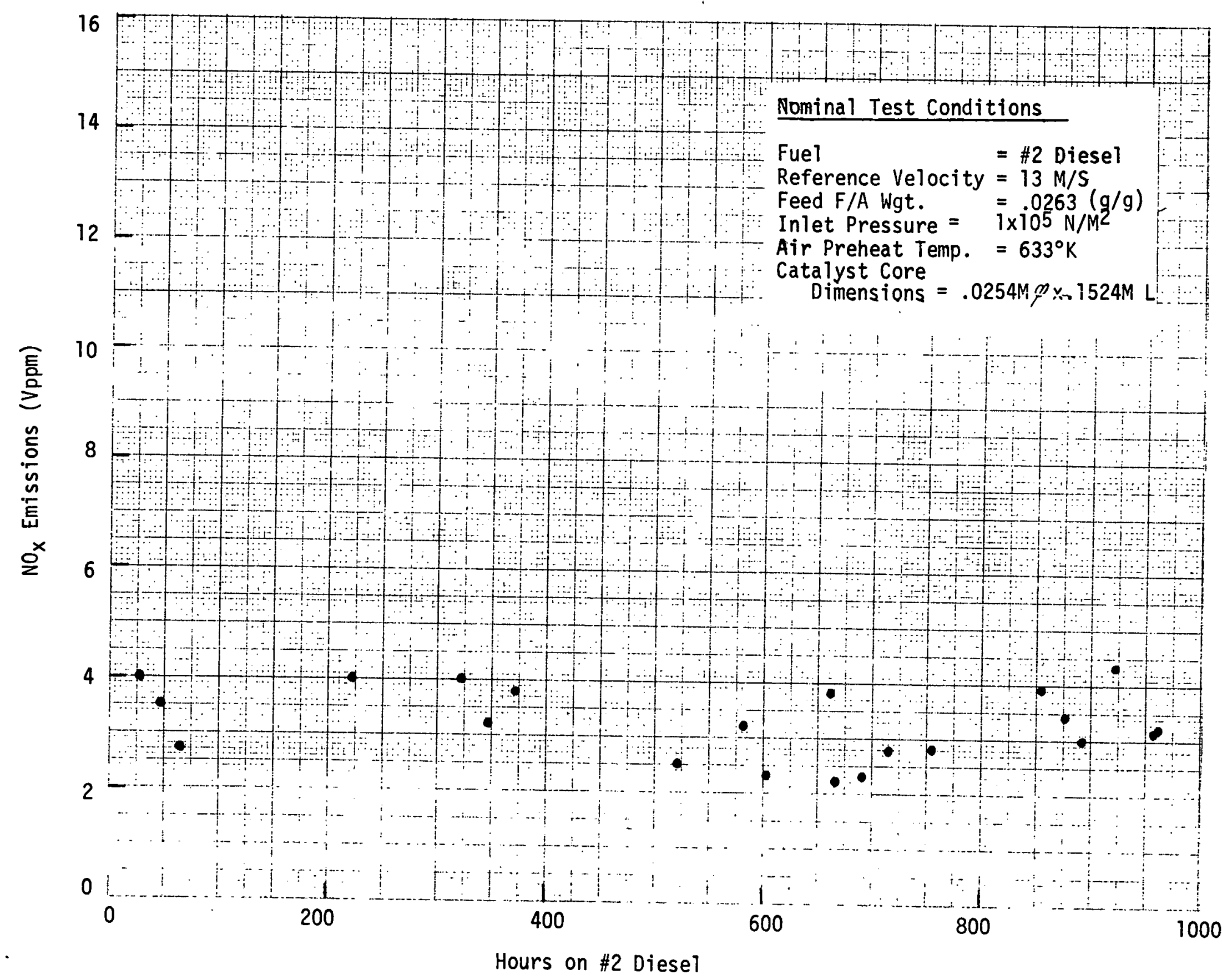




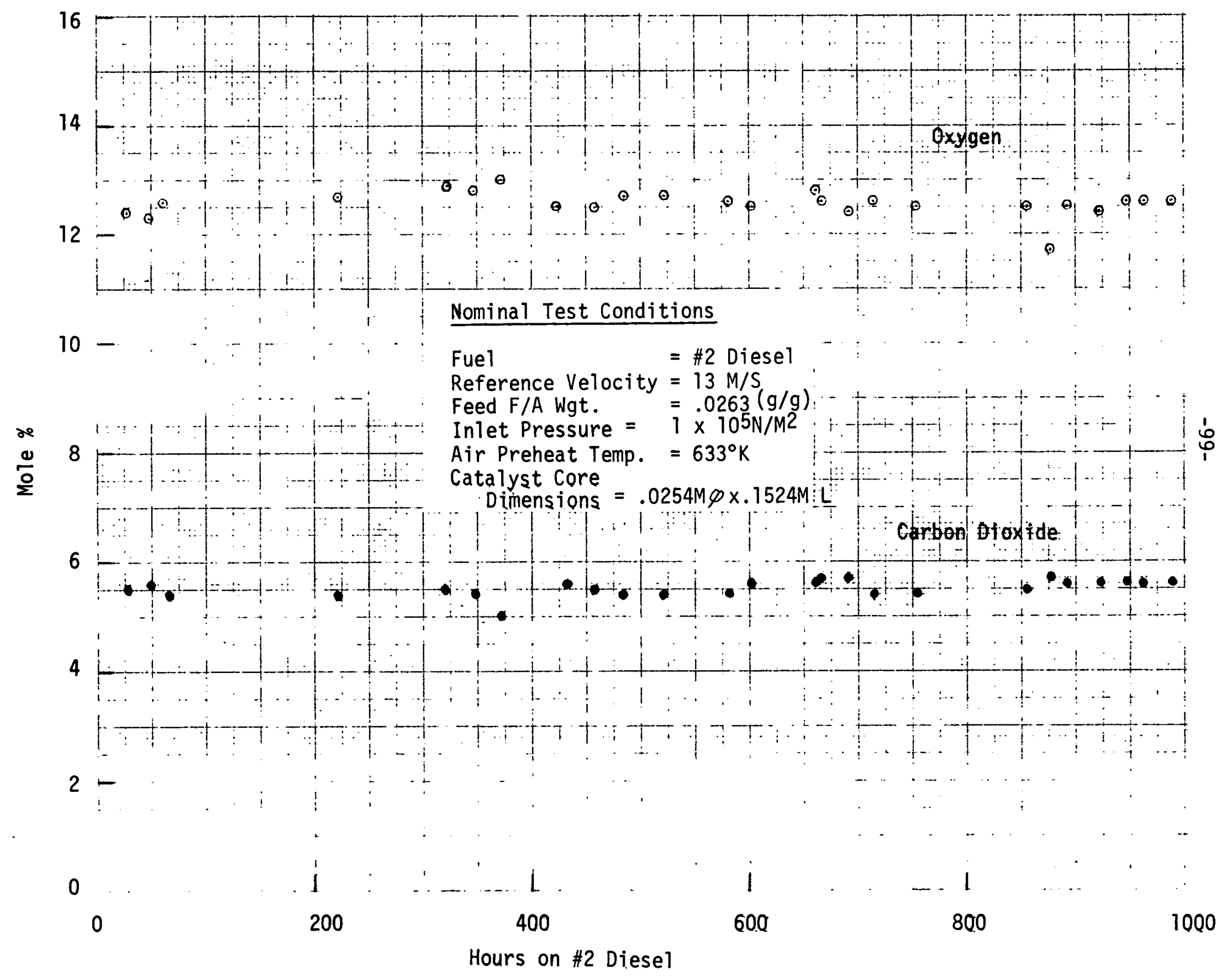


Figure V-18 Temperature Control Chart During Life Testing of Catalyst Core DXC-532

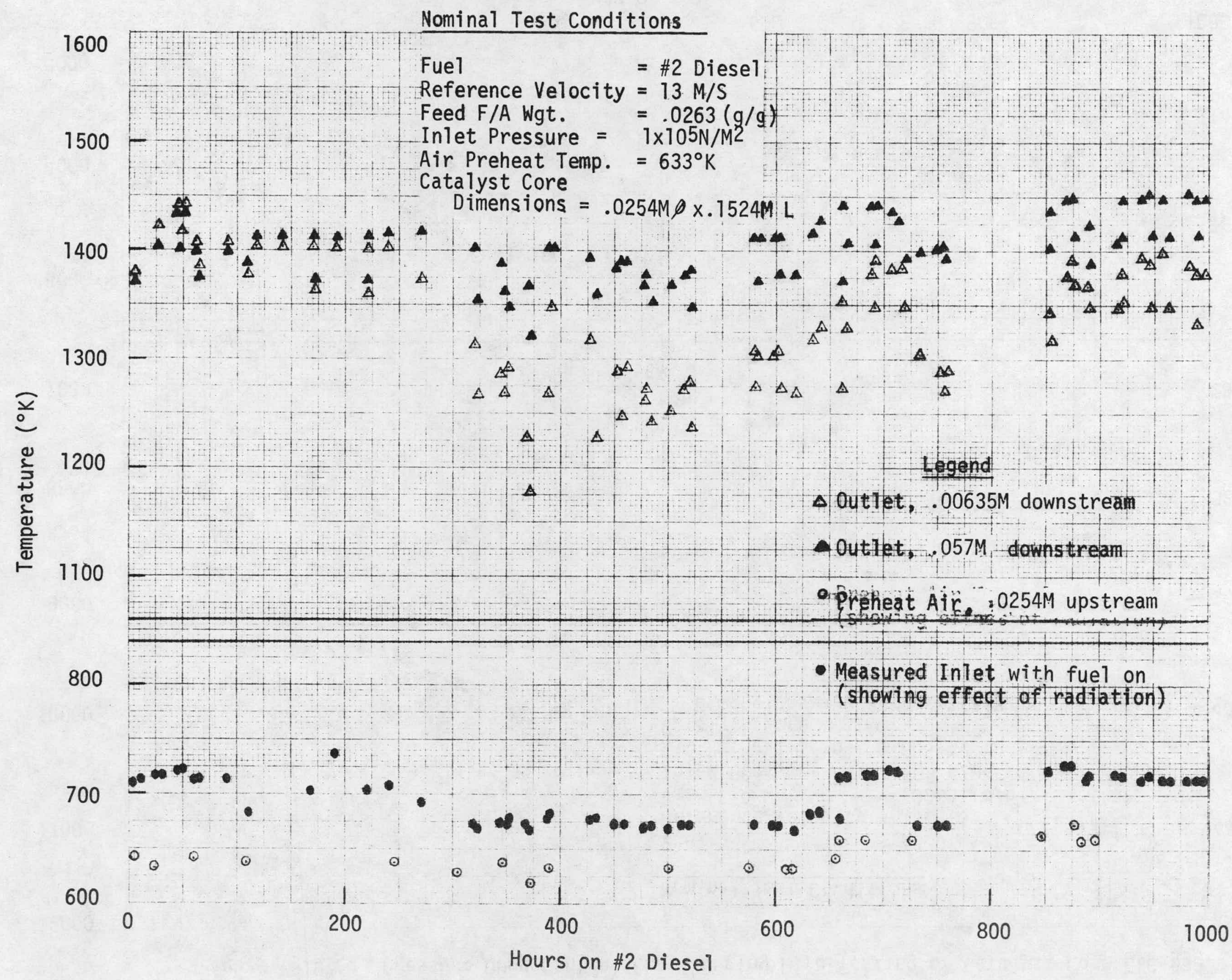




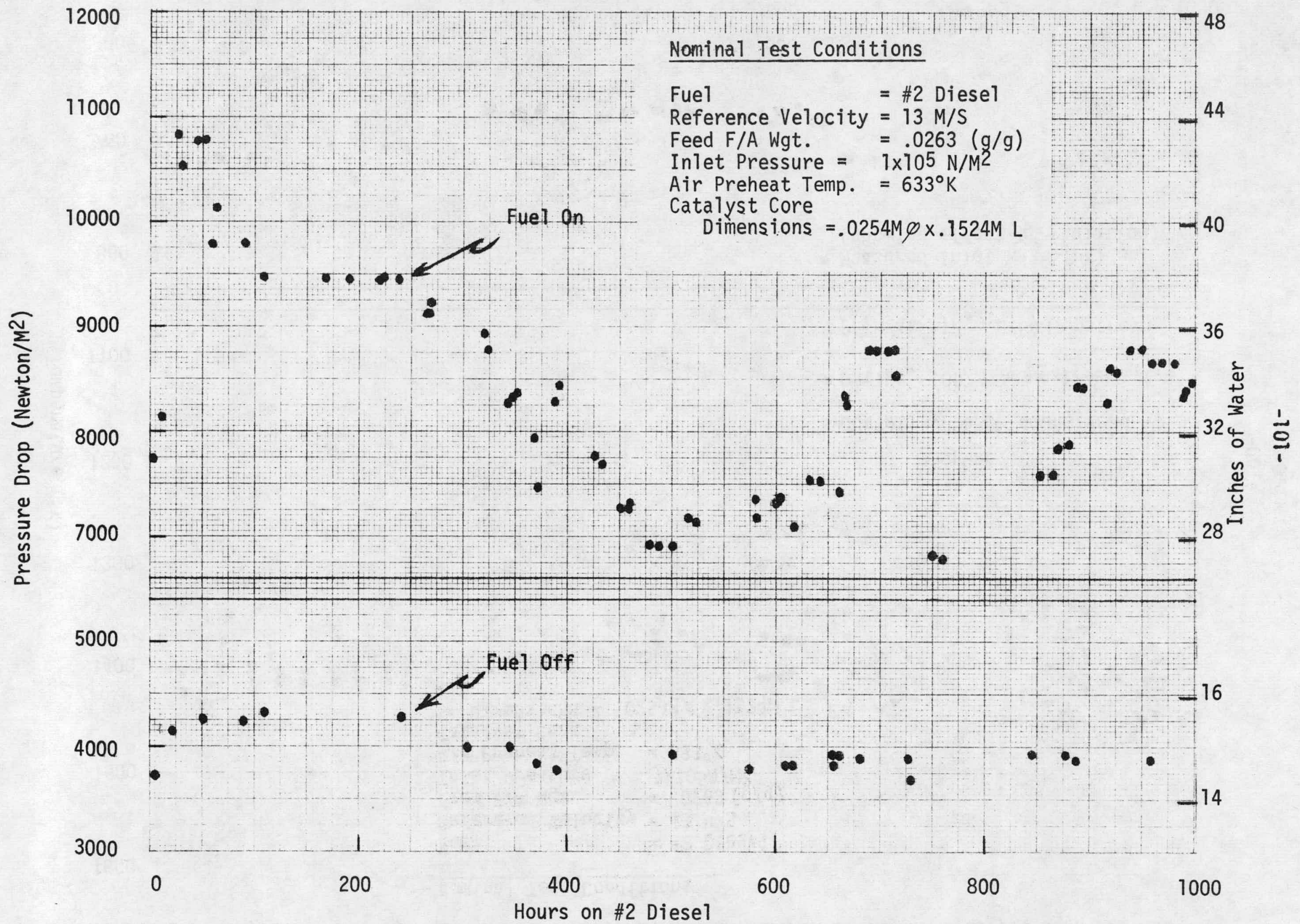


stabilizing as shown in Figure V-22. Therefore, after 600 hours of 1 ife testing, the conversion across the catalyst core DXC-532 had decreased to the extent that low emissions was not obtained at the original life teșt operating conditions.

The low combustion efficiency operation with DXC-532 was easily corrected by raising the air preheat temperature from $633^{\circ} \mathrm{K}$ to $673^{\circ} \mathrm{K}$ gradually over the last 400 hours of life testing. The temperature response upon startup during the last 400 hours was as shown in Figure V-20 with this compensation in air preheat temperature. These increases in air preheat temperature are depicted on the temperature control chart (Figure $\mathrm{V}-18$ ). Therefore, the emissions control charts during the last 400 hours life testing represents the emissions after the increase in air preheat temperature.

Considering the overal1 performance of DXC-532 during the 1,000 hour diesel life test, the following information on emissions are obtained:

Standard

Emission

UHC (vppm as $C_{3}$ )

CO (vppm)

$\mathrm{NO} \mathrm{X}_{\mathrm{X}}(\mathrm{vppm})$
Mean

0.6

49.6

3.3
Deviation

0.9

17

0.6 


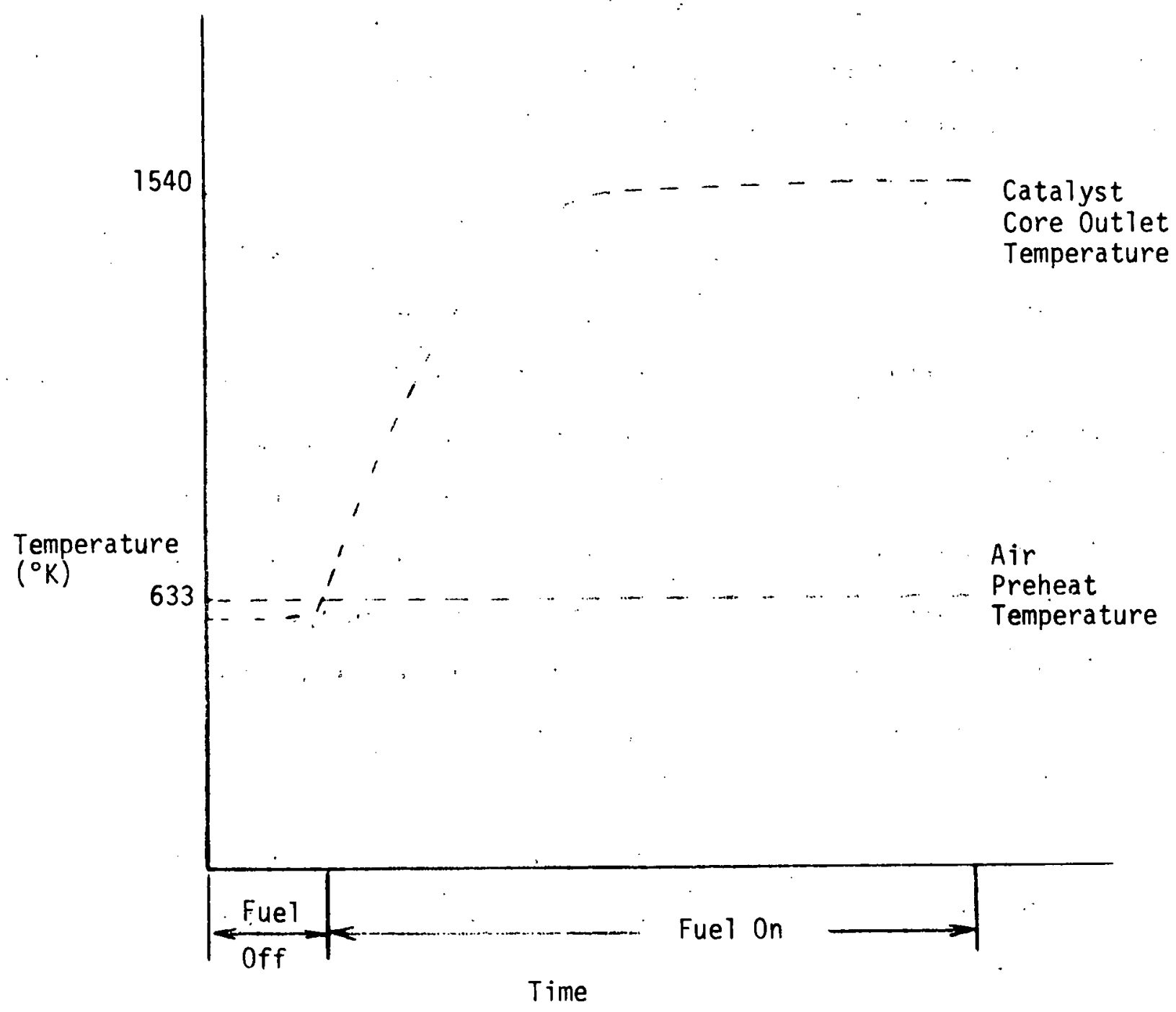

Figure VI $20 \quad$ Typical Startup Response for Catalyst Core Resulting in Low Emissions Operation 


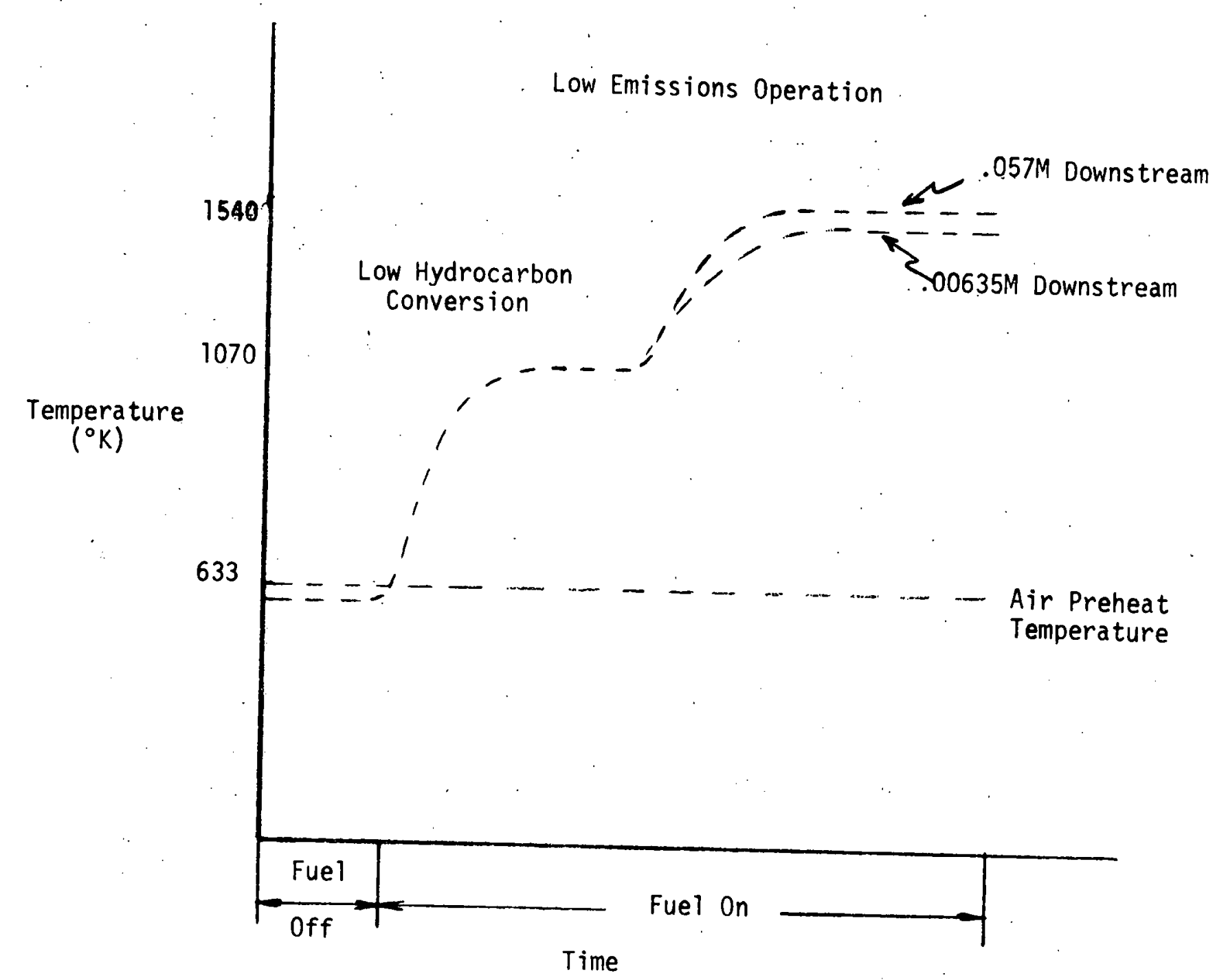

Figure $v-21$

Typical Startup Response of Catalyst Core DXC-532 After 400 Hours Life Testing 


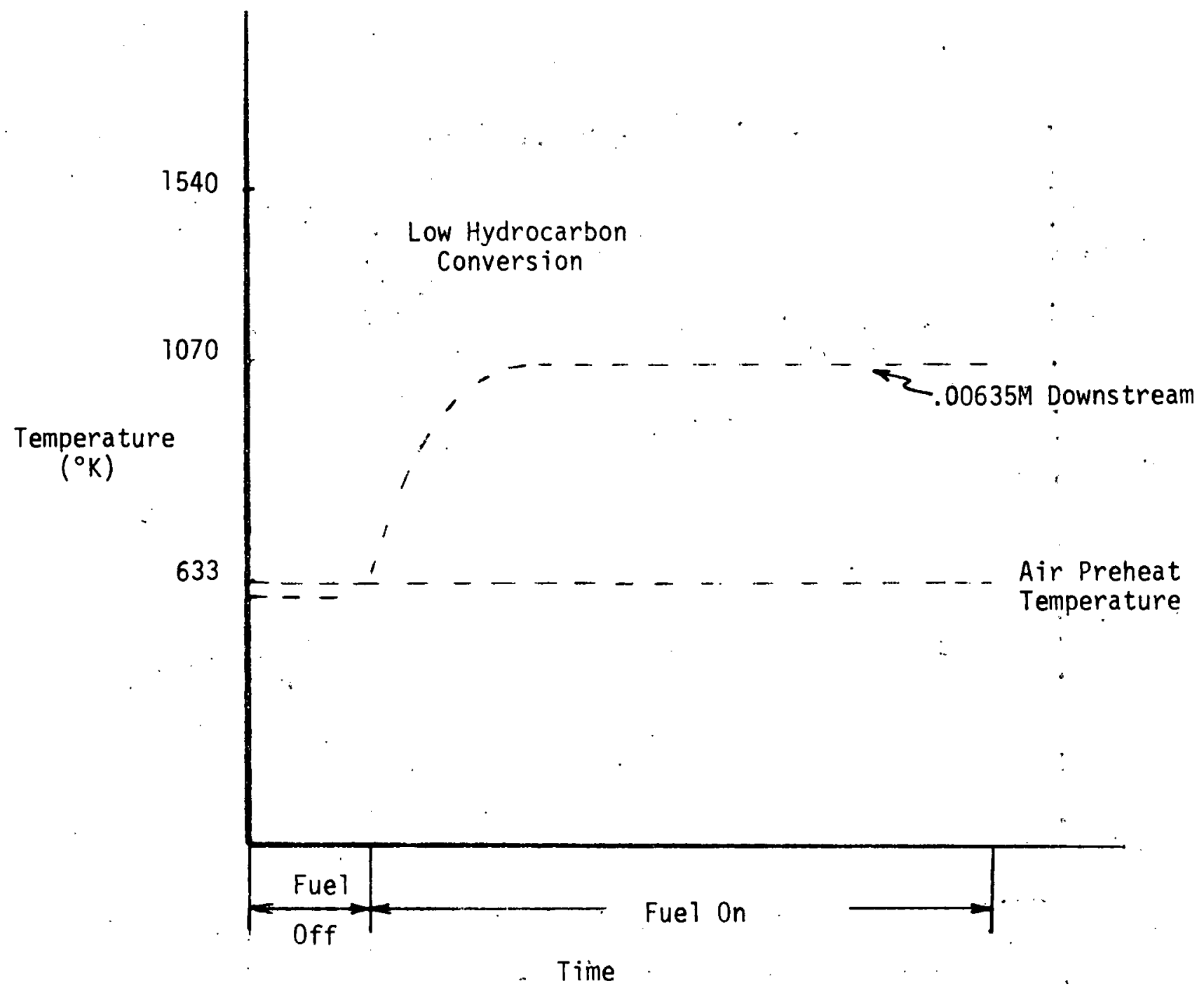

Figure V-22 Typical Startup Response of Catalyst Core DXC-532 After 600 Hours Life Testing 


\section{$-106-$}

The $\mathrm{NO}_{\mathrm{x}}$ emissions during this life test are probably the result of the essentially quantitative oxidation of the bound nitrogen in the \#2 diesel fuel. No $\mathrm{NO}_{\mathrm{x}}$ formation is predicted due to nitrogen fixation at the life test operating conditions.

On the average, these emission results correspond to a steady state operation at a combustion efficiency of $99.9 \%$ over the 1,000 hour life test of DXC-532.

The emissions performance of DXC-532 during life testing was well below anticipated regulatory standards for stationary gas turbines (7), and can be translated for comparison to automotive standards by assuming steady state operation of an automotive gas turbine with an average fuel consumption of $10 \mathrm{mpg}$ with the following results:

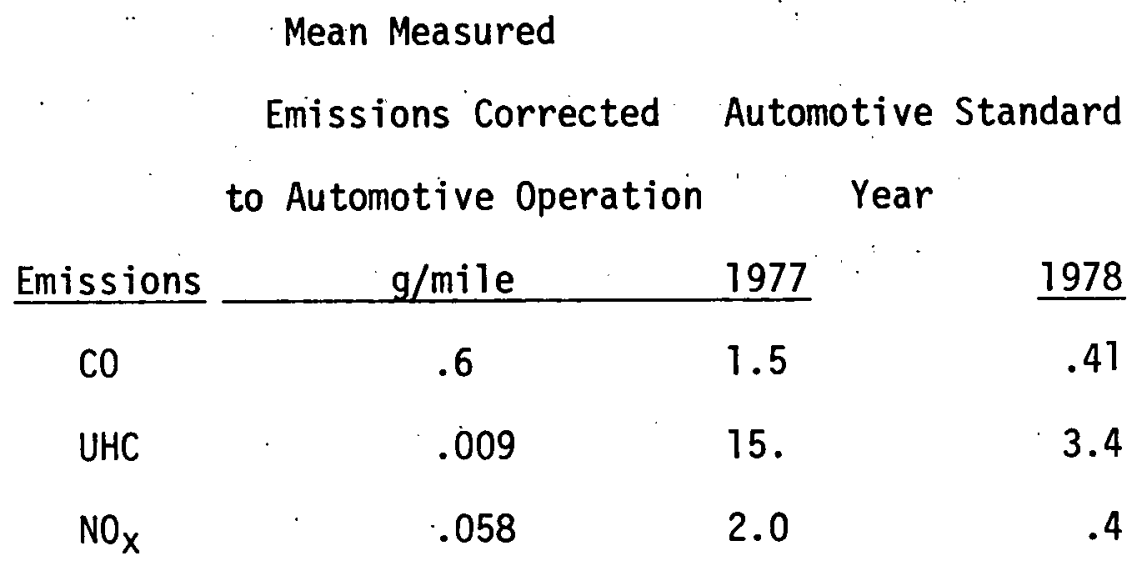


This comparison is strictly based on steady state operation and does not account for transients nor cold starts.

The control chart maintained to indicate pressure drop through catalyst core DXC-532 (see Figure V-19) indicated an abrupt decrease in pressure drop around 300 hours aging. This proved to be an operational problem caused by loosening of the fiberfrax packing around the catalyst holder. The catalyst holder was repacked around 600 hours operation and the pressure drop returned to the normal value. Repacking was also required around 800 hours. The lowering in pressure drop indicates that some feed was bypassing the catalyst core resulting in erroneous experimental observations.

The control charts depicting $\mathrm{CO}_{2}$ vent gas analys is (Figure V-17) shows the variation in \#2 diesel fuel feed during the 1,000 hour life test. This variation in fuel feed corresponds to a variation in adiabatic flame temperature from 1511 to $1575^{\circ} \mathrm{K}$ during the 1,000 hour life test of DXC-532.

The changes in operating conditions and the responses for DXC-532 between the beginning and end of life test can be compared by referring to Table $\mathrm{V}-10$. The only significant change that was made during the life test was the $40^{\circ} \mathrm{K}$ increase in air preheat temperature, which was needed to maintain low emissions operation.

The life test results, as reflected by the emissions performance of DXC-532, show that deactivation has occurred, but that the low emissions operation can be restored by increasing the air 
Date

Hours on \#2 Diesel Fue?

Air Flow ( $\mathrm{Kg} / \mathrm{sec}$.

Fuel/Air Ratio $(\mathrm{g} / \mathrm{g})$

Preheat Air Temp. $\left({ }^{\circ} \mathrm{K}\right)$

Outlet Temp. $\left({ }^{\circ} \mathrm{K}\right)$

Adiabatic Flame Temp. $\left({ }^{\circ} \mathrm{K}\right)$

Inlet Pressure $\left(\mathrm{N} / \mathrm{M}^{2}\right)$

Pressure Drop $\left(N / M^{2}\right)$

Percent Pressure Drop

Reference Velocity (M/S)

Combustion Efficiency (\%)

Space Velociyty, NTP Nominal $\left(\mathrm{Sec}^{-1}\right)$

Heat Release Rate (Joules/sec. M2 ATM)
4/20/76

27

$3.22 \times 10^{-3}$

0.0264

633

1421

1530

$1.1 \times 10^{5}$

10806

9.6

12.8

99.88

34.7

$4.2 \times 10^{7}$
$6 / 9 / 76$

964

$3.22 \times 10^{-3}$

0.0272

663

1413

1587

$1.1 \times 10^{5}$

8678

7.9

13.8

99.91

34.7

$4.4 \times 10^{7}$

Emissions 1 (Nominally $0 \quad 12.5 \% \quad 0_{2}$ )

CO (Vppm)

UHC, as $C_{3}$ (Vppm)

NOX (Vppm)

Catalyst Core Dimension, Nominal
49

3

4

$0.0254 \mathrm{M}^{\circ}$ in diameter by $0.152 \mathrm{M}$ long

42

0

3.2

1 All emissions measured with water cooled sampling probe located at $0.102 \mathrm{M}$ downstream of catalyst core. 
preheat temperature from $533^{\circ} \mathrm{K}$ to $573^{\circ} \mathrm{K}$. With this adjustment, the emissions performance of DXC-532 was extremely low during the remainder of the 1,000hour life test.

Another aspect of the life test was to determine the physical durability of the catalyst core, particularly, the support material. Figure $\dot{V}-23$ shows the photographs taken of catalyst core UXC-532 after the 1,000 hours testing. The color gradients along the direction of flow are normal, and reflect the temperature gradient through the catalyst at an adiabatic operating temperature of $1527^{\circ} \mathrm{K}$. No collapse in channels nor physical damage to the support were visually apparent. The catalyst support appears to be adequate for extended operation at combustion conditions.

Analytical tests were conducted on catalyst core DXC532 upon completion of the test series to determine the retention of the precious metal catalytic component and the thermal stability of the catalyst core. Assay results indicated that DXC -532 retained about $40 \%$ of the original precious metal after 1,000 hours operation. The BET surface area results showed that about $30 \%$ of the original area is retained after aging. These results are all relative to a lined-in sample of $D X C-532$ (i.e., aged for 24 hours at life test conditions). At present, it is felt that the most probable mechanism for the precious metal loss is detachment of the washcoat from the support. Techniques, gained from experience in auto exhaust catalyst preparation, are available for increasing the adhesion of the washcoat to the monolith. These improved techniques should reduce the precious metal loss without decreasing the performance durability of DXC- $5 \dot{3} 2$.

Further analyses were conducted on the aged DXC-532 with a scanning electron microscope and an x-ray diffractometer. These analyses both indicated that deposits of lead were present on catalyst core DXC-532 after 1,000 hours life testing. (See Section VI for discussion of these results.) 

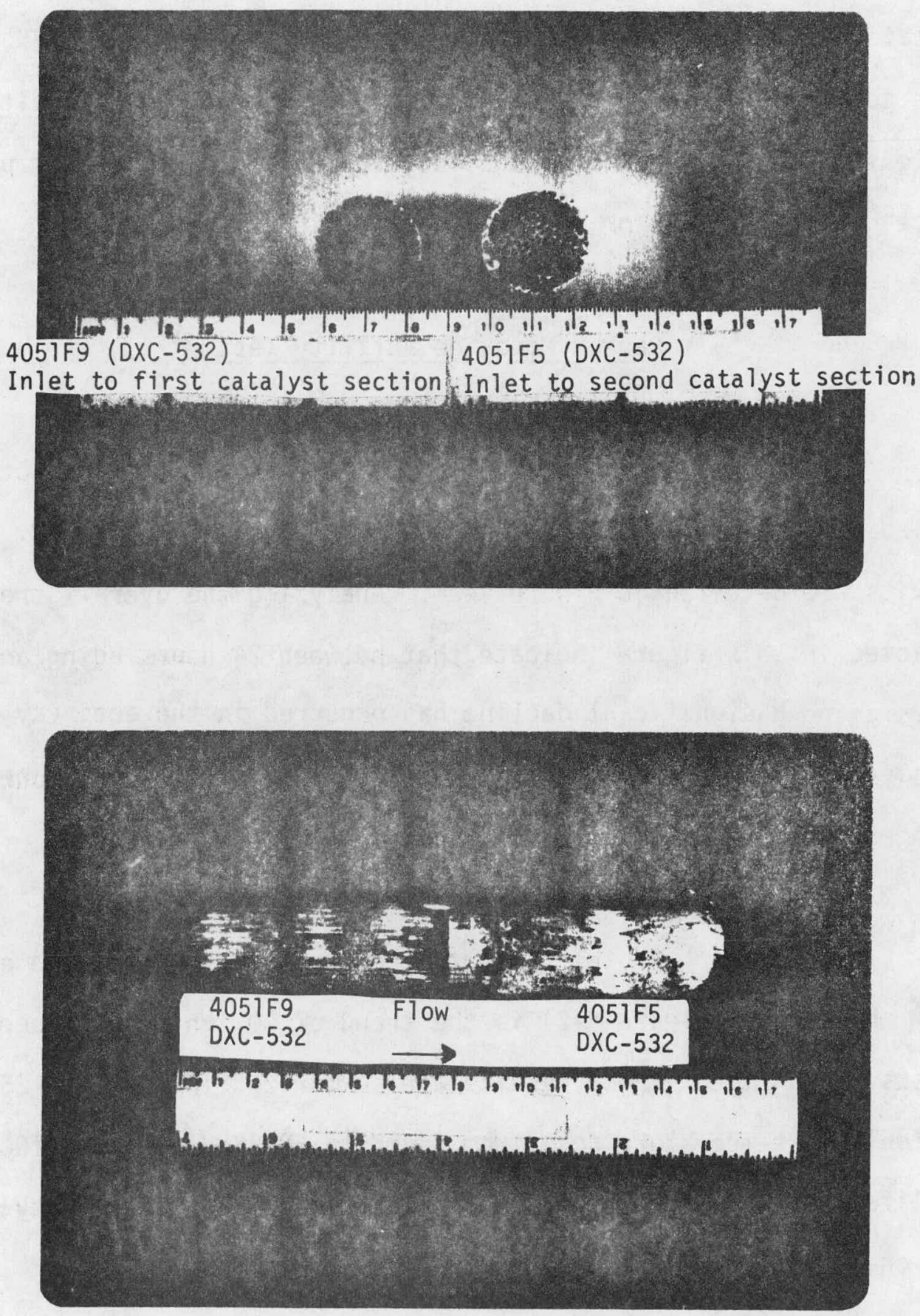

Figure $V-23$

Photographs of Catalyst Core DXC -532 After 1000 Hours Life Testing 
The results of this 1,000-hour life test on catalyst core DXC-532 indicate that the deactivation that occurred can be compensated for by increasing the air preheat temperature by $40^{\circ} \mathrm{K}$. With this compensation, DXC-532 can operate under CATATHERMAL conditions for at least 1000 hours without substantial loss of low emissions performance due to physical or chemical degradation.

\section{b. Carbon Monoxide Activity Test}

Carbon monoxide activity tests were conducted periodically during the life testing of catalyst core DXC-532. The results are detailed in Figure V-24. Analyzing the overall trends depicted in this figure indicate that between 24 hours aging and 250 hours aging a significant decline has occurred in the activity of the catalyst core DXC-532 for carbon monoxide fuel. After 250 hours, the changes are very minor as determined by this test procedure.

Another important observation that can be extracted from the data in Figure $\mathrm{V}-24$ is the trend of $\mathrm{CO}$ ignition temperature versus aging time. These results are summarized in Figure V-25. The CO ignition temperature rose from $473^{\circ} \mathrm{K}$ to $503^{\circ} \mathrm{K}$ during the 1000 hours of life testing. Apparently, the intrinsic catalytic activity for co has changed during the life test. 
Figure V-24 Carbon Monoxide Activity Test Response During Life Testing of Catalyst Core DXC-532.

Legend

I 24 Hours Aging

2240 Hours Aging

3500 Hours Aging

4660 Hours Aging

51000 Hours Aging
Run Conditions

Reference Velocity $=36.5 \mathrm{M} / \mathrm{S}$

Feed $\mathrm{CO}=4000 \mathrm{Vppm}$

Pressure $=1 \times 10^{5} \mathrm{~N} / \mathrm{M}^{2}$

Catalyst Core Dimensions $=$ $.0254 M \varphi \times .1524 M \mathrm{~L}$

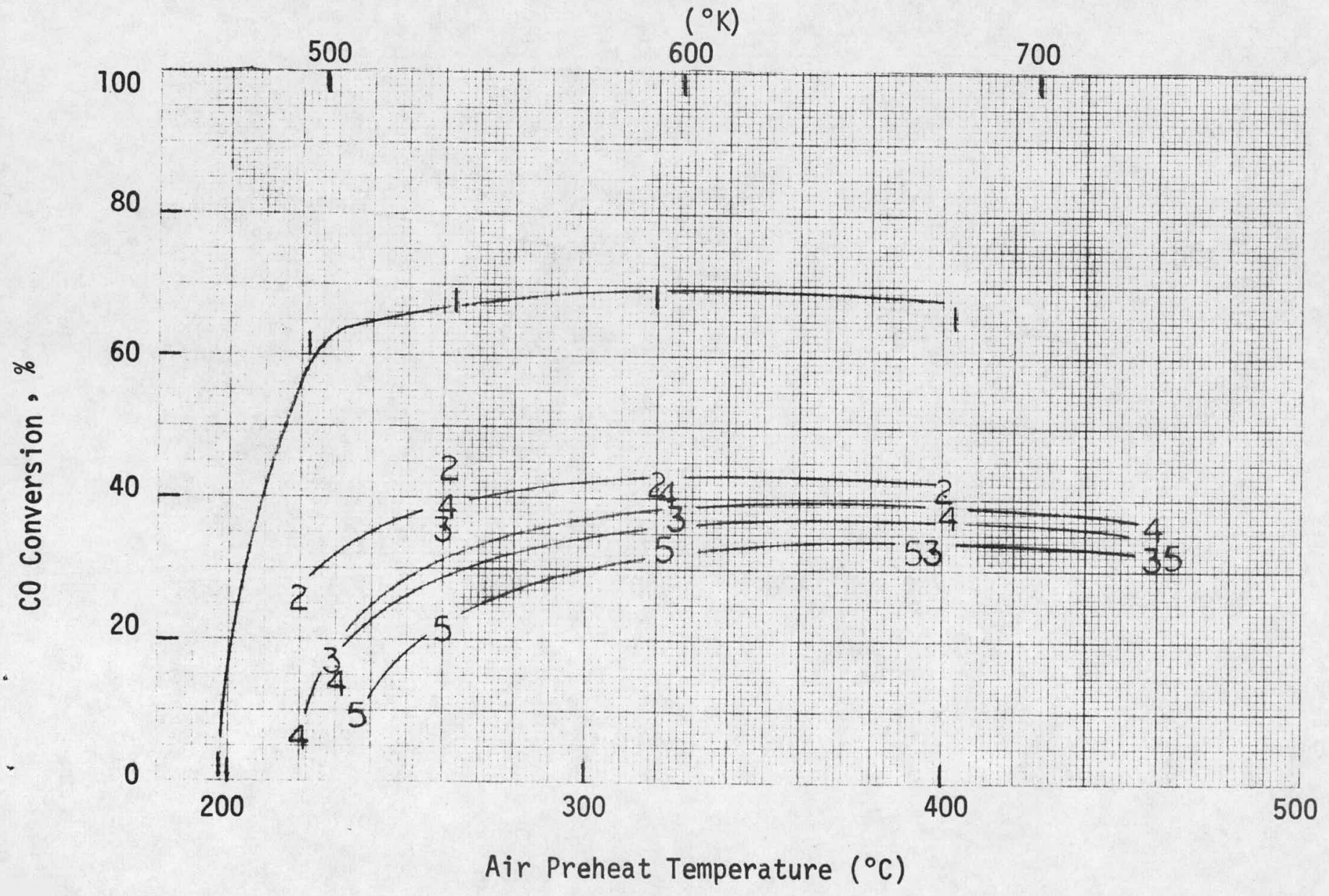


Figure V-25 Response of Ignition Temperature of Carbon Monoxide During Activity Tests on Catalyst Core DXC-532.

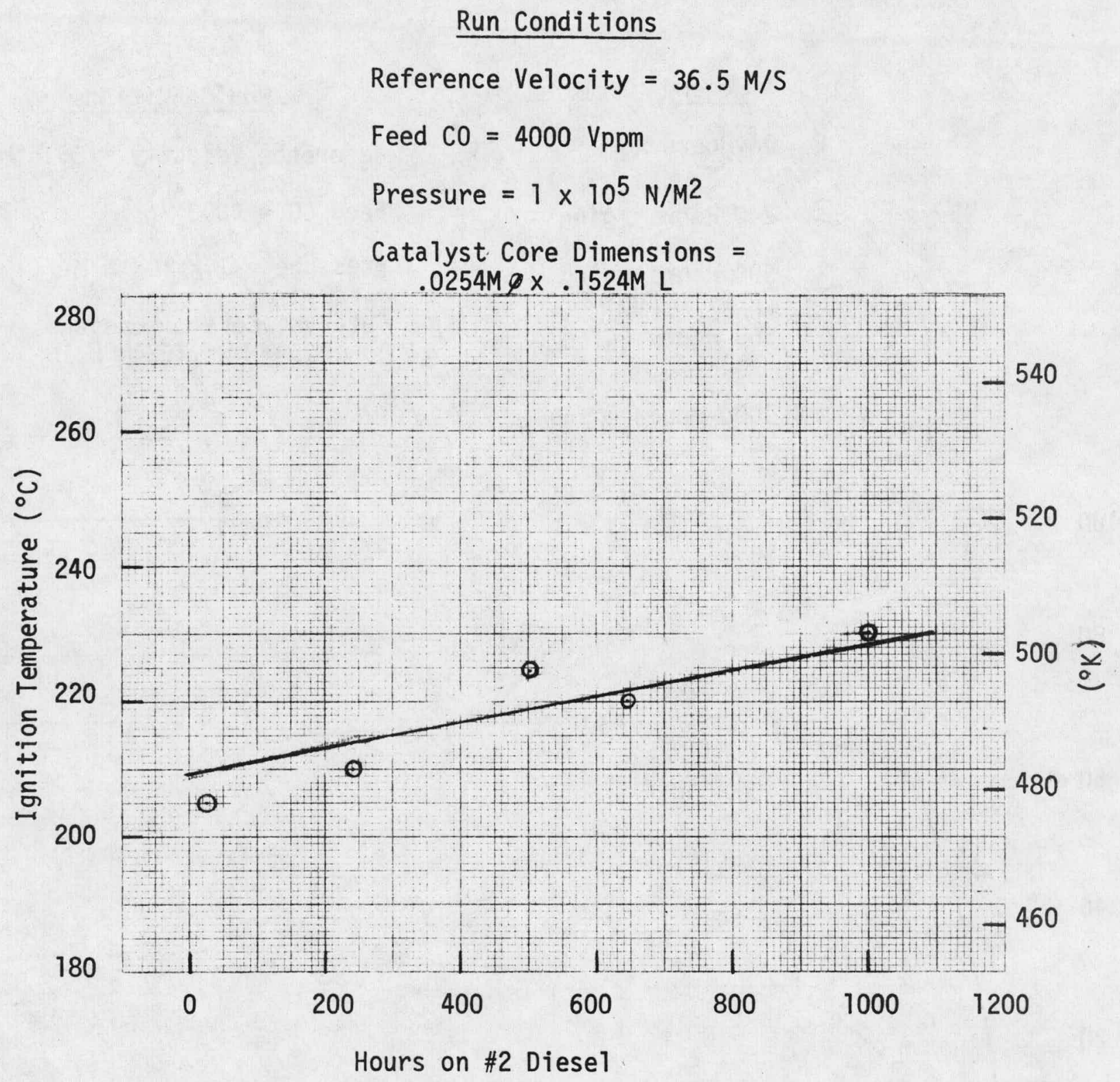


Additional inforination can be obtained from Figure $V-24$ by plotting the mass transfer limited CO conversion, as shown in Figure V-26. This figure further confirms that the mass transfer limited conversion indeed declined rapidly during the first 250 hours of aging, but thereafter further decline is negligible for DXC-532. The decline in mass transfer conversion represents a $36 \%$ change in the apparent mass transfer area .

The $\mathrm{CO}$ activity results indicate that apparent mass transfer area appears to have stabilized on DXC-532 after 250 hours aging. However, the $\mathrm{CO}$ ignition temperature increases gradually during the entire 1000 hours.

\section{c. Propane Parametric Study}

The propane parametric studies conducted on catalyst core DXC-532 at the beginning of the life test provided information on the low emissions operating region of this catalyst with C. P. Propane. The final propane parametrics provided information on the effect of diesel aging time on the retention of catalytic activity for low emissions operation.

The responses of combustion efficiency from the $1 / 3$ replicate factorial design are shown in Table V-10. Considering the 
$-115-$

Figure V-26 Response of Mass Transfer Limited Conversion of Carbon Monoxide Conversion From Activity Tests On Catalyst Core DXC-532.

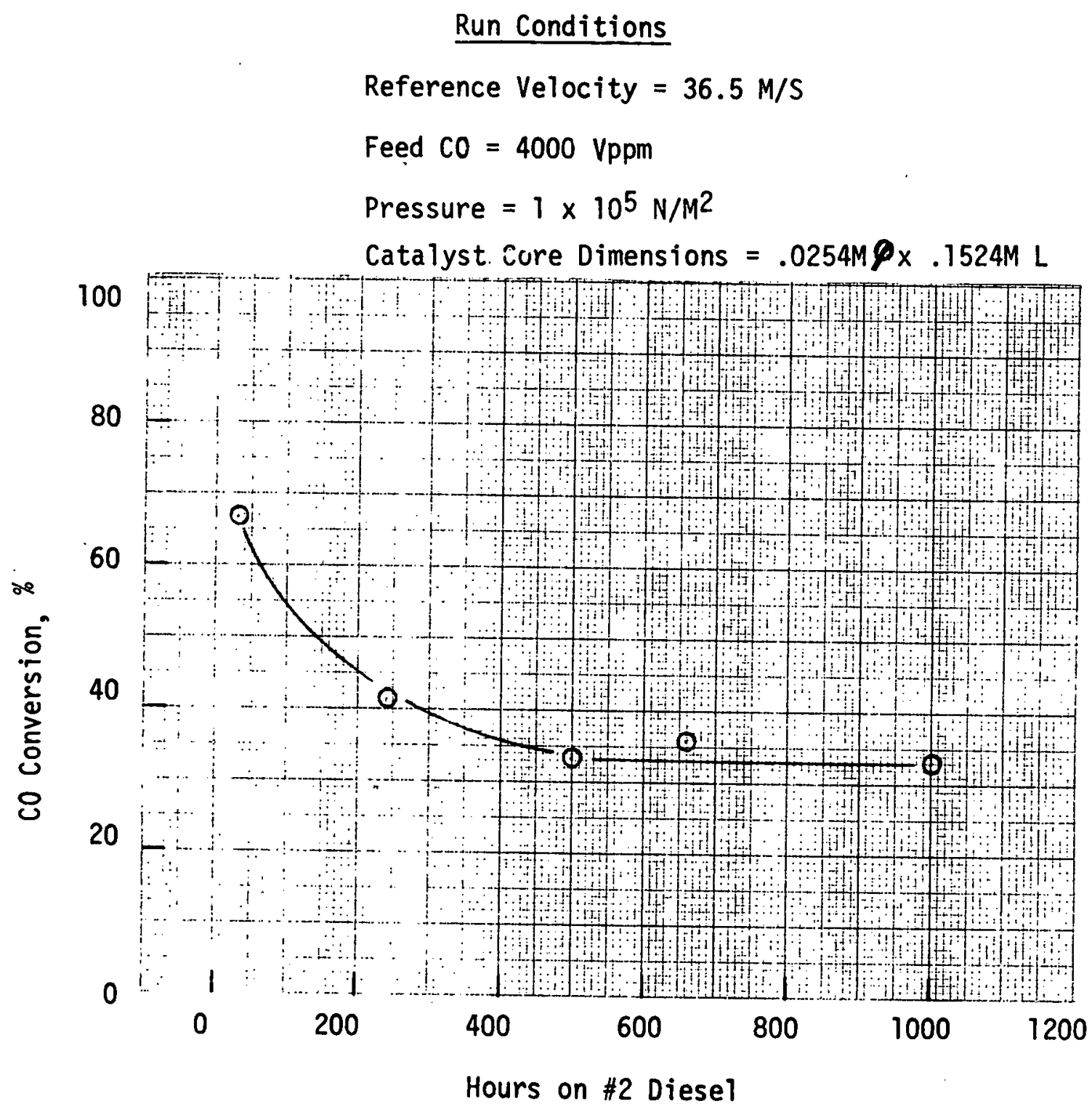


combustion efficiency responses for the initial parametrics, the initial region of low emissions operation is as follows:

$$
\begin{array}{ll}
\text { Air Preheat Temperature: } & \geq 653^{\circ} \mathrm{K} \\
\text { Adiabatic Operating Temperature: } & \geq 1449^{\circ} \mathrm{K} \\
\text { Reference Velocity: } & \leq 30 \mathrm{M} / \mathrm{S} \\
\text { Pressure: } & \leq 5 \times 10^{5} \mathrm{~N} / \mathrm{M}^{2}
\end{array}
$$

The low emissions operating region for DXC-532 with C. P. Propane is quite broad. The only regions of marginal operation are at low air preheat $\left(\leq 653^{\circ} \mathrm{K}\right)$ and low adiabatic flame temperature $\left(\leq 1449^{\circ} \mathrm{K}\right)$.

After the 1,000-hour life test, only seven parametric runs, as shown in Table V-11, were conducted on DXC-532. These runs were at operating conditions considered to have the highest probability of successful low emissions operation. The results indicated low hydrocarbon conversion for all seven experiments. Since the other 20 runs in the parametric matrix were at more stringent operating conditions, it was concluded that after 1,000 hours life testing, catalyst core DXC-532 had no acceptable region of low emissions operation for $C$. P. Propane, over the range of variables studied.

\section{d. Analysis of Propane Parametrics}

Detailed analysis of the initial propane parametrics on DXC-532 were conducted to determine a graphical representation and 
TABLE $V-11$

Combustion Efficiency Response of Propane Parametrics

Before and After 1000 Hour Life Test on Catalyst Core DXB-532

\begin{tabular}{|c|c|c|c|c|c|c|}
\hline Run \# & $\begin{array}{l}\text { Inlet } \\
\text { Pressure } \\
\left(\times 10^{-5}\right) \\
\mathrm{N} / \mathrm{M}^{2} \\
\end{array}$ & $\begin{array}{c}\text { Preheat } \\
\text { Air } \\
\text { Temperature } \\
{ }^{\circ} \mathrm{K} \\
\end{array}$ & $\begin{array}{l}\text { Reference } \\
\text { Velocity } \\
\text { M/S } \\
\end{array}$ & $\begin{array}{c}\text { Adiabatic } \\
\text { Flame } \\
\text { Temperature } \\
{ }^{\circ} \mathrm{K} \\
\end{array}$ & $\begin{array}{r}\text { Combus } \\
\text { Efficier } \\
\text { Initial } \\
\end{array}$ & $\begin{array}{l}\text { tion } \\
\text { icy }(\%) \\
\text { Final } \\
\end{array}$ \\
\hline $\begin{array}{l}6-47 A 3 \\
6-66 A\end{array}$ & $\begin{array}{l}3.1 \\
3.1\end{array}$ & $\begin{array}{l}723 \\
723\end{array}$ & $\begin{array}{l}14.5 \\
14.5\end{array}$ & $\begin{array}{l}1477 \\
1477\end{array}$ & 99.89 & 9.70 \\
\hline $6-47 B 3 R$ & $5: 1$ & 653 & 15 & 1482 & 99.87 & 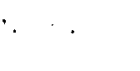 \\
\hline $6-47 C 3$ & 5.1 & 723 & 14.5 & 1394 & 98.78 & \\
\hline $6-4703$ & 5.1 & 813 & 22.7 & 1480 & 99.86 & \\
\hline $6-47 E 3$ & 3.1 & 813 & 30.87 & 1480 & 99.65 & \\
\hline $\begin{array}{l}6-47 F 3 \\
6-66 \mathrm{~B}\end{array}$ & $\begin{array}{l}1.2 \\
1.2\end{array}$ & $\begin{array}{l}718 \\
723\end{array}$ & $\begin{array}{l}14.4 \\
14.5\end{array}$ & $\begin{array}{l}1540 \\
1545\end{array}$ & 99.88 & 17.73 \\
\hline $4-13403$ & 3.1 & 658 & 23.8 & 1487 & 97.39 & \\
\hline $6-5563$ & 3.1 & 723 & 31.3 & 1545 & 99.78 & \\
\hline $\begin{array}{l}4-135 B 3 \\
6-66 C\end{array}$ & $\begin{array}{l}3.1 \\
3.1\end{array}$ & $\begin{array}{l}653 \\
653\end{array}$ & $\begin{array}{l}16.17 \\
15.1\end{array}$ & $\begin{array}{l}1554 \\
1554\end{array}$ & 99.97 & 4.65 \\
\hline $4-134 A 3$ & 1.3 & 715 & 21.5 & 1466 & 97.05 & \\
\hline $6-5503$ & 1.2 & 653 & 21.59 & 1544 & 99.72 & \\
\hline $6-54 F 3$ & 5.1 & 718 & 30.87 & $1469^{\circ}$ & 27.51 & \\
\hline $6-55 A 3$ & 3.1 & 723 & 22.83 & 1394 & 64.85 & \\
\hline $\begin{array}{l}6-49 B 3 \\
6-66 D\end{array}$ & $\begin{array}{l}1.2 \\
1.2\end{array}$ & $\begin{array}{l}813 \\
806\end{array}$ & $\begin{array}{l}14.4 \\
14.4\end{array}$ & $\begin{array}{l}1480 \\
1473\end{array}$ & 99.92 & 23.82 \\
\hline $6-49 c 3$ & 3.1 & 808 & 14.33 & 1394 & 99.88 & \\
\hline $\begin{array}{l}6-49 D 3 \\
6-66 G\end{array}$ & $\begin{array}{l}5.1 \\
5.1\end{array}$ & $\begin{array}{l}808 \\
812\end{array}$ & $\begin{array}{l}14.52 \\
14.5\end{array}$ & $\begin{array}{l}1541 \\
1541\end{array}$ & 99.98 & 11.23 \\
\hline $6-49 E 3$ & 5.1 & 723 & 22.77 & $1545^{\circ}$ & 99.96 & \\
\hline $6-54 C 3$ & 5.1 & 653 & 32.3 & 1528 & 95.49 & \\
\hline $\begin{array}{l}6-50 A 3 \\
6-66 E\end{array}$ & $\begin{array}{l}1.2 \\
1.2\end{array}$ & $\begin{array}{l}811 \\
814\end{array}$ & $\begin{array}{l}30.96 \\
30.94\end{array}$ & $\begin{array}{l}1548 \\
1551\end{array}$ & 99.44 & 13.11 \\
\hline
\end{tabular}


$-118-$

TABLE V-11 (continued)

Combustion Efficiency Response of Propane Parametrics

Before and After 1000 Hour Life Test on Catalyst Core DXB-532

\begin{tabular}{|c|c|c|c|c|c|c|}
\hline Run \# & $\begin{array}{l}\text { Inlet } \\
\text { Pressure } \\
\left(\times 10^{-5}\right) \\
\mathrm{N} / \mathrm{M}^{2} \\
\end{array}$ & $\begin{array}{c}\text { Preheat } \\
\text { Air } \\
\text { Temperature } \\
{ }^{\circ} \mathrm{K} \\
\end{array}$ & $\begin{array}{l}\text { Reference } \\
\text { Velocity } \\
\\
M / S \\
\end{array}$ & $\begin{array}{c}\text { Adiabatic } \\
\text { Flame } \\
\text { Temperature } \\
{ }^{\circ} \mathrm{K} \\
\end{array}$ & $\begin{array}{r}\text { Combus } \\
\text { Efficien } \\
\text { Initial } \\
\end{array}$ & $\begin{array}{l}\text { tion } \\
\text { icy }(\%) \\
\text { Final } \\
\end{array}$ \\
\hline $6-56 \mathrm{~B} 3$ & 1.2 & 721 & 22.79 & 1475 & 98.43 & \\
\hline $4-134 C 3$ & 1.2 & 653 & 13.0 & 1406 & 99.15 & \\
\hline $6-5003$ & 3.1 & 653 & 32.07 & 1406 & 28.61 & \\
\hline $6-55 F 3$ & 1.2 & 658 & 33.7 & 1487 & 33.39 & \\
\hline $\begin{array}{l}6-50 \mathrm{~F} 3 \\
6-66 \mathrm{~F}\end{array}$ & $\begin{array}{l}3.1 \\
3.1\end{array}$ & $\begin{array}{l}813 \\
809\end{array}$ & $\begin{array}{l}22.66 \\
22.68\end{array}$ & $\begin{array}{l}1550 \\
1546\end{array}$ & 91.94 & 9.33 \\
\hline $4-134 B$ & 1.4 & 723 & 27.9 & 1394 & 37.88 & \\
\hline $6-54 A 2$ & 1.2 & 723 & 22.85 & 1474 & $99: 23$ & \\
\hline $6-5403$ & 5.1 & 658 & 23.65 & 1411 & 40.97 & \\
\hline $6-54 E 3$ & 5.1 & 813 & 30.78 & 1399 & 37.86 & \\
\hline $4-136 A 3$ & 1.2 & 808 & 24.64 & 1394 & 93.62 & \\
\hline
\end{tabular}


a statistical model to adequately describe the responses of combustion efficiency, CO emissions and pressure drop. The models considered in this study were multiple 7 inear regressions of all first, second and third order variable interactions. These models were all of the following form: Combustion Efficiency $=A+B$ (Reference Velocity) $+C$ (Air Preheat Temperature) (Adiabatic Flame Temperature). This section contains a synopsis of the results obtained from these analyses.

\section{1) Combustion Efficiency}

Because of the usefulness of being able to predict satisfactory or unsatisfactory operation with $C$. P. Propane, a number of graphical techniques were tried to represent the combustion efficiency of catalyst core DXC-532. The details of the graphical approaches considered are found in Appendix D. In summary, no suitable. graphical representation of the combustion efficiency response was found for $D X C-532$.

A stepwise multiple regression computer program was used to determine the best statistical model for $C$. P. Propane combustion efficiency. This program analyzes all the main effects and interactions and then presents only the most significant model as output. The most significant model consisted of interaction terms involving the main variables of reference velocity, air preheat temperature and adiabatic flame temperature. The multiple correlation 
coefficient for this best model was 0.8356 but the standard error was $15.9 \%$ absolute. This indicates that a fair amount of scatter would result between predicted and actual results if this model were used as a predictive tool.

2) Carbon Monoxide Emissions

Employing a stepwise multiple regression computer routine, the best regression model consisted of interactions of the main variables of reference velocity, air preheat temperature and adiabatic flame temperature. The multiple correlation coefficient was 0.807 with a standard error of $295 \mathrm{vppm}$. This model is not a useful predictor because of the large standard error.

No satisfactory graphical presentation of the CO emissions data was found for the results on DXC-532.

\section{3) Pressure Drop}

Analysis of the pressure drop response from the propane parametrics on catalyst core DXC-532 resulted in excellent graphical representations and regression correlations for both isothermal and combustion conditions. The models that should be used for prediction of pressure drop are as follows: 
Isotherma ?

$$
\begin{aligned}
& \frac{\% \mathrm{P}}{\mathrm{P}}=\frac{0.0497 \mathrm{~V}^{1.6}}{\mathrm{p}^{0.548}} \\
& \text { Standard Error }=0.709 \% \\
& \text { Maximum Error }=1.99 \% \\
& \text { Correlation Coefficient }=0.993
\end{aligned}
$$

\section{Combustion}

$$
\% \frac{\Delta P}{P}=\frac{0.219 \mathrm{~V}^{1.3}}{\mathrm{p}^{0.77}}
$$

Standard Error $=1.57 \%$

Maximum Error $=3.16 \%$

Correlation Coefficient $=0.9852$

Where

$$
\begin{aligned}
& P=A \text { tm. }\left(1 \times 10^{5} \mathrm{~N} / \mathrm{M}^{2}\right) \\
& V=M / S
\end{aligned}
$$

The excellent agreement between predicted and experimental results is further indicated in Figure V-27: 
Figure V-27. Comparison of Experimental and Predicted Percent Pressure Drop of Catalyst Core DXC-532 (Combustion Condition).

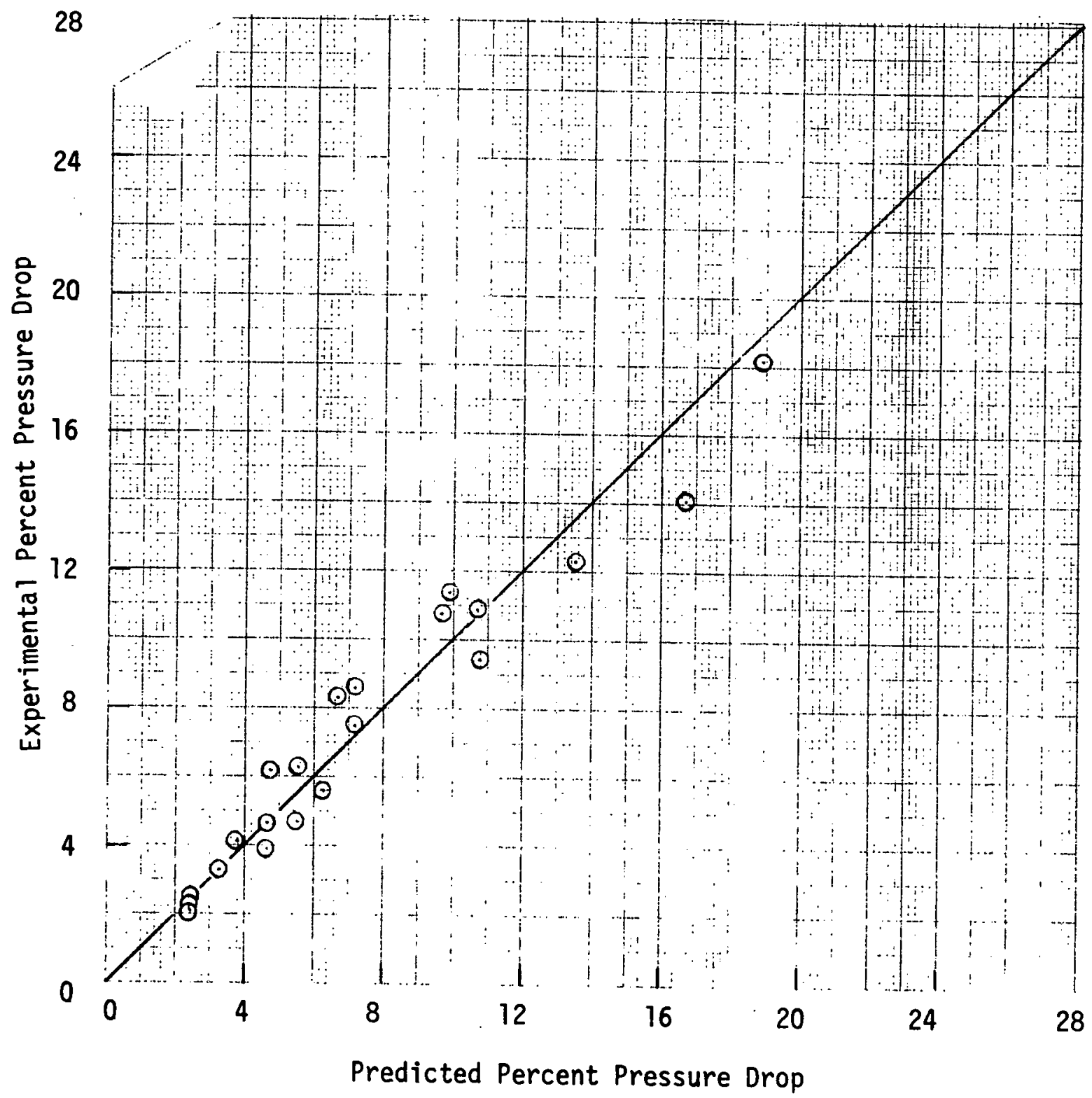


VI. DISCUSSION OF TEST RESULTS AND SELECTION OF PREFERRED CATALYST CORE

In selecting the preferred catalyst core, the primary criteria were the maintenance of low emissions operation and physical durability of the catalyst core after 1,000 hours of aging with \#2 diesel fuel. The secondary criteria considered, in the event the primary criteria could not detect significant differences, were the maintenance of carbon monoxide activity, the range of low emission performance on C. P. Propane and the maintenance of activity on C. P. Propane fuel.

\section{A. LIFE TEST RESULTS}

Overa11, the results from the \#2 diesel life test indicate that catalyst cores DXB-222 and DXC-532 are both capable of sustained operation at combustion operating temperatures. The support selected. for the catalyst core appears quite durable despite operation at $1527^{\circ} \mathrm{K}$.

However, there are some significant differences in the operation of the two catalyst cores to maintain this acceptable performance, as shown in Table VI-1. Catalyst core DXB-222 retains enough activity after 1,000 hours aging to attain low emissions operation at the preheat temperature of $633^{\circ} \mathrm{K}$ set at the start of the life test. However, the activity of DXC-532 has declined such that an air preheat temperature of $673^{\circ} \mathrm{K}$ is required at the end of the 1,000 hours to attain low emissions operation. Even with increased air preheat, downstream burning was still present for DXC-532 indicating incomplete combustion was occurring in the catalyst core. This increase in temperature of $40^{\circ} \mathrm{K}$ represents a significant decline in the activity of DXC-532 for diesel fuel. 
TABLE VI-1

Comparison of Operating Conditions And

Test Responses After 1000 Hours Life Testing

Catalyst Core

$\underline{\mathrm{DXB}-222}$

$\underline{\text { DXC-532 }}$

Operating Conditions:

Air Preheat Temperature $\left({ }^{\circ} \mathrm{K}\right)$

Adiabatic Flame Temperature $\left({ }^{\circ} \mathrm{K}\right)$

Inlet Pressure $\left(\mathrm{N} / \mathrm{M}^{2}\right)$

Reference Velocity (M/S)
628

1540

$1.1 \times 10^{5}$

12.9
663

1585

$1.1 \times 10^{5}$

13.8

Responses:

Outlet Temperature $\left({ }^{\circ} \mathrm{K}\right)$

$.00635 M\left(1 / 4^{\prime \prime}\right)$ Downstream .03175 M (2-1/4") Downstream

1470

1475

1365

8.6

Percent Pressure Drop (\%)

Combustion Efficiency (\%)

99.89

1450

7.9

99.91

Emissions: (Nominally a $12.5 \% 0_{2}$ )*

CO (Vppm)

$\mathrm{UHC}(\mathrm{Vppm})$

$\mathrm{NO} \cdot(\mathrm{Vppm})$
60

1

4.2
42

0

3.2

* Measured $.1016 \mathrm{M}\left(4^{\prime \prime}\right)$ downstream with .00635M (1/4" $\varphi$ ) water cooled sampling probe. 
For combustion applications with air preheat temperature considerably above $700^{\circ} \mathrm{K}$, both catalyst core DXB-222 and DXC-532 possess the potential of functioning with low emissions for extended time periods. However, for air preheat temperatures between 630 and $700^{\circ} \mathrm{K}$, or for transient engine conditions over a wide range of air preheat temperatures (e.g., 630 to $1000^{\circ} \mathrm{K}$ ), only catalyst core DXB-222 appears to have suitable life characteristics.

The physical appearance of the catalyst cores and the analytical results indicated very little difference between DXB-222 and DXC532. Unfortunately, catalyst core DXB-222 was exposed to very high temperatures during the final diesel parametrics causing some channels to collapse, probably contributing to a lower retention of BET surface area. In addition, this exposure to high temperatures could have vaporized any $\mathrm{Pb}$ that may have been deposited on $\mathrm{DXB}-222$. Therefore, the lead deposited on DXC-532 may not be unique to this catalyst core but only indicative of a lower operating temperature. Since these analytical results are inconclusive, they were not considered further in selection of the preferred catalyst core. It should be noted that if indeed significantly more $\mathrm{Pb}$ was in the fuel used for the life test on DXC-532 then these aforementioned conclusions may not be completely. valid. 


\section{B. PROPANE PARAMETRICS}

The initial propane parametrics on both DXB-222 and DXC532 gave essentially identical results. Both catalysts exhibited a very broad range of low emissions operation for C. P. Propane over the range of variables studies. After 1,000 hours aging, the activity towards low emissions operation declined significantly for both catalysts:

However, DXB-222 was at least active over some of the range of variables studied. Since propane fuel is a more difficult fuel to combust than \#2 diesel, any decline in diesel activity would naturally reflect a significant decline in propane activity. Since DXC-532 lost some activity towards diesel fuel during life testing, it is not surprising that DXC-532 had lost its activity completely for low emissions operation with C. P. Propane.

\section{CARBON MONOXIDE ACTIVITY TESTING}

The CO activity tests for both DXB-222 and DXC-532 indicated. very similar trends in that the most significant decrease in co conversion occurred during the first 250 hours of life testing. The mass transfer limited CO conversion level for DXB-222 was $44 \%$ while DXC532 lined-out at $35 \%$. 


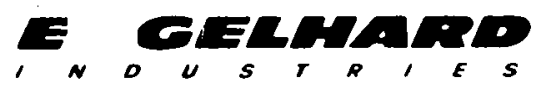

\section{DIESEL PARAMETRICS}

The diesel parametrics, conducted with catalyst core DXB-222 after 1000 hours 1 ife. testing, indicate that a very broad range of operation is possible with this catalyst which result in low emissions operation. The impurities in \#2 diesel have not affected the performance of $D X B-222$.

In examining these results obtained on catalyst cores DXB-222 and DXC-532, and summarized in Table VI-2, it becomes apparent that the main difference is the loss in diesel activity that occurred on catalyst core DXC-532 during life testing. Since the life test was terminated at 1,000 hours, there is no supportive evidence that the diesel activity of catalyst core DXC-532 had indeed stabilized. Catalyst core DXB-222 had not lost any measurable activity for \#2 diesel from these test results and gave very stable operation up to 1,000 hours of life testing. Based on these life test results, catalyst core DXB-222 possesses the potential for maintenance of low emission diesel operation beyond 1,000 hours over a wide range of operating conditions. Future work on extended life test and fuel durability studies, as well as scaled-up engine tests, should be conducted with catalyst core DXB-222 to obtain further data on its performance capabilities. 
Summary of Test Results on Catalyst Cores DXB-222 and DXC-532

\section{\#2 Diesel Life Test}

Emissions: Same for both catalysts during the 1000 hour test.

Activity: For DXC -532 , a $30-40^{\circ} \mathrm{K}$ higher inlet temperature was needed to initiate low emission combustion after 600 hours life testing.

Propane Parametric Studies

Initial Test: No difference.

After Aging: DXC-532 deactivated completely for high efficiency combustion. DXB-222 retained high efficiency combustion over a narrow range of operation.

Co Activity Test $\therefore$

1. DXB-222 retained about $44 \%$ mass transfer limited conversion while DXC-532 had 35\% mass transfer limited conversion left after aging.

2. Significant deactivation of both catalyst cores apparently occurred between 24 and 250 hours of aging. 
VII. CONCLUSIONS AND RECOMMENDATIONS

From the experimental test results obtained under this contract, the following conclusions were reached:

1. The two catalyst cores tested, DXB-222 and DXC-532, maintained extremely low emissions for 1,000 hours of continuous operation with \#2 diesel fuel. Emissions were:

$\begin{array}{lr}\left.\text { Unburned Hydrocarbons ( } C_{3} \mathrm{vppm}\right) & 4 \\ \text { Carbon Monoxide (vppm) } & 50 \\ \text { Nitrogen Oxides (vppm) } & 4\end{array}$

2. Comparison of the steady state emissions for both catalyst cores after 1,000 hours aging were well below the 1977 and 1978 automotive standards and typically were as follows:

\begin{tabular}{lcccc} 
& \multicolumn{4}{c}{ Federal Standards $(\mathrm{g} / \mathrm{mi})}$. \\
Unburned Hydrocarbons & .04 & $\mathrm{~g} / \mathrm{mile}$ & $\frac{1977}{1.5}$ & $\frac{1978}{.41}$ \\
Carbon Monoxide & .59 & $\mathrm{~g} / \mathrm{mile}$ & 15. & 3.4 \\
NO $_{\mathrm{X}}$ & .06 & $\mathrm{~g} / \mathrm{mile}$ & 2.0 & .4
\end{tabular}

These emissions are calculated based on steady-state operation, assuming a fuel consumption of $10 \mathrm{miles} / g a l l o n$.

3. Both catalyst cores can maintain their physical integrity for at least 1,000 hours of life testing at operating temperatures characteristic of catalytically-supported thermal combustion (ca. $1527^{\circ} \mathrm{K}$ ). 
4. Excellent predictive models were obtained for the pressure drop through both catalyst cores, using the propane parametric data. No simple linear models were found satisfactory for correlating combustion efficiency and emissions responses from the propane parametrics.

5. During the 1,000 hours 1 ife testing of DXB-222, no changes in operating conditions were required to maintain low emissions. The air preheat temperature had to be increased $40^{\circ} \mathrm{K}$ to maintain low emissions operation of DXC-532.

6. Catalyst core DXB-222 had not lost any measurable activity for \#2 diesel and retained a broad range of low emissions operation with this fuel, exhibiting stable operation through 1,000 hours of testing.

7. The preferred catalyst core was selected as DXB-222 bașed on its broader operating range for \#2 diesel fuel after 1,000 hours 1ife testing.

8. Catalyst cores, DXB-222 and DXC-532, can operate for at least 1,000 hours under simulated steady state gas turbine operations, and yet maintain their durability and excellent low emissions performance.

9. The main difference between the two catalyst cores is the loss in diegsel activity that occurred with catalys core DXC-532 in life testing. Since the life test was terminated at 1,000 hours, there is no supportive evidence that the diesel activity of catalyst core $D X C-532$ had indeed stabilized. 
It is recommended that additional life testing of DXB-222 be carried out at higher pressures, in order to more closely simulate gas turbine engine operating conditions. It is further recommended that a parallel effort be carried out to test DXB-222 in realistic combustion hardware. 


\section{LIST OF REFERENCES}

1. Pfefferle, W. C., Heck, R. M., Carrubba, R. V. and Roberts, G. W., "CATATHERMAL Combustion: A New Process for Low-Emissions Fuel Conversion", ASME-75-WA/FU-1.

2. Carrubba, R. V., Chang, M., Pfefferle, W. C. and Polinski, L. M., "Catalytically-Supported Thermal Combustion for Emissions Control", Paper presented at the Electrical Power Research Institute $\mathrm{NO}_{\mathrm{x}}$ Control Technology Seminar, San Francisco, Calif., Feb. 6, 1976.

3. Anderson, D. N., Tacina, R. R. and Mroz, T. S., "Performance of a Catalytic Reactor at Simulated Gas Turbine Combustor Operating Conditions", NASA-TMX-71747.

4. Blazowski, W. S. and Bresowar, G. E., "Prel iminary Study of the Catalytic Combustor Concept, As Applied to Aircraft Gas Turbines", AFAPL-TR-74-32.

5.. DeCorso, S. M., Mumford, S., Carrubba, R. V. and Heck, R. M., "Catalysts for Gas Turbine Combustors - Experimental Test Results", Presented at ASME Gas Turbine Division Conference, New Orleans, La., March, 1976.

6. 40 CFR 86, "Control of Air Pollution From New Motor Vehicles and New Vehicle Engines: Certification and Test Procedures."

7. "Draft Copy of the Preamble and Regulation for the New Service Performance for Stationary Gas Turbines", Apri1, 1977.

8. "Fluid Meters: Their Theory and Applications" - Edited by Howard S. Bean, Sixth Edition ASME, 1971.

9. Hougen, 0., Watson, K. and Ragatz, R., "Chemical Process Applications, Part I", John Wiley and Sons, N.Y., 1962. 
APPENDIX A

WORK STATEMENT

FOR TASKS I, II AND III

OF NAS3-19416 


\section{GENERAL REQUIREMENTS}

Emission measurements shall be made of carbon monoxide $(\mathrm{CO})$, carbon dioxide $\left(\mathrm{CO}_{2}\right)$, unburned hydrocarbons $(\mathrm{HC})$ and oxides of nitrogen ( $\mathrm{NO}$ ). This shall be performed per SAE Standard ARP-1256, "Procedure for Continuous Sampling and Measurement of Gaseous Emissions from Aircraft Turbine Engines". The following instrumentation and methods are required for testing of sub-scale catalytic substrates in Task III:

A. CARBON MONOXIDE AND CARBON DIOXIDE

Carbon monoxide and carbon dioxide shall be measured by the non-dispersive infrared (NDIR) method. Recommended accuracy is:

$$
\begin{aligned}
& \text { Co } \quad \text { - } 100 \mathrm{ppm} \pm 2 \text { percent full scale } \\
& \text { 0-500 ppm } \pm 1 \text { percent full scale } \\
& \mathrm{CO}_{2} \pm 1 \text { percent full scale }
\end{aligned}
$$

B. OXIDES OF NITROGEN $\left(\mathrm{NO}_{\mathrm{X}}\right)$

The chemiluminescent method of optical NO detection shall be used. The instrument shall be provided with a switchable converter so that total $\mathrm{NO}$ and $\mathrm{NO}_{2}$ may be measured. 
C. HYDROCARBONS (HC)

Hydrocarbons shall be measured with a heated flame ionization detector (FID). Instrument and sample line temperatures shall be maintained at approximately $150^{\circ} \mathrm{C}$. Accuracy shall be $1 / 2 \mathrm{ppm}$ carbon on the $0-10 \mathrm{ppm}$ scale.

II. SPECIFIC REQUIREMENTS

A. TASK I - SURVEY AND SELECTION OF CONTRACTORS' CATALYSTS AND CATALYTIC SUBSTRATES FOR PARAMETRIC AND ENDURANCE TESTING.

Within fourteen (14) days after the date of this contract, the Contractor shall review the results of his in-house screening tests performed on his catalysts and catalytic substrates. Based on the results of this review, the Contractor shall select ani recommend three catalytic substrates for parametric and endurance testing in Task III. The selected items shall be the best candidates for low emission, catalytic combustion of hydrocarbon fuels at the operational conditions cited in Table I. The selected catalytic substrates shall reflect the best potential of success for a turbine engine catalytic combustor application.

In support of this selection, the Contractor shall provide to the NASA in-house screening test data, identification of the catalysts and substrates and the reasons and justification for selecting 
and recommending the three catalytic substrates for parametric and endurance testing. The test data, catalyst and substrate identification and catalytic substrate identification and catalytic substrate selection shall be submitted to the NASA Contracting officer for approval by the NASA Project Manager.

Five (5) days after this submittal, the Contractor shall present an oral discussion of the test results and recommendations to the NASA Project Manager at the Lewis Research Center. The proprietary information submitted to the Contracting Officer and presented in the oral discussion will be restricted and considered proprietary by NASA Lewis Research Center and EPA unti1 February 1, 1977.

As a minimum, the information and recommendations submitted by the Contractor to the NASA Contracting officer shall consider and include the following information:

1. Durability and life of the catalysts and substrate at the specified operation conditions.

2. Low emission ( $\mathrm{NO}_{\mathrm{x}}, \mathrm{CO}$ and $\mathrm{HC}$ - refer to Table I) characteristics and operation at the specified operating conditions.

3. Ignition characteristics.

4. Cost of catalyst materials.

5. Availability of catalyst. 
6. Compounds or elements which act as poisons to the catalysts.

7. Catalyst and substrate degradation.

8. Catalyst and substrate maximum operational temperature.

9. Developmental status.

10. Contractor's in-house screening test parameters (inlet and outlet temperature, inlet pressures, reference velocity, heat release rates, test fuels, test duration and fuel-air ratios).

11. In-house screening test results $\left(\mathrm{NO}_{\mathrm{x}}, \mathrm{CO}\right.$ and $\mathrm{HC}$ emissions, combustion efficiency, ignition characteristics, $\triangle P / P$ and. degradation, if any).

12. Identification of substrate materials.

13. Identification of catalyst including catalyst system constituents.

14. Differences between the screened and recommended catalytic substrates. 
B. TASK II - TEST FACILITIES

Within thirty (30) days after date of this contract, the Contractor shall submit the following information to the NASA Project Manager for approval:

1. Five (5) copies of the test system layout.

2. Five (5) copies of assembly drawing, including a bill of materials and identifying and showing all instrumentation and components integral in the test system.

3. Five (5) copies of the test system schematics.

The test system layout shall include: Design pressure rating, maximum operational pressure and maximum air flow at 600,800 , and $1000^{\circ} \mathrm{F}$ inlet temperature and pressure of 1,3 and 5 atmospheres.

After approval of the design drawings by the NASA Project Manager, the Contractor shal1: (1) Proceed to procure and fabricate the necessary parts and items for assembly and modification of the existing test apparatus; (2) assembly the test apparatus; and, (3) perform operational check out tests. 
C. TASK III - SUB-SCALE CATALYTIC SUBSTRATE PARAMETRIC AND ENDURANCE TESTING.

In this task the Contractor shall perform parametric and endurance testing with the three (3) catalytic substrates selected in Task I. Each sub-scale (1.0" O.D. nominal) candidate catalytic substrate shall be tested through a total operational test period of 1,000 hours. The objective of this task is to evaluate and establish the performance and emission characteristics of the three catalytic substrates through a range of operating conditions during the course of the parametric and endurance testing.

Within four (4) weeks after date of this contract, the Contractor shall submit three (3) copies of a test plan to the NASA Project Manager for approval. The test plan shall include:

1. Test objectives.

2. Detailed test procedures.

3. Testing sequence of the candidate catalytic substrates.

4. Schematic of test apparatus and location of installed instrumentation.

5. List of installed instrumentation. 
6. Data to be recorded.

7. Test conditions.

8. Identification of the fuel(s) to be used.

9. Method of determining combustion efficiency.

10. Method of fuel-air premixing and distribution.

This submittal shall include: (1) Criteria for evaluating the performance and rating of the three candidate catalytic substrates during testing and at the end of the 1,000-hour test period; (2) criteria establishing failure or cause for rejection of the candidate catalytic substrate due to poor performance or degradation; (3) criteria for discerning and evaluating degradation of the catalyst(s) separately from that of the substrate material.

The sub-scale catalytic substrates shall be tested at steady state conditions through a total test period of 1,000 hours. The inlet operational parameters of fuel-air ratio, reference velocity, temperature and pressure are to be varied at scheduled intervals to establish emission characteristics through a broad operational range. The ignition temperature shall be determined for each catalytic substrate. An evaluation shall be made of the ignition temperature and emission characteristics of each catalytic substrate at specific check points in the test cycle to detect any rate of catalyst degradation (chemical or physical): This shall be performed at: 
1. Beginning of test.

2. 250 hours of testing.

3. 500 hours of testing.

4. 750 hours of testing.

5. 1,000 hours of testing.

- Each catalytic substrate shall be tested within the inlet pressure range of 1-5 atmospheres, inlet temperature range of $400-1000^{\circ} \mathrm{F}$ and outlet temperature range of $2000-2400^{\circ} \mathrm{F}$.

For each catalyst, as a minimum, the test procedure shall include the following test points:

$\begin{array}{lrr}\frac{\mathrm{P}_{1}}{3 \mathrm{~atm} .} & \frac{\mathrm{T}_{\text {l Inlet }}}{600^{\circ} \mathrm{F}} & \frac{T_{2} \text { Outlet }}{2000-2400^{\circ} \mathrm{F}} \\ & 1000^{\circ} \mathrm{F} & 2000-2400^{\circ} \mathrm{F} \\ 5 \mathrm{~atm} . & 600^{\circ} \mathrm{F} & 2000-2400^{\circ} \mathrm{F} \\ & 1000^{\circ} \mathrm{F} & 200-2400^{\circ} \mathrm{F}\end{array}$

Testing at each temperature shall include three different fuel-air ratios. The testing shall include a minimum average and 


\section{A-10}

maximum reference velocity for each fuel-air ratio. As a part of the task, the Contractor shall measure the emissions $\left(\mathrm{NO}_{\mathrm{x}}, \mathrm{CO}, \mathrm{CO}_{2}\right.$ and unburned hydrocarbons, inlet and outlet temperature, inlet pressure, $\Delta P / P$, fuel-air ratio, reference velocity, inlet air humidity, and auto ignition temperature. The combustion efficiency and heat release rate shall be computed for each test point. Testing can be performed with a gaseous fuel such as propane. The Contractor shall advise the NASA Project Manager of the extent to which the use of lead-free gasoline and JP-5 would affect the ranking of the catalyst. The Contractor shall promptly notify the NASA Project Manager if accidental damage of a catalytic substrate occurred or if poor performance, degradation, or failure is detected during the testing of any of the three candidate catalytic substrates.

The decision to continue testing of the affected test.item will be made by the NASA Project Manager after a review of test data, condition of the catalytic substrate and recommendation by the Contractor.

Upon completion of the testing in this task, the Contractor shall review and evaluate the test results and examine the catalytic substrates for chemical and/or physical degradation. The Contractor shall submit three (3) copies of all test data and results, conclusions and recommendations to the NASA Project Manager for review and approval. Plots shall be provided for each catalytic substrate showing: 
1. Effect of fuel-air ratio on combustion efficiency and emissions.

2. Effect of reference velocity on combustion efficiency and emissions.

3. Effect of inlet temperature and pressure on combustion efficiency and emissions.

4. Optimum low emission operating band. 
B-1

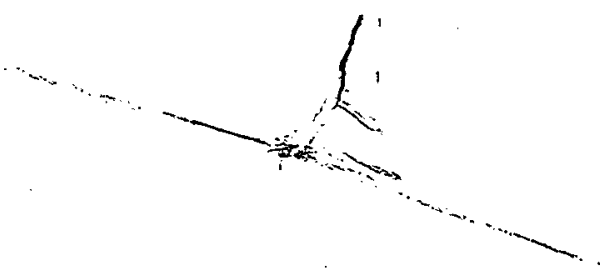

APPENDIX B

COMPUTER PRINTOUTS

OF \#2 DIESEL LIFE TESTS 


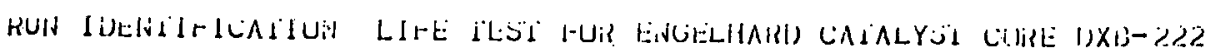

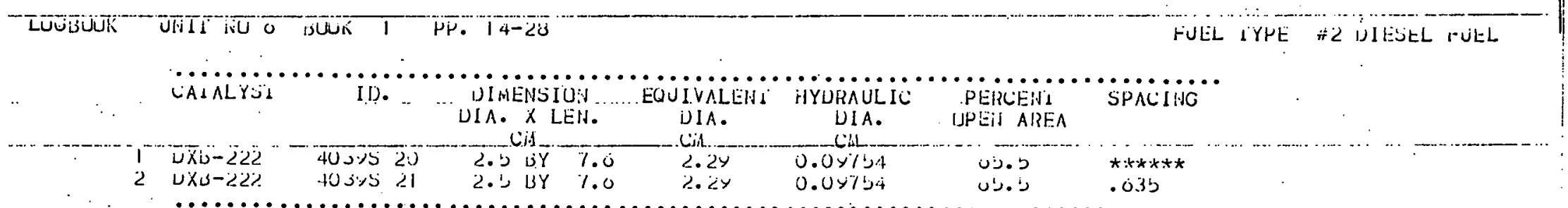

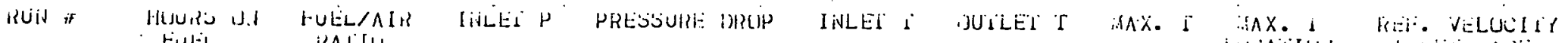

- ilM! I

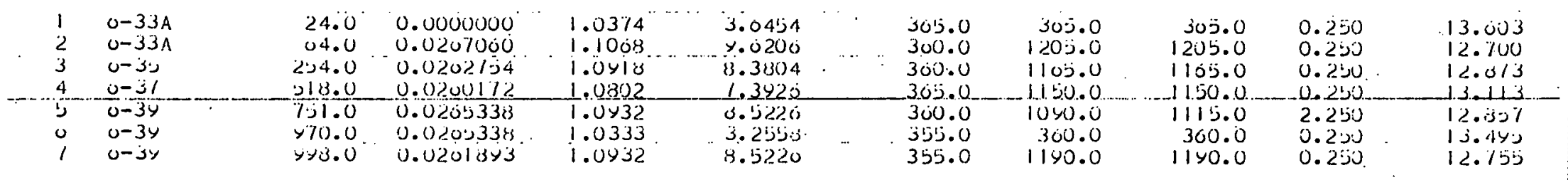




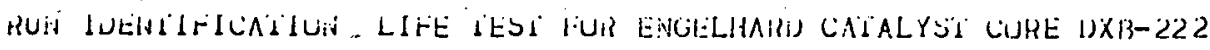

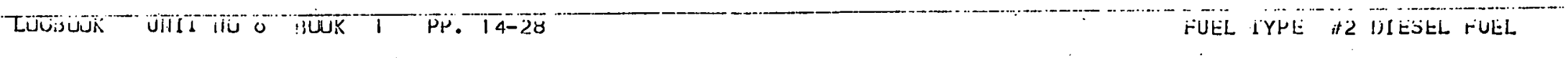

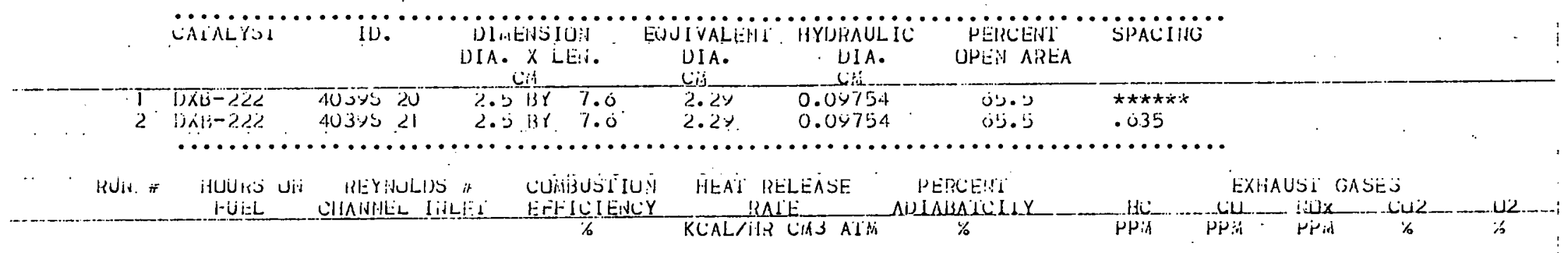

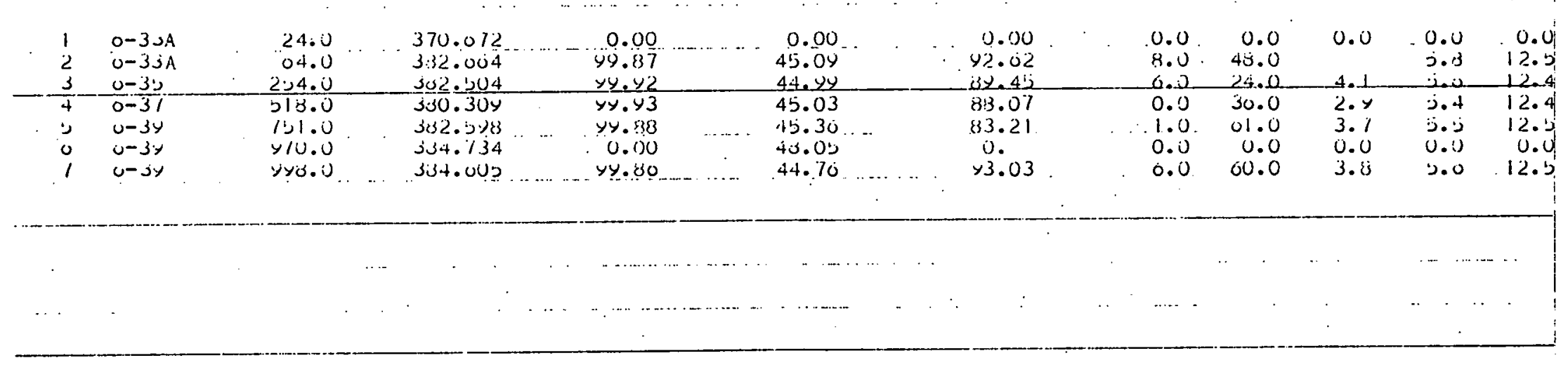




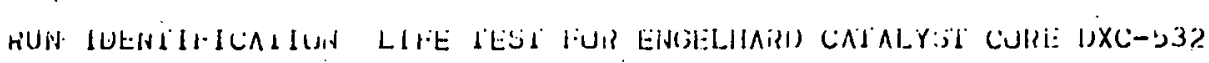

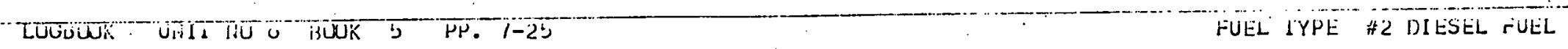

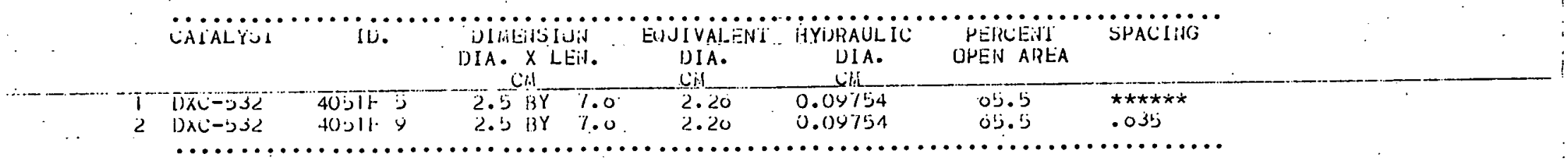

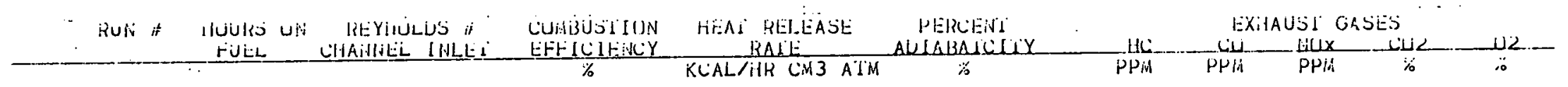

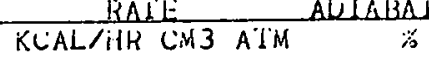

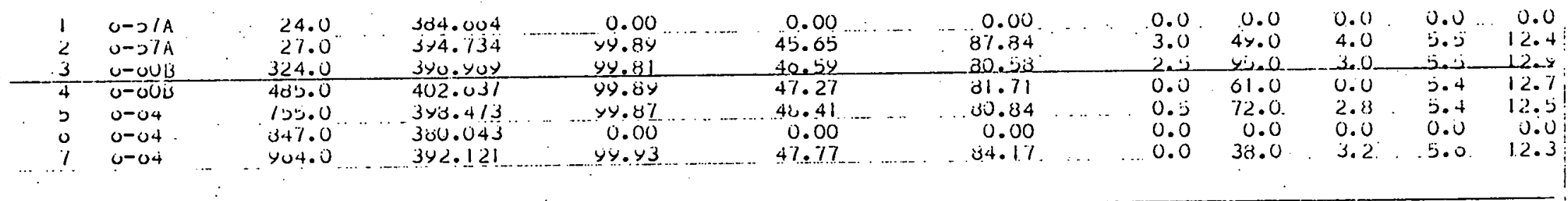


APPENDIX C

COMPUTER PRINTOUTS OF

PROPANE PARAMETRICS 


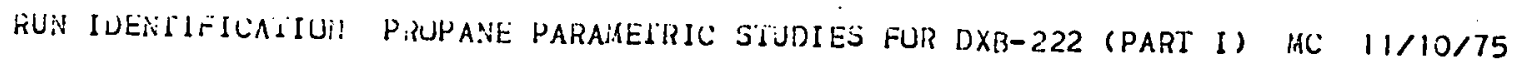

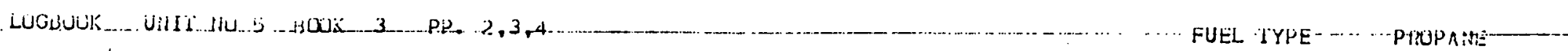

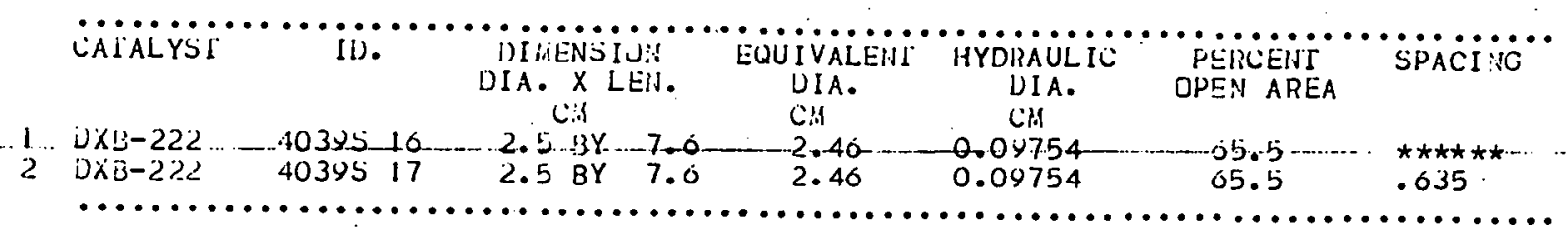

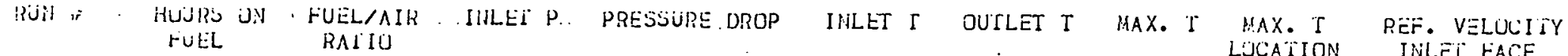

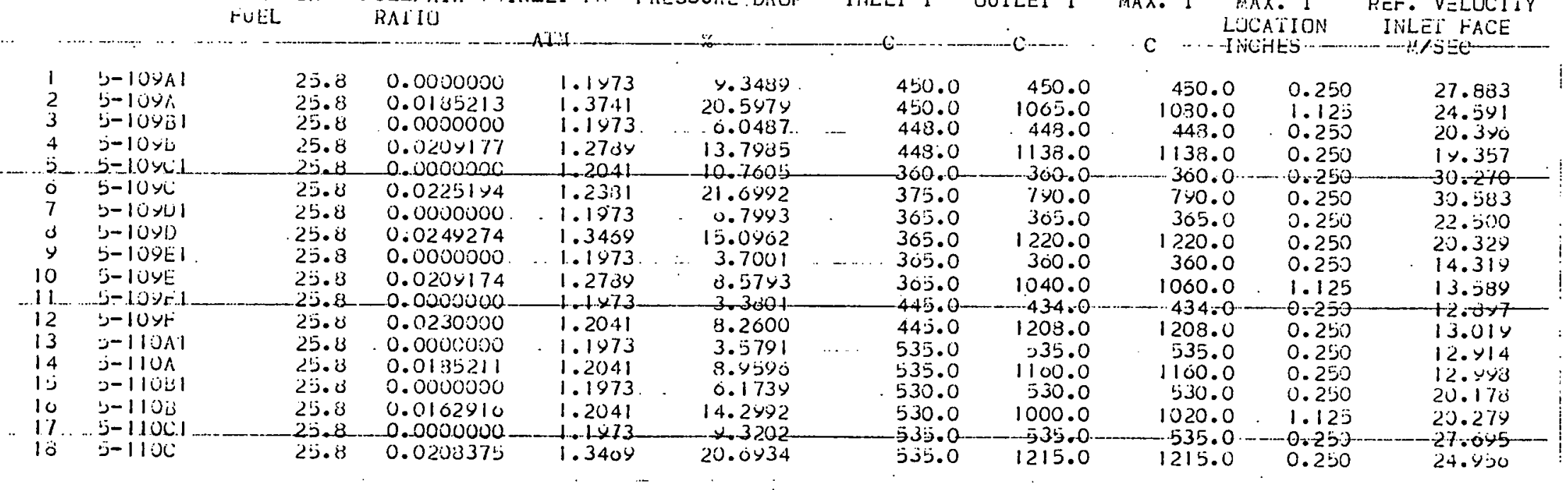




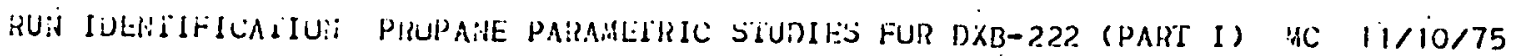

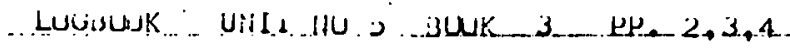

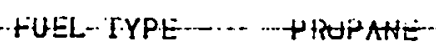

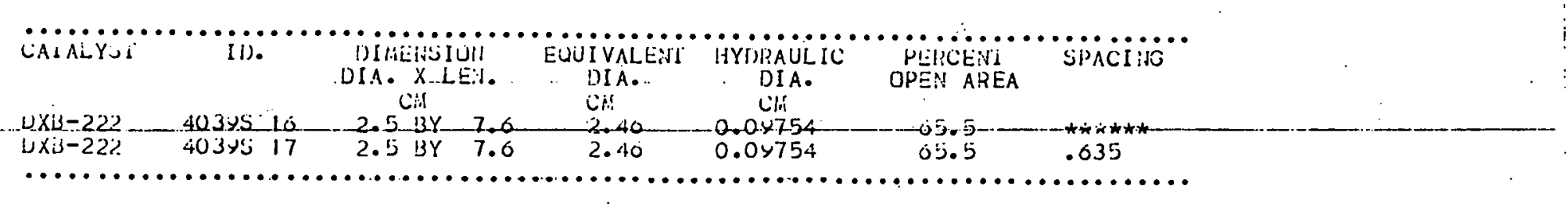

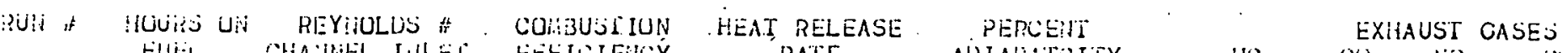

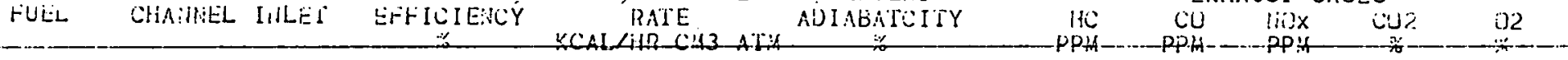

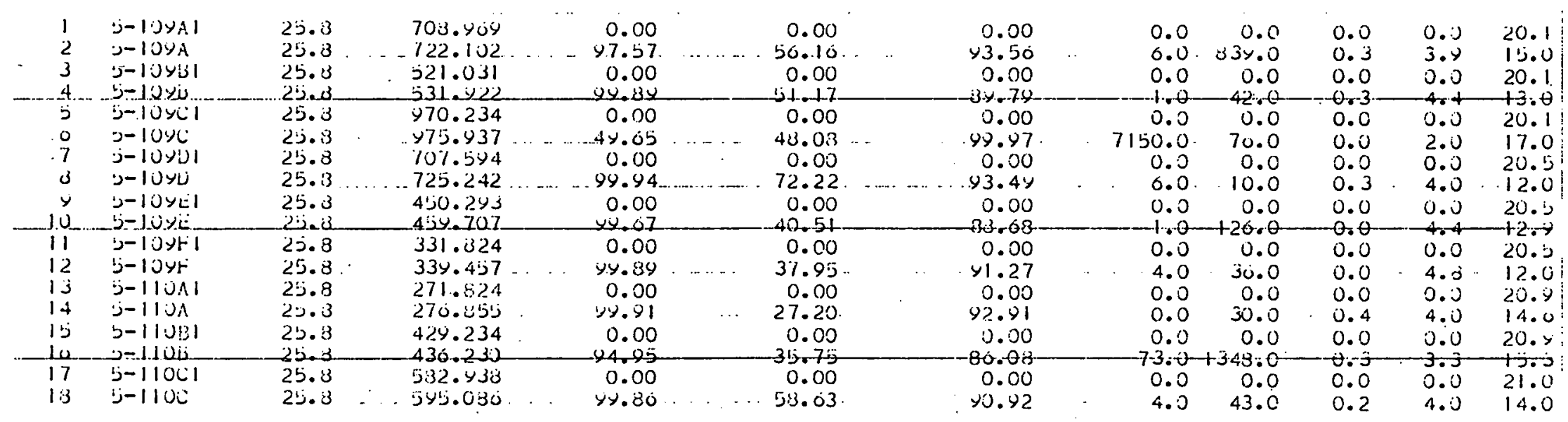




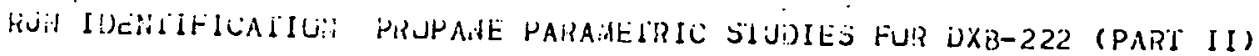

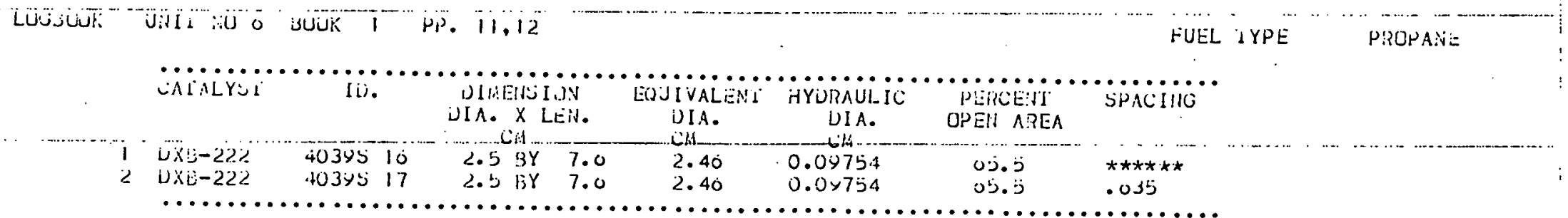

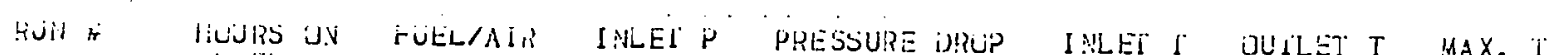

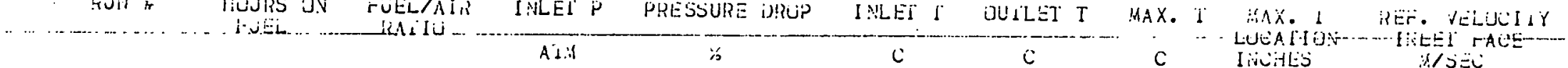

\begin{tabular}{|c|c|c|c|c|c|c|c|c|c|c|}
\hline $\begin{array}{l}1 \\
2 \\
3 \\
4\end{array}$ & $\begin{array}{l}0-2011 \\
0-201 \\
0-2001 \\
0-2033\end{array}$ & $\begin{array}{l}25.3 \\
25.8 \\
25.8 \\
25.23\end{array}$ & $\begin{array}{l}0.0000000 \\
0.0205170 \\
0.0000000 \\
0.0000000\end{array}$ & $\begin{array}{l}3.0007 \\
3.033 y . \\
4 . y 9 y 9 \\
4.5 x y 9\end{array}$ & $\begin{array}{l}1.3051 \\
3.910 \% \\
1.5501 \\
1.50 \times 2\end{array}$ & $\begin{array}{l}401.0 \\
401.0 \\
350.0 \\
330.0\end{array}$ & $\begin{array}{r}401.0 \\
1203.0 \\
350.0 \\
-.380 .0\end{array}$ & $\begin{array}{r}461.0 \\
1203.0 \\
350.0 \\
300.0\end{array}$ & $\begin{array}{l}0.250 \\
0.250 \\
0.200 \\
0.250\end{array}$ & $\begin{array}{l}13.132 \\
13.170 \\
12.773 \\
13.340\end{array}$ \\
\hline b & $0-2001$ & 23.8 & 0.0000000 & $4 . y Y y y$ & $1.44 \times 4$ & 445.0 & .145 .0 & 445.0 & $0.25 j$ & $\begin{array}{l}13.340 \\
12.0311\end{array}$ \\
\hline 0 & $0-200^{\circ}$ & 25.8 & 0.0135211 & 4. yyyy & 2.0001 & 445.0 & 940.0 & 1100.0 & 2.25 & 13.034 \\
\hline 7 & $0-2001$ & $2 \cdot .0 .8$ & 0.0000000 & 4. YySiy & 2.0501 & $53 \% .0$ & 535.0 & 335.0 & 0.250 & 20.200 \\
\hline u & $0-200$ & 20.83 & 0.0187007 & 4. Yy./Yy... & $4 .\{3 y \times 88$ & 335.0 & 1025.0 & 1200.0 & $2.2 \div 0$ & 20.510 \\
\hline $\begin{array}{r}9 \\
10\end{array}$ & $\begin{array}{l}0-20 E 1 \\
0-200\end{array}$ & $\begin{array}{l}25.8 \\
25.0\end{array}$ & $\begin{array}{l}0.0000000 \\
0.01157001\end{array}$ & $\begin{array}{l}2 . y y \times y \\
2.0 . y . y .40\end{array}$ & $\begin{array}{r}3.7300 \\
-19.3003\end{array}$ & $\begin{array}{l}530.0 \\
530.0\end{array}$ & 330.0 & 1330.0 & 0.250 & 21.433 \\
\hline 11 & $0-2|A|$ & 25.8 & 0.00000000 & 2.9949 & 3.0902 & 305.0 & 3015.0 & 305.0 & 0.250 & $\begin{array}{l}-24073-103 \\
20.553\end{array}$ \\
\hline 12 & $0-2 / A$ & 25.8 & 0.02301303 & $2 . \times Y Y Y y$. & 0.7001 & $30 j .0$ & $y 70.0$ & 1220.0 & 2.250 & 2).800 \\
\hline 13 & $0-2131$ & 25.33 & 0.0000000 & 3.0007 & נ. yzy.y & 433.0 & 433.0 & 430.0 & 0.250 & 27.270 \\
\hline $\begin{array}{l}14 \\
10\end{array}$ & $0-210$ & 25.3 & 0.02211133 & $2.4 \times 49 \ldots$ & $10.31 y$ & 43.3 .0 & $\div \times 3.0$ & 1240.0 & $2.20^{i}$ & 21.731 \\
\hline 10. & $0-2 \Delta A$ & 23.8. & 0.0 .1 .30211 & $\begin{array}{l}2.9498 \\
2 . y 4 x \times x\end{array}$ & $\begin{array}{r}3.1000 \\
-0.9 .301\end{array}$ & $\begin{array}{l}450.0 \\
490.0\end{array}$ & 450.0 & $\begin{array}{r}450.0 \\
+1.23\end{array}$ & 0.200 & $20.3 / y$ \\
\hline 17 & $0-2|r|$ & ن. & 0.0000000 & 4. YYYY & 4.83497 & 44.50 & 440.0 &.+40.0 & 0.280 & 28.001 \\
\hline 13 & $0-2 i 5$ & 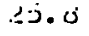 & 0.0259177 & $.4 . У 4 У 9$ & $\% .3000$ & $44 j .0$ & 030.0 & 0 & 2.200 & 21.111 \\
\hline
\end{tabular}




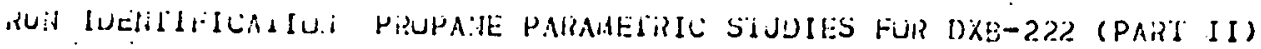

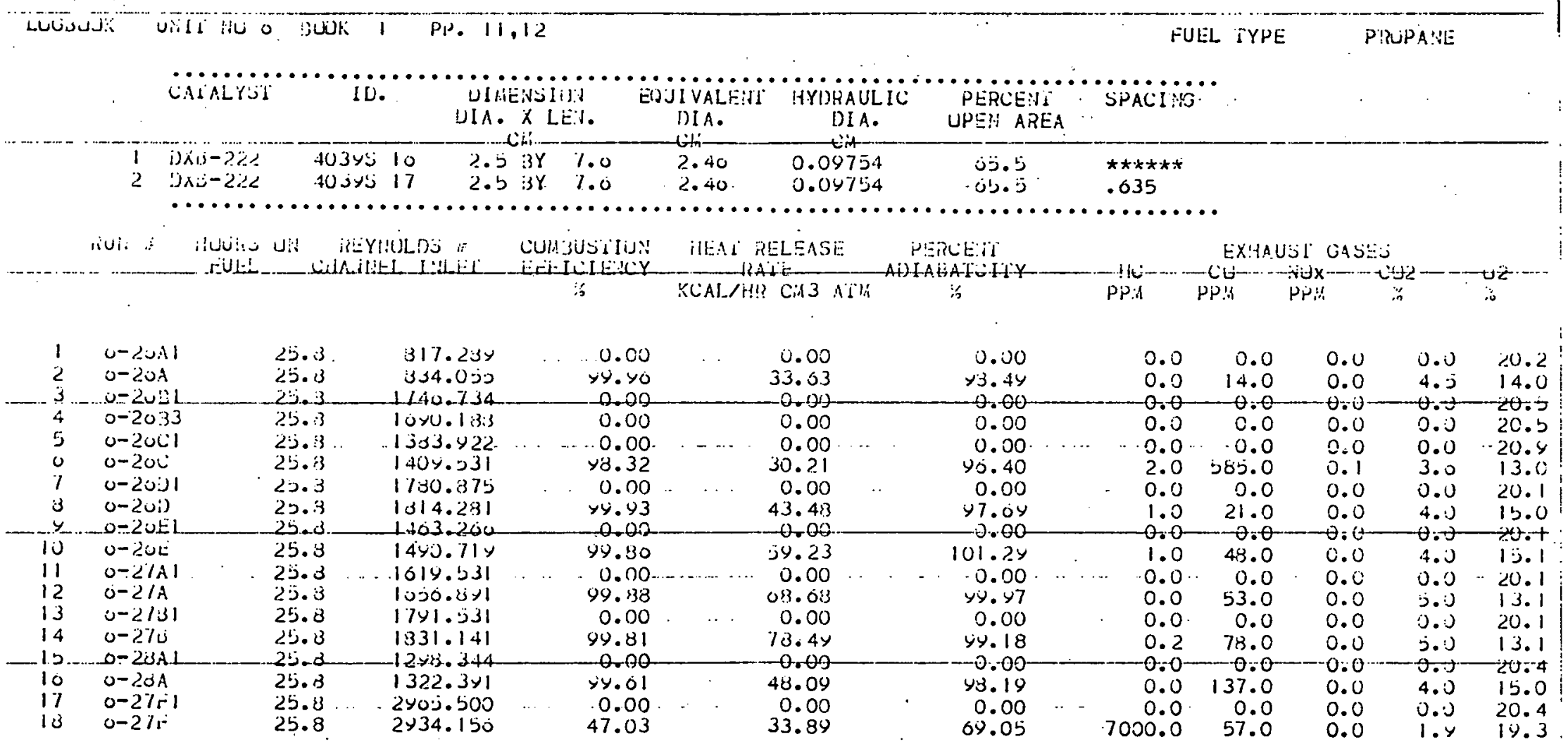




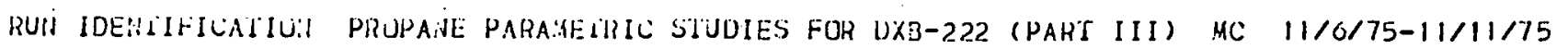

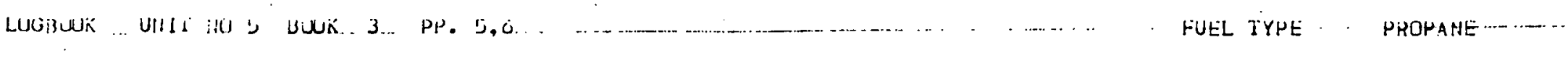

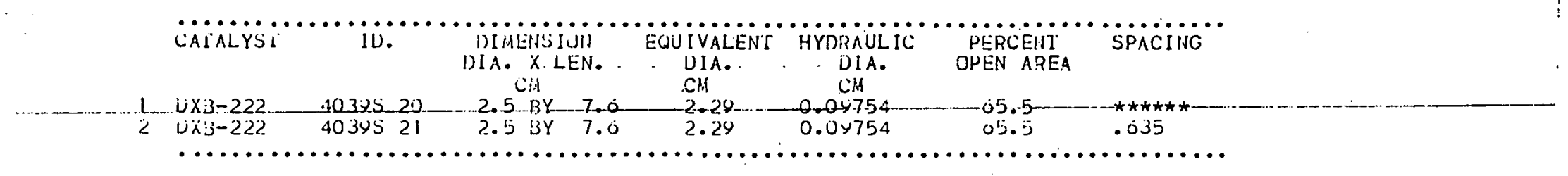

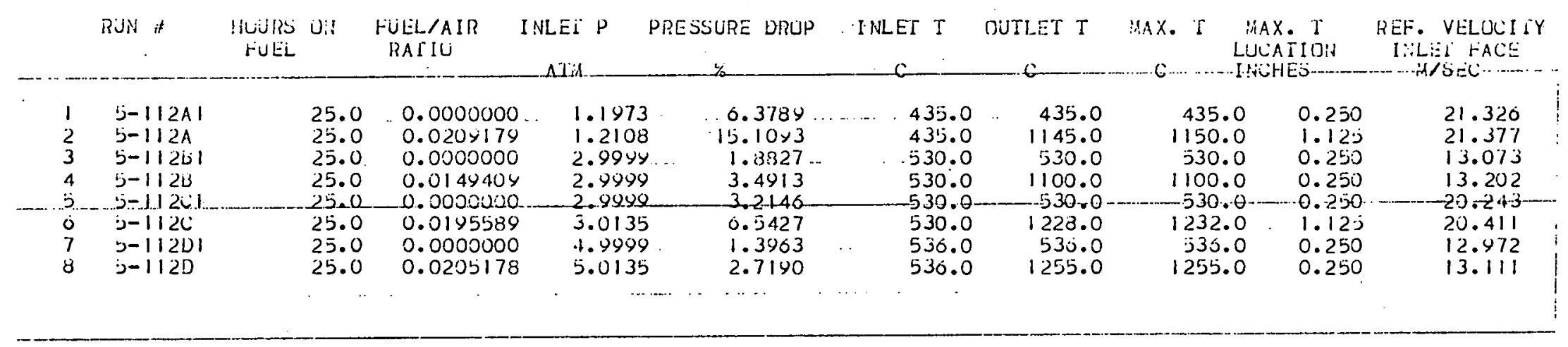




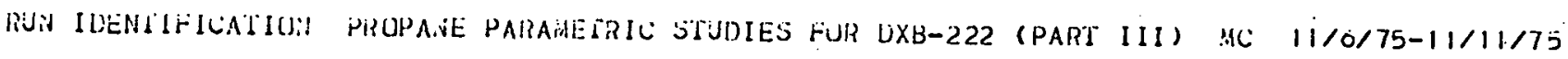

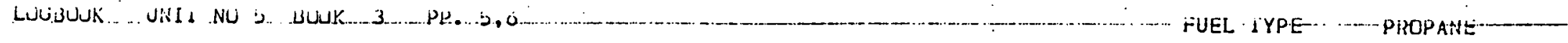

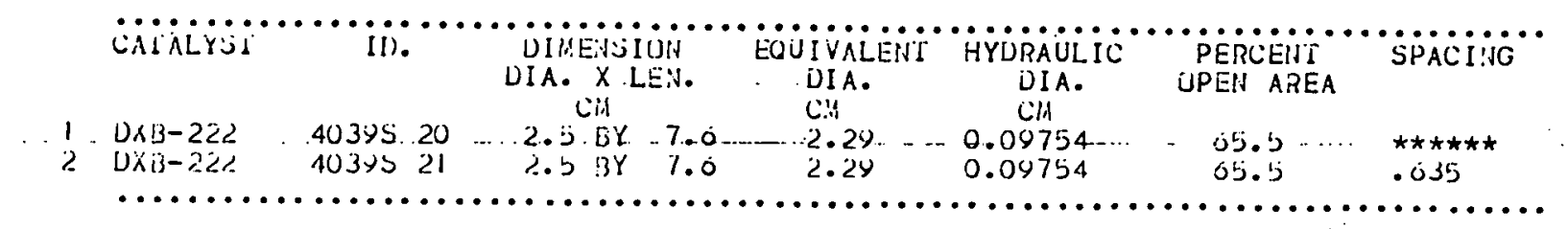

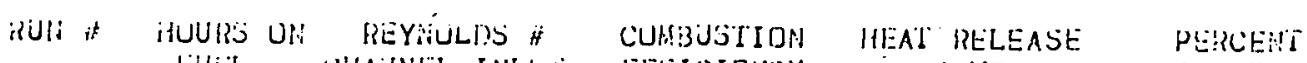
HULL LIAATNEL INLLI EFFICIENCY RAIE ADIABATCITY

HC CXYAUSL GASES KCALAHR-GHZ-AITH

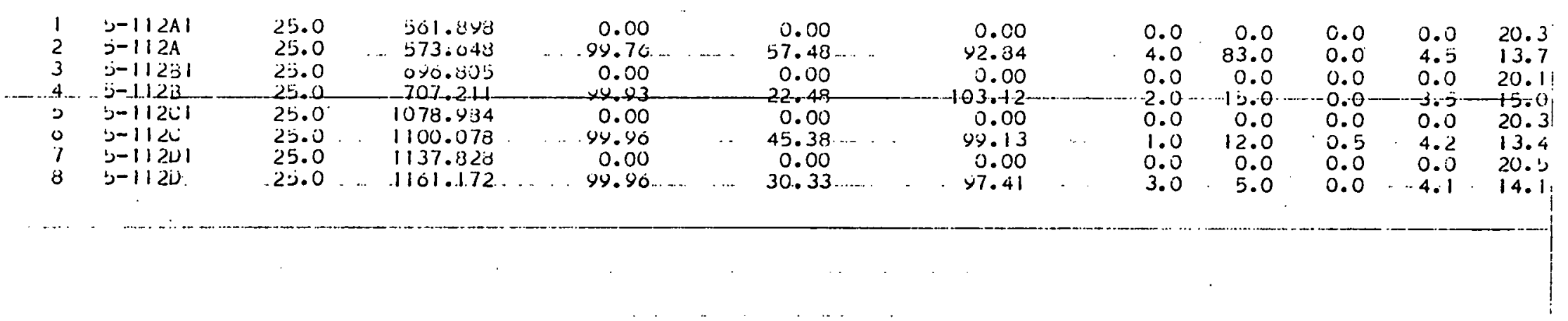




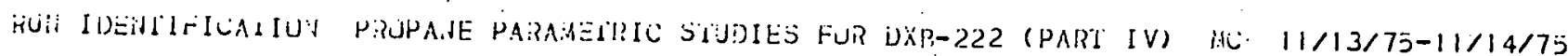

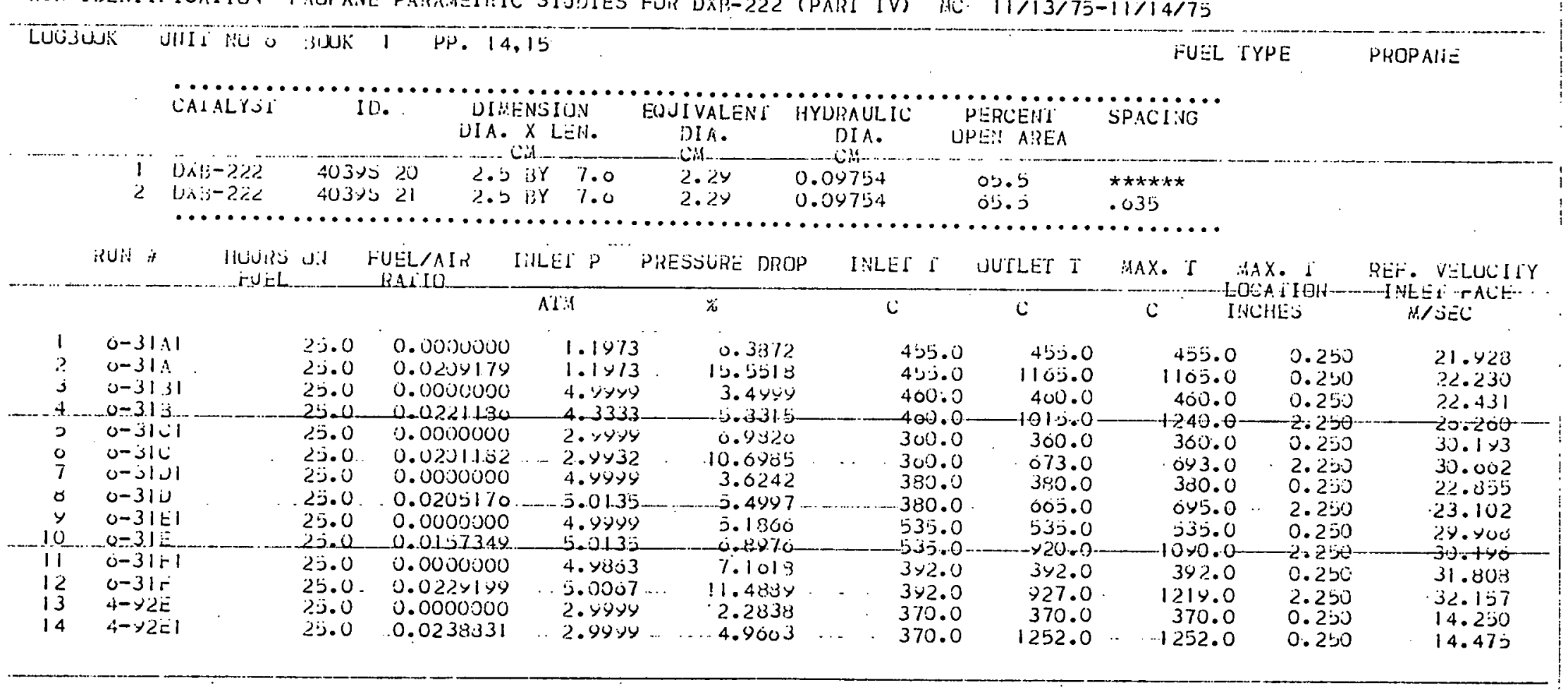




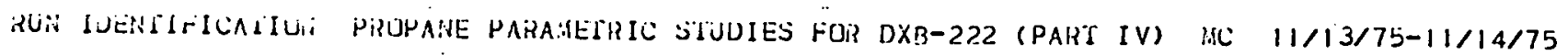

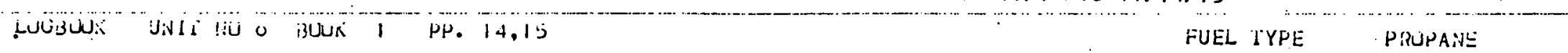

\begin{tabular}{|c|c|c|c|c|c|c|}
\hline CNAALY:SI & IL. & $\begin{array}{l}\text { JIAEN IUH } \\
\text { UIA. } \times \text { LEII. }\end{array}$ & $\begin{array}{c}\text { EOUIVALEili } \\
\text { DIA. }\end{array}$ & $\begin{array}{c}\text { IYYDRAULIC } \\
\text { DIA. }\end{array}$ & $\begin{array}{l}\text { PEPCENI } \\
\text { OPEN AZSEA }\end{array}$ & SPACING \\
\hline $\begin{array}{l}x i-222 \\
x i-222\end{array}$ & $\begin{array}{lll}403 y S & 20 \\
40 j y S j & 21\end{array}$ & $\begin{array}{lll}2.5 & 3 Y & 7 . \\
2.5 & B Y & 7 .\end{array}$ & $\begin{array}{l}2.2 y \\
2.2 y\end{array}$ & $\begin{array}{l}0.0 \times 754 \\
0.0 \times 754\end{array}$ & $\begin{array}{l}05.5 \\
05.5\end{array}$ & $\begin{array}{l}\star \star \star \star \star x \\
.035\end{array}$ \\
\hline
\end{tabular}

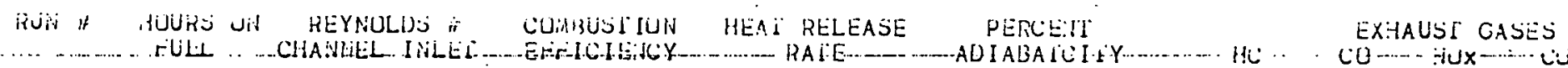

$\%$ KCAL/HRC CISAIH

\begin{tabular}{|c|c|c|c|c|c|c|c|c|c|c|c|}
\hline $\begin{array}{l}1 \\
2 \\
3 \\
\end{array}$ & $\begin{array}{l}0-3|A| \\
0-3 \mid A \\
0-3 \mid B]\end{array}$ & $\begin{array}{l}25.0 \\
25.0 \\
25.0\end{array}$ & $\begin{array}{r}50.003 \\
302.330 \\
2320.370 .\end{array}$ & $\begin{array}{r}0.00 \\
y=.74 \\
0.00 \\
\end{array}$ & $\begin{array}{r}0.00 \\
58.12 \\
-0.00\end{array}$ & $\begin{array}{r}0.00 \\
42.70 \\
-0.00\end{array}$ & $\begin{array}{l}0.0 \\
0.0 \\
0.0\end{array}$ & $\begin{array}{r}0.0 \\
102.0 \\
\ldots .0 .0\end{array}$ & $\begin{array}{l}0.0 \\
0.0 \\
0.0\end{array}$ & $\begin{array}{r}0.0 \\
4.3 \\
-0.0\end{array}$ & $\begin{array}{l}20.5 \\
14.0 \\
20.5\end{array}$ \\
\hline 4 & $u-3 \mid B$ & 25.0 & $237 i 3.344$ & 99.90 & 72.20 & 90.80 & 0.0 & 13.0 & 0.0 & 4.7 & 13.4 \\
\hline נ' & $0-3|c|$ & 20.0 & 2.411 .150 & 0.00 & 0.00 & 0.00 & 0.0 & 0.0 & 0.0 & 0.0 & 20.9 \\
\hline 0 & $0-31 c$ & 25.0 & 2459.0300 & 44.19 & 39.30 & पy. 02 & 7100.0 & 47.0 & 0.5 & 2.0 & 10.4 \\
\hline 7 & $0-3|1|$ & 25.0 & 23315.400 & 0.00 & 0.00. & 0.00 & 0.0 & 0.0 & 0.0 & 0.0 & 20.0 \\
\hline 8 & $0-310$ & 25.0 & 2944.023 & 38.29 & 25.35 & 100.33 & 8000.0 & 07.0 & 1.0 & 2.0 & 17.5 \\
\hline$-\ldots$ & $.0-31 E 1$ & 25.0 & $2=34.1+3\}$ & 0.00 & -0.00 & -0.00 & 0.0 & 0.0 & & & $-20 .-4$ \\
\hline 10 & $0-31=$ & 25.0 & 2075.050 & $y y .23$ & 53.41 & 40.51 & 4.0 & 220.0 & 0.0 & $2 \cdot y$ & 10.0 \\
\hline $\begin{array}{l}11 \\
12\end{array}$ & $\begin{array}{l}0-3 \mid r 1 \\
0-3 \mid r\end{array}$ & $\begin{array}{l}25.0 \\
25.0\end{array}$ & $\begin{array}{l}\sin 2.050 \\
3 y 11.54\end{array}$ & $\begin{array}{r}0.00 \\
y 4.83\end{array}$ & $\begin{array}{r}0.00 \\
100.80\end{array}$ & 0.00 & 0.0 & 0.0 & 0.0 & 0.0 & 20. \\
\hline 13 & $4-y 2 E$ & $\begin{array}{l}25.0 \\
25.0\end{array}$ & 1103.094 & $\begin{array}{r}94.83 \\
0.00\end{array}$ & $\begin{array}{r}100.80 \\
0.00\end{array}$ & $\begin{array}{r}.47 .98 \\
0.00\end{array}$ & $\begin{array}{l}4.0 \\
0.0\end{array}$ & $\begin{array}{r}02.0 \\
0.0\end{array}$ & 0.3 & 4.8 & 13.11 \\
\hline 14 & $4-У 2 E 1$ & 20.0 & 1134.247 & $9 . .94$ & 48.92 & 100.14 & 7.5 & 5.5 & 0.4 & 4.3 & 13.2 \\
\hline
\end{tabular}




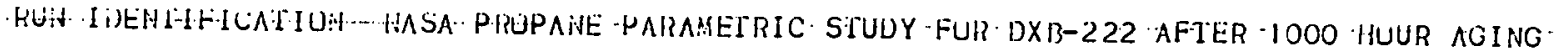

LUUDUUUK UNIT INU O BUIJK 1 PP. 30-37

\section{FUEL IYPE}

PIXPAILE

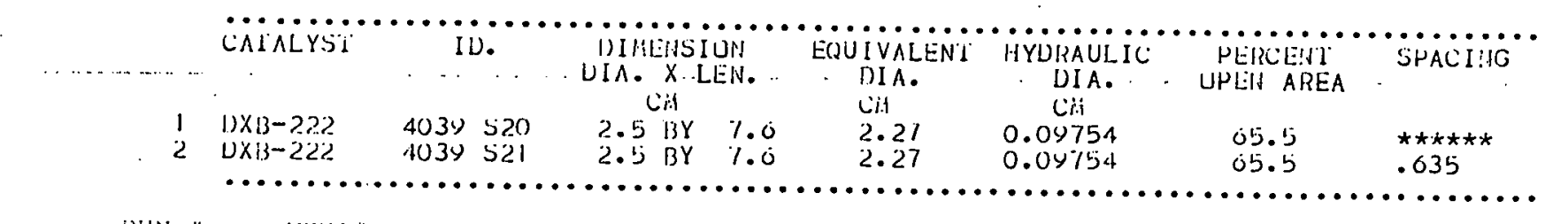

....... RUN ... . ... HUURS UN ... FUEL/AIK - INLEI. P . PRESSURE IIROP INLET T OUTLET T- MAX T

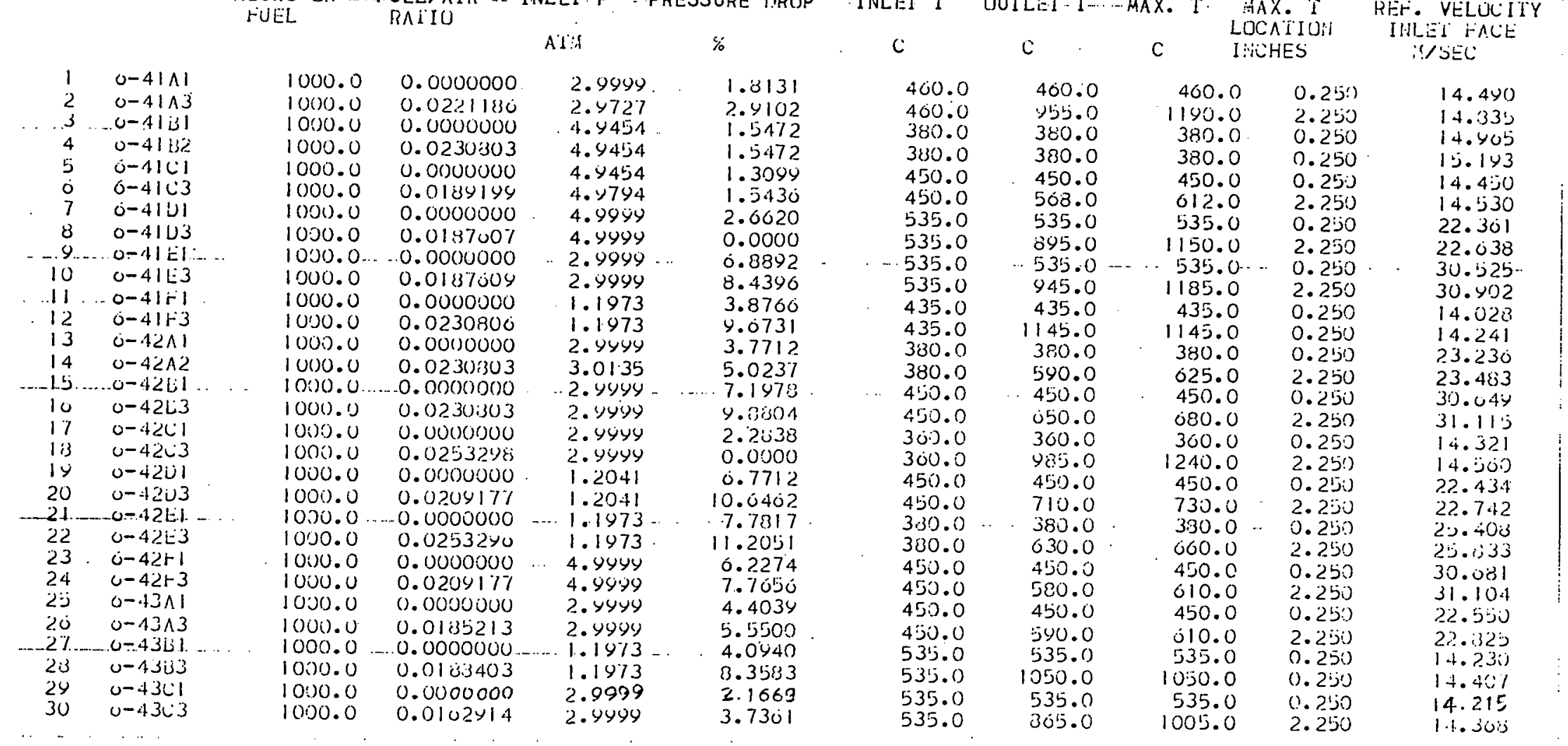




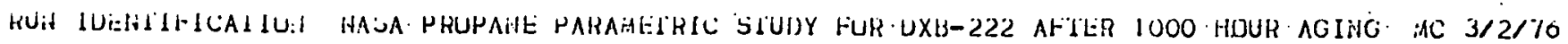

LUGBSUKK UHII HU O HUUK 1 PP. 30-37

FUEL TYPE

PIXOPANE

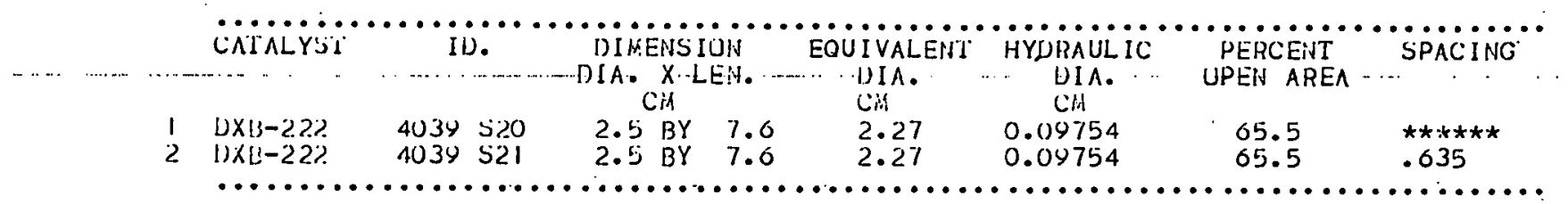

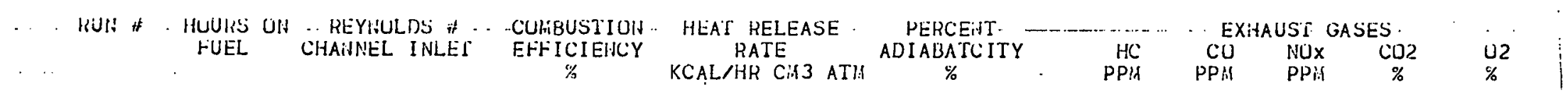

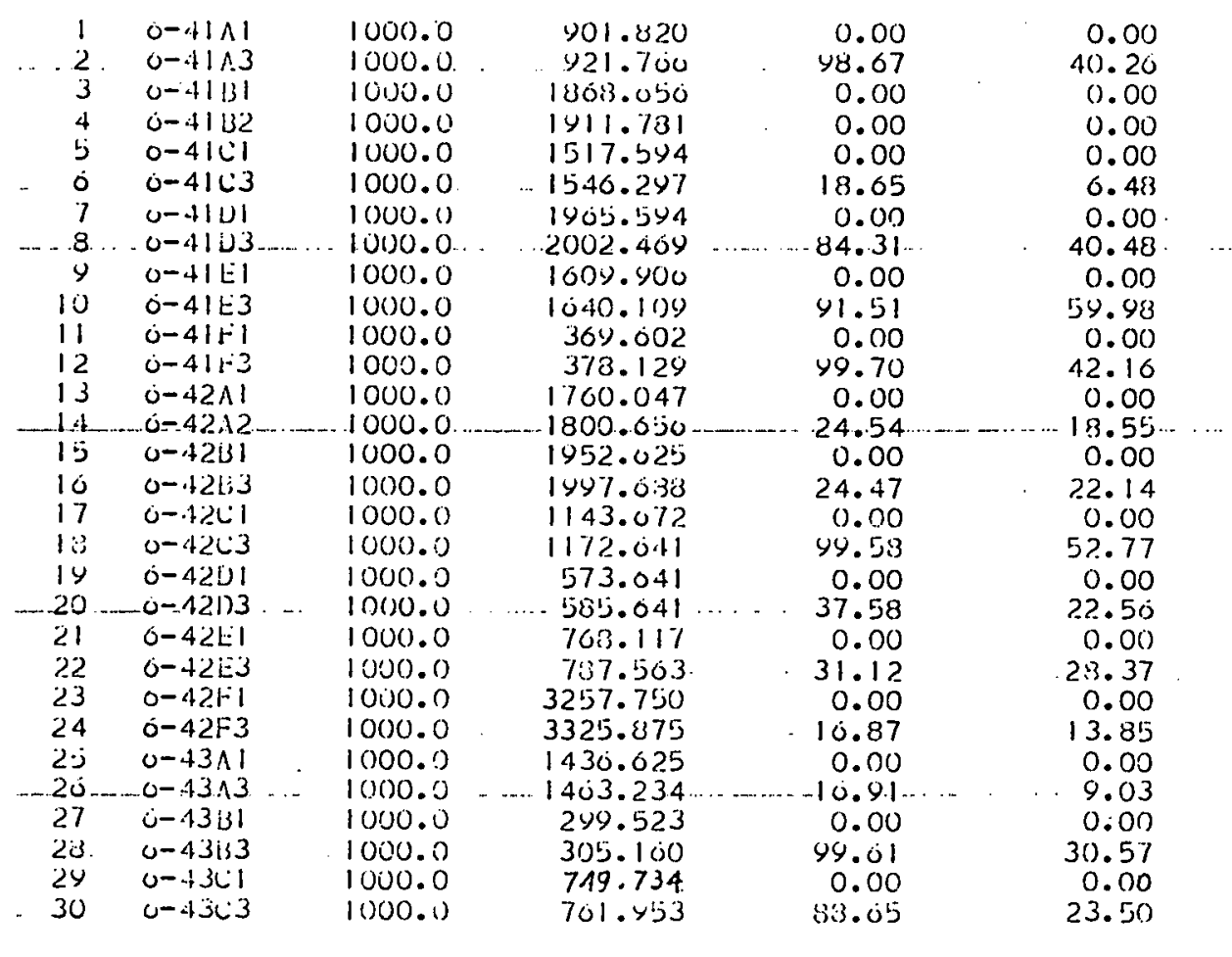

$\begin{array}{rrrr}0.00 & 0.0 & 0.0 & 0.0 \\ 81.84 & 42.0 & 432.0 & 1.3 \\ 0.00 & 0.0 & 0.0 & 0.0 \\ & 14000.0 & 0.0 & 0.0 \\ 0.00 & 0.0 & 0.0 & 0.0 \\ & 9750.0 & 37.0 & 1.3 \\ 0.00 & 0.0 & 0.0 & 0.0 \\ 0.00 & 1000.0 & 2000.0 & 1.3 \\ 0.0 & 0.0 & 0.0 & 0.0 \\ 0.00 & 460.0 & 1650.0 & 1.3 \\ 84.02 & 0.0 & 0.0 & 0.0 \\ 0.00 & 35.0 & 23.0 & 1.3 \\ & 0.0 & 0.0 & 0.0 \\ 0.00 & 11000.0 & 51.0 & 1.3 \\ & 0.0 & 0.0 & 0.0 \\ 0.00 & 11000.0 & 81.0 & 1.3 \\ 95.13 & 0.0 & 0.0 & 0.0 \\ 0.00 & 3.0 & 191.0 & 1.3 \\ 90.91 & 8250.0 & 0.0 & 0.0 \\ 0.00 & 0.0 & 0.0 & 1.3 \\ 47.30 & 11000.0 & 60.0 & 0.0 \\ 0.00 & 0.0 & 0.0 & 0.0 \\ & 11000.0 & 44.0 & 1.3 \\ 0.00 & 0.0 & 0.0 & 0.0 \\ & 9750.0 & 40.0 & 1.0 \\ 0.00 & 0.0 & 0.0 & 0.0 \\ 73.00 & 34.0 & 30.0 & 1.3 \\ 0.00 & 0.0 & 0.0 & 0.0 \\ 83.53 & 800.0 & 1125.0 & 1.3\end{array}$

0.0
0.0
0.0
0.7
0.0
3.0
0.0
3.0
4.0
1.0
0.0
1.3
0.0
3.0
1.0
0.0
1.3
0.0
0.0
0.0
0.0
3.0
0.0
3.2 


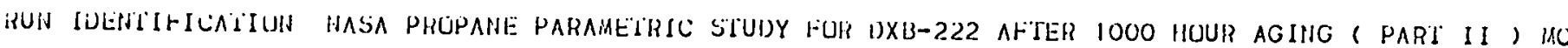

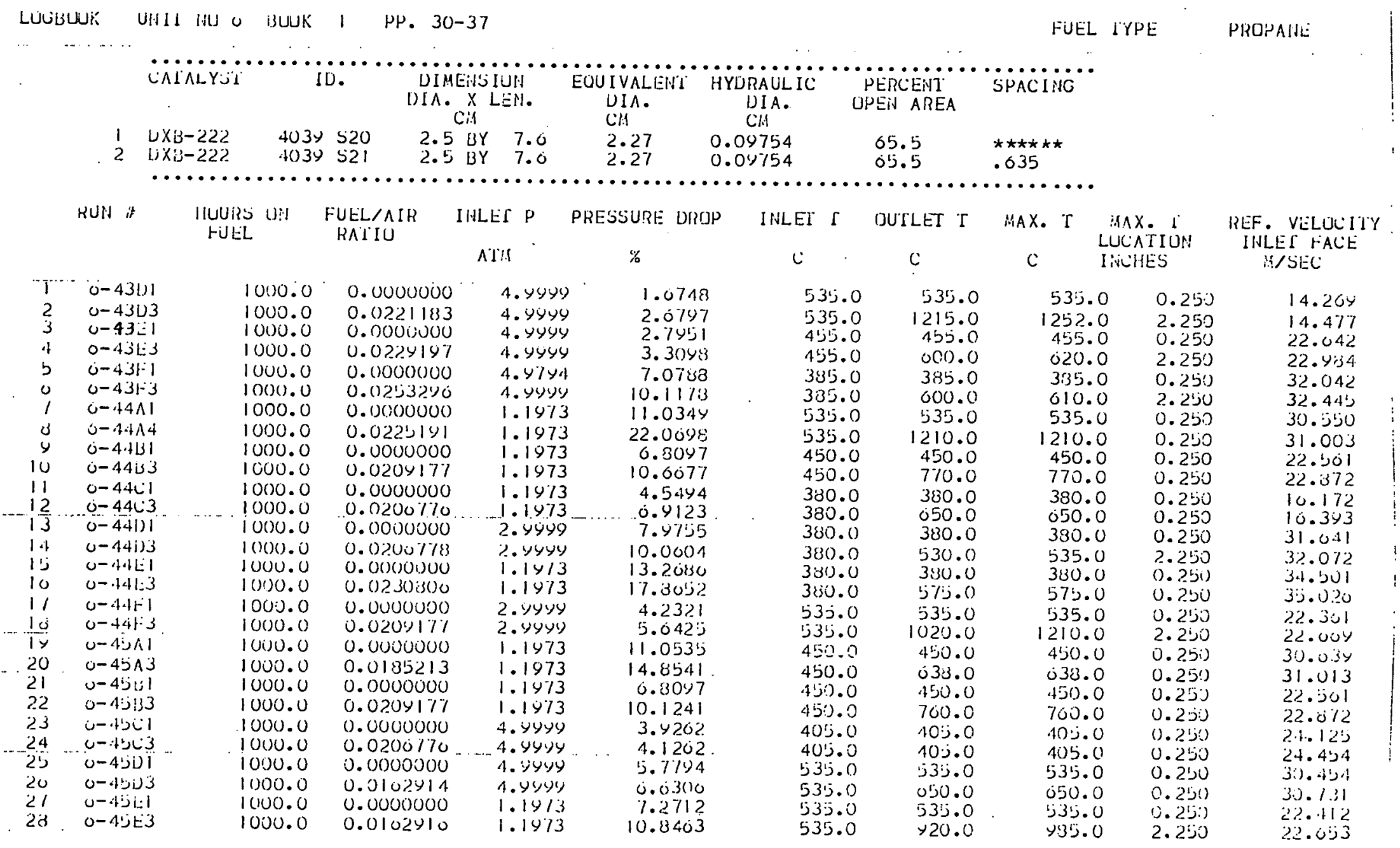




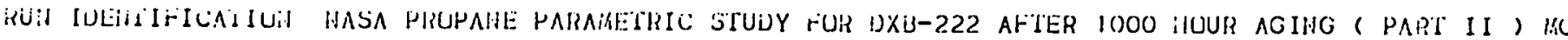

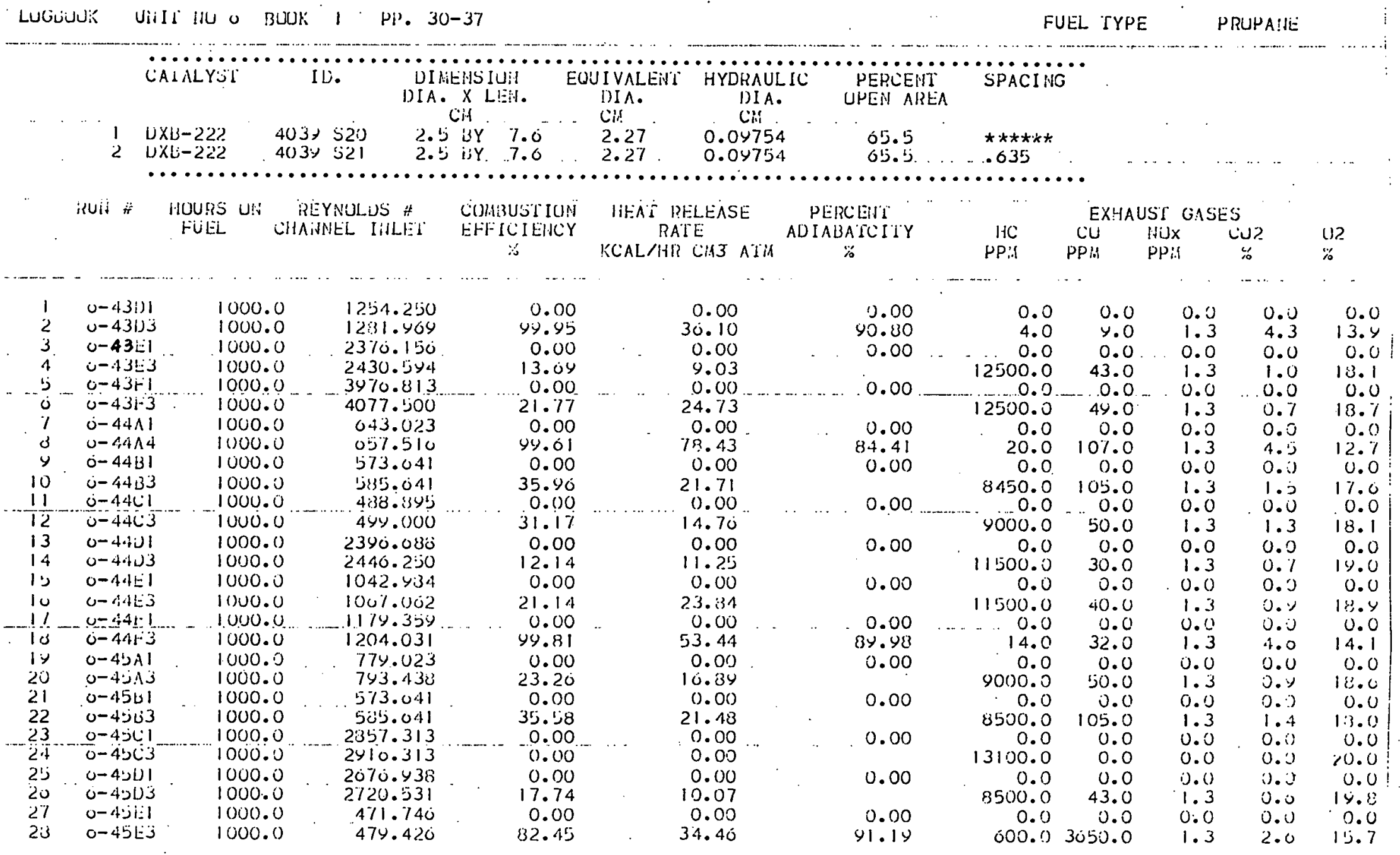




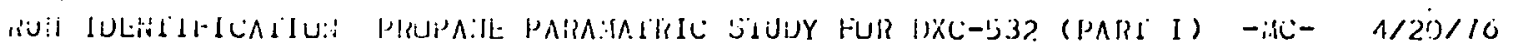

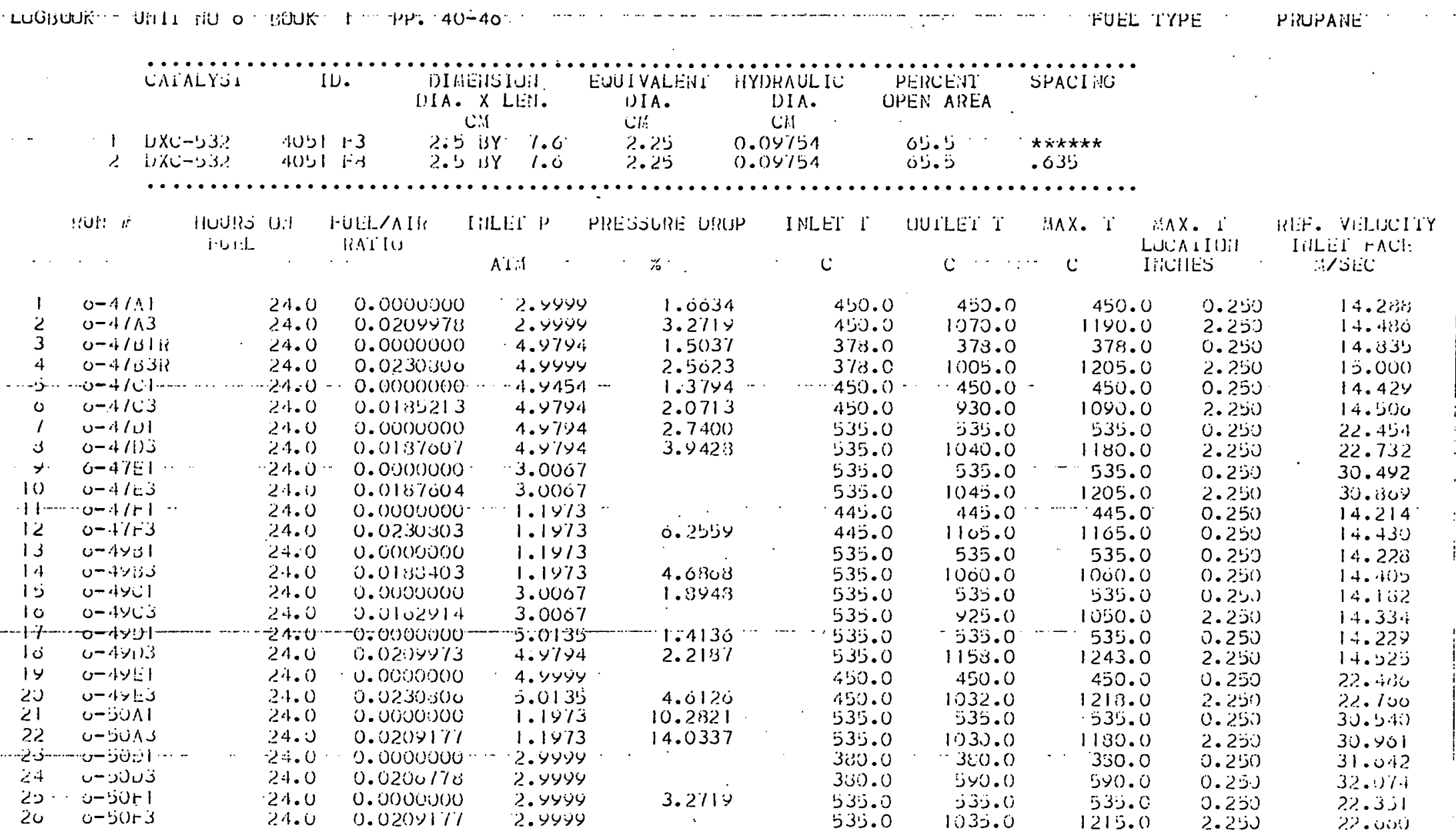




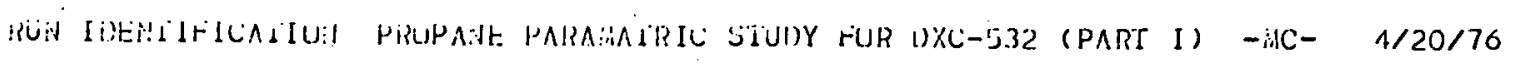

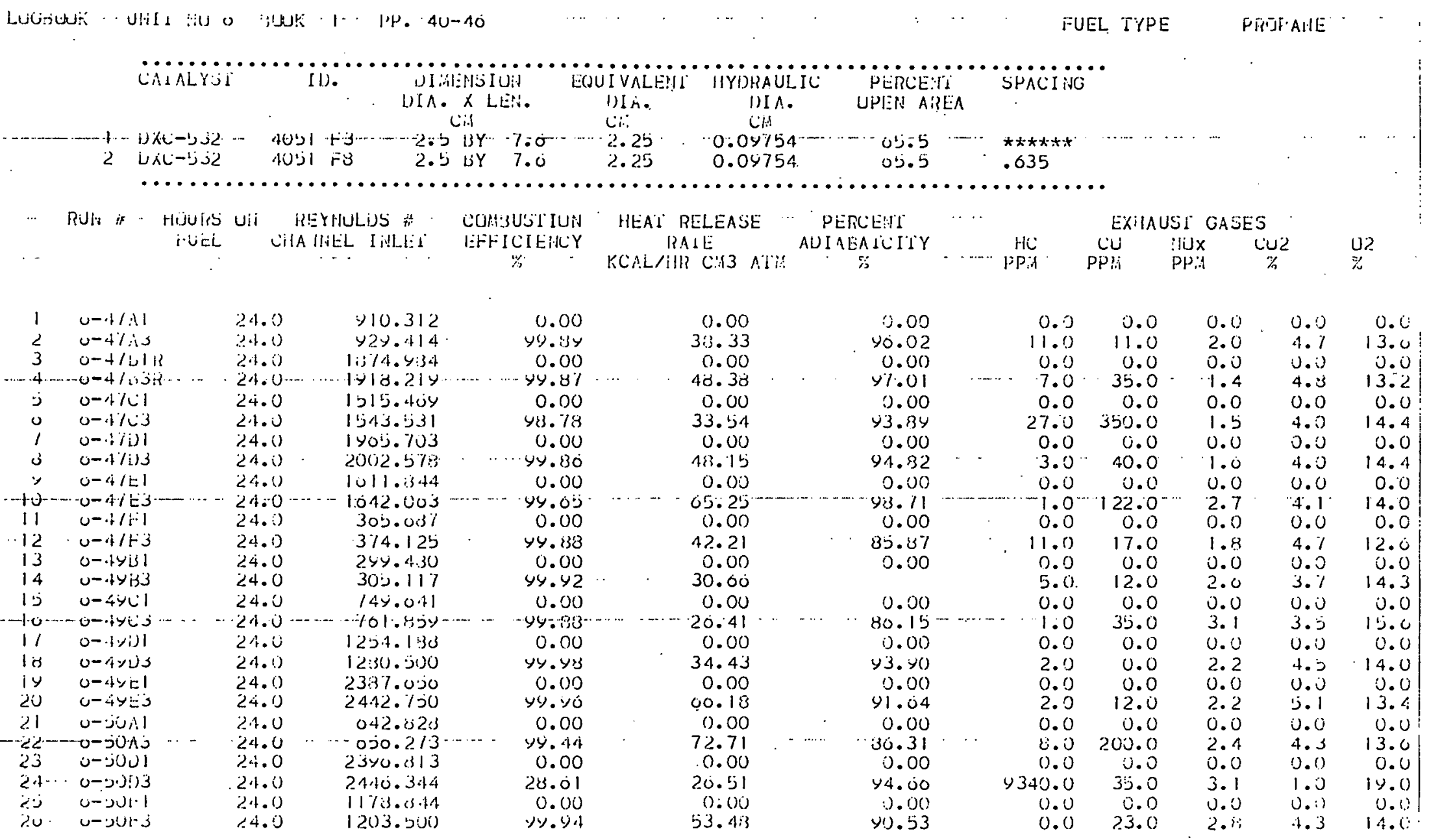




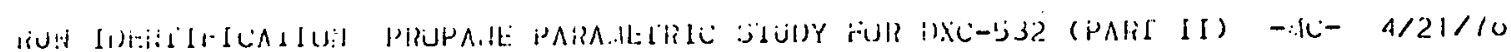

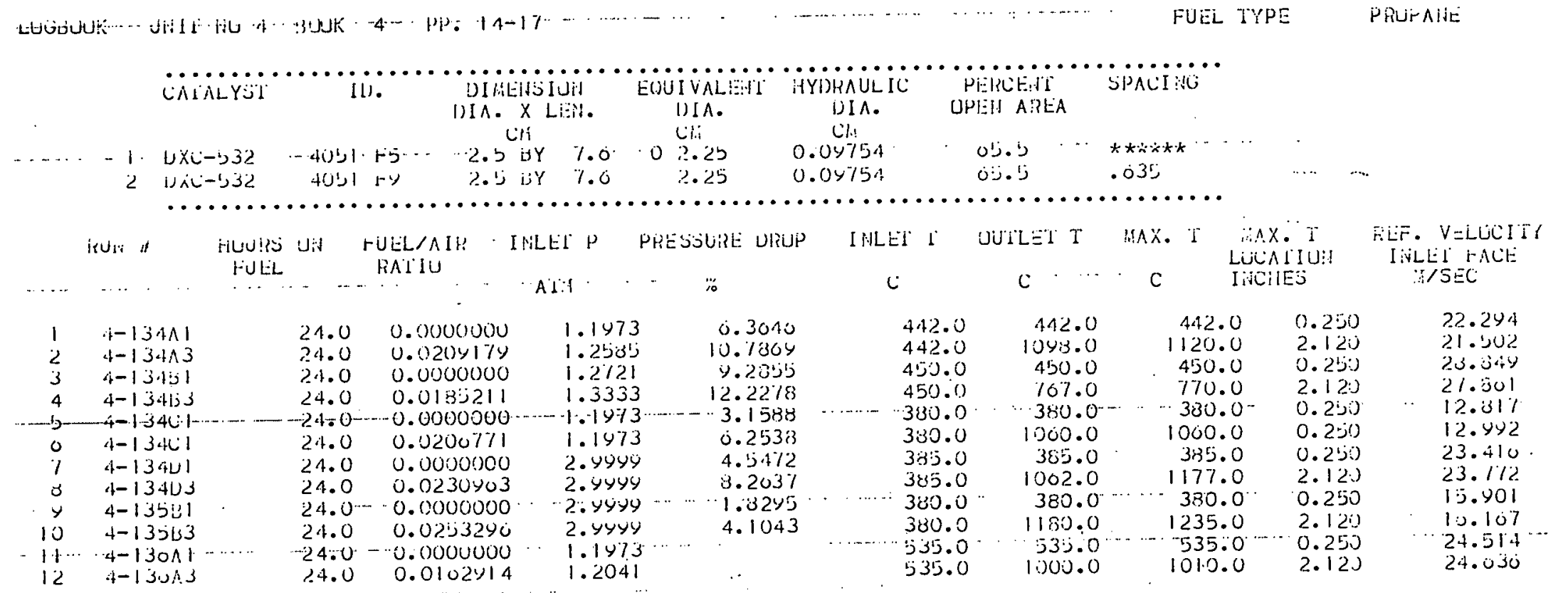




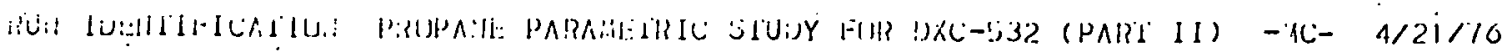

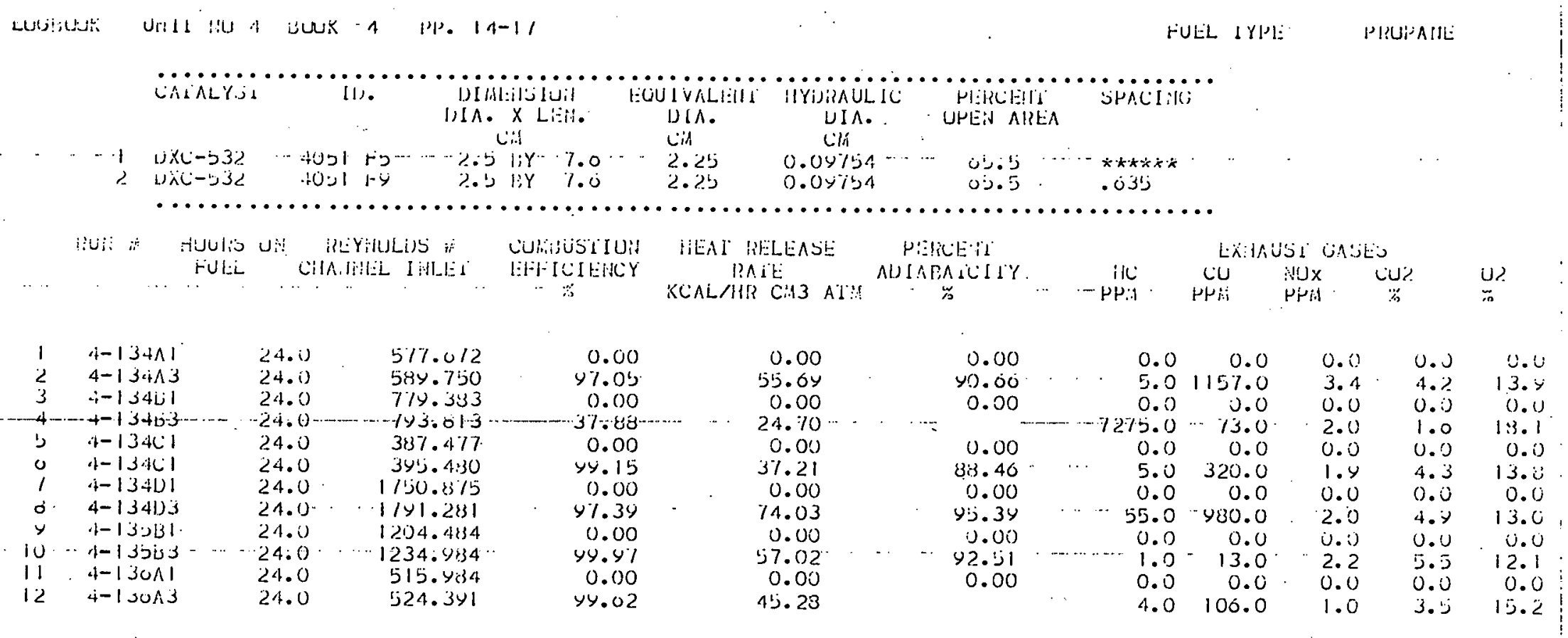




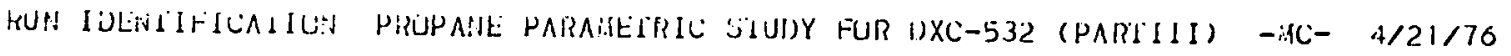

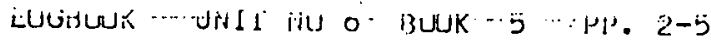

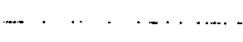

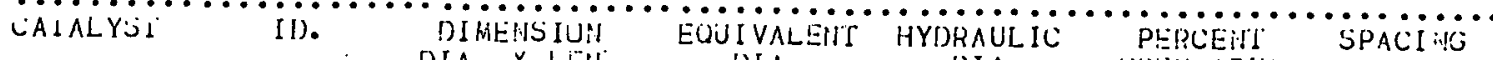

DIA. $X$ LEN. DIA. DIA. UPLE AREA

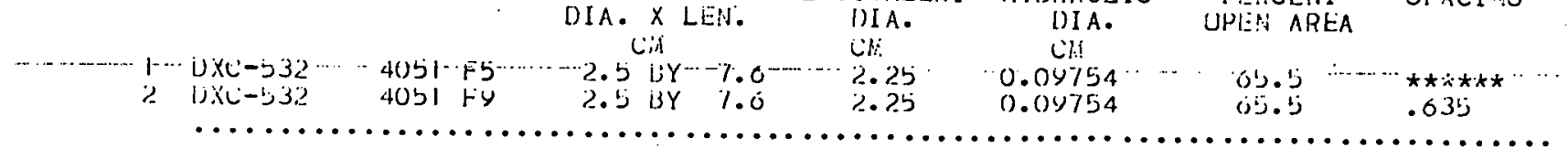

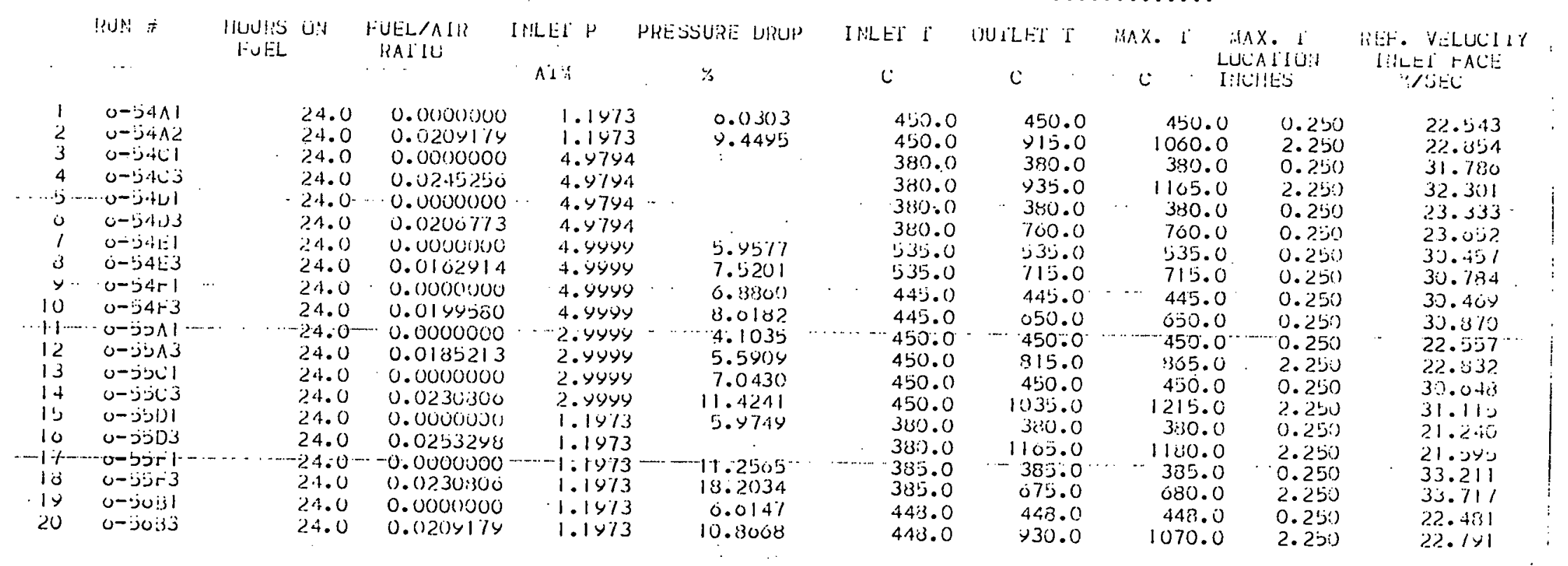




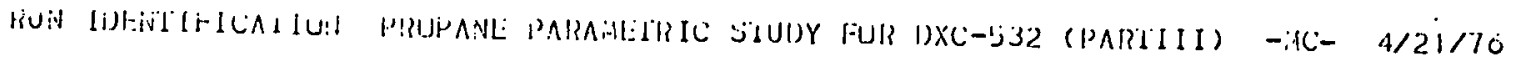

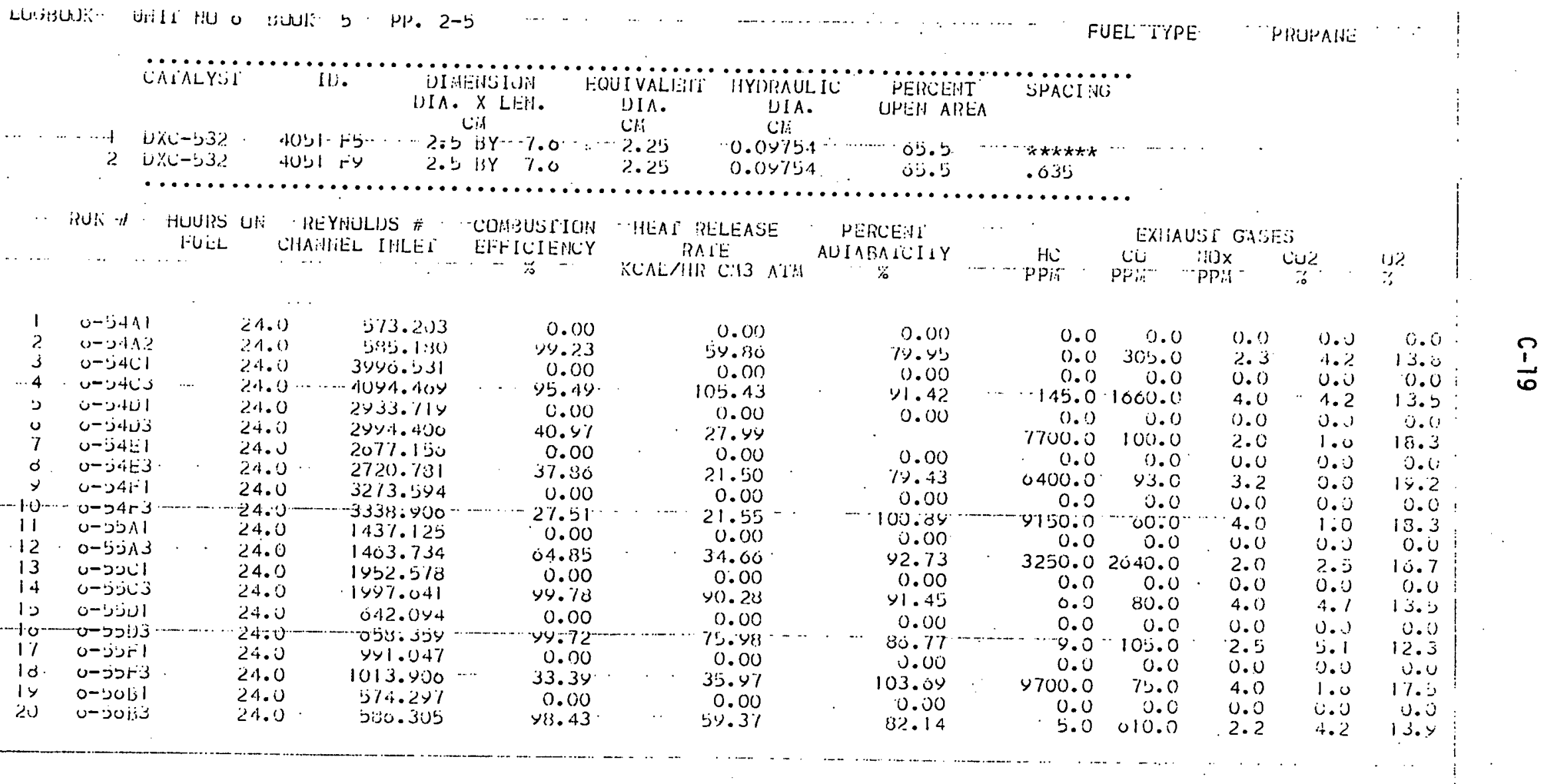


RUN IDENIIFICATION PROPANE PARAMEIRIC STUDIES FUR DXC-532 AFTER 1000 HOUR AGING - HC- 6/14/76

LUGUWK UHIT HU O BWW is PI'. 28,29,30

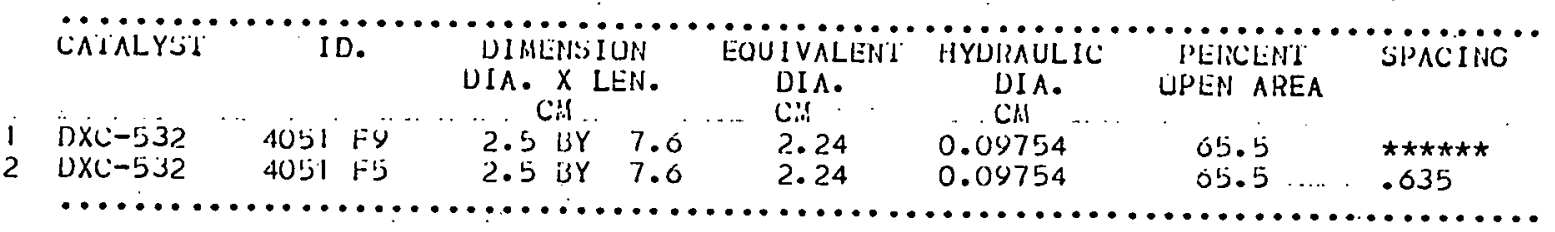

\begin{tabular}{|c|c|c|c|c|c|c|c|c|c|c|c|}
\hline & $\begin{array}{l}\text { RUI! it } \\
\text {. - }\end{array}$ & $\begin{array}{c}\text { HOURS UH } \\
\text { HUEL }\end{array}$ & $\begin{array}{l}\text { FUEL/AIR } \\
\text { HAIIU }\end{array}$ & $\begin{array}{l}\text { INLES } P \\
\text { ALIA }\end{array}$ & $\begin{array}{l}\text { PRESSURE DRUP } \\
\%\end{array}$ & $\begin{array}{c}\text { INLET } \Gamma \\
\mathrm{C}\end{array}$ & $\begin{array}{c}\text { UUTLET T } \\
c\end{array}$ & $\begin{array}{c}M \wedge x \\
c\end{array}$ & & $\begin{array}{l}\text { MAX. I } \\
\text { LOCA IUN } \\
\text { INCHES }\end{array}$ & $\begin{array}{l}\text { REF. VELUCITY } \\
\text { INLET FACE } . . . \\
\text { NVSEL. }\end{array}$ \\
\hline $\begin{array}{r}1 \\
2 \\
3 \\
4 \\
4 \\
13 \\
6 \\
7 \\
0 \\
4 \\
10 \\
11 \\
12 \\
13 \\
14\end{array}$ & $\begin{array}{l}0-00 A 1 \\
0-00 A 3 \\
0-00 B 1 \\
0-00 B 3 \\
0-00 C 1 \\
0-60 C 3 \\
0-00 D 1 \\
0-00 D 3 \\
0-00 E 1 \\
0-0013 \\
j-0011 \\
0-0013 \\
0-0001 \\
0-60 G 3\end{array}$ & $\begin{array}{l}1005.0 \\
1005.0 \\
1005.0 \\
1005.0 \\
1005.0 \\
1005.0 \\
1005.0 \\
1005.0 \\
1005.0 \\
1005.0 \\
1005.0 \\
1005.0 \\
1005.0 \\
1005.0\end{array}$ & $\begin{array}{l}0.0000000 \\
0.0204418 \\
0.0000000 \\
0.0230200 \\
0.0000000 \\
0.0253290 \\
0.0000000 \\
0.0187007 \\
0.0000000 \\
0.0209174 \\
0.0000000 \\
0.0209177 \\
0.0000000 \\
0.0209174\end{array}$ & $\begin{array}{l}2.4727 \\
3.0067 \\
1.1700 \\
1.2041 \\
3.0067 \\
3.0007 \\
1.1973 \\
1.2041 \\
1.1973 \\
1.2041 \\
3.0007 \\
3.0067 \\
5.0135 \\
4.9999\end{array}$ & $\begin{array}{r}1.7240 \\
1.9258 \\
3.5890 \\
4.1912 \\
1.8131 \\
2.0214 \\
3.4807 \\
4.0729 \\
9.4495 \\
10.5015 \\
3.2318 \\
3.6905 \\
1.3274 \\
1.4376\end{array}$ & $\begin{array}{l}450.0 \\
450.0 \\
450.0 \\
450.0 \\
380.0 \\
380.0 \\
535.0 \\
535.0 \\
535.0 \\
531.0 \\
535.0 \\
535.0 \\
5,35.0 \\
535.0\end{array}$ & $\begin{array}{r}450.0 \\
508.0 \\
450.0 \\
560.0 \\
380.0 \\
405.0 \\
535.0 \\
620.0 \\
535.0 \\
030.0 \\
535.0 \\
598.0 \\
535.0 \\
605.0\end{array}$ & 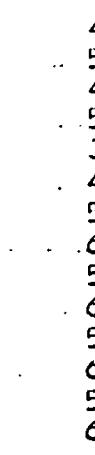 & $\begin{array}{l}450.0 \\
508.0 \\
450.0 \\
560.0 \\
330.0 \\
41.0 .0 \\
535.0 \\
620.0 \\
535.0 \\
650.0 \\
535.0 \\
618.0 \\
535.0 \\
615.0\end{array}$ & 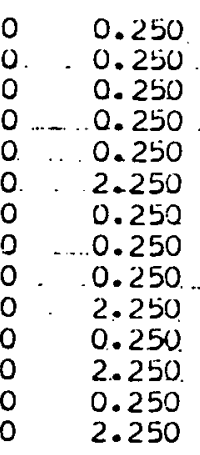 & 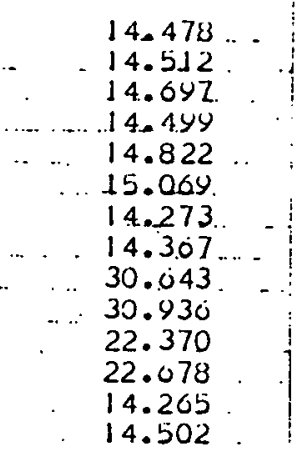 \\
\hline
\end{tabular}


RUN IDENIIFILATIUN PRUPANE PARAMETRIC STUDIES FO! UXC-532 AFIER 1000 HOUR AGING -MC- 6/14/70

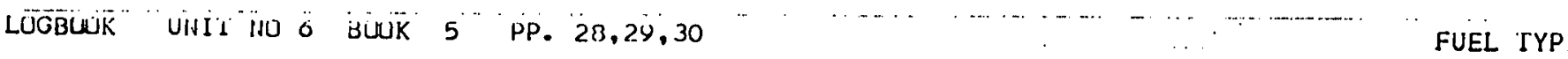

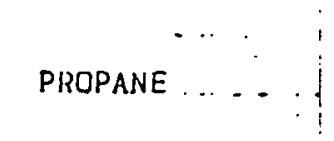

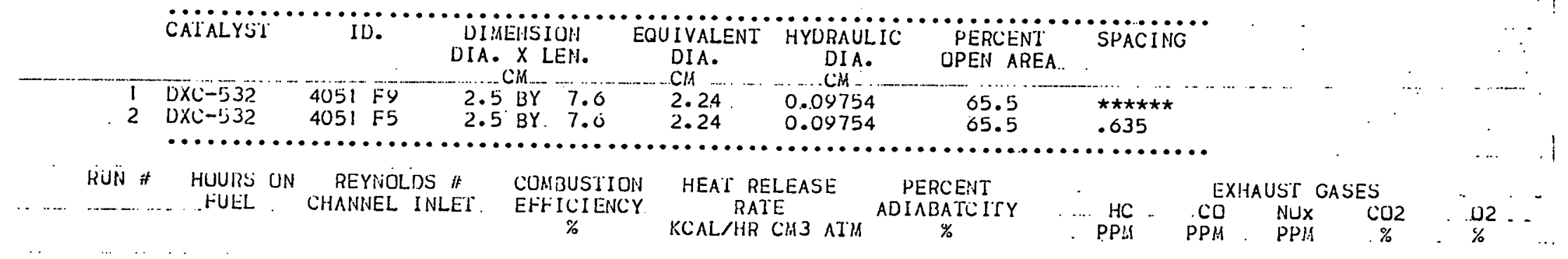

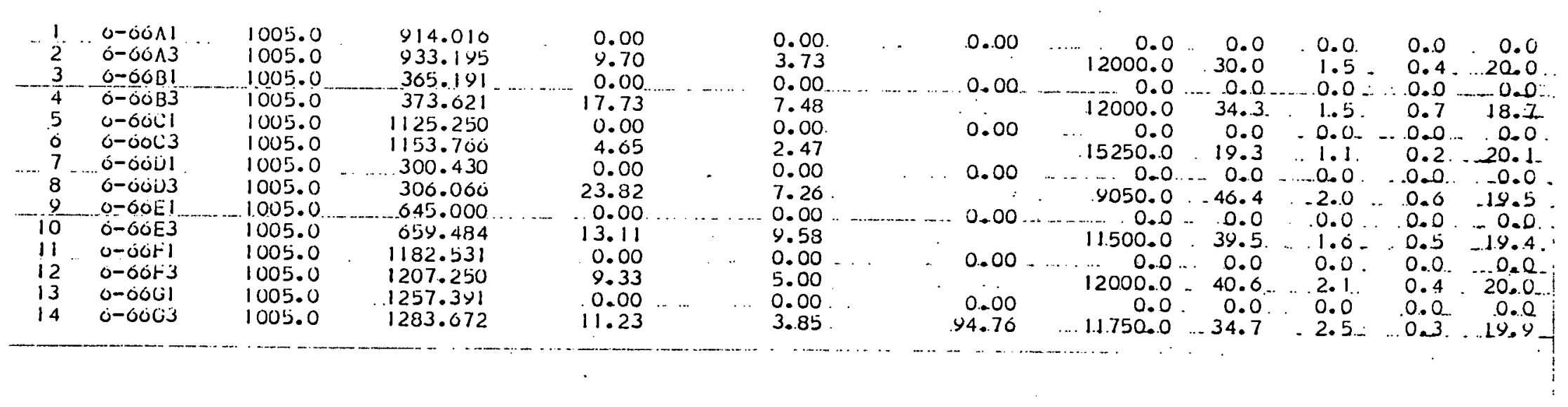


D-1

APPENDIX D

DETAILS OF GRAPHICAL ANALYSIS

OF PROPANE PARAMETRIC DATA FOR

DXB-222 AND DXC-532 
In the analysis of the results from the propane parametrics on catalyst cores DXB-222 and DXC-532, an extensive attempt was made to obtain a suitable graphical representation of the propane combustion efficiency as a function of the four main control variables (i.e., air preheat temperature, operating pressure, reference velocity and adiabatic flame temperature). The standard graphical techniques considering first, second and third order interactions were unsuccessfut. However, a plotting routine considering average responses proved to be quite successful. For the sake of completeness in this report, the graphical analysis for the propane combustion efficiency on catalyst core DXB-222 is presented. Similar analyses were made with the data on combustion efficiency of DXC-532 and only the plots of average responses clearly represented the data.

\section{A. FIRST ORDER INTERACTIONS.}

The initial analysis involved plotting the propane combustion efficiency from the initial parametrics on catalyst core DXB-222 as a function of the main control variables. Figures $D-1$, $D-2, D-3$ and $D-4$ indicate that no satisfactory presentation of the data is possible based on the first order interactions.

\section{B. HIGH ORDER INTERACTIONS}

Since a first order or non-interacting combination of variables proved unsuccessfur, a number of second and third order combinations of variables were tried with varying degrees of success. 
Figure D-1 Combustion Efficiency Versus Air Preheat Temperature For Catalyst Core DXB-222 (Initial Propane Parametric).

\section{Legend}

$\odot \quad 1.2 \mathrm{~atm} .\left(1.21 \times 10^{5} \mathrm{~N} / \mathrm{M}^{2}\right)$

$\triangle 3$ atm. $\left(3.04 \times 10^{5} \mathrm{~N} / \mathrm{M}^{2}\right)$

๑ $5 \mathrm{~atm} .\left(5.06 \times 10^{5} \mathrm{~N} / \mathrm{M}^{2}\right)$

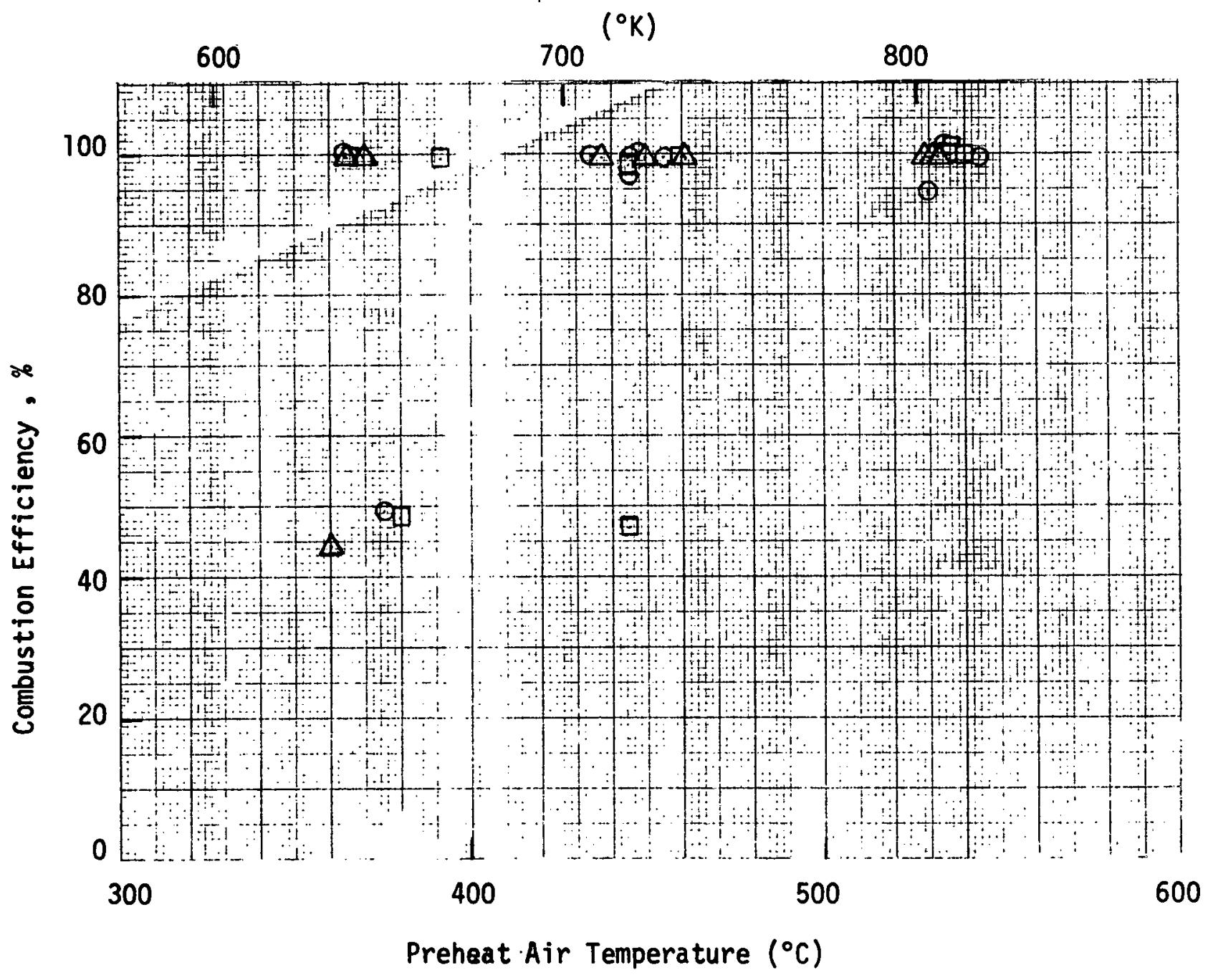




\section{D-4}

Figure D-2 Combustion Efficiency Versus Reference Velocity for Catalyst Core DXB-222

(Initial Propane Parametric).

Legend

$\odot 1.2 \mathrm{~atm} .\left(1.21 \times 10^{5} \mathrm{~N} / \mathrm{M}^{2}\right)$

$\triangle 3 \mathrm{~atm} .\left(3.04 \times 10^{5} \mathrm{~N} / \mathrm{M}^{2}\right)$

口 $5 \mathrm{~atm} .\left(5.05 \times 10^{5} \mathrm{~N} / \mathrm{M}^{2}\right)$

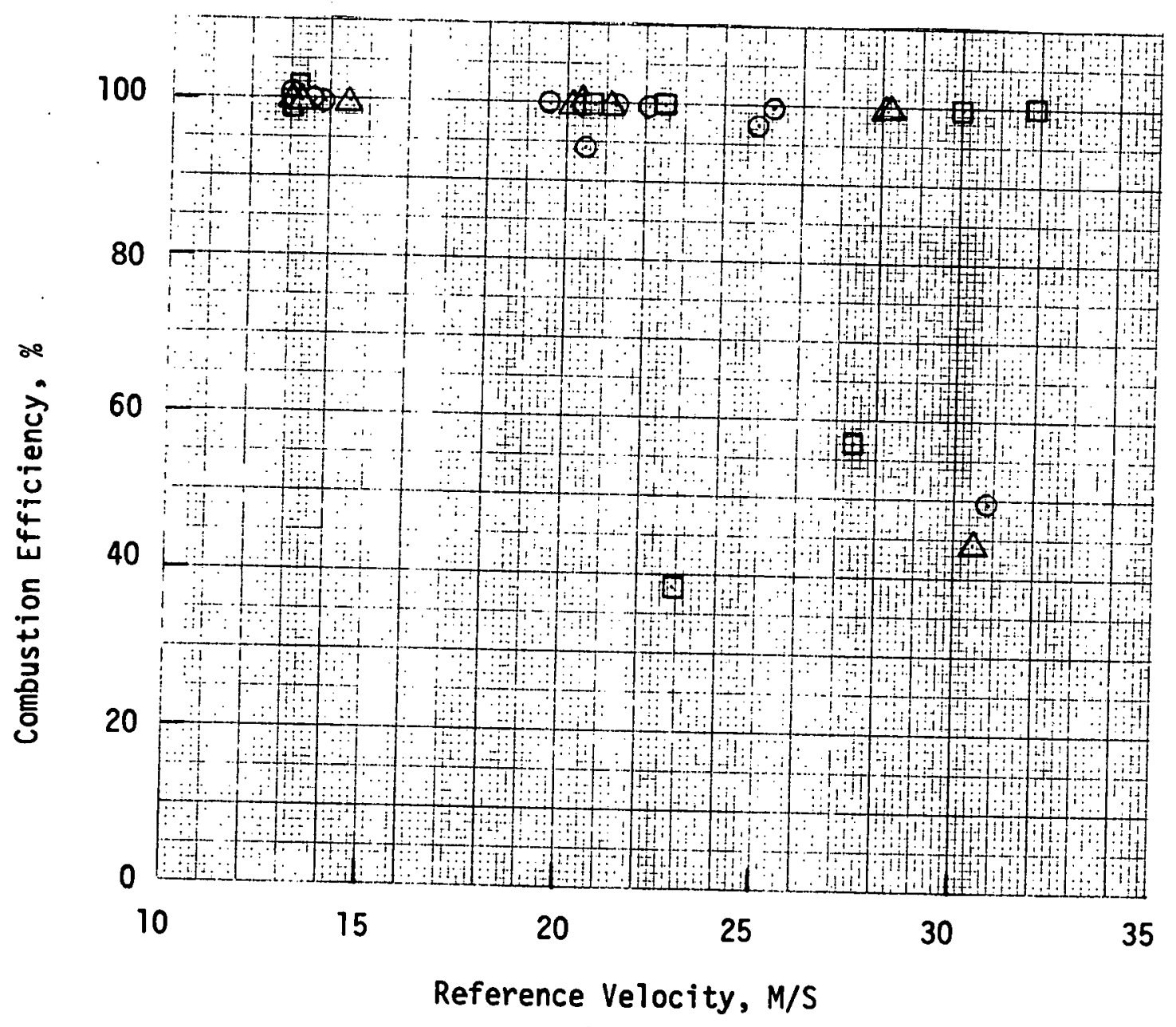


Figure D-3 Combustion Efficiency Versus Operating Pressure For Catalyst Core DXB-222

(Initial Propane Parametric).

\section{Legend}

$\odot 1.2 \mathrm{~atm} .\left(1.21 \times 10^{5} \mathrm{~N} / \mathrm{M}^{2}\right)$

$\triangle 3 \mathrm{~atm} .\left(3.04 \times 10^{5} \mathrm{~N} / \mathrm{M}^{2}\right)$

๑5 atm. $\left(5.05 \times 10^{5} \mathrm{~N} / \mathrm{M}^{2}\right)$

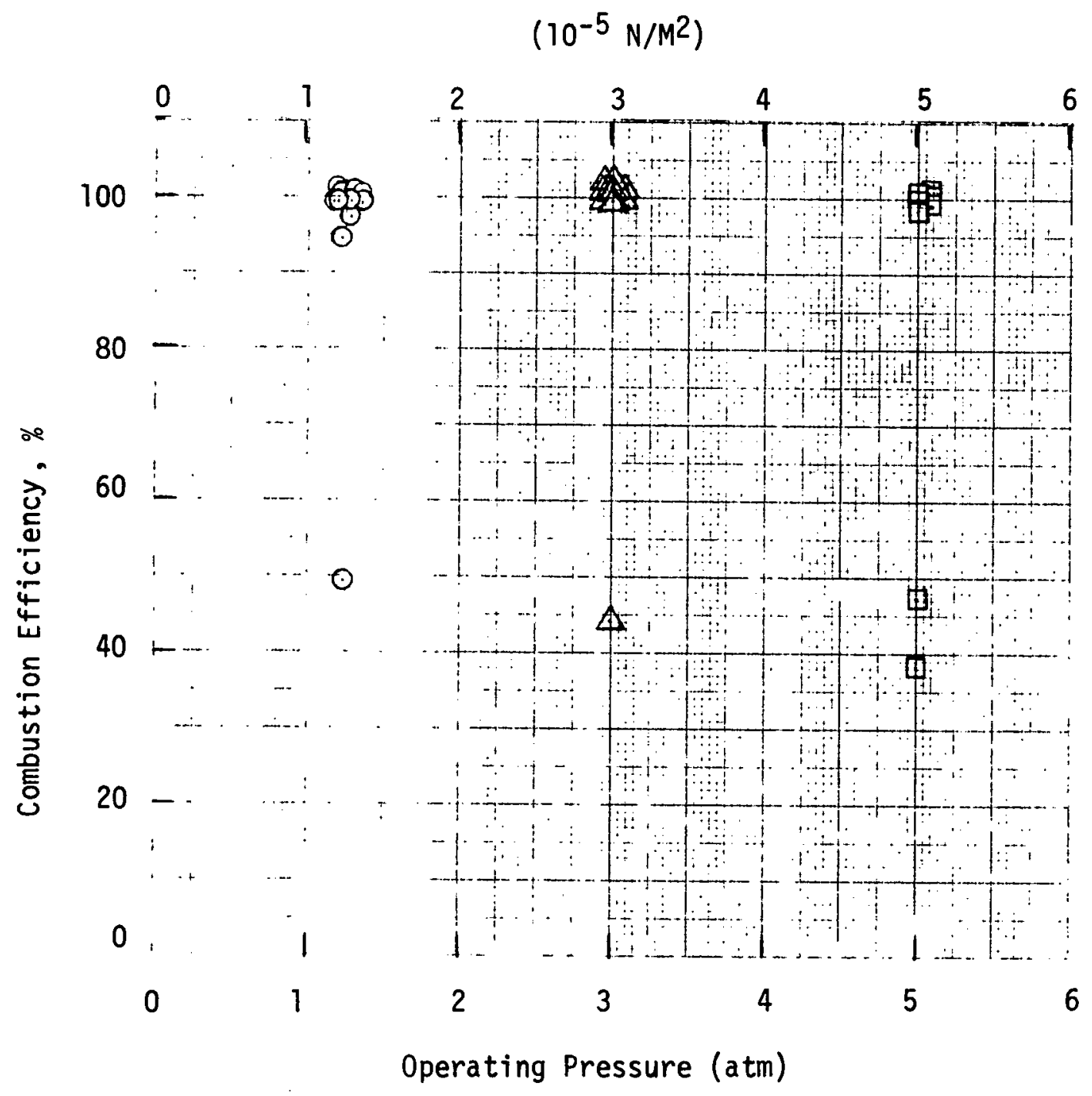


Figure D-4 Combustion Efficiency Versus Adiabatic Operating Temperature For Catalyst Core DXB-222 (Initial Propane Parametric)!.

\section{$\underline{\text { Legend }}$}

$\odot \quad 1.2 \mathrm{~atm} .\left(1.21 \times 10^{5} \mathrm{~N} / \mathrm{M}^{2}\right)$

$\triangle 3 \mathrm{~atm} .\left(3.04 \times 10^{5} \mathrm{~N} / \mathrm{M}^{2}\right)$

․ $5 \mathrm{~atm} .\left(5.06 \times 10^{5} \mathrm{~N} / \mathrm{M}^{2}\right)$

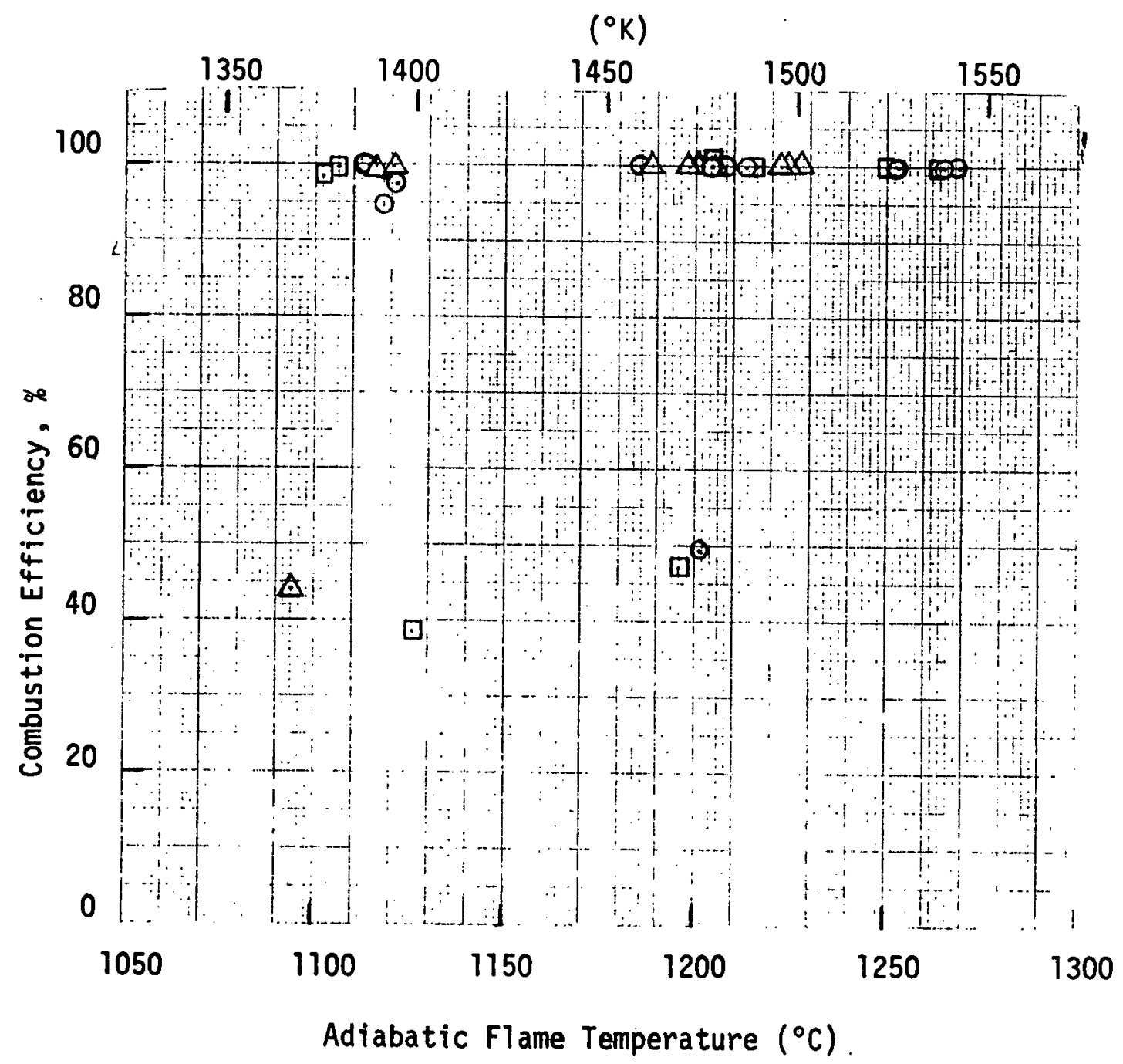


The best representation of the data is shown in Figure $\dot{0}-5$, which is a plot of propane combustion efficiency versus the product of the air preheat temperature and the adiabatic flame temperature divided by the reference velocity. Again, this graphical presentation has an overlapping region below abscissa values of $40,000{ }^{\circ} \mathrm{K} 2 / \mathrm{M} / \mathrm{S}$. Above this region, high combustion efficiency is depicted but below 40,000 ${ }^{\circ} K^{2} / M / S$, multiple values are depicted.

\section{AVERAGE RESPONSES}

A plotting routine which proved to be most successful involved plotting the average response of combustion efficiency at each of the true levels of a single control variable. This, in effect, neglects the simultaneous changes that occur in the other three control variables. The examination of the average responses from a statistical experimental design is a common technique used to determine significant trends of the responses versus functions of the control variables.

The plots showing the average responses are shown in Figures D-6 and D-7. This technique gives the clearest graphical interpretation of the results from the propane parametrics. The response of average combustion efficiency to air preheat, reference velocity and adiabatic operating temperature are similar to results found in previous studies (ref. 1, 2). Operating pressure appears to have a minor effect as shown. 
Figure D-5 Combustion Efficiency Versus Combinded Independent Variables for Catalyst Core DXB-222.

(Initial Propane Parametric)

Note: The numbers designate Run Serials.

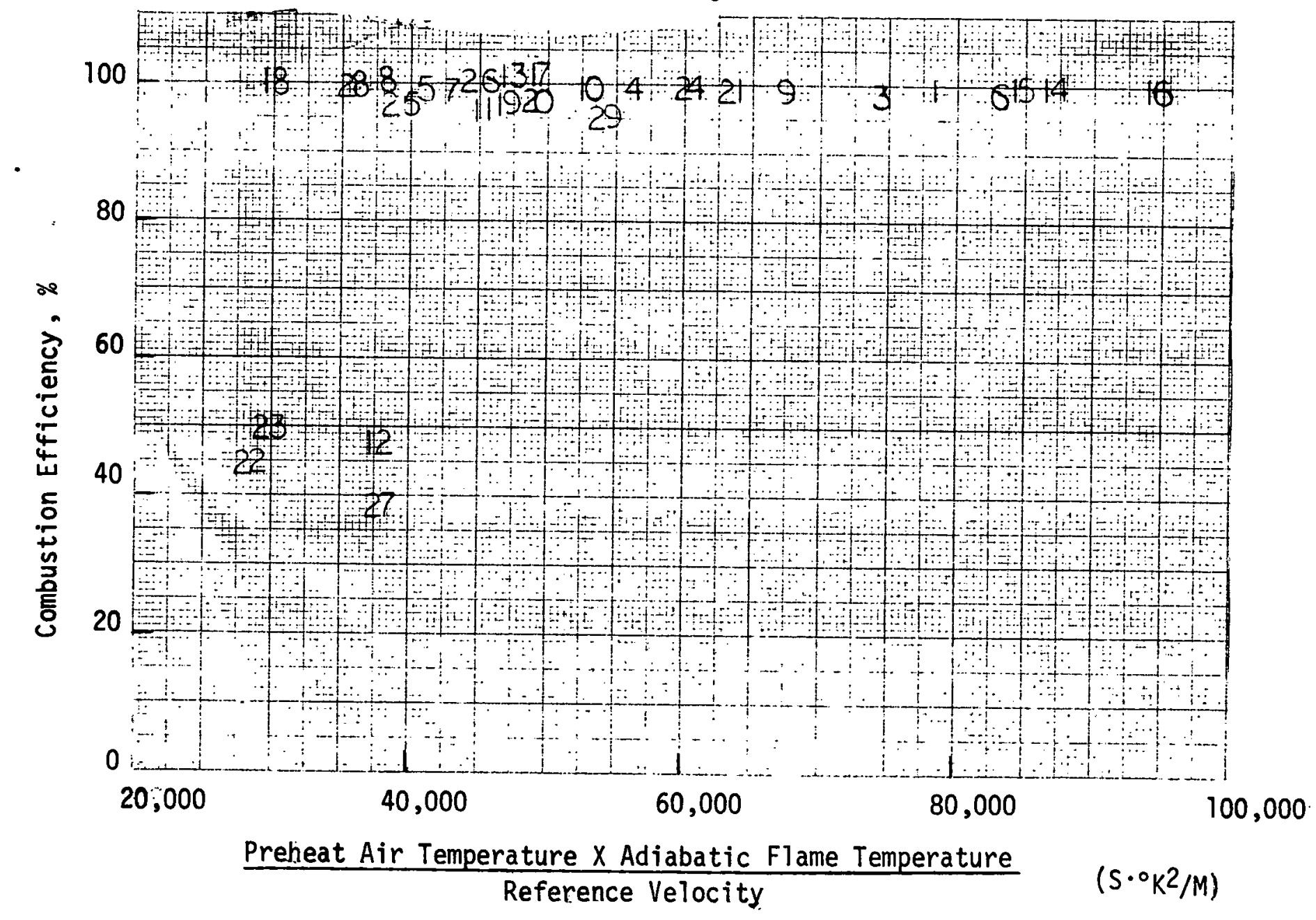


Figure D-6 Averaged Response of Combustion Efficiency Versus Preheat Air Temperature And Operating Pressure For Catalyst Core DXB-222 (Initial Propane Parametric).

$\left({ }^{\circ} \mathrm{K}\right)$

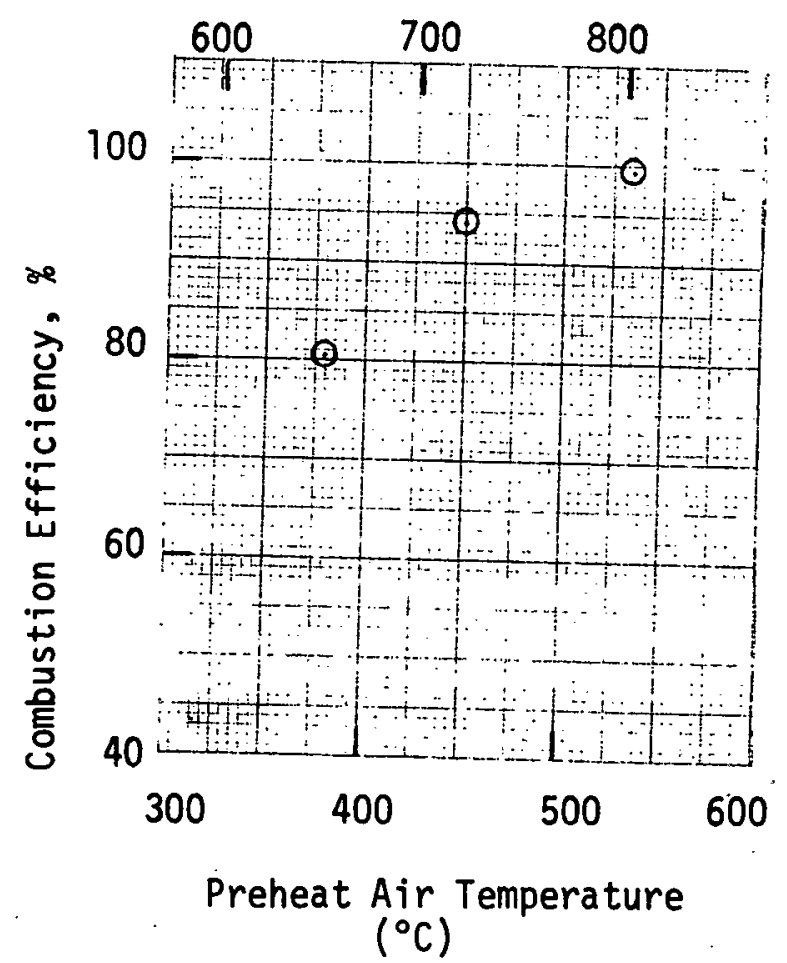

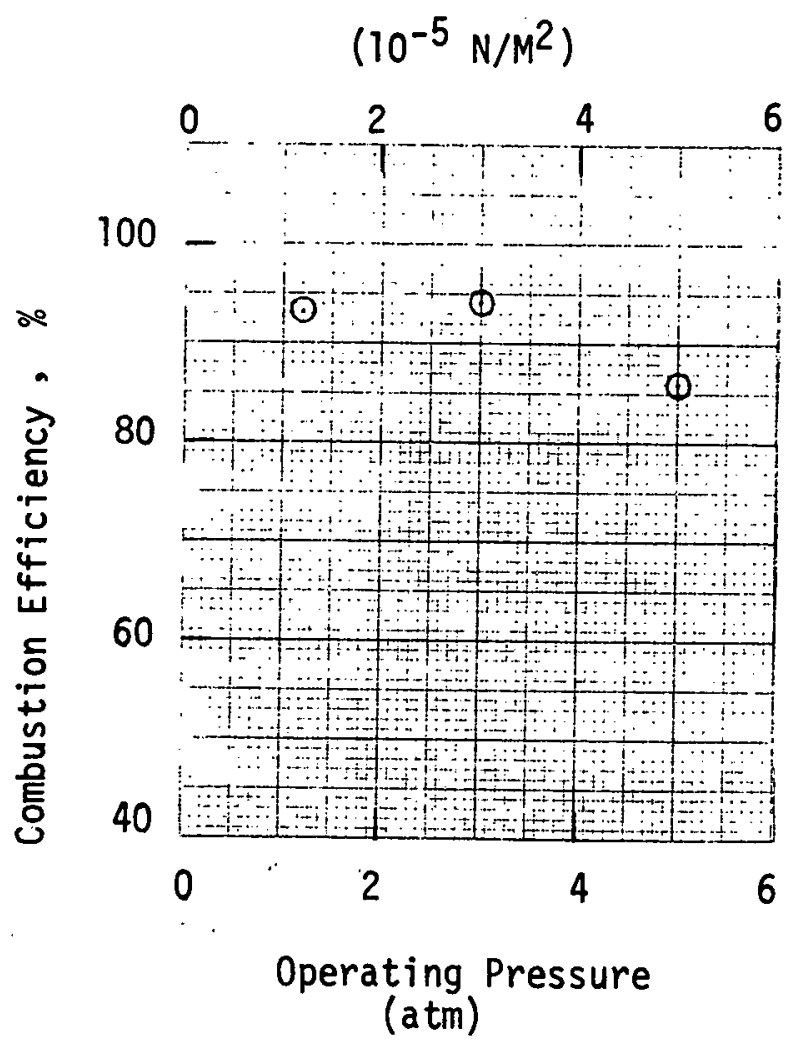

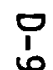




\section{Figure D-7. Averaged Response Of Combustion Efficiency Versus Reference Velocity and Adiabatic Operating Temperature For Catalyst Core DXB-222 (Initial Propane Parametric)}
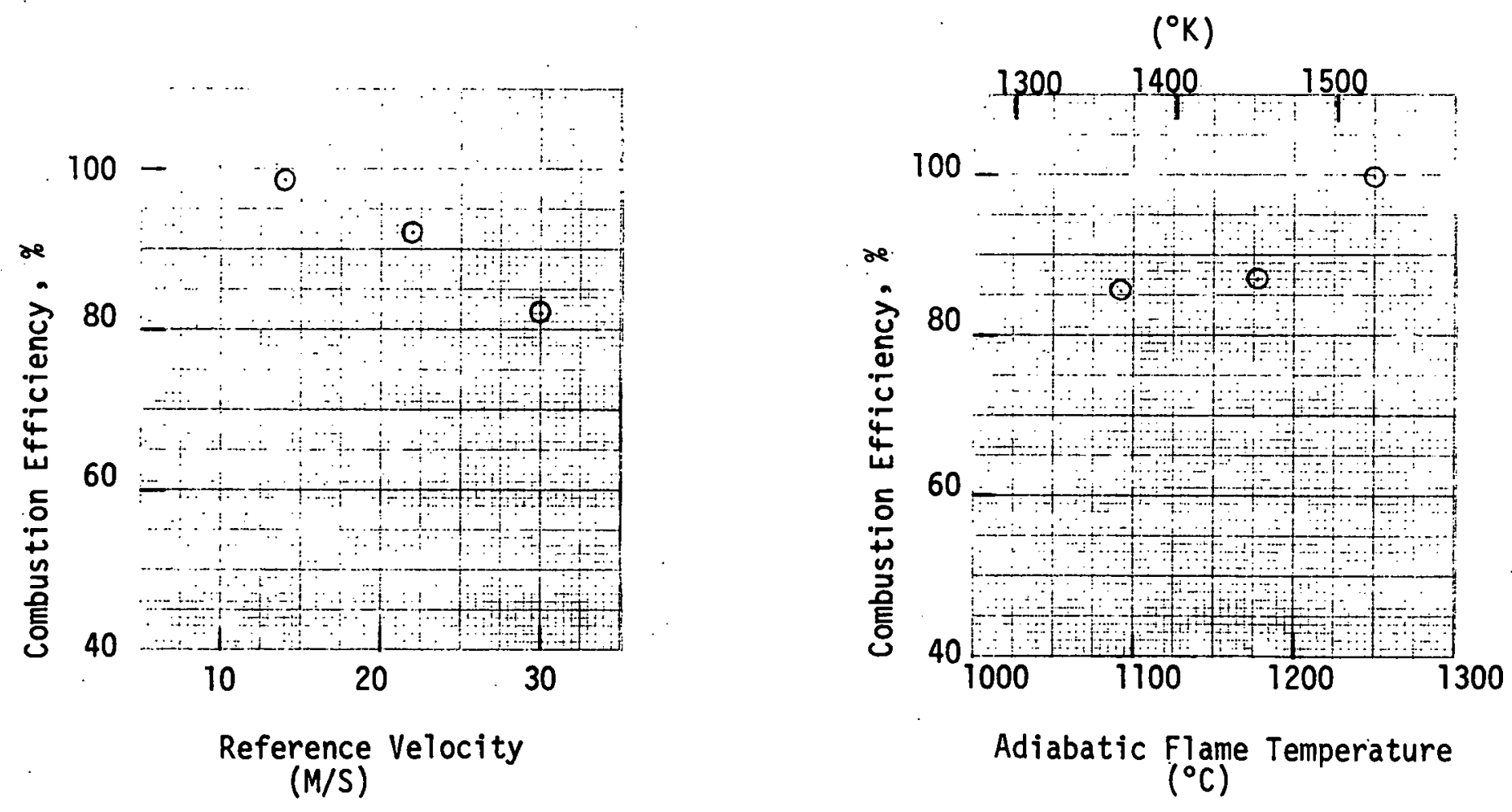
APPENDIX E

DETAILED OPERATING INSTRUCTIONS

I. LIFE TEST

II. ACTIVITY TESTING

III. PARAMETRIC TESTING

IV. ANALYTICAL EQUIPMENT

v. CATALYST CHARGING

VI. UNIT SHUTDOWN

VII. ROUTINE DATA REDUCTION

VIII. DATA ANALYSIS (MISCELLANEOUS CALCULATIONS) 


\section{LIFE TEST PROCEDURE}

A. START-UP PROCEDURES

1. Set Up Reactor Conditions

a. Switch on power to every instrument.

b. Set air supply pressure at 50 psig with air regulator.

c. Set air flow rate on automatic control loop at $416 \mathrm{scfh}(32 \mathrm{lb} . / \mathrm{hr}$.$) .$

d. Set air preheat $S C R$ controller at $360^{\circ} \mathrm{C}$ reactor inlet temperature.

e. Select furnace to be used and open valves for flow.

f. While unit is heating, check safety shutdown system for performance (refer to Safety Shutdown).

g. Calibrate analytical train as shown in "Analytical Start-Up Section". 
h. When the inlet temperature is lined out within $\pm 5^{\circ} \mathrm{C}$ of control point, take a set of readings for "no fuel" conditions.

i. Make sure the automatic level control on the vent cooler system is turned on and functioning properly.

\section{Fuel Presentation}

a. Set liquid fuel pump to give $447 \mathrm{cc} / \mathrm{hr}$. \#2 diesel fuel. This is an A/F wgt. ratio of $38 / 1$.

b. Bring liquid feed on slowly by having bypass valve open and fuel feed line closed. With bypass open, slowly open fuel feed line valve. When fuel feed line is fully open, close the bypass line.

c. Once a day the fuel flow should be checked by flowing through the calibrated flow through gauge glass. Record results under comments on log sheet.

\section{ACTIVITY TEST PROCEDURE}

A. INTRODUCTION

For each catalyst core an activity test will be taken at $0,250,500,750$ and 1,000 hours of life testing. The test procedure is as follows: 
1. Set the air flow using the air flow rotameter at $1088 \mathrm{scfh}$.

2. Preheat the air to the previous test ignition temperature. For virgin catalyst, begin at $180^{\circ} \mathrm{C}$.

3. Using C. P. carbon monoxide (at $4000 \mathrm{ppm}$ in feed stream) as the activity test fuel, determine ignition temperature by stepping in $20^{\circ} \mathrm{C}$ temperature increases until ignition occurs. While increasing temperature, fuel (CO) should be off.

4. After ignition is obtained, proceed in $40^{\circ} \mathrm{C}$ increments to obtain conversion data. Remember that background data should be taken before fuel is brought on.

5. Stop conversion data at $400^{\circ} \mathrm{C}$ inlet temperature.

\section{PARAMETRIC TESTING}

A. INTRODUCTION

Parametric tests will be performed on each catalyst core at 0 and 1,000 hours of life testing using C. P. Propane. The following procedures should be followed:

1. Start-Up

a. Set air flow rate as specified in operating instructions. Set pressure at 70 psig on rotameter. 
b. Set air preheat temperature as specified in operating instructions.

c. Select furnace (or furnaces) to be used and open valves for flow.

d. Calibrate analytical train as shown in "Analytical Start-Up. Section".

e. Set reactor operating pressure given in operating instructions by adjusting valve on reactor vent line.

f. When the inlet temperature is lined out within ... $\pm 5^{\circ} \mathrm{C}$ of control point, take a set of readings for "no fuel" conditions.

\section{Fuel Presentation}

This procedure should be followed for any gaseous fuel runs in which the anticipated outlet temperature is over $1000^{\circ} \mathrm{C}$. The basic idea is to bring in fuel slowly and do not ever overshoot the fuel.

a. Check FID calibration against the standard. Select the one closest to the desired fuel level you want to set. 
b. Adjust the inlet sample flow to obtain about the same flow ( 4 scfh) as when you calibrate it.

c. Check the back pressure gauge and make sure it reads 4.5 psig exactly.

d. FID should read zero. If not, zero it with zero gas.

e. Check the pressure in the fuel line between the metering valve and solenoid valves. If high pressure is found, bleed it off.

f. Open the solenoid valves and set fuel pressure regulation to the desired pressure.

g. Turn recorder chart on and open the metering valvè s.lowly.

h. Bring in the fuel to $3 / 4$ of the final setting according to the FID. Wait for the outlet temperature to turn such that it is beginning to line-out (about 10 minutes). Then, gradually increase the fuel to the specified level. Note that there is a time delay between the change of the setting of the valve and the FID response. Therefore, every change that is made should give you sufficient time (at least one minute) to line out on recorder. 
i. At no time should the outlet temperature exceed $1260^{\circ} \mathrm{C}$. If it is likely to occur, shut fuel off and report to the engineer.

j. After fuel is set, mark the chart and turn off inlet sample stream and recorder chart. If there is any doubt about the inlet fuel concentration during the run, it should be rechecked.

IV. ANALYTICAL EQUIPMENT PROCEDURES

Start-Up Procedures for $\mathrm{CO}, \mathrm{CO}_{2}, \mathrm{NO} / \mathrm{NO}_{x}, \mathrm{O}_{2}$ and $\mathrm{FID}$ Analyzers

A. GENERAL

1. Power-switch on on FID and Beckman Console - $\mathrm{Also} \mathrm{NO}^{\mathrm{NO}} \mathrm{X}$. This is for warming up the units electrical circuits.

2. Turn off house air on $\mathrm{N}_{2}$ at the back of the unit that was on for overnight purge.

3. Selector valves at the control panel should be in closed position to prevent any leaks or flow surges. Then turn on all tanks and one zero air: tank. 
B. CONSOLE PANEL

1. Open $\mathrm{CO}$ purge valve to give a flow of 7.0 on rotameter.

2. Sample valve calibration valve should be in calibration position.

3. Turn on pump and open span valve $\mathrm{CO} / \mathrm{CO}_{2} / \mathrm{O}_{2}$ also to give flow of 7.0 .

4. Turn $\mathrm{CO}$ and $\mathrm{CO}_{2}$ analyzers from the tune position to Range -1 .

5. Selector valve LO-CO, Hi-CO should be in Hi-CO position.

6. $\quad \mathrm{CO}$ and $\mathrm{CO}_{2}$ chopper switches on.

7. Selector valve span zero, 1, 2 and 3 should be in zero position to zero analyzers.

8. Recorders off-on switch should be in on position. Check pens on recorders by turning recorder chart switch on to see if pens write. (If pens don't write, use thin wire or suction bottle to draw ink through tip.)

9. Check filter paper in pancake valve on sample line and change if necessary. 
10. $0_{2}$ analyzer should be on Range 25 .

\section{CALIBRATION PROCEDURE FOR CO ANALYZER}

1. Range 1 calibration (CO span gas from 500 to $5000 \mathrm{ppm}$ ).

a. From control panel select span gas labelled co 1 .

b. On console selector valve span zero, 1, 2 and 3 should be turned to $\mathrm{CO} \# 2$ position.

c. Control flow through rotameter to setting of 7.0 by regulating $\mathrm{CO} / \mathrm{CO}_{2} / \mathrm{O}_{2}$ span valve.

d. At this point you can actually calibrate on any gas from 500 to $5000 \mathrm{ppm}$.

e. Check the reading at the meter which corresponds to the span gas at Range 1. Verify at CO curve.

f. If reading is not verified, adjust gain potentiometer to verify curve.

2. Range 2 calibration (CO span gas from 50 to $500 \mathrm{ppm}$ ).

a. From the control panel select span gas labelled co 2 .

b. Hi-CO, Lo-CO selector valve should be in $\mathrm{LO}-\ddot{-C O}$

position. 
c. Regulate flow setting at 7.0 by adjusting co$\mathrm{CO}_{2}-\mathrm{O}_{2}$ span valve if necessary.

d. At this point you are actually calibrating any gas from $50-500 \mathrm{R} 2,0-50 \mathrm{R} 3$.

e. Check the meter reading and at CO curve for Range 2 . Verify reading.

f. If reading is not verified according to reference curve, open and pull out analyzer and adjust potentiometer labeled D for $R 2$ to verify curve.

3. Range 3 calibration ( $C O$ span gas from 0 to 50 ).

a. From control panel select span gas labeled co 3 .

b. Follow Steps b through e as in Range 2 calibration.

c. If reading is not verified according to reference curve, open and pull out analyzer and adjust potentiometer labeled as R 3 to verify curve.

D. CALIBRATION OF $\mathrm{CO}_{2}$ ANALYZER

1. Range 1 calibration (any $\mathrm{CO}_{2}$ span gas from $2.5 \% \cdot$ to $15 \%$ ). 
a. From the control panel select span gas labeled $\mathrm{CO}_{2}^{-1}$

b. On console selector valve span zero 1,2 and 3 should be turned to $\mathrm{CO}_{2} \# 1$ position.

c. Control flow through rotameter to setting of 7.0 by regulating $\mathrm{CO} / \mathrm{CO}_{2} / \mathrm{O}_{2}$ span valve on console.

d. At this point you are calibrating on any gas from $2.5 \%$ to $15 \%$.

e. Check the reading at the meter which corresponds to the span gas at Range 1. Verify at $\mathrm{CO}_{2}$ curve. If not verified, adjust gain potentiometer.

2. Range 2 calibration (any $\mathrm{CO}_{2}$ gas from 0 to $2.5 \% \quad \mathrm{CO}_{2}$ ).

a. From the control panel select span gas labeled $\mathrm{CO}_{2}-2$

b. Regulate from console a flow of 7.0 setting by adjusting $\mathrm{CO} / \mathrm{CO}_{2} / \mathrm{O}_{2}$ span valve, if necessary.

c. If reading is not verified according to reference curve, open and pull out analyzer and adjust potentiometer labeled as R-2 to verify curve. 
3. Range 3 calibration is not in use.

E. O2 $_{2}$ ANALYZER CALIBRATION

Note: All readings are taken on Range 25 unless otherwise specified.

1. Select the gas from the control panel (zero-air).

2. Span selector valve zero, 1,2 and 3 should be at $\operatorname{span} 3$. Verify flow to 7.0 setting on console by regulating $\mathrm{CO} / \mathrm{CO}_{2} / \mathrm{O}_{2}$ span valve.

3. Verify reading on meter by calibrating zero air to $21 \%$.

4. After calibrating selector valve span zero, 1,2 and 3 should be back to zero position (zero instrument).

5. Verify zero readings on $\mathrm{CO} / \mathrm{CO}_{2} / \mathrm{O}_{2}$ analyzers.

F. SET UP FOR SAMPLING - BECKMAN CONSOLE $\left(\mathrm{CO} / \mathrm{CO}_{2} / \mathrm{O}_{2}\right)$.

1. Selector valve, sample calibrate goes to sample position.

2. Lo-CO and $\mathrm{Hi}-\mathrm{CO}$ valve goes to $\mathrm{Hi}-\mathrm{CO}$ position. Also CO analyzer to $\mathrm{R} 1$. 
3. Shut off $\mathrm{CO} / \mathrm{CO}_{2} / \mathrm{O}_{2}$ span valves on console.

4. Verify rotameter flow at 7.0 by means of $\mathrm{CO} / \mathrm{CO}_{2} / \mathrm{O}_{2}$ sample valves on console.

5. Open valve that is marked Unit \#2, \#3, \#4 or \#5 respectively for sampling to Beckman Console.

6. Read and record data. (If not reading, notify engineer). Mark charts for easy data retrieval on each sample.

G. NO/NOX ANALYZER CALIBRATION

1. $\mathrm{NO}_{\mathrm{x}}$ sample valve on console fully open. Close $\mathrm{NO}_{\mathrm{x}}$ span valve on console.

2. NO mode selector switch in zero position to zero analyzer with range switch preferably on Range 10. (If not zeroed, adjust zero knob).

3. Open door to analyzer to see if there is a flow setting of 8.0 on bypass rotameter, 20 psig ozone and 4 psig sample. Let door stay open.

4. From the control panel select respective span gas, preferably NO 3 (gas is 4.2 ppm). 


\section{$E-14$}

5. On analyzer turn NO mode switch to read sample. Flow on bypass rotameter should read 4.0 setting. (If flow is too great, regulate to 4.0 setting by $\mathrm{NO}_{\mathrm{X}}$ sample valve on console. If flow is too small, regulate to 4.0 setting only when sampling for $\mathrm{NO}^{2} \mathrm{NO}_{\mathrm{x}}$ by adjusting $\mathrm{CO} / \mathrm{CO}_{2} / \mathrm{O}_{2}$ sample valve on console. $\mathrm{NO}_{x}$ sample should be fully open.

6. On analyzer turn NO mode switch to read span. From console open slowly $\mathrm{NO}_{\mathrm{x}}$ span valve so as to give a flow of 4.0 setting on bypass rotameter.

7. Switch back and forth NO mode selector switch from span to sample. (Do this three times giving each time to respond). All pressures and flows should remain the same. Leave switch in span position.

8. Close door to analyzer and whatever gas is selected will read at meter. Adjust reading to calibration gas if incorrect by using span knob.

9. The above procedures are done for $\mathrm{NO}_{\mathrm{x}}$ gas also in $\mathrm{NO}_{\mathrm{X}}$ mode side.

10. Use the above standard procedure for any other calibration gas selecting, of course, the appropriate calibration range.

11. When calibration is finished, leave NO mode or $\mathrm{NO}_{\mathrm{X}}$ mode switch in zero position. Turn off $\mathrm{NO}_{X}$ span valve on console. 
12. Turn to sample position only when sampling.

H. FID ANALYZER (402) CALIBRATION

\section{Ignition Procedure}

a. After air and fuel are turned on fron tanks (cylinders), ignition is made by pushing up (or down) ignition button and listening for popping sound, indicating that flame is lit.

\section{Calibration Procedure}

a. At this time sample pump can be turned on in back of analyzer and air and fue 1 adjusted to 25 psig each. Sample pressure regulator should be at $4 \mathrm{psig.} \mathrm{Make} \mathrm{sure} \mathrm{to} \mathrm{check} \mathrm{pressure} \mathrm{gauge}$ zero reading before adjusting to 4 psig. Any offset on zero should be added to 4 to get correct actual pressure.

b. At this time zero air or house $\mathrm{N}_{2}$ is flowing through the unit and temperature of oven is stable at 350 to $375^{\circ} \mathrm{F}$.

c. Zero analyzer by turning range multiplier switch to Range 10 and let set for awhile (if not zeroed, use zero adjustment knob to zero).

d. When zero is OK, turn range multiplier switch to 5000. Close zero air valve at lower left corner and slowly open span gas valve. 
e. From control panel select gas marked $\mathrm{HC}-1 \quad(15,000$ or $19,000 \mathrm{ppm})$. All pressures should be the same as in Step \#2.

f. If meter does not read according to calibration standard, adjust gas by using span knob. (Ex. for a 19,000 ppm gas meter should read $3.8 \times 5,000-19,000.0 \mathrm{ppm})$.

g. All other calibration gas $\mathrm{HC}-2$ and $\mathrm{HC}-3$ are done the same way as $\mathrm{HC}-1$, but on the appropriate range. (Fx. for a $20 \mathrm{ppm}$ gas meter should read $4.0 \times 5=20.0 \mathrm{ppm}$ or $2.0 \times 10=20.0 \mathrm{ppm}$ ).

h. After calibration normal override switch goes to normal. Sample calibrate valve turn to sample and zero and span valve closed.

i. Range multiplier switch to 5000. You are now sampling from whatever unit you selected.

j. At control panel turn all selector valves at $\mathrm{NO}$ selection.

I. CONSOLE SHUTDOWN PROCEDURES

1. Daily Shutdown

a. Sample pump off. 
b. $\mathrm{CO}_{-} \mathrm{CO}_{2}$ choppers off.

c. Ail charts - off.

d. $\mathrm{NO} / \mathrm{NO}_{x}$ sample valve, $\mathrm{NO}_{x}$ span valve, $\mathrm{CO}-\mathrm{CO}_{2}-\mathrm{O}_{2}$ span. valve, CO purge closed.

e. All tanks - off.

f. $N O / N O_{x}$ analyzer left on, NO mode selector valve to NO sample position.

g. Sample calibrate valve, to sample position.

h. Lo-CO - Hi-CO valve, adjusted at mid-position, so as to give a flow to both co cells.

i. Turn on house air $\left(\mathrm{N}_{2}\right)$ at the back of the unit, by adjusting metering valve to give a flow to all analyzers.

j. Verify the flow by observing rotameters in front to read anywhere from $0-7.0$.

k. Analyzers $\mathrm{CO}-\mathrm{CO}_{2}$ goes to tune position.

1. FID analyzers pump off. 
m. FID analyzers sample calibrate valve goes to. calibrate position. FID analyzers normal override switch to override position.

n. FID air regulator to $0-5$ psig.

o. FID analyzer, sample regulator to 2 psig.

p. FID analyzer, zero house air $\left(\mathrm{N}_{2}\right)$ flow through analyzer for purging.

q. All valves go to non-selecting position at control panel.

V. CATALYST CHARGING

The catalyst charging procedure is a very important step in the evaluation of each catalyst. A proper job will insure correct pressure drop measurements and prevent reactor bypassing. Monitor the pressure drop control charts during tests to detect failure of packing. Abrupt changes in pressure drop may indicate that fiberfrax has become loose and repacking is needed.

A. Weigh catalyst and record dimensions (diameter, length, number of full channels). Apply a 1/4" wide layer of ceramic cement around the middle periphery of the catalyst core to prevent bypassing. 
Wrap a layer of fiberfrax, recessed 1/4" from each end, around the catalyst core.

B. Place the catalyst core in the metal holder, pushing the catalyst core into the bottom of the holder. Inspect catalyst core in holder and make sure no fiberfrax has slipped and is covering channels. If so, remove and start over again.

C. Remove all fiberfrax from reactor that may be stuck to the reactor wall from previous tests.

D. Wrap fiberfrax around catalyst holder and insert in reactor. Make sure the fiberfrax wrapping provides a snug fit. Set air flow at 1000 scfh and see if holder stays in place. If not, remove, rewrap and place in reactor. Retest at $1000 \mathrm{scfh}$ for bypassing.

E. Insert holder pin through reactor wall and pull down the holder flush with this pin. A schematic showing the placement of the packed catalysts in the reactor is shown in Figure -1 .

F. Secure reactor flanges, thermocouples, etc. for testing. Pressure test reactor at 50 psig for 30 minutes for leak checks. 
$E-20$

FLOW

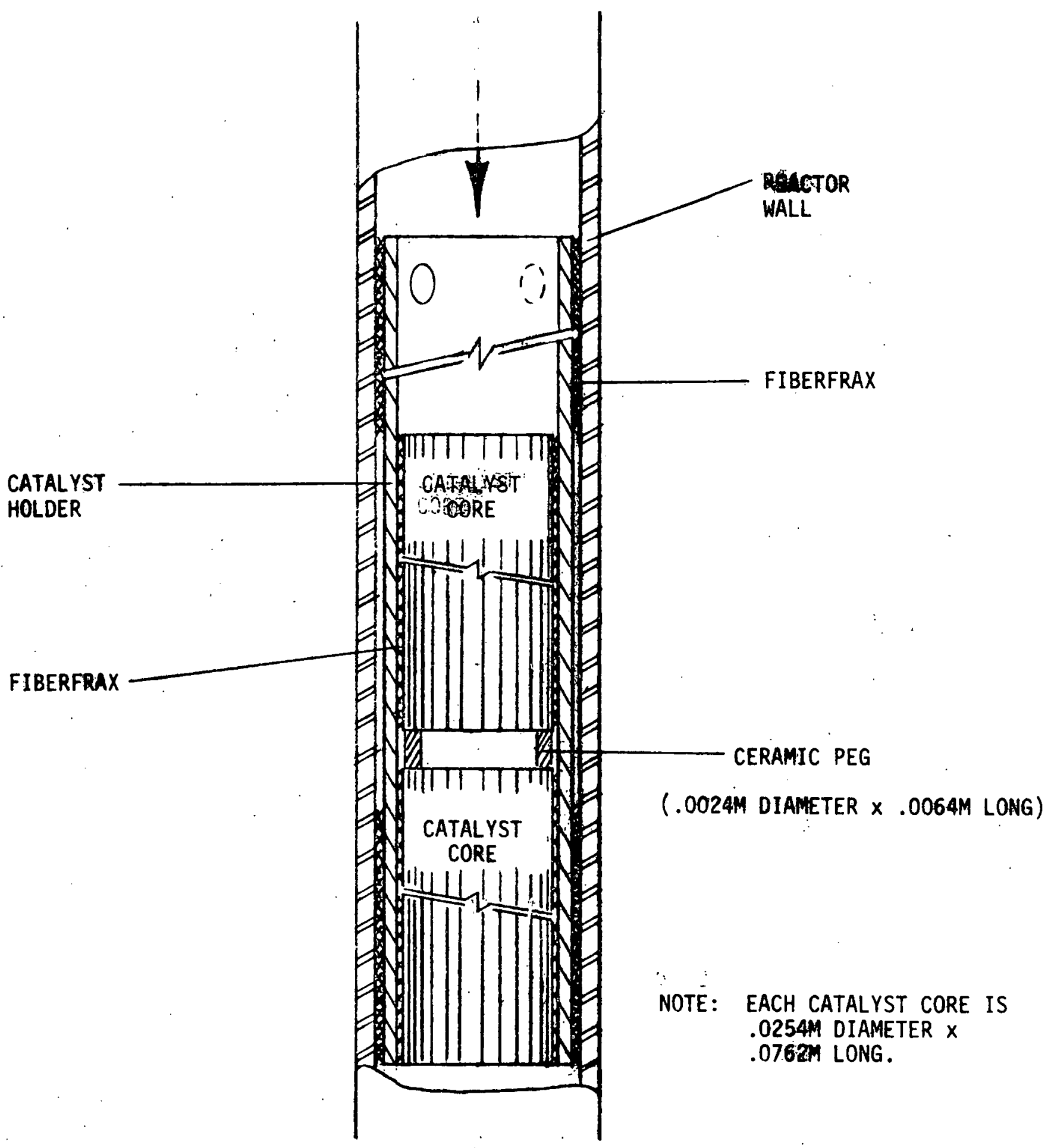

Figure f-1: Schematic Showing Details of Packing of Test Catalyst Cores 
VI. UNIT SAFETY SHUTDOWN

A. INTRODUCTION

The unit shutdown is designed for operating personnel safety and for protecting the catalyst core from process upsets. When an automatic shutdown occurs, the fuel line solenoids cut off fuel to the reactor and air preheat. If the cause of the shutdown is removed, the air preheat is restored but the fuel must be reset manually.

Before resetting the fuel the technician should determine the cause of the shutdown, correct the problem and record the occurrence on the logsheet. Always bring fuel back on "on bypass" as standard operating procedure.

The proper functioning of the shutdown system should be checked every 500 hours of life testing. Use the check list in Attachment I. Problems should be corrected and noted in the log sheet.

VII. ROUTINE DATA REDUCTION

Data was processed using the following procedure:

A. Data recorded on standard $\log$ sheets.

B. The data is transferred from the $\log$ sheets to standardized computer forms with subsequent keypunching. 
C. Data is inputted to computer and reduced on CATCOM computer programs.

D. Computer output in tabular form and plots.

This entire sequence is handled by technicians in the CATCOM group.

A subroutine is also available for taking the reduced data and providing plots. This is used routinely for life tests to detect trends with operation time (e.g., emissions plotted vs. operating time). For life tests, the operating time is defined as the time on stream at life test conditions.

The routine data reduction program performs the calculations listed in Table E-I with the nomenclature explained in Table E-3. Because of the fact that a one-inch core is removed from the catalyst block, the outside channels are ineffective in converting the fuel. This is taken into account by defining an effective catalyst core diameter based on the ratio of the number of open channels actually in the 1" diam. test core compared with the calculated number of channels. Note that the reference velocity, the space velocity, Reynolds' number and heat release rate all contain this correction factor.

The combustion efficiency is calculated on fuel conversion for this study and not on a heat balance. Similarly, the heat release rate is based on hydrocarbon conversion and not a heat balance. 
For 1" diam. laboratory test rigs, the percent adiabaticity is a very important guide post. It represents the percent heat loss in the reactor. This is inherent in small test rigs because of the high surface to volume ratio available for heat transfer to the atmosphere. The calculation shows how much the actual measured temperature rise across the catalyst core deviates from the calculated adiabatic temperature rise based on heats of combustion and hydrocarbon conversion levels. 


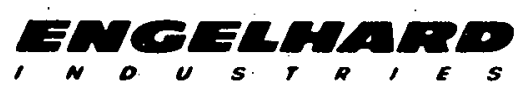

$E-24$

TABLE E-1

EQUATIONS FOR DATA REDUCTION COMPUTER PROGRAM

- Reference Velocity: $=[A / \rho A+F / \rho F] /[E / C I]$

$\because$ Space Velocity: $=[\mathrm{A} / \rho \mathrm{\rho}+\mathrm{F} / \rho \mathrm{F}] /[\mathrm{C} / \mathrm{CI}]\left[L_{L}\right]$

- Emissions: $\mathrm{CO}, \mathrm{NO}_{X}, \mathrm{UHC}=\mathrm{PPM}[\mathrm{M} / \mathrm{MW}] /[\mathrm{A}+\mathrm{F} / \mathrm{F}]$

- Combustion Efficiency: $\frac{100 \times \mathrm{HCI} \times \mathrm{NC} \times 10^{6}-[\mathrm{CO}+3 \mathrm{HC}]}{\mathrm{HCI} \times \mathrm{NC} \times 10^{6}}$

- Percent Adiabaticity: $=\left(T_{0}-T_{I}\right) /\left(T_{O D}-T_{I}\right) \times 100$

- Reynolds' Number: $=(A+F) D h /\left[C / C_{I}\right]_{\mu}$

- Heat Release Rate: = FQ $\mathrm{F}_{\mathrm{C}} /\left[\mathrm{C} / \mathrm{C}_{\mathrm{I}}\right]$.

- Carbon Balance: = (IC - OC)/IC $\times 100$

- Hydraulic Diameter: = (Channel Cross Section Area)/(Wetted Perimeter)

- Equivalent Diameter: $=\left[\mathrm{C} / \mathrm{C}_{\mathrm{I}}\right]^{1 / 2}[4 / \pi]$

- Percent Pressure Drop: $\left(\left[P_{I N}-P_{\text {OUT }}\right] /\left[P_{I N}\right]\right) \cdot[100]$ 


\section{NOMENCLATURE FOR DATA REDUCTION}

A - Air mass flow rate

F - Fuel mass flow rate

C - Actual number of open channels in 1" catalyst core

$c_{I}$ - Theoretical number of channels per area for catalyst core

$\rho A$ - Density of air

$\rho F$ - Density of fuel

L - Catalyst core length

PPM - Parts per million of emission as measured in exhaust

M - Emission molecular weight

MW - Exhaust mixture molecular weight

HCI - Mole fraction of fuel in feed

NC - Number of carbons in fue?

CO - ppm of carbon monoxide in exhaust

HC - ppm of hydrocarbons measured as propane in exhaust

$\mathrm{T}_{0}$ - Measured outlet catalyst core temperature

$T_{I}$ - Measured inlet catalyst core temperature

Tod - Calculated adiabatic temperature rise for air/fuel ratio in feed (adiabatic flame temperature)

$D_{c}$ - Equivalent honeycomb diameter calculated from number of open channels in 1" catalyst core

$\mu$ - Gas mixture viscosity

$F_{C}$ - Conversion of fuel in catalyst core

$P_{I}$ - Inlet pressure to catalyst core

IC - Number of carbon atoms in feed

$O C$ - Number of carbon atoms in exhaust

$D_{h}$ - Hydrautic diameter

$V_{r}$ - Reference velocity 
VIII.DATA ANALYSIS (MISCELLANEOUS CALCULATIONS)

Supplementing the routine data reduction were miscellaneous calculations for

A. Emissions Index

B. Adiabatic Flame Temperature

Because of their importance, these calculations are detailed below.

\section{A. EMISSIONS INDEX}

Emissions in grams/mile were calculated using Equation (1) (refer to Table E-2 for nomenclature).

(1) $(\mathrm{g} / \mathrm{mile})=[\mathrm{A} / 29+\mathrm{F} / 199]\left[\mathrm{PPM} \times 10^{-6}\right][\mathrm{MW}]$ $\frac{\mathrm{F}}{\rho \mathrm{F}} \times\left[\frac{2.642 \times 10^{-4} \text { gallons }}{\mathrm{CC}}\right] \times \frac{10 \mathrm{miles}}{\text { gallon }}$

Example Calculation:

$$
\begin{aligned}
& \text { For UHC as } \mathrm{C}_{3} \mathrm{H}_{8} \\
& \text { and } A / F=38 / 1 \\
& \mathrm{MW}=44 \\
& P P M=3.8 \\
& \rho_{F}=: 864 \mathrm{~g} / \mathrm{cc} \\
& (\mathrm{g} / \mathrm{mile})=0.072
\end{aligned}
$$




\section{$E-27$}

B: ADIABATIC FLAME TEMPERATURE CALCULATION

1. Basis: Feed Air/Fuel Ratio

Material Balance

To complete the material balance the stoichiometry of the diesel oil combustion must be known. Using the analytical results for

- API gravity of 34.4

- $50 \%$ distillation temperature of $523^{\circ} \mathrm{K}$ the molecular weight of diesel oil is calculated using the method in Reference 9 as 192 grams/gram-mole. For carbon/hydrogen ratio of .566 (obtained by analysis), a formula of $\mathrm{C}_{13.93} \mathrm{H}_{24.67}$ is calculated for the \#2 diesel fuel. The stoichiometry for diesel oil combustion can then be represented by:

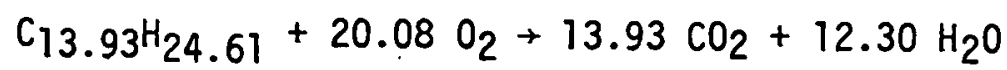

In the life tests on DXB-222 and DXC-532, the typical air/fuel ratio of $38 / 1$ results in the following molar balance:

\begin{tabular}{ccc} 
Component & $\begin{array}{c}\text { Feed } \\
(\%)\end{array}$ & $\begin{array}{c}\text { Product } \\
(\%)\end{array}$ \\
\cline { 2 - 2 } & 0.396 & - \\
$\mathrm{O}_{2}$ & 20.92 & 12.71 \\
$\mathrm{~N} 2$ & 78.69 & 77.12 \\
$\mathrm{CO}_{2}$ & - & 5.39 \\
$\mathrm{H}_{2} \mathrm{O}$ & - & 4.77
\end{tabular}

The mean molecular weight of the product is 29.04 
Energy Balance

The adiabatic flame temperature is calculated using the assiomptión shown schematically:

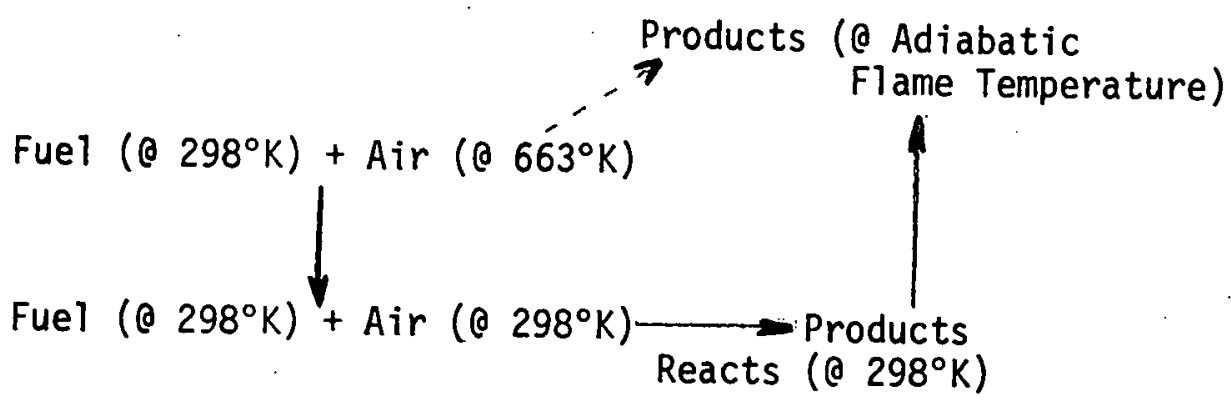

The calculation involves assuming an adiabatic flame temperature to obtain the mean molar heat capacities of the product gases for use in Equation (1).

(1) (Heat content of products at adiabatic flame temperature)

+ Heat of combustion at $298^{\circ} \mathrm{K}$

- (Heat content of feed at feed temperature)

$=0$

The calculated adiabatic flame temperature is then compared to the assumed and a trial and error solution is used to converge to the final solutions. Using this technique, an adiabatic flame temperature of $1527^{\circ} \mathrm{K}$ is obtained for an air/fuel weight of $38 / 1$. 
Sample Carculation:

Step (1) Assume adiabatic flame temperature of $1527^{\circ} \mathrm{K}$

Step (2) Mean molar heat capacity of product

$\begin{array}{cccc}\text { Component } & \begin{array}{l}\text { Mole } \\ \text { Percent }\end{array} & \begin{array}{l}\text { *Pure Component } \\ \text { Mean Molar } \\ \text { Heat Capacity } \\ 01527^{\circ} \mathrm{K}\end{array} & \begin{array}{c}\text { Heat Capacity } \\ \text { Contribution } \\ \left(\mathrm{kcal} / \mathrm{kg} \cdot{ }^{\circ} \mathrm{K}\right)\end{array} \\ \mathrm{H}_{2} \mathrm{O} & 5.39 & 12.32 & \frac{.664}{\left(\mathrm{kcal} / \mathrm{kg} \cdot{ }^{\circ} \mathrm{K}\right)} \\ \mathrm{O}_{2} & 4.77 & 9.6 & .458 \\ \mathrm{~N}_{2} & 77.12 & 8.7 & 1.03 \\ & 7.71 & 7.67 & 5.915\end{array}$

Mean Molar Heat

Capacity of

$8.067 \mathrm{kcal}$

Products from

$298^{\circ} \mathrm{K}$ to $1527^{\circ} \mathrm{K}$

(*from Reference 9 )

Step (3) The mean molar heat capacity of air from $298^{\circ} \mathrm{K}$ to $633^{\circ} \mathrm{K}$ is $7.12 \frac{\mathrm{kcal}}{\mathrm{kg} \cdot{ }^{\circ} \mathrm{K}}$ (from Reference 9). 
Step (4) The overall energy balance is ( 1 mole basis in feed)

$$
\begin{aligned}
& \left(1.02 \frac{\mathrm{kg} \cdot \text { moles }}{\mathrm{Hr} .}\right)\left(8.067 \frac{\mathrm{kcal}}{\mathrm{kg} \cdot{ }^{\circ} \mathrm{K}}\right)\left(T_{A D}-298^{\circ} \mathrm{K}\right) \\
+ & \left(.00396 \frac{\mathrm{kg} \cdot \text { moles }}{\mathrm{Hr} .}\right)\left(-1.957 \times 10^{6} \mathrm{kcal} / \mathrm{kg} \cdot \mathrm{mole}\right) \\
- & \left(.9961 \frac{\mathrm{kg} \cdot \mathrm{mole}}{\mathrm{Hr} .}\right)\left(7.12 \frac{\mathrm{kcal}}{\mathrm{kg} \cdot{ }^{\circ} \mathrm{K}}\right)\left(633-298^{\circ} \mathrm{K}\right) \\
= & 0 \\
T_{A D}= & 1528^{\circ} \mathrm{K}
\end{aligned}
$$

Therefore, the assumed adiabatic flame temperature of $1527^{\circ} \mathrm{K}$ is within $1^{\circ} \mathrm{K}$ of the calculated value. This is well within the accuracy of the calculation method.

\section{Basis: $\mathrm{CO}_{2}$ Vent Gas Analysis}

Another technique that is frequently used in calculating the adiabatic flame temperature is based on the $\mathrm{CO}_{2}$ produced in the combustion process. The steps used in this calculation are:

a. Using the $\mathrm{CO}_{2}$ vent gas analysis and the stoichiometry of the combustion reaction, back calculate the corresponding feed component material balance.

b. Using the material balance results, calculate the feed air/fuel weight ratio. 
c. With the calculated air/fuel ratio perform an energy balance calculation to obtain the adiabatic flame temperature. This last step is an iterative process as explained in Appendix E-VII-B-I.

The equations for stoichiometry and the energy balance are identical to those contained in Appendix E-VII-B-i.

Analysis of the $\mathrm{CO}_{2}$ control charts maintained during the life tests of DXB-222 and DXC-532 showed the following:

\begin{tabular}{cc}
$\begin{array}{c}\text { Catalyst } \\
\text { Core }\end{array}$ & $\begin{array}{c}\text { Mean of } \mathrm{CO}_{2} \\
\text { Vent Gas Analysis } \\
\text { Over } 1,000 \text { Hours }\end{array}$ \\
\hline DXB-222 & $5.46 \%$ \\
DXC-532 & $5.53 \%$
\end{tabular}
Standard Deviation of of $\mathrm{CO}_{2}$ Vent Gas Analys is Over 1,000 Hours $.11 \%$ $.11 \%$

Using these results to make a material and energy balance for the adiabatic combustion gave:

\begin{tabular}{cc}
$\begin{array}{c}\text { Catalyst } \\
\text { Core }\end{array}$ & $\begin{array}{c}\text { Adiabatic Flame } \\
\text { Temperature } \\
\text { Based on Mean } \\
\mathrm{CO}_{2} \text { Analysis }\end{array}$ \\
\hline DXB-222 & $1533^{\circ} \mathrm{K}$ \\
DXC-532 & $1545^{\circ} \mathrm{K}$
\end{tabular}

$\begin{aligned} & \text { Range of } \\ & \text { Flame Temperature } \\ & \text { at } 95 \% \\ & \text { Confidence } \\ & \text { Range }\end{aligned}$
$\begin{aligned} & 1499-1565^{\circ} \mathrm{K} \\ & 1511-1575^{\circ} \mathrm{K}\end{aligned}$

This data indicates that during the course of the life tests, temperatures ranged from approximately $1505^{\circ} \mathrm{K}\left(2294^{\circ} \mathrm{K}\right)$ to $1570^{\circ} \mathrm{K}\left(2366^{\circ} \mathrm{F}\right)$. 


\section{GLOSSARY OF TERMS}

Catalytic Combustor: Flange to flange assembly of catalytic combustion equipment, including fuel presentation system, ignition system and catalytic substrate, including provision for instrumentation. Catalytic Core (Catalyst Core): Composite of catalyst and catalyst support.

Catalyst Support: Structure upon which the catalyst is supported. Catalyst: Active catalytic material.

Full Scale: Applies to components, equipment and test rigs for testing under simulated gas turbine engine conditions.

Sub-scale: Applies to components, equipment and test rigs for testing on a one-inch diameter catalytic bed scale.

Test Rig: Facility used for test and evaluation of catalytic combustors. Ignition Temperature: The temperature at which spontaneous catalytic combustion occurs for a given fuel/air catalytic core combination. Space Velocity: Volumetric flow rate of reactants per volume of catalyst core. NTP refers to $298^{\circ} \mathrm{K}$ and atmospheric pressure. 
ENGEMPATR

F-1

APPENDIX F

DESIGN DRAWINGS

FOR NASA TEST RIG

230 

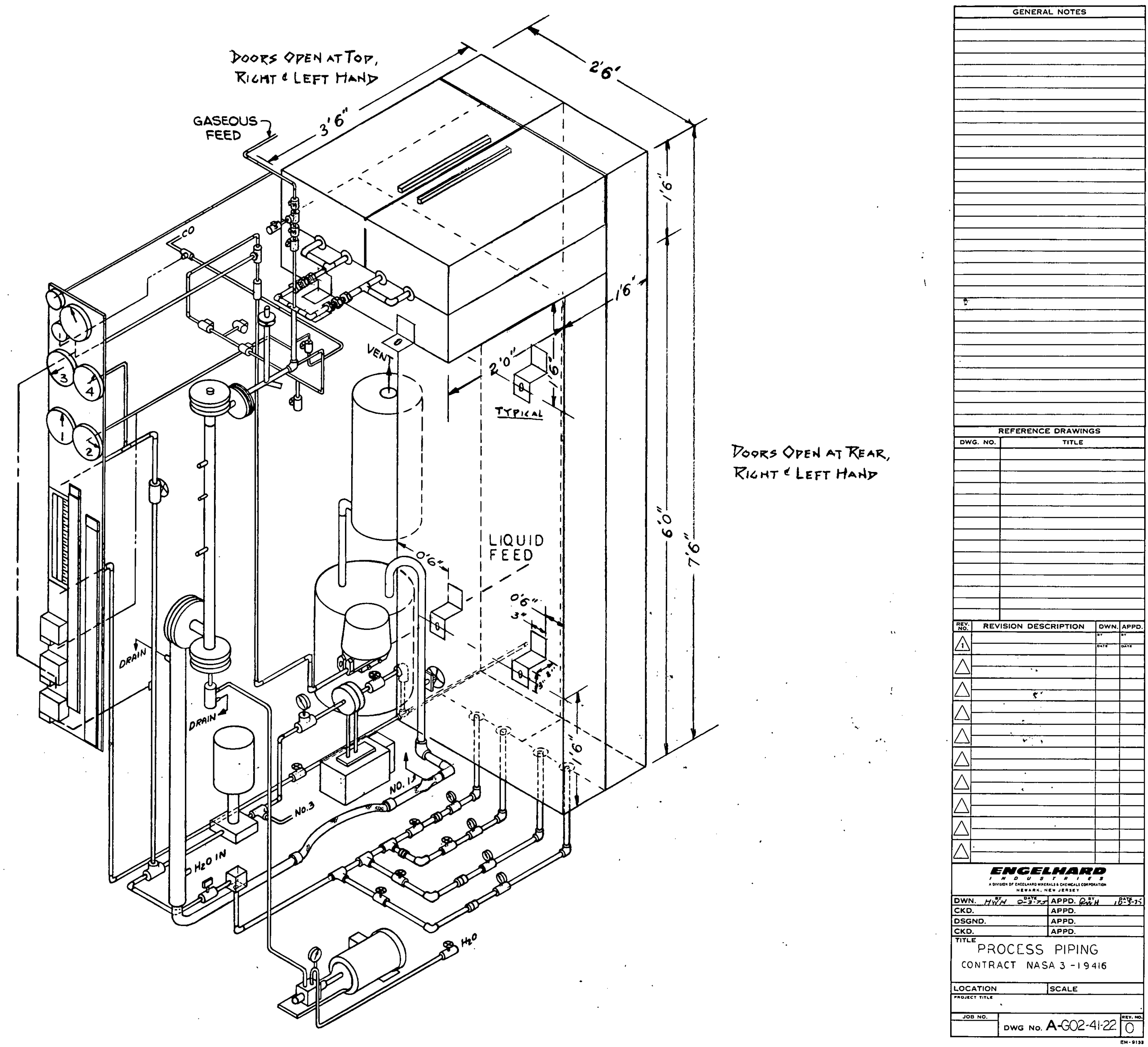
G-1

APPENDIX G

DISTRIBUTION LIST

) 
CONTRACT NAS3-19416 - FIXAL REPORT - DIS'TRIBUTION LIST

\section{GOVERNMIFNT}

NASA T,ewis Research Center

21000 Brookpar! Road

Cleveland, OH 44135

Attention:

Report Control Office

Library

G. M. Ault

R. E. English

R. A. Rudey

L. I. Shure

R.J. Priem

M. H. Krasner

W. E. Goette

R. E. Jones

J. S. Grobran

L. A. Diehl

L. I.. Schopen

T. S. Mroz
MS $5-5$

$60-3$

$3-5$

$3-15$

$500-202$

$500-202$

$500-202$

$500-210$

$500-210$

$60-5$

$60-6$

$60-4$

$500-313$

$500-202$
(1)

(2)

(1)

(1)

(1)

(1)

(I)

(1)

(1).

(1)

(1)

(1)

(1)

(15)

Other Government igencies:

Energy Research and Development Adrinistration

office of Highray iehicle Systers

20 Massachusetts irenue, $\mathrm{Ni}$

Washington, DC 20545

Attn: George $\because$ Thur

(5)

Robert A. Yercure

(1)

Energy Research and Development Administration Division of Conservation Research $\&$ Technology 20 Massachusetts Avenue, Ni:

Washington, DC 20545

Attn: Dr. Karl Bastress

(1)

J. Neal

FAA Headquarters

2100 2nd Street, $\mathrm{SH}$

Washington, DC 20591

Attn: W. Westfield ARD-SSO 
5. NASA Headquarters

600 Independence Avenue, SW

Washington, DC 20546

Attn: P. R. Miller (NE)

(1)

R. D. Ginter (NE)

(1)

6. Department of the Air Force

Air Force Aero Propulsion Laboratory

Wright-Patterson Air Force Base

Ohio 45433

Attn: L. Obery, NASA/AFADL Liaison

A. Churchill, AFADL/SFE Area B, Bldg. $180^{\circ}$

J. Rosfjord, Capt., AFADL/SFF

Area B, Bldg 180

7. NASA Scientific and Technical. Information Facility

P. 0. Box 8757

Baltimore/Washington International Airport

Maryland 21240

Attn: Accessioning Dept.

Environmental Protection Agency

26 . West St. Clair St.

Cincinnati, $\mathrm{OH} 45268$

Attn: W. Cain

Environmental Protection Agency

Control Systems Laboratory

Research Triangle Park,

North Carolina 27711

Attn: Blair Martin

(1)

Steve Lanier

(1)

NCAR National Center Atmospheric Research

P. O. Box 1470

Boulder, Co 80302

Attn: Dr. Grams

(1)

Energy Research and Technology Administration

Division of Fossil Energy

400 . Ist Street, NW

Washington, DC 20545

Attn: Mr. F. Crim 
NOAA National Oceanic \& Atmospheric Administration

Air Resources Division

(1) 8060 13th Street

Silver Springs, MD 20190

Attn: Dr. L. Machta

Navy Encrgy \& Natural Resources R\&O office

(1)

Navy Ship R\&D Center

Annapolis Laboratories

Annapolis; MD 21402

Attn: CDR. P. A. Petzrick (MAT-03Z)

NASA Johnson Space Center

Environmental Effects Project Office

(1)

Houston, TX 77058

Attn: Dr. R. D. Hudson

United States Army

Larry Bell

ABSCOM, AMSAV-EFP

Box 209

St. Louis, MO 63166

Air Force Office of Scientific Research

(1)

Bolling AFB, DC 20332

Attn: J. F. Masi

NA/Dr. B. T. Wolfson

Defense Documentation Center (DDC)

(1)

Cameron Station

5010 Duke Street

Alexandria, VA 22314

Applications Engineering Office

National Space Technology Laboratories

(1)

National Aeronautics \& Space Administration

Bay St. Louis, MI 39520

David Taylor Naval Shipyard

Research and Development Center (DTNSRDC)

Code 2720

Annapolis, MD 21402

Attn: Rolf Nuench

Naval Air Propulsion Test Center

(1)

Trenton, NJ 03628

(1)

Attn: Anthony Klarman

Environmental Protection Agency

(1)

401 Main Street, SIV

Washington, DC 20460

Attn: George Kittredge 
United States Army

Kent Smith, SAVDL/EU-TAT

(1)

Commanding officer

Eustis Directorate - USA AMRDL

Fort Eustis, VA 23604

\section{INDUSTRY}

Dr. W. B. Retallick

(1)

Oxy-Catalyst, Inc.

East Biddle Street

West Chester, PA 19380

Vir. G. Peitsch

The Ford Motor Co.

Turbine Engineering Det.

20000 Rotunda Drive

P. 0. Box 2053

Dearborn, MI 48121

Mr. Dennis Larson

The Institute of Gas Technology

(1)

IIT Center

3424 South State

Chicago, IL 60616

Mr. Charles Wagner

Chrysler Corporation

Box 1118

CIMSC $4 i 8-3 i-18$

Detroit, MI 48231

Dr. J. M. Maselli

W. R. Grace Co.

Research Division

Washington Research Center

7379 Route 32

Columbia, MD 21044

Dr. George R. Lester

Universal 0il Products

Corporate Research

Ten UOP Plaza

Algonquin and Mt. Pleasant Blvds.

Des Plaines, IL 60016

Dr. George McGuire

(I)

Mathey Bishop, Inc.

(1)

Malvern, PA 19355

Dr. Henry Shaw

Exxon Research and Engineering Company

Government Research Laboratories

P. O. Box 8

Linden, NJ 07036 
Teledyne CAE

1330 Laskcy Road

Toledo, $\mathrm{OH} 43697$

Attn: L. A. Chuslo

Norman R. Dibelius, Manager

(1)

Combustion Environmental Effects

General Electric Company

1 River Road - \#53-324

Gas Turbine Engineering Dept.

Schenectady, NY 12345

Robert R. Conrad

(1)

Parker Hannifin

17325 Euclid Avenue

Cleveland, $\mathrm{OH} 44112$

James R. Baker

Gas Turbine Products Div.

(1)

Delavan Mfg. Company

811 Fourth Street

West Des Moines, Iowa 50265

R. Hugh Gaylord

(1)

Turbodyne Corp.

Systems Engineering Dept.

st. Cloud, MN 56301

John M. Haasis

AiResearch Mfg. Company of Ariz.

402 S. 36th Street

Phoenix, Arizona 85010

Donald W. Bahr, Manager

Combustion \& Emissions

General Electric Company (H-52)

Cincinnati, OH 45215

Richard Lee Marshall

(1)

Pratt \& Whitney Aircraft (EB2F)

400 Main Street

East Hartford, CT 06108

General Electric Company

(1)

1000 Western Avenue

West Lynn, MA 01905

Attn: Library Bldg.

Dr. C. W. Smith, 2-40M

Curtiss-Wright Corporation

(1)

One Passaic Street

Woodridge, NJ 07075

Attn: S. Moskowitz 
Mr. Walter Cornelius

(1)

General Motors Research Labs.

Warren, MI 48090

Mr. David L. Dimick

(1)

General Notors Engineering Staff

12 Mile and lound Roads

Warren, MI 48090

Mr. Stephen P. Cauley

Petroleum Consulting Services

(1)

17230 Libertad Drive

San Diego, CA 92127

Mr. Fredrick W. Lipfert

(1)

Long Island Lighting Company

175 East old Country Road

Hicksville, NY 11801

Mr. W. Bruce Nicol

Chief Engineer

Turbo Division

Ingersoll Rand Corporation

Phillipsburg, NJ 08865

Mr. Herbert R. Hazard

(1)

Battelle Nemorial Institute

Columbus Labonatories

505 King sivenue

Columbus, $\mathrm{OH} 43201$

Mr. H. C. Sinunond

Director of Engineering

Parker-Hannifin Corporation

(1)

Accessories Division

17325 Euclid Avenue

Cleveland, $\mathrm{OH} 44112$

Mr. Jack M. Vaught (U27A)

Mr. Frank Verkamp

Combustion Res. \& Development

Detroit Diesel Allison

Div. of General Motors

P. 0. Box 894

Indianapolis, Indiana 46206

(2)

Dr. Marshall Lapp

Corporate Research \& Development

General Electric Company

Schenectady, NY 12301 
Mr. Stanley Mosier

Mr. M. A. Siegel

Pratt \& Whitney Aircraft

(2)

Florida Research \& Development Center

P. 0. Box 2691

West Palm Beach, Florida 33402

Mr. Harold J. Taback

KVB , Inc.

17332 Irvine BIvd.

Tustin, CA 92680

Mr. Roy Norster

Northern Research and

Engineering Corporation

219 Vassar Street

Cambridge, MA 02139

Dr. Danny L. Hartley

(1)

Sandia Laboratories

Livermore, CA 94550

(1)

Mr. Frank Pompei.

Scientific Energy Systems Corp.

Four Tech Circle

Natick, MA 01760

Mr. Wayne Burwell,

Mr. R, Marshall

United Technolories Research Center

East Hartford, CT 06108

Westinghouse Electric Corp.

Research \& Development Center

Pittsburgh, PA 15235

Attn: Richard A. Chamberlin

(1)

Mr. Charles E. Hussey

Mr. S. M. DeCorso

Gas Turbine Engine Div. (A-605)

(2)

Westinghouse Electric Corp.

Lester Bram h P. 0. Box 9175

Philadelphia, PA 19113

Mr. Richard T. Lecren

Solar, A. Division of International

Harvester Co.

P. 0. Box 80966

San Diego, CA 92138

Mr. Richard Kao

(1)

Advanced Power Systems

Engine Engineering Div.

John Deere Waterloo Tractor

Waterloo, Iowa 50704 
Mr. Ralph Kress

Manager - Technical Engrg.

Solar Division, Inter. Harvester Co.

2200 Pacific llighway

San Diego, CA 92112

Mr. George Opdyke, Jr., Manager

Combustor Section AVCO Lycoming Div.

550 S. Main Street

Stratford, CT 06497

Mr. Wallace R. Wade

Engine Research, Rm Ell42

Ford Motor Co.

20000 Rotunda Drive

Dearborn, MI 48121

Rocketdyne

North American Rockwell

6630 Canoga Avenue

Canoga Park, CA 91304

Attn: S. D. Clapp

McDonnel-Douglas Company

Lambert-St. Louis Municipal Airport

P. 0. Box $5 i 6$

St. Louis, 1063166

Attn: F. D. McVey

Ling-Temco Vought

MissiJes \& Space Div.

P. 0. Box 6267

Dallas, TX 75222

Attn: R. 0. Guthrie

Will.iams Research Corp.

2280 W. Maple Road

Walled Lake, MI 48088

Attn: Arnold Plumley

Aerospace Corp.

2350 E. El Segundo Blvd.

El Segundo, CA

Attn: Orven W. Dykema

UNIVERSITY

Professor Jack Kerrebrock

Dept. of Aeronautical Engineering

Massachusetts Institute of Technology

Cambridge, MA 02139

Professor J. A. Nichols

Dept. of Aerospace Engineering

University of Vichigan

Ann Arbor, NI 48109 
Professor Naeim Henein

Wayne State University

College of Engineering

Detroit, MI 48202

Dr. Frederick Gouldin

(1)

Cornell University

Ithaca, NY 14850

Mr. Wes.ley Menard

(1)

Jet Propulsion Laboratory

California Institute of Technology

Pasadena, CA 91103

Professor Frank Marble

California Institute of Technology

Pasadena, CA 91103

Professor Irvin Glassman

Dept. Aerospace \& 'lechanical

Sciences

Princeton University

Princeton, NJ 08540

Professor A. H. Lefebrre

(1)

Dept. Mechanicai Engineering

Purdue University

West Lafayeite, Indiana 47907

Professor R. F. Saryer

Mail Stop $0: 65$

(1)

Dept. Mechanical Engineering

University of Calijornia, Berkeley

Berkeley, CA 94720

Prof. Robert C. Fellinger

Dept. of Nechanical Engineering

(I)

Iorva State Univ. of Science

and Technology'

Ames, Iowa 50010

Prof. C. William Kaufiman

Dept. of Aerospace Eng.

Univ. of Cincinnati

Cincinnati, OH 45221

Mr. Anthony J. Cirrito

(1)

Lowell Technological Inst.

Lowell, $\mathrm{NA}$

Professor Ben Zinn

Georgia Inst. of Technology

Atlanta, GA 30332 